IUPAC Technical Report

PAC-REP-14-05-02

\title{
Standard Electrode Potentials Involving Radicals in Aqueous Solution: Inorganic Radicals
}

\author{
IUPAC Task Group on Radical Electrode Potentials
}

David A. Armstrong (deceased) (task group member) Department of Chemistry, University of Calgary, Alberta, Canada

\begin{abstract}
Robert E. Huie (task group member)
formerly of the Physical and Chemical Properties Division, National Institute of Standards and Technology, Gaithersburg, MD 20899, USA
\end{abstract}

\author{
Willem H. Koppenol (task group member) \\ Institute of Inorganic Chemistry, Swiss Federal Institute of Technology, CH-8093 Zürich, \\ Switzerland
}

Sergei V. Lymar (task group member) Chemistry Department, Brookhaven National Laboratory, Upton NY 11973, USA

\author{
Gábor Merényi (task group member) \\ Department of Applied Physical Chemistry, The Royal Institute of Technology, S-10044, \\ Stockholm 70, Sweden
}
Pedatsur Neta (task group member)
Physical and Chemical Properties Division, National Institute of Standards and Technology, Gaithersburg, MD 20899, USA

\begin{abstract}
Chemical Sciences and Engineering Division, Argonne National Laboratory, Argonne, IL, 60439, USA, and Computation Institute, University of Chicago, Chicago, IL, 60637, USA

David M. Stanbury (task group leader)
\end{abstract}
Branko Ruscic


Steen Steenken (task group member)

Mülheim, Germany

Peter Wardman (task group member)

43 formerly of the University of Oxford, Gray Cancer Institute, Department of Oncology, Old Road

Abstract: Recommendations are made for standard potentials involving select inorganic radicals in aqueous solution at $25{ }^{\circ} \mathrm{C}$. These recommendations are based on a critical and thorough literature review and also by performing derivations from various literature reports.

49 The recommended data are summarized in tables of standard potentials, Gibbs energies of

50 formation, radical $\mathrm{p} K_{\mathrm{a}}$ 's, and hemicolligation equilibrium constants. In all cases, current best

51 estimates of the uncertainties are provided. An extensive set of Data Sheets is appended that

52 provide original literature references, summarize the experimental results, and describe the

53 decisions and procedures leading to each of the recommendations.

\section{Contents}

1. Introduction

59

2. Definitions and Conventions

60

3. Methods for Determination of Standard Potentials

61 5. Uncertainties

62 6. Network Problems

$637 . \quad$ Important Reference Couples

64 Acknowledgments

65 References

66 Tables

67 Data Sheets 1-117

68 Supplementary Data Sheets S1-S12

69 


\section{Introduction}

Radicals, both organic and inorganic, tend to be highly reactive. Nevertheless, they are widely encountered as intermediates in chemical reactions; their individual reactivities are central among the factors that determine the rates and products of the overall reactions in which they are involved. For reactions where the radicals are present in the aqueous phase, electrode potentials involving the radicals are among the most powerful indicators of reactivity. Electrode potentials involving radicals are often more directly related to reactivity than are electrode potentials of non-radicals, because the former more often correlate to specific steps in the reaction mechanisms.

The determination of radical electrode potentials has greatly expanded in the last three decades, largely through the application of pulse radiolysis and flash photolysis. These are techniques that are well suited to the generation of transient radicals and the measurement of their reaction equilibria. It is largely through the manipulation of the radical equilibrium constants that the current bounty of radical electrode potentials has been obtained.

In 1989 two comprehensive reviews on radical standard potentials appeared. Wardman's review emphasized organic radicals [1], while Stanbury's review considered inorganic radicals exclusively [2]. Both of those reviews are now rather dated. Another valuable compendium is Steenken's 1985 list of electron transfer equilibria involving radicals [3]. A related review emphasizing H-atom bond dissociation "free" (Gibbs) energies has also appeared [4]. The relevant primary literature has expanded greatly and numerous major corrections have been made. Moreover, with the benefit of these prior reviews, we are now in an improved position to appreciate the interconnected complexity of the various measurements. The work of the current IUPAC Task Group differs from those two prior reviews in that it doesn't attempt to make recommendations on all known radical electrode potentials but rather it focuses on a subset that has been judged to be of greater importance, and it makes a greater effort to apply the principles of error propagation in assessing the various potentials. This document presents the results of the IUPAC Task Group as they bear on inorganic radicals. Of necessity, some careful consideration of organic radicals is also included, because in some cases the inorganic radical potentials are derived from measurements of equilibrium constants for reactions with organic radicals. Some of the standard potentials discussed here were presented at the "Medicinal Redox Inorganic

\section{Definitions and Conventions}


We limit the scope to those species, radical or otherwise, having sufficient lifetime to be vibrationally equilibrated with the solvent; this restriction allows the full forces of classical

108 thermodynamics to be employed. We consider radicals to be species either neutral or ionic that

109 bear an unpaired electron, and we exclude transition-metal complexes as a matter of

110 convenience.

Use of the radical "dot" in chemical formulas to indicate radical species is redundant

112 when the exact elemental composition and electronic charge of the species is specified, as is

113 usually the case with the species in the current review. On the other hand, its use can be helpful

114 for those who are not intimately familiar with the chemistry involved. In the present document,

115 an effort has been made to use the dots consistently in the summary Tables, but in the supporting

116 data sheets its use is less consistent. Both practices are in agreement with the current guidelines

117 for inorganic nomenclature [6,7].

118 By the term "standard electrode potential", $E^{\circ}$, we refer to half reactions of the following 119 type:

where $n$ is an integer often 1, either Ox or Red can be a radical, and $E^{\circ}$ is taken relative to the normal hydrogen electrode (NHE). On occasion we use here the shorthand expression "standard potential" to refer to standard electrode potentials. By convention, these reactions are always written as reductions - the associated potentials were previously known as "standard reduction potentials" - and they can be more complex than the simple example given above. Standard electrode potentials, rigorously speaking, refer to electrode potentials specified under conditions where all species are at unit activity. The standard state for such activities in the present review is usually the ideal $1 \mathrm{M}$ aqueous solution. Species in solution that can also exist as gases, such as $\mathrm{O}_{2}$, can be referred to the $1 \mathrm{M}$ aqueous standard state or to the $100 \mathrm{kPa}(\sim 1 \mathrm{~atm})$ pressure standard state, and in such cases we have taken care to designate the state explicitly. For water the standard state is the pure solvent (at unit activity, not 55.5 M). Standard electrode potentials are related to equilibrium constants $\left(K_{\text {eq }}\right)$ through the relationship

$$
E^{\circ}=-(R T / n F) \ln K_{\text {eq }}
$$


radicals, it is usually easier to determine equilibrium constants than it is to measure equilibrium electrode potentials directly.

It is often necessary to report formal potentials, $E^{\circ}$, rather than standard potentials because of a lack of reliable means to estimate the activity coefficients $(\gamma)$. This is typically the case when the reaction involves ionic species and the measurement is performed at high ionic strength. Formal potentials are defined in the IUPAC Green Book as in eq 3 [8]:

$$
E_{\mathrm{eq}}=E^{\mathrm{O}}-(R T / n F) \sum v_{\mathrm{i}} \ln \left(c_{\mathrm{i}} / c^{\circ}\right)
$$

Here, $c_{\mathrm{i}}$ represents the concentration of species $i, c^{\circ}$ is a normalizing standard concentration (usually $1 \mathrm{M}$ ), and $v_{\mathrm{i}}$ is that species stoichiometric coefficient. This definition is analogous to the Nernst equation except that it is expressed in terms of concentrations, and it allows for various species concepts. For example, in the case of $\mathrm{S}(\mathrm{IV})$ the species might be $\mathrm{SO}_{3}{ }^{2-}, \mathrm{HSO}_{3}{ }^{-}, \mathrm{SO}_{2}$, or the sum of all. This definition also allows for $E^{\circ \prime}$ values to be defined at specific nonstandard $\mathrm{pH}$ values. To avoid ambiguity in the species definitions, in the present work we generally write out the relevant half-cell reaction, and for reactions involving the proton we normally refer to $\mathrm{pH} 0$. Formal potentials for the species' under consideration here can often be related to standard potentials through the activity coefficients:

$$
E^{\circ}=E^{\circ \prime}+R T / n F \ln \left(\Pi \gamma_{\text {prod }^{\mathrm{x}}} / \Pi \gamma_{\text {react }^{\mathrm{y}}}\right)
$$
Likewise, it is often useful or necessary to report formal equilibrium quotients $\left(K_{\mathrm{f}}\right)$ rather than equilibrium constants. These are related through the expression

173 knowledge of the $\mathrm{p} K_{\mathrm{a}}$ values involved. For a detailed discussion of these points the reader is 174 referred to the introductory material in Wardman's review on the potentials of radicals [1].

175 Related to midpoint potentials are apparent potentials, $E_{\text {ap. Apparent potentials are defined at a }}^{\circ}$ 
Nernst equation do not take the state of protonation into account. Thus, apparent potentials do not necessarily imply any knowledge of the $\mathrm{p} K_{\mathrm{a}}$ 's involved.

\section{Methods for Determination of Standard Potentials}

involving inorganic radicals, as has been reviewed elsewhere [9]. A brief summary is given here.

a) Electrochemical Methods.

a, i) Potentiostatic methods have been used only in a few special cases, such as in the chemistry of $\mathrm{ClO}_{2}{ }^{\bullet}$. The reason for this limitation is that inorganic radicals are usually highly reactive, so it is impossible to establish conditions where the concentrations are stable on the time frame of the measurements.

a, ii) Cyclic voltammetry (CV) shortens the time frame of the electrochemical methods, and it has been used successfully in a few cases. However, the lifetimes of most inorganic radicals are too brief even for $\mathrm{CV}$.

a, iii) Pulse radiolysis provides an entry into very short time frames, and attempts have been made to apply electrochemical measurements to species generated by pulse radiolysis. Unfortunately, these efforts have not as yet provided reliable measurements or estimates of standard potentials involving inorganic radicals.

a, iv) An intriguing technique is to generate photoelectrons in solution by laser irradiation of an electrode and then to use the electrode to probe the electrochemistry of the radicals generated from the photoelectrons. The method, however, remains to be developed as a reliable source of thermodynamic data.

b) Equilibrium Constant Measurements. The vast majority of standard electrode potentials summarized in this review have been obtained by Hess' law methods where an equilibrium constant is measured somehow and combined with other thermodynamicchemical data to derive the reported potential. These derivations frequently make use of published values of $\Delta_{\mathrm{f}} G^{\circ}$, and this review normally makes the assumption that the values published in the NBS tables [10] are of reference quality. The various types of radical equilibrium constants used in these derivations are described below.

b, i) Solubilities. The solubilities of $\mathrm{ClO}_{2}{ }^{\bullet}$ and $\mathrm{NO}^{\bullet}$ have been measured unambiguously because solutions of these radicals are stable. These solubility measurements then afford a method to determine the solution-phase standard potentials from the known gas-phase energetics of these species. The solubility of $\mathrm{NO}_{2}{ }^{\bullet}$ has also been measured, but in this case the method is complex and relies on an understanding of the kinetics of dissolution and of disproportionation of $\mathrm{NO}_{2}{ }^{\circ}(a q)$. 
b, ii) Homolysis Equilibria. Homolysis at sigma bonds generally yields radicals, and determination of these equilibrium constants can lead rather directly to electrode potentials. In the case of $\mathrm{S}_{2} \mathrm{O}_{4}{ }^{2-}$ it has been possible to measure the homolysis equilibrium constant by direct ESR detection of the $\mathrm{SO}_{2}{ }^{\bullet-}$ radicals. Homolysis equilibrium constants have been measured for unstable species such as $\mathrm{N}_{2} \mathrm{O}_{4}$ by use of transient methods such as flash photolysis and pulse radiolysis to establish the equilibria. A third method is to derive the equilibrium constant from the ratio of the forward and reverse rate constants $\left(K_{\mathrm{eq}}=k_{\mathrm{f}} / k_{\mathrm{r}}\right)$; an example of this method is provided by $\mathrm{S}_{2} \mathrm{O}_{8}{ }^{2-}$, where $k_{\mathrm{f}}$ is determined from the kinetics of its oxidation of various substrates and $k_{\mathrm{r}}$ is obtained from transient measurements on the recombination of $\mathrm{SO}_{4}{ }^{\bullet-}$.

b, iii) Electron-Transfer Equilibria. Equilibrium constants for electron-transfer reactions are probably the most widely used data for deriving standard potentials involving radicals. A typical example is the reaction of $\mathrm{O}_{3}$ with $\mathrm{ClO}_{2}{ }^{-}$:

$$
\mathrm{O}_{3}+\mathrm{ClO}_{2}^{-} \rightleftharpoons \mathrm{O}_{3}^{\bullet-}+\mathrm{ClO}_{2}^{\bullet}
$$

In this case the equilibrium constant was determined from the ratio of $k_{\mathrm{f}}$ and $k_{\mathrm{r}}$, and it was used to determine the standard one-electron electrode potential of $\mathrm{O}_{3}$ relative the well-established reference potential of $\mathrm{ClO}_{2}{ }^{\circ}$. Equilibrium constants have also been measured for a substantial number of electron transfer reactions where neither of the component half reactions can be considered as having a reliable reference potential; nevertheless, such reactions are valuable in determining standard potentials, although the thermodynamicchemical derivations are necessarily more lengthy.

b, iv) Acid/Base Equilibria. Proton-transfer reactions can be crucial in understanding the reactivity of radicals, as is exemplified by superoxide. $\mathrm{HO}_{2} \bullet$ has a $\mathrm{p} K_{\mathrm{a}}$ of 4.8 . It is thermodynamically unstable with respect to disproportionation. Disproportionation via the reaction of $\mathrm{HO}_{2}{ }^{\bullet}$ with itself or $\mathrm{O}_{2}{ }^{\bullet-}$ is very fast. However, direct disproportionation via reaction of $\mathrm{O}_{2}{ }^{\bullet-}$ with itself is undetectably slow, so alkaline solutions of $\mathrm{O}_{2}{ }^{\bullet-}$ are remarkably persistent. Determinations of $\mathrm{p} K_{\mathrm{a}}$ 's have been performed for a significant number of radicals, and they have been performed by a large suite of techniques. These $\mathrm{p} K_{\mathrm{a}}$ 's have been used in a large number of derivations of radical standard potentials, and, because of their intrinsic importance, they are summarized below in Table 3.

b, v) Hemicolligation Equilibria. Reactions in which radicals bind to non-radical species are defined as hemicolligations. They can occur between a radical and its reduced form that produce a symmetrical radical adduct or between a radical and some other non-radical to 
Reactions of this type can have a profound effect on the net reactivity of the radicals, and they are often unavoidable in reactive systems. Equilibrium constants have been measured for a good number of hemicolligation reactions, have been used extensively in deriving radical standard potentials, and are summarized in Table 4.

b, vi) Nucleophilic Displacement Equilibria. In these reactions a nucleophile displaces another nucleophile from a radical. A typical example is

Although these reactions can be considered as equivalent to the sum of two hemicolligations, their equilibrium constants often can be more easily measured than those of the component hemicolligations. These displacement equilibria are important in the present review primarily for their use in deriving standard potentials through thermodynamicchemical cycles.

c) Methods Involving Estimates. For certain important radicals there is no complete experimental thermodynamicchemical cycle available, and portions of the cycle must be obtained by making reasonable estimates. An important example is the hydrogen atom: although equilibrium constants have been measured for reactions that convert the aqueous hydrogen atom into other species (notably the hydrated electron), none of these reactions connects to a suitable reference redox couple. The best current solution to the problem is to make an estimate of the solvation energy of the hydrogen atom and then combine this estimate with other reliable data to derive the $\mathrm{H}^{+} / \mathrm{H}^{\bullet}$ electrode potential. There is good reason to believe that the uncertainties introduced in this example are relatively small. In general the current report relies on such thermodynamicchemical estimates only when direct experimental data are unavailable.

d) Quantum Calculations. It is becoming increasingly common to use quantum calculations to obtain radical electrode potentials. The methods typically entail a relatively accurate calculation of the energetics of the gas-phase radical and another calculation of the radical solvation energy. It has recently been shown that these computational methods can fail disastrously [11], so the present review makes little use of them.

\section{Criteria for Selection of Recommended Data}


The recommended values in the Tables of this report are based on results published in the peer-reviewed scientific literature. The Task Group has reviewed these primary publications to confirm their plausibility, scientific soundness, and adherence to established chemical principles. When there are multiple independent reports on the same results, the individual reports have been compared to determine the degree of agreement among them, and to identify outliers and assess whether there is just cause for rejecting them. Individual reports may be rejected because the experimental method or conditions are insufficiently documented and the method has been shown to be unreliable. Non-rectifiable errors have been identified in the data handling, or the results are not internally consistent. In cases where there are multiple acceptable reports of a given result, the reviewers have assigned a subjective weighting to each report based on an assessment of the care taken in the experiments and the typical accuracy of the method. These filtered results are then averaged, optimized, and their uncertainties assigned as described below.

\section{Uncertainties}

In the present review, all recommended data ( $E^{\circ}$ values, $\mathrm{p} K_{\mathrm{a}}$ 's, $\Delta_{\mathrm{f}} G^{\circ}$ values $)$ are presented with associated uncertainties in two significant digits, up to 19. These uncertainties are given as $\pm 1 \sigma$, and they are intended to indicate the best estimate of the overall uncertainty as arising from all contributions. Typically the least of these contributions are the statistical fluctuations in the direct measurements of a given quantity. Much more important are systematic errors, many of which are difficult to anticipate. Many of the recommended data are derived by combining various thermodynamicchemical quantities, and hence propagation of error must be taken into account. The level of uncertainty in the NBS $\Delta_{\mathrm{f}} G^{\circ}$ values is frequently underappreciated in the broader chemical community. For some results there are multiple independent reports for the same quantity, for example as with the $\mathrm{p} K_{\mathrm{a}}$ of $\mathrm{HO}^{\bullet}$; in such situations each individual report is examined for plausibility and technical excellence, outliers are rejected, then remaining reports are averaged, and a subjective assessment of the uncertainty is assigned. The specific rationale for these assignments is provided in the detailed data sheets appended. In the language of metrology, these uncertainty estimates are of Type A (from statistical treatment of repeated measurements) and Type B (estimates from experience), and ISO standards mandate that both

317 reviewed elsewhere [12]. 
As is discussed above, a large number of radical equilibrium constants of various types have been measured and combined with the standard potentials of reference couples to derive standard potentials of radicals through Hess' law-type calculations. Some of these equilibria share common radical species and hence lead to thermodynamicchemical networks. These networks can be very useful for determining radical standard potentials. When the networks are linear or branched it is a simple process to combine adjacent equilibrium constants with appropriate reference potentials to derive potentials of interest; in such calculations appropriate attention must be paid to the cumulative effects of error propagation. Occasionally there are loops in the networks, which form closed thermodynamicchemical cycles. These closed thermodynamicchemical cycles afford excellent tests of the data, because the associated Gibbs energy changes must sum to zero. Failure to meet this criterion within reasonable uncertainty limits is a signal that at least some of the data are seriously flawed. When this criterion is met, suitable adjustments of the individual equilibrium constants (within their uncertainties) can be made to achieve exact closure. Assessment and use of these thermodynamicchemical networks can be performed manually, although consistent results are difficult to achieve when the networks are large. Larger networks can be solved in an automated and consistent way through use of appropriate computerized approaches such as ATcT, Active Thermodynamicchemical Tables [13]. In the present review, some of the recommended data are the result of manual assessment while others have been generated by use of ATcT. In its standard format, the ATcT software is optimized for evaluation of gas-phase enthalpies; for the present purposes the ATcT software has been adapted to work with Gibbs energies in solution. The method thus consists of defining the reaction network, converting relevant reference potentials and equilibrium constants to $\Delta G^{\circ}$ values and associated uncertainties, and localizing the thermodynamicchemical network

344 by incorporating auxiliary values of $\Delta_{\mathrm{f}} G^{\circ}$ (usually from the NBS tables) as network termini; the 345 ATcT output then consists of a set of optimized $\Delta_{\mathrm{f}} G^{\circ}$ values and uncertainties for the radicals of interest, and these are then combined with reference values of $\Delta_{\mathrm{f}} G^{\circ}$ to derive the $E^{\circ}$ values. This method has been applied to a subset of the data presented here, as described in Data Sheet 7.

\section{Important Reference Couples}

There are a few redox couples that have attained particular significance, either because of their centrality as reference couples for determining other standard potentials or because of their general importance in inorganic radical chemistry. Aspects of these redox couples are highlighted here.

The $\mathrm{ClO}_{2} / \mathrm{ClO}_{2}^{-}$couple $\left(\mathrm{ClO}_{2}{ }^{\bullet}+\mathrm{e}^{-} \rightleftharpoons \mathrm{ClO}_{2}^{-}\right)$is of great importance in this review because it has been used extensively in establishing equilibria with other radicals and because its 
standard potential is known with unusually high accuracy. These characteristics are largely a consequence of the remarkable stability of both $\mathrm{ClO}_{2}{ }^{\circ}$ and $\mathrm{ClO}_{2}{ }^{-}$in aqueous solution and the facile inter-conversions between them. As a result, it is not difficult to obtain reversible electrochemistry with this couple, perform classical equilibrium potentiostatic measurements, and extrapolate them to conditions of thermodynamicchemical ideality. The outcome is a reliable and genuinely standard value for $E^{\circ}$.

The hydroxyl radical is of general importance because it is one of the three radicals intrinsic to water $\left(\mathrm{HO}^{\bullet}, \mathrm{H}^{\bullet}\right.$, and $\mathrm{e}^{-}$aq $)$, it is the only one of the three to have its electrode potential determined without extra-thermodynamic assumptions or approximations, and occupies a central position in the largest of the thermodynamicchemical networks in this review. Its potential has been determined by two independent routes. The first of these has its origins in thallium chemistry and rests specifically on the redox potentials of the unstable species $\mathrm{Tl}^{2+}$, which are determined relative to the well-established $\mathrm{Fe}^{3+} / \mathrm{Fe}^{2+}$ reference potential. The second route depends on the $\mathrm{p} K_{\mathrm{a}}$ of $\mathrm{HO}^{\bullet}$, the hemicolligation of $\mathrm{O}^{\bullet-}$ with $\mathrm{O}_{2}$, the electron-transfer equilibrium of $\mathrm{O}_{3}{ }^{-}-$with $\mathrm{ClO}_{2}{ }^{\bullet}$, and the use of the $\mathrm{ClO}_{2} \% \mathrm{ClO}_{2}{ }^{-}$redox couple as a reliable reference. The excellent agreement between these two routes provides strong support for the recommended potential of this important species.

$\mathrm{Br}_{2}{ }^{--}$is widely used as an oxidant, and equilibrium constants have been measured for at least 12 of its reactions. Its electrode potential is considered well established because of the good agreement between several independent derivations. Notable among these are a derivation based on the equilibrium constants for 1) its reaction with $\mathrm{OH}^{-}$to form $\mathrm{BrOH}^{\bullet-}$ and bromide and 2) the dissociation of $\mathrm{BrOH}^{\bullet-}$ to form $\mathrm{Br}^{-}$and $\mathrm{HO}^{\bullet}$.

The trinitrogen $(\bullet)$ radical, $\mathrm{N}_{3}{ }^{\bullet}$, is important generally because it is often used as a mild nonspecific oxidant. It holds special importance in this review because of its frequent use in establishing redox equilibria that can be used to establish electrode potentials that involve radicals. The standard electrode potential of the $\mathrm{N}_{3}{ }^{\bullet} / \mathrm{N}_{3}{ }^{-}$redox couple has been determined in several ways with good agreement. It has been measured electrochemically (under irreversible conditions), and it has been derived from equilibria with four other reference redox couples $\left(\left[\mathrm{IrCl}_{6}\right]^{2-} /\left[\mathrm{IrCl}_{6}\right]^{3-},\left[\mathrm{Ru}(\text { bpy })_{3}\right]^{3+} /\left[\mathrm{Ru}\left(\mathrm{bpy}_{3}\right]^{2+}, \mathrm{ClO}_{2} / \mathrm{ClO}_{2}^{-}\right.\right.$, and $\left.\mathrm{Br}_{2}{ }^{\bullet-} / 2 \mathrm{Br}^{-}\right)$. Note that use of $\mathrm{N}_{3}{ }^{\bullet} / \mathrm{N}_{3}{ }^{-}$as a reference potential at very high azide concentrations requires consideration of the association between $\mathrm{N}_{3}{ }^{\bullet}$ and $\mathrm{N}_{3}{ }^{-}$(Data Sheet 86).

There are also some organic radicals that are important in providing reference potentials

391 Evaluations of their electrode potentials are provided in the supplementary data sheets. 
394 We thank IUPAC, ETH \& ETH Stiftung for financial support of this project. The work at 395 Argonne National Laboratory was supported by the US Department of Energy, Office of

396 Science, Office of Basic Energy Sciences, Division of Chemical Sciences, Geosciences and 397 Biosciences under Contract No. DE-AC02-06CH11357. This material is partially based upon 398 work at Brookhaven National Laboratory supported by the U.S. Department of Energy, Office of 399 Science, Office of Basic Energy Sciences, Division of Chemical Sciences, Geosciences, and 400 Biosciences under contract DE-AC02-98CH10886.

\section{REFERENCES}

404 1. P. Wardman. J. Phys. Chem. Ref. Data 18, 1637-1755 (1989).

405 2. D. M. Stanbury. Adv. Inorg. Chem. 33, 69-138 (1989).

406 3. Steenken, S. In Landolt-Börnstein, New Series, Vol. 13e, (Fischer, H., ed.), p. 147-293.

407 Springer-Verlag, New York (1985).

408 4. J. J. Warren, T. A. Tronic, J. M. Mayer. Chem. Rev. 110, 6961-7001 (2010).

409 5. D. A. Armstrong, R. E. Huie, S. Lymar, W. H. Koppenol, G. Merenyi, P. Neta, D. M.

410 Stanbury, S. Steenken, P. Wardman. Bioinorg. React. Mech. 9, 59-61 (2013).

411 6. N. G. Connelly, T. Damhus, R. M. Hartshorn, A. T. Hutton. Nomenclature of Inorganic

412 Chemistry. IUPAC Recommendations 2005, Royal Society of Chemistry, Cambridge (2005).

413 7. W. H. Koppenol. Pure Appl. Chem. 72, 437-446 (2000).

414 8. E. R. Cohen, T. Cvitaš, T. G. Frey, B. Holmström, K. Kuchitsu, R. Marquardt, A. Mills,

415 F. Pavese, M. Quack, J. Stohner, H. L. Strauss, M. Takami, A. J. Thor. Quantities, Units and

416 Symbols in Physical Chemistry, 3rd edition, RSC Publishing, Cambridge, UK, pp 70-76 (2007).

417 9. Stanbury, D. M. In General Aspects of the Chemistry of Radicals, (Alfassi, Z. B., ed.), p. 418 347-384. John Wiley \& Sons, New York (1999).

419 10. D. D. Wagman, W. H. Evans, V. B. Parker, R. H. Schumm, I. Halow, S. M. Bailey, K. L. 420 Churney, R. L. Nuttall. J. Phys. Chem. Ref. Data 11, Suppl. No. 2 (1982).

421 11. G. A. Poskrebyshev, V. Shafirovich, S. V. Lymar. J. Phys. Chem. A 112, 8295-8302

422 (2008).

423 12. B. Ruscic. Int. J. Quantum Chem. 114, 1097-1101 (2014).

424 13. B. Ruscic, R. E. Pinzon, M. L. Morton, G. von Laszevski, S. J. Bittner, S. G. Nijsure, K. 425 A. Amin, M. Minkoff, A. F. Wagner. J. Phys. Chem. A. 108, 9979-9997 (2004). 


\begin{tabular}{|c|c|c|}
\hline Half-reaction & Electrode Potential / V & Data Sheet \# \\
\hline \multicolumn{3}{|l|}{ Table 1.1: Electron, Hydrogen and Oxygen } \\
\hline $\mathrm{e}^{-} \rightleftharpoons \mathrm{e}^{\bullet-}(a q)$ & $-2.88 \pm 0.02$ & 1.1 \\
\hline $\mathrm{H}^{+}+\mathrm{e}^{-} \rightleftharpoons \mathrm{H}^{\bullet}(a q)$ & $-2.31 \pm 0.03$ & 1.3 \\
\hline $\mathrm{O}\left({ }^{3} P\right)+\mathrm{e}^{-} \rightleftharpoons \mathrm{O}^{-}$ & $+1.6 \pm 0.1$ & 2 \\
\hline $\left.\mathrm{O}^{3} P\right)+\mathrm{H}^{+}+\mathrm{e}^{-} \rightleftharpoons \mathrm{HO}^{\bullet}$ & $+2.3 \pm 0.1$ & 2 \\
\hline $\mathrm{O}_{2}(\mathrm{~g})+\mathrm{e}^{-} \rightleftharpoons \mathrm{O}_{2}^{\bullet-}$ & $-0.35 \pm 0.02$ & 3 \\
\hline $\mathrm{O}_{2}(\mathrm{aq})+\mathrm{e}^{-} \rightleftharpoons \mathrm{O}_{2}^{\bullet-}$ & $-0.18 \pm 0.02$ & 3 \\
\hline${ }^{1} \Delta_{\mathrm{g}} \mathrm{O}_{2}(\mathrm{~g})+\mathrm{e}^{-} \rightleftharpoons \mathrm{O}_{2}{ }^{\bullet-}$ & $+0.64 \pm 0.01$ & 4 \\
\hline${ }^{1} \Delta_{\mathrm{g}} \mathrm{O}_{2}(\mathrm{aq})+\mathrm{e}^{-} \rightleftharpoons \mathrm{O}_{2}^{\bullet-}$ & $+0.81 \pm 0.01$ & 4 \\
\hline $\mathrm{O}_{2}(\mathrm{~g})+\mathrm{e}^{-}+\mathrm{H}^{+} \rightleftharpoons \mathrm{HO}_{2}^{\bullet}$ & $-0.07 \pm 0.02$ & 3 \\
\hline $\mathrm{O}_{2}(\mathrm{aq})+\mathrm{H}^{+}+\mathrm{e}^{-} \rightleftharpoons \mathrm{HO}_{2}^{\bullet}$ & $+0.10 \pm 0.02$ & 3 \\
\hline $\mathrm{HO}_{2}^{\bullet}+\mathrm{e}^{-}+\mathrm{H}^{+} \rightleftharpoons \mathrm{H}_{2} \mathrm{O}_{2}$ & $+1.46 \pm 0.01$ & 5 \\
\hline $\mathrm{H}_{2} \mathrm{O}_{2}+\mathrm{e}^{-}+\mathrm{H}^{+} \rightleftharpoons \mathrm{HO}^{\bullet}+\mathrm{H}_{2} \mathrm{O}$ & $+0.80 \pm 0.01$ & 6 \\
\hline $\mathrm{HO}^{\bullet}+\mathrm{e}^{-}+\mathrm{H}^{+} \rightleftharpoons \mathrm{H}_{2} \mathrm{O}$ & $+2.730 \pm 0.017$ & 7 \\
\hline $\mathrm{OH}^{\bullet}+\mathrm{e}^{-} \rightleftharpoons \mathrm{OH}^{-}$ & $+1.902 \pm 0.017$ & 7 \\
\hline $\mathrm{O}_{3}(\mathrm{~g})+\mathrm{e}^{-} \rightleftharpoons \mathrm{O}_{3}^{\bullet-}$ & $+0.91 \pm 0.02$ & 23 \\
\hline $\mathrm{O}_{3}(\mathrm{aq})+\mathrm{e}^{-} \rightleftharpoons \mathrm{O}_{3}^{\bullet^{-}}$ & $+1.03 \pm 0.02$ & 23 \\
\hline \multicolumn{3}{|l|}{ Table 1.2: Halogens } \\
\hline \multicolumn{3}{|l|}{ Table 1.2a: Chlorine } \\
\hline $\mathrm{Cl}^{\bullet}(a q)+\mathrm{e}^{-} \rightleftharpoons \mathrm{Cl}^{-}(a q)$ & $+2.432 \pm 0.018$ & 7 \\
\hline $\mathrm{Cl}_{2}^{\bullet-}(a q)+\mathrm{e}^{-} \rightleftharpoons 2 \mathrm{Cl}^{-}(a q)$ & $+2.126 \pm 0.017$ & 7 \\
\hline $\mathrm{Cl}_{2}(a q)+\mathrm{e}^{-} \rightleftharpoons \mathrm{Cl}_{2}^{\bullet-}(a q)$ & $+0.666 \pm 0.017$ & 7 \\
\hline $\mathrm{ClOH}^{\bullet}(a q)+\mathrm{e}^{-} \rightleftharpoons \mathrm{Cl}^{-}+\mathrm{OH}^{-}(a q)$ & $+1.912 \pm 0.018$ & 7 \\
\hline $\mathrm{ClOH}^{\bullet-}(a q)+\mathrm{e}^{-}+\mathrm{H}^{+}(a q) \rightleftharpoons \mathrm{Cl}^{-}(a q)+\mathrm{H}_{2} \mathrm{O}(l)$ & $+2.740 \pm 0.018$ & 7 \\
\hline $\mathrm{HOCl}(a q)+\mathrm{e}^{-} \rightleftharpoons \mathrm{ClOH}^{\bullet-}(a q)$ & $+0.25 \pm 0.08$ & 7 \\
\hline $\mathrm{ClO}_{2}^{\bullet}(a q)+\mathrm{e}^{-} \rightleftharpoons \mathrm{ClO}_{2}^{-}$ & $+0.935 \pm 0.003$ & 24 \\
\hline $\mathrm{ClO}_{3} \cdot(a q)+\mathrm{e}^{-} \rightleftharpoons \mathrm{ClO}_{3}^{-}(a q)$ & $+2.38 \pm 0.03$ & 7 \\
\hline $\mathrm{ClO}^{\bullet}(a q)+\mathrm{e}^{-} \rightleftharpoons \mathrm{ClO}^{-}(a q)$ & $+1.39 \pm 0.03$ & 25 \\
\hline \multicolumn{3}{|l|}{ Table 1.2b: Bromine } \\
\hline $\mathrm{Br}_{2}^{\bullet-}(a q)+\mathrm{e}^{-} \rightleftharpoons 2 \mathrm{Br}^{-}(a q)$ & $+1.63 \pm 0.02$ & 26 \\
\hline $\mathrm{Br}_{2}(a q)+\mathrm{e}^{-} \rightleftharpoons \mathrm{Br}_{2}{ }^{\circ-}(a q)$ & $+0.55 \pm 0.02$ & 26 \\
\hline $\mathrm{Br}^{\circ}(a q)+\mathrm{e}^{-} \rightleftharpoons \mathrm{Br}^{-}(a q)$ & $+1.96 \pm 0.02$ & 26 \\
\hline $\mathrm{BrO}_{2}{ }^{\circ}(a q)+\mathrm{e}^{-} \rightleftharpoons \mathrm{BrO}_{2}^{-}(a q)$ & $+1.290 \pm 0.005$ & 40 \\
\hline \multicolumn{3}{|l|}{ Table 1.2c: Iodine } \\
\hline $\mathrm{I}_{2}^{\bullet^{-}}+\mathrm{e}^{-} \rightleftharpoons 2 \mathrm{I}^{-}$ & $+1.05 \pm 0.02$ & 45 \\
\hline $\mathrm{I}^{\bullet}+\mathrm{e}^{-} \rightleftharpoons \mathrm{I}^{-}$ & $+1.35 \pm 0.02$ & 45 \\
\hline
\end{tabular}




\begin{tabular}{|c|c|c|}
\hline $\mathrm{I}_{2}(a q)+\mathrm{e}^{-} \rightleftharpoons \mathrm{I}_{2}^{\bullet-}$ & $+0.19 \pm 0.02$ & 45 \\
\hline \multicolumn{3}{|l|}{ Table 1.3: Chalcogens } \\
\hline $\mathrm{SO}_{4}^{4^{\bullet}}(a q)+\mathrm{e}^{-} \rightleftharpoons \mathrm{SO}_{4}^{2-}(a q)$ & $+2.437 \pm 0.019$ & 7 \\
\hline $\mathrm{S}_{2} \mathrm{O}_{8}{ }^{2-}(a q)+\mathrm{e}^{-} \rightleftharpoons \mathrm{SO}_{4}^{4^{-}}(a q)+\mathrm{SO}_{4}{ }^{2-}(a q)$ & $+1.44 \pm 0.08$ & 7 \\
\hline $\mathrm{SO}_{3} \cdot(a q)+\mathrm{e}^{-} \rightleftharpoons \mathrm{SO}_{3}^{2-}(a q)$ & $+0.73 \pm 0.02$ & 59 \\
\hline $\mathrm{SO}_{5}^{\bullet^{-}}(a q)+\mathrm{e}^{-} \rightleftharpoons \mathrm{SO}_{5}^{2-}$ & $+0.81 \pm 0.01$ & 66 \\
\hline $\mathrm{S}_{2} \mathrm{O}_{3}{ }^{-}(a q)+\mathrm{e}^{-} \rightleftharpoons \mathrm{S}_{2} \mathrm{O}_{3}^{2-}$ & $+1.35 \pm 0.03$ & 71 \\
\hline $\mathrm{S}_{4} \mathrm{O}_{6}{ }^{\cdot 3-}(a q)+\mathrm{e}^{-} \rightleftharpoons 2 \mathrm{~S}_{2} \mathrm{O}_{3}{ }^{2-}$ & $+1.10 \pm 0.01$ & 71 \\
\hline $\mathrm{HS}^{\bullet}(a q)+\mathrm{H}^{+}+\mathrm{e}^{-} \rightleftharpoons \mathrm{H}_{2} \mathrm{~S}(a q)$ & $+1.54 \pm 0.03$ & 77 \\
\hline $\mathrm{S}^{\bullet-}+\mathrm{e}^{-}+\mathrm{H}^{+} \rightleftharpoons \mathrm{HS}^{-}$ & $+1.33 \pm 0.03$ & 77 \\
\hline $\mathrm{S}^{\bullet-}+\mathrm{e}^{-}+2 \mathrm{H}^{+} \rightleftharpoons \mathrm{H}_{2} \mathrm{~S}(a q)$ & $+1.74 \pm 0.03$ & 77 \\
\hline $\mathrm{HS}^{\bullet}(a q)+\mathrm{e}^{-} \rightleftharpoons \mathrm{HS}^{-}$ & $+1.13 \pm 0.03$ & 77 \\
\hline $\mathrm{HS}_{2}^{-}+\mathrm{e}^{-} \rightleftharpoons \mathrm{HS}_{2}{ }^{\bullet-}$ & $-1.13 \pm 0.05$ & 77 \\
\hline $\mathrm{SeO}_{3}{ }^{--}+\mathrm{e}^{-} \rightleftharpoons \mathrm{SeO}_{3}^{2-}$ & $+1.68 \pm 0.03$ & 78 \\
\hline $\mathrm{SeO}_{3}{ }^{--}+\mathrm{H}^{+}+\mathrm{e}^{-} \rightleftharpoons \mathrm{HSeO}_{3}^{-}$ & $+2.18 \pm 0.03$ & 78 \\
\hline $\mathrm{TeO}_{3}^{\bullet^{-}}+\mathrm{e}^{-} \rightleftharpoons \mathrm{TeO}_{3}^{2-}$ & $+1.74 \pm 0.03$ & 79 \\
\hline $\mathrm{TeO}_{3}{ }^{--}+\mathrm{H}^{+}+\mathrm{e}^{-} \rightleftharpoons \mathrm{HTeO}_{3}^{-}$ & $+2.31 \pm 0.03$ & 79 \\
\hline \multicolumn{3}{|l|}{ Table 1.4: Group 5} \\
\hline $\mathrm{NO}_{3} \cdot(a q)+\mathrm{e}^{-} \rightleftharpoons \mathrm{NO}_{3}^{-}(a q)$ & $+2.466 \pm 0.019$ & 7 \\
\hline $\mathrm{N}_{3} \cdot(a q)+\mathrm{e}^{-} \rightleftharpoons \mathrm{N}_{3}^{-}(a q)$ & $+1.33 \pm 0.01$ & 80 \\
\hline $\mathrm{NO}^{\bullet}(\mathrm{aq})+\mathrm{H}^{+}+\mathrm{e}^{-} \rightleftharpoons \mathrm{HNO}(a q)$ & $-0.15 \pm 0.02$ & 22 \\
\hline $\mathrm{HNO}(\mathrm{aq})+\mathrm{H}^{+}+\mathrm{e}^{-} \rightleftharpoons \mathrm{H}_{2} \mathrm{NO}^{\circ}(\mathrm{aq})$ & $+0.52 \pm 0.04$ & 87 \\
\hline $\mathrm{H}_{2} \mathrm{NO}^{\bullet}+2 \mathrm{H}^{+}+\mathrm{e}^{-} \rightleftharpoons \mathrm{NH}_{3} \mathrm{OH}^{+}$ & $+1.253 \pm 0.010$ & 87 \\
\hline $\mathrm{H}_{2} \mathrm{NO}^{\bullet}+\mathrm{H}^{+}+\mathrm{e}^{-} \rightleftharpoons \mathrm{NH}_{2} \mathrm{OH}$ & $+0.900 \pm 0.010$ & 87 \\
\hline $\mathrm{NO}_{2}{ }^{\bullet}(a q)+\mathrm{e}^{-} \rightleftharpoons \mathrm{NO}_{2}^{-}$ & $+1.04 \pm 0.02$ & 88 \\
\hline $\mathrm{PO}_{3}{ }^{2-}+\mathrm{H}^{+}+\mathrm{e}^{-} \rightleftharpoons \mathrm{HPO}_{3}^{2-}$ & $+1.54 \pm 0.04$ & 96 \\
\hline $\mathrm{H}_{2} \mathrm{PO}_{4}{ }^{\bullet}+\mathrm{e}^{-} \rightleftharpoons \mathrm{H}_{2} \mathrm{PO}_{4}^{-}$ & $+2.75 \pm 0.01$ & 97 \\
\hline \multicolumn{3}{|l|}{ Table 1.5: Group 4} \\
\hline $\mathrm{CO}_{2}(a q)+\mathrm{e}^{-} \rightleftharpoons \mathrm{CO}_{2}^{\bullet-}$ & $-1.90 \pm 0.02$ & 98 \\
\hline $\mathrm{CO}_{3}^{-\bullet}(a q)+\mathrm{e}^{-} \rightleftharpoons \mathrm{CO}_{3}^{2-}$ & $+1.57 \pm 0.03$ & 99 \\
\hline $\mathrm{CO}_{2}{ }^{-}+\mathrm{H}^{+}+\mathrm{e}^{-} \rightleftharpoons \mathrm{HCO}_{2}^{-}$ & $+1.52 \pm 0.03$ & 100 \\
\hline $\mathrm{SCN}^{\bullet}+\mathrm{e}^{-} \rightleftharpoons \mathrm{SCN}^{-}$ & $+1.61 \pm 0.02$ & 101 \\
\hline$(\mathrm{SCN}) 2^{\bullet}+\mathrm{e}^{-} \rightleftharpoons 2 \mathrm{SCN}^{-}$ & $+1.30 \pm 0.02$ & 101 \\
\hline \multicolumn{3}{|l|}{ Table 1.6: Group 3} \\
\hline $\mathrm{Tl}^{2+}+\mathrm{e}^{-} \rightleftharpoons \mathrm{Tl}^{+}$ & $+2.225 \pm 0.007$ & 21 \\
\hline $\mathrm{Tl}^{3+}(a q)+\mathrm{e}^{-} \rightleftharpoons \mathrm{Tl}^{2+}(a q)$ & $+0.34 \pm 0.08$ & 7 \\
\hline $\mathrm{TlOH}^{+}(a q)+\mathrm{e}^{-}+\mathrm{H}^{+}(a q) \rightleftharpoons \mathrm{Tl}^{+}(a q)+\mathrm{H}_{2} \mathrm{O}(l)$ & $+2.507 \pm 0.013$ & 7 \\
\hline
\end{tabular}




\begin{tabular}{|l|l|c|}
\hline $\mathrm{TlOH}^{2+}(a q)+\mathrm{e}^{-} \rightleftharpoons \mathrm{TlOH}^{+}(a q)$ & $+0.12 \pm 0.08$ & 7 \\
\hline $\mathrm{TlOH}^{2+}(a q)+\mathrm{e}^{-}+\mathrm{H}^{+}(a q) \rightleftharpoons \mathrm{Tl}^{2+}(a q)+\mathrm{H}_{2} \mathrm{O}(l)$ & $+0.40 \pm 0.08$ & 7 \\
\hline & & \\
\hline Table 1.7: $\mathrm{Zn}, \mathrm{Cd}, \mathrm{Hg}$ & & 102 \\
\hline $\mathrm{HgCl}_{2}(a q)+\mathrm{e}^{-} \rightleftharpoons \mathrm{HgCl}(a q)+\mathrm{Cl}^{-}$ & $-0.55 \pm 0.02$ & \\
\hline & & \\
\hline
\end{tabular}

429

430 
431 Table 2. Gibbs Energies of Formation, $\Delta_{\mathrm{f}} G^{\circ}$

432

\begin{tabular}{|c|c|c|}
\hline Radical & $\Delta_{\mathrm{f}} G^{\circ} / \mathrm{kJ} \mathrm{mol}^{-1}$ & Data Sheet \# \\
\hline $\mathrm{e}_{\mathrm{aq}}^{-}$ & $+278 \pm 2$ & 1.1 \\
\hline $\mathrm{O}^{\bullet-}$ & $+93.1 \pm 1.7$ & 2 \\
\hline $\mathrm{OH}^{\bullet}$ & $+26.3 \pm 1.6$ & 7 \\
\hline $\mathrm{O}_{2}^{\bullet-}$ & $+33.8 \pm 1.9$ & 3 \\
\hline $\mathrm{HO}_{2}{ }^{\bullet}(a q)$ & $+7 \pm 2$ & 3 \\
\hline $\mathrm{O}_{3}^{\bullet-}$ & $+75 \pm 2$ & 23 \\
\hline $\mathrm{H}^{\bullet}(a q)$ & $+223 \pm 2$ & 1.1 \\
\hline $\mathrm{Cl}^{\circ}(a q)$ & $+103.4 \pm 1.7$ & 7 \\
\hline $\mathrm{Cl}_{2}{ }^{\bullet-}(a q)$ & $-57.3 \pm 1.6$ & 7 \\
\hline $\mathrm{ClOH}^{\bullet-}(a q)$ & $-104.0 \pm 1.7$ & 7 \\
\hline $\mathrm{ClO}^{\bullet}(a q)$ & $+97 \pm 3$ & 25 \\
\hline $\mathrm{ClO}_{2}{ }^{\circ}(a q)$ & $+110 \pm 10$ & 24 \\
\hline $\mathrm{ClO}_{3}{ }^{\bullet}(a q)$ & $+221.6 \pm 3$ & 7 \\
\hline $\mathrm{Br}_{2}^{\bullet-}$ & $-51 \pm 2$ & 26 \\
\hline $\mathrm{Br}^{\bullet}$ & $+85 \pm 2$ & 26 \\
\hline $\mathrm{BrO}_{2}^{\bullet}(a q)$ & $+152 \pm 4$ & 40 \\
\hline $\mathrm{BrOH}^{\circ-}$ & $-93 \pm 2$ & 26 \\
\hline $\mathrm{BrSCN}^{\bullet-}$ & $+129 \pm 3$ & 26 \\
\hline $\mathrm{I}_{2}^{\bullet-}$ & $-2.1 \pm 1.9$ & 45 \\
\hline $\mathrm{I}^{\bullet}$ & $+78.8 \pm 2$ & 45 \\
\hline $\mathrm{IOH}^{\bullet-}$ & $-82.7 \pm 2$ & 45 \\
\hline $\mathrm{S}^{\bullet-}$ & $+140 \pm 3$ & 77 \\
\hline $\mathrm{HS}^{\bullet}$ & $+121 \pm 3$ & 77 \\
\hline $\mathrm{HSS}^{\bullet 2-}$ & $+129 \pm 4$ & 77 \\
\hline $\mathrm{SO}_{3}{ }^{--}$ & $-416 \pm 2$ & 59 \\
\hline $\mathrm{SO}_{4}{ }^{\bullet-}(a q)$ & $-509.4 \pm 1.8$ & 7 \\
\hline $\mathrm{SO}_{5}{ }^{\bullet-}(a q)$ & $-506 \pm 3$ & 66 \\
\hline $\mathrm{S}_{2} \mathrm{O}_{3}^{--}$ & $-392 \pm 8$ & 71 \\
\hline $\mathrm{S}_{4} \mathrm{O}_{6}{ }^{\bullet 3-}$ & $-939 \pm 8$ & 71 \\
\hline $\mathrm{SeO}_{3}^{\bullet-}$ & $-202 \pm 3$ & 78 \\
\hline $\mathrm{HSeO}_{4}{ }^{\bullet 2-}$ & $-358 \pm 3$ & 78 \\
\hline $\mathrm{TeO}_{3}{ }^{--}$ & $-214 \pm 3$ & 79 \\
\hline $\mathrm{HTeO}_{4}{ }^{\bullet 2-}$ & $-394 \pm 3$ & 79 \\
\hline $\mathrm{TeO}_{4}{ }^{\bullet 3-}$ & $-319 \pm 3$ & 79 \\
\hline $\mathrm{N}_{3} \bullet(a q)$ & $+476 \pm 8$ & 80 \\
\hline $\mathrm{NO}^{\bullet}(a q)$ & $+102.0 \pm 0.2$ & 90 \\
\hline $\mathrm{H}_{2} \mathrm{NO}^{\bullet}(a q)$ & $+66 \pm 3$ & 87 \\
\hline $\mathrm{NO}_{2}^{\bullet}(a q)$ & $+62.3 \pm 0.5$ & 88 \\
\hline $\mathrm{NO}_{3}{ }^{\circ}(a q)$ & $+126.7 \pm 1.8$ & 7 \\
\hline $\mathrm{CO}_{2}^{\circ-}$ & $-205 \pm 2$ & 98 \\
\hline
\end{tabular}


$\mathrm{CO}_{3}{ }^{\circ}$

$\mathrm{SCN}^{\bullet}$

$(\mathrm{SCN})_{2}{ }^{\bullet-}$

$\mathrm{ISCN}^{\bullet}$

$\mathrm{Tl}^{2+}$

$\mathrm{TlOH}^{+}$
$-373 \pm 3$

$+248 \pm 2$

$+310 \pm 2$

$+152 \pm 2$

$+182.3 \pm 1.2$

$-27.6 \pm 1.3$
99

101

101

45

7

7

433

434 
Table 3. Inorganic radical $\mathrm{p} K_{\mathrm{a}} \mathrm{s}$ and related hydrolysis

\begin{tabular}{|c|c|c|c|}
\hline Reaction & $K_{\mathrm{a}} / \mathrm{M}$ & $\mathrm{p} K_{\mathrm{a}}$ & Data Sheet \# \\
\hline $\mathrm{H}^{\bullet}(a q) \rightleftharpoons \mathrm{e}^{-}(a q)+\mathrm{H}^{+}$ & $(2.48 \pm 0.24) \times 10^{-10}$ & & 1.2 \\
\hline $\mathrm{OH}^{\bullet}(a q) \rightleftharpoons \mathrm{O}^{\bullet-}+\mathrm{H}^{+}$ & & $11.7 \pm 0.1$ & 116 \\
\hline $\mathrm{HO}_{2}^{\bullet}(a q) \rightleftharpoons \mathrm{O}_{2}^{\bullet-}+\mathrm{H}^{+}$ & & $4.8 \pm 0.1$ & 3 \\
\hline $\mathrm{HO}_{3}^{\bullet}(a q) \rightleftharpoons \mathrm{O}_{3}^{\bullet-}+\mathrm{H}^{+}$ & No recommendation & & 23 \\
\hline $\mathrm{Cl}^{\bullet}(a q)+\mathrm{H}_{2} \mathrm{O}(l) \rightleftharpoons \mathrm{ClOH}^{\bullet-}+\mathrm{H}^{+}$ & $\begin{array}{l}5 \times 10^{-6}, \text { within a } \\
\text { factor of } 2\end{array}$ & & 7 \\
\hline $\mathrm{Br}^{\bullet}(a q)+\mathrm{H}_{2} \mathrm{O}(l) \rightleftharpoons \mathrm{BrOH}^{\bullet-}+\mathrm{H}^{+}$ & & $\begin{array}{l}10.50 \pm \\
0.07\end{array}$ & 26 \\
\hline $\mathrm{I}^{\bullet}(a q)+\mathrm{H}_{2} \mathrm{O}(l) \rightleftharpoons \mathrm{IOH}^{\bullet-}+\mathrm{H}^{+}$ & & $13.3 \pm 0.5$ & 45 \\
\hline $\mathrm{HS}^{\bullet}(a q) \rightleftharpoons \mathrm{S}^{\bullet-}+\mathrm{H}^{+}$ & & $3.4 \pm 0.7$ & 77 \\
\hline $\mathrm{HS}_{4} \mathrm{O}_{6}{ }^{\bullet 2-} \rightleftharpoons \mathrm{S}_{4} \mathrm{O}_{6}{ }^{\bullet 3-}+\mathrm{H}^{+}$ & & 6.2 & 71 \\
\hline $\mathrm{NH}_{2} \mathrm{OH}^{\bullet+} \rightleftharpoons \mathrm{NH}_{2} \mathrm{O}^{\bullet}+\mathrm{H}^{+}$ & & $<-5$ & 105 \\
\hline $\mathrm{NH}_{2} \mathrm{O}^{\bullet} \rightleftharpoons \mathrm{NHO}^{\bullet-}+\mathrm{H}^{+}$ & & $12.6 \pm 0.3$ & 105 \\
\hline $\mathrm{HPO}_{3}^{\bullet-} \rightleftharpoons \mathrm{PO}_{3}^{\bullet 2-}+\mathrm{H}^{+}$ & & $5.75 \pm 0.05$ & 106 \\
\hline $\mathrm{H}_{2} \mathrm{PO}_{3}^{\bullet} \rightleftharpoons \mathrm{HPO}_{3}^{\bullet-}+\mathrm{H}^{+}$ & 1.1 & & 107 \\
\hline $\mathrm{H}_{3} \mathrm{PO}_{3}^{\bullet+} \rightleftharpoons \mathrm{H}_{2} \mathrm{PO}_{3}^{\bullet}+\mathrm{H}^{+}$ & 54 & & 107 \\
\hline $\mathrm{H}_{2} \mathrm{PO}_{4}^{\bullet} \rightleftharpoons \mathrm{HPO}_{4}^{\bullet-}+\mathrm{H}^{+}$ & & $5.7 \pm 0.4$ & 108 \\
\hline $\mathrm{HPO}_{4}{ }^{\bullet-} \rightleftharpoons \mathrm{PO}_{4}^{\bullet 2-}+\mathrm{H}^{+}$ & & $8.9 \pm 0.2$ & 108 \\
\hline $\mathrm{HPO}_{5}{ }^{\bullet-} \rightleftharpoons \mathrm{PO}_{5}{ }^{\bullet-}+\mathrm{H}^{+}$ & & $3.4 \pm 0.2$ & 109 \\
\hline $\mathrm{As}(\mathrm{OH})_{4}{ }^{\bullet} \rightleftharpoons \mathrm{As}(\mathrm{OH})_{3} \mathrm{O}^{\bullet-}+\mathrm{H}^{+}$ & & $7.38 \pm 0.06$ & 110 \\
\hline $\begin{array}{l}\mathrm{As}(\mathrm{OH})_{4}{ }^{\bullet} \rightleftharpoons \mathrm{HAsO}_{3}{ }^{\bullet-}+\mathrm{H}_{2} \mathrm{O}+ \\
\mathrm{H}^{+}\end{array}$ & & $3.85 \pm 0.05$ & 110 \\
\hline $\mathrm{HAsO}_{3}{ }^{\bullet-} \rightleftharpoons \mathrm{AsO}_{3}{ }^{\bullet 2-}+\mathrm{H}^{+}$ & & $7.81 \pm 0.04$ & 110 \\
\hline $\mathrm{HCO}_{2}^{\bullet} \rightleftharpoons \mathrm{CO}_{2}^{\bullet-}+\mathrm{H}^{+}$ & & NR & 100 \\
\hline $\mathrm{HCO}_{3}^{\bullet} \rightleftharpoons \mathrm{CO}_{3}^{\bullet-}+\mathrm{H}^{+}$ & & $<0$ & 99 \\
\hline $\mathrm{SCN}^{\bullet}+\mathrm{H}_{2} \mathrm{O} \rightleftharpoons \mathrm{HOSCN}^{\bullet-}+\mathrm{H}^{+}$ & & $12.5 \pm 0.1$ & 111 \\
\hline $\mathrm{Tl}^{2+}+\mathrm{H}_{2} \mathrm{O}(l) \rightleftharpoons \mathrm{TlOH}^{+}+\mathrm{H}^{+}$ & $(1.7 \pm 0.3) \times 10^{-5}$ & & 7 \\
\hline
\end{tabular}


Table 4: Hemicolligation Equilibria

440

\begin{tabular}{|l|l|l|}
\hline Reaction & $K / \mathrm{M}^{-1}$ & Data Sheet \# \\
\hline & & \\
\hline $\mathrm{O}_{2}(a q)+\mathrm{O}^{\bullet-} \rightleftharpoons \mathrm{O}_{3}^{\bullet-}$ & $(1.4 \pm 0.1) \times 10^{6}$ & 23 \\
\hline $\mathrm{Cl}^{\bullet}(a q)+\mathrm{Cl}^{-} \rightleftharpoons \mathrm{Cl}_{2}^{\bullet-}$ & $(1.4 \pm 0.2) \times 10^{5}$ & 10 \\
\hline $\mathrm{OH}^{\bullet}(a q)+\mathrm{Cl}^{-} \rightleftharpoons \mathrm{ClOH}^{\bullet-}$ & $0.70 \pm 0.13$ & 12 \\
\hline $\mathrm{Br}^{\bullet}(a q)+\mathrm{Br}^{-} \rightleftharpoons \mathrm{Br}_{2}^{\bullet-}$ & $(3.9 \pm 1.2) \times 10^{5}$ & 33 \\
\hline $\mathrm{OH}^{\bullet}(a q)+\mathrm{Br}^{-} \rightleftharpoons \mathrm{BrOH}^{\bullet-}$ & $(3.2) \times 10^{2}$ within factor of 2 & 34 \\
\hline $\mathrm{I}^{\bullet}(a q)+\mathrm{I}^{-} \rightleftharpoons \mathrm{I}_{2}^{\bullet-}$ & $1.35 \times 10^{5}$ & 52 \\
\hline $\mathrm{S}^{\bullet-}+\mathrm{SH}^{-} \rightleftharpoons \mathrm{HSS}^{\bullet-}$ & $(9 \pm 2) \times 10^{3}$ & 117 \\
\hline $\mathrm{S}_{2} \mathrm{O}_{3}^{\bullet-}+\mathrm{S}_{2} \mathrm{O}_{3}^{2-} \rightleftharpoons \mathrm{S}_{4} \mathrm{O}_{6}^{\bullet-}{ }^{--}$ & $\mathrm{Log} K=4.1 \pm 0.5$ & 71 \\
\hline $\mathrm{N}_{3}^{\bullet}(a q)+\mathrm{N}_{3}^{-} \rightleftharpoons \mathrm{N}_{6}^{\bullet-}$ & $0.24 \pm 0.08$ & 85 \\
\hline $\mathrm{HAsO}_{3}^{\bullet-}+\mathrm{H}_{2} \mathrm{O} \rightleftharpoons \mathrm{As}^{-}\left(\mathrm{OH}_{3} \mathrm{O}^{\bullet-}\right.$ & $\mathrm{p} K=3.53 \pm 0.11$ & 110 \\
\hline $\mathrm{SCN}^{\bullet}(a q)+\mathrm{SCN}^{-} \rightleftharpoons\left(\mathrm{SCN}_{2}{ }^{\bullet-}\right.$ & $(2.0 \pm 0.3) \times 10^{5}$ & 101 \\
\hline $\mathrm{S}_{2} \mathrm{O}_{3}{ }^{\bullet-}+\mathrm{SCN}^{-} \rightleftharpoons \mathrm{SCNS}_{2} \mathrm{O}_{3}^{\bullet-}$ & $1.2 \times 10^{3}$ within a factor of 2 & 75 \\
\hline $\mathrm{Tl}^{\bullet}(a q)+\mathrm{Tl}^{+} \rightleftharpoons \mathrm{Tl}_{2}^{+}$ & $140 \pm 7$ & 112 \\
\hline $\mathrm{Tl}^{+}+\mathrm{OH}^{\bullet}(a q) \rightleftharpoons \mathrm{TlOH}^{+}$ & $(5.8 \pm 1.0) \times 10^{3}$ & 19 \\
\hline $\mathrm{Tl}^{2+}+\mathrm{Cl}^{-} \rightleftharpoons \mathrm{TlCl}^{+}$ & $(6.2 \pm 0.7) \times 10^{4}$ & 113 \\
\hline $\mathrm{TlCl}^{+}+\mathrm{Cl}^{-} \rightleftharpoons \mathrm{TlCl}_{2}$ & $(1.9 \pm 0.4) \times 10^{3}$ & 114 \\
\hline $\mathrm{TlCl}_{2}+\mathrm{Cl}^{-} \rightleftharpoons \mathrm{TlCl}_{3}^{-}$ & $13 \pm 3$ & 115 \\
\hline
\end{tabular}

441

442

443

444 


\section{Data Sheet 1}

\subsection{Reaction of $\mathrm{e}^{-}$aq with $\mathrm{H}_{2} \mathrm{O}$ and $\mathrm{NH}_{4}{ }^{+}$}

Chemical equilibrium: $\mathrm{e}^{-}{ }_{\mathrm{aq}}+\mathrm{H}_{2} \mathrm{O} \rightleftharpoons \mathrm{H}^{\bullet}+\mathrm{OH}^{-}$

The equilibrium constant for this reaction can be obtained either through the direct study of the reaction, or indirectly through the study of a reaction of the electron with a protonated species, coupled with the protonation constant for that species.

\section{List of reports:}

\section{Forward reaction}

Fielden \& Hart, 1967 [1].

Solution contains $0.7 \mathrm{mM} \mathrm{H}_{2}$

$$
k_{\mathrm{f}}=890 \mathrm{~s}^{-1} \quad E_{\mathrm{a}}=28 \pm 3 \mathrm{~kJ} \mathrm{~mol}^{-1}\left(6.7 \pm 0.7 \mathrm{kcal} \mathrm{mol}^{-1}\right)
$$

Pulse radiolysis of a solution containing $\mathrm{Ba}(\mathrm{HO})_{2}$ and formate, at $\mathrm{pH} \sim 11$. Hydrated electron decay monitored by absorption spectrophotometry. Rate constant determined by extrapolation to zero $\left[\mathrm{HCO}_{2}^{-}\right]$, not corrected for the reaction of $\mathrm{e}^{-}{ }_{\text {aq }}$ with $\mathrm{H}_{2} \mathrm{O}_{2}$.

474 Schwarz, $1992[3]$.

476 Pulse radiolysis of $\mathrm{H}_{2}$-saturated water and in deaerated formate solutions, following the optical 477 absorption of the hydrated electron.

1. Results extrapolated to $\left[\mathrm{e}^{-}\right.$aq $]=0$ to remove second-order effects. Conditions: $\mathrm{H}_{2}$-saturated, borate-buffered water, $\mathrm{pH} 8.27$ : 


$$
k_{\mathrm{f}}=1050 \mathrm{~s}^{-1} \quad E_{\mathrm{a}}=30.7 \mathrm{~kJ} \mathrm{~mol}^{-1}\left(7.33 \mathrm{kcal} \mathrm{mol}^{-1}\right)
$$

484 Values in any solution were reproducible to $\pm 5 \%$; between solutions: $\pm 10 \%$.

2. Results extrapolated to $\left[\mathrm{e}^{-} \mathrm{aq}\right]=0$, to remove second-order effects. Conditions: de-aerated, borate-buffered formate solution, $\mathrm{pH}$ 9.16. Corrected for the reaction of $\mathrm{e}^{-}$aq with $\mathrm{C}_{2} \mathrm{O}_{4}{ }^{2-}, \mathrm{H}_{2} \mathrm{O}_{2}$ and $\mathrm{H}^{+}$, and for the reaction of $\mathrm{H}^{\bullet}$ with $\mathrm{HO}^{-}$and with $\mathrm{HCO}_{2}^{-}$.

The calculation of the rate constant involves an explicit correction for the reaction of $\mathrm{e}^{-}$aq with $\mathrm{H}_{2} \mathrm{O}_{2}$. These studies were more reproducible than those above, but no specific error limit was

\section{Reverse reaction}

Matheson \& Rabani, 1965 [4].

$$
k_{\mathrm{r}}=(1.8 \pm 0.6) \times 10^{7} \mathrm{M}^{-1} \mathrm{~s}^{-1}
$$

Pulse radiolysis and optical absorption on solutions in the $\mathrm{pH}$ range 7-14 with up to $10.1 \mathrm{MPa}$ (100 atm) $\mathrm{H}_{2}$

Hickel and Sehested, 1985 [5].

Formation of absorbance from $\mathrm{e}^{-}$aq in $\mathrm{H}_{2}$-saturated solutions from 9.01 $\mathrm{MPa}$ to $10.1 \mathrm{MPa}(90-$ $100 \mathrm{~atm}) ; \mathrm{pH} 11.7$ and 12. $t=(15-60){ }^{\circ} \mathrm{C}$.

Activation parameters: $\Delta H^{\ddagger}=23.8 \pm 2.5 \mathrm{~kJ} \mathrm{~mol}^{-1}\left(5.7 \pm 0.6 \mathrm{kcal} \mathrm{mol}^{-1}\right)$ and $\Delta S^{\ddagger}=-25 \pm 8 \mathrm{~kJ} \mathrm{~K}^{-1}$ $513 \mathrm{~mol}^{-1}\left(-6 \pm 2 \mathrm{cal} \mathrm{K}^{-1} \mathrm{~mol}^{-1}\right)$ reported.

515 From these, $\Delta G^{\ddagger}=31.4 \mathrm{~kJ} \mathrm{~mol}^{-1}\left(7.5 \mathrm{kcal} \mathrm{mol}^{-1}\right)$ and $k_{\mathrm{r}}=2.0 \times 10^{7} \mathrm{M}^{-1} \mathrm{~s}^{-1}$ at $298 \mathrm{~K}$. But, Figure 5164 [5] suggests that $k_{\mathrm{f}}=2.9 \times 10^{7} \mathrm{M}^{-1} \mathrm{~s}^{-1}$. Total error estimate: $<20 \%$ 
Buxton et al., 1988 [6].

$$
k_{\mathrm{r}}=2.2 \times 10^{7} \mathrm{M}^{-1} \mathrm{~s}^{-1} \text { (selected value in compilation) }
$$

Han and Bartels, 1992 [7].

Pulse radiolysis of aqueous solutions containing $0.1 \mathrm{~mol} \mathrm{~L}^{-1} t$-BuOH (EPR experiments) or 0.01 mol L ${ }^{-1} \mathrm{Na}_{2} \mathrm{SO}_{3}$ (optical experiments).

Both optical and EPR free induction decay (FID) were utilized to follow $\mathrm{e}^{-}$aq decay after pulse radiolysis. Optical weighted at half of FID results. $\mathrm{Na}_{2} \mathrm{SO}_{3}$ added to remove $\mathrm{O}_{2}$ and $\mathrm{H}_{2} \mathrm{O}_{2} . T=$ $(280-370) \mathrm{K}$. These values supplant earlier ones from the same laboratory.

Marin, et al. 2005 [8].

Optical spectrophotometry used to follow $\mathrm{e}^{-}$aq decay after pulse radiolysis of hydrogenated solutions at $25.0 \mathrm{MPa}$ over the temperature range $(100 \text { to } 300)^{\circ} \mathrm{C}$. At $100{ }^{\circ} \mathrm{C}$, the results were in good agreement with the earlier study from the same laboratory [5]. At the higher temperatures, the activation energy decreased to $25.4 \pm 0.8 \mathrm{~kJ} \mathrm{~mol}^{-1}$.

$$
k_{\mathrm{r}}=(2.51 \pm 0.44) \times 10^{7} \mathrm{M}^{-1} \mathrm{~s}^{-1}
$$$$
A=(1.33 \pm 0.16) \times 10^{14} \mathrm{M}^{-1} \mathrm{~s}^{-1} ; E_{\mathrm{a}}=38.38 \pm 0.31 \mathrm{~kJ} \mathrm{~mol}^{-1}
$$

Renault, et al. 2008 [9]. 


\section{List of reports:}

Schwarz, 1991 [10].

From measurements of the initial absorbance and the absorbance at equilibrium:

$\Delta H^{\mathrm{o}}=-8.4 \pm 0.8 \mathrm{~kJ} \mathrm{~mol}^{-1} ; \Delta S^{\mathrm{o}}=-21 \pm 2 \mathrm{~J} \mathrm{~K}^{-1} \mathrm{~mol}^{-1}$ and $\Delta C_{\mathrm{p}}{ }^{\mathrm{o}}=159 \pm 42 \mathrm{~J} \mathrm{~K}^{-1} \mathrm{~mol}^{-1}$ where the reported error limits include the standard deviations from the fit and possible systematic errors in the correction required to derive the fraction of electrons in the $\mathrm{H}^{\bullet}+\mathrm{e}^{-}$aq pool. These uncertainties indicate a range of $\Delta_{\mathrm{r}} G^{\mathrm{o}}$ from $(-0.7$ to -3.5$) \mathrm{kJ} \mathrm{mol}^{-1}$ and thus a range in $K_{1.1 .2}$ at $298 \mathrm{~K}$ of 4.2 to 1.3 .

$$
k_{\mathrm{f}}=1.5 \times 10^{6} \mathrm{M}^{-1} \mathrm{~s}^{-1} \text { (measured) }
$$

572

573

574

575

576

Chen et al., 1994 [11].

From a study of the solvent effect on the reactivity of the solvated electron, rate constants were measured over the range $(280-370) \mathrm{K}$.

$$
k_{\mathrm{f}}=1.5 \times 10^{6} \mathrm{M}^{-1} \mathrm{~s}^{-1}
$$

$$
E_{\mathrm{a}}=20 \mathrm{~kJ} \mathrm{~mol}^{-1} \text { at } 298 \mathrm{~K}
$$

582

Shiraishi et al., 1994 [12].

584

Pulse radiolysis of solutions containing $\sim 0.1 \mathrm{~mol} \mathrm{~L}^{-1} \mathrm{NH}_{4}^{+}$. 
590 A complex analysis due, in part, to an impurity problem, results in a complicated equation that 591 was "examined by a curve-fitting method". $t=(25-250){ }^{\circ} \mathrm{C}$

\section{Discussion}

595 The results of Han and Bartels [7] for the reverse reaction (-1.1.1) and of Schwarz [3] for the 596 forward reaction (1.1.1) are in very good agreement with the earlier published values. In both 597 cases, however, they represent significant improvements to reduce uncertainties and ensure 598 accurate values. Thus, these are the preferred values for these rate constants.

From the forward and reverse rate constants at $298 \mathrm{~K}$, we obtain the equilibrium constant for the 601 reaction:

602

$$
\mathrm{e}^{-} \mathrm{aq}+\mathrm{H}_{2} \mathrm{O} \rightleftharpoons \mathrm{H}^{\bullet}+\mathrm{OH}^{-}
$$

604 uncertainty, $20 \%$, is based on the combined estimated uncertainties of $10 \%$ for $k_{\mathrm{f}}$ and $17.5 \%$ for $k_{\text {r. }}$.

For the indirect determination of this value, the equilibrium constant reported by Schwarz [10] is preferred, $K_{1.1 .2}=2.23$ corrected to zero ionic strength. It is substantiated by the somewhat less certain study of Shiraishi, et al. [12] and by the kinetic result of Chen, et al. [11] on the

611 forward rate constant. An examination of the results and the good agreement with the other 612 measured value, suggest an uncertainty range of no more than \pm 0.5 . for reaction 1.1 .2

$$
K_{1.1 .2}=2.2 \pm 0.5
$$

616 Combination with the ionization constant for aqueous ammonia:

$$
K_{1.1 .1}=K_{\mathrm{i}} \times K_{1.1 .2}=(3.95 \pm 0.53) \times 10^{-5} \mathrm{~mol} \mathrm{~L}^{-1}
$$


The values derived for $K_{1.1 .1}$ are quite close. Thus, we simply average to get $K_{1.1 .1}=(4.0 \pm$ $0.5) \times 10^{-5} \mathrm{~mol} \mathrm{~L}^{-1}$ as the recommended value and $\Delta_{\mathrm{r}} G(1.1 .1)=+(25.1 \pm 0.3) \mathrm{kJ} \mathrm{mol}^{-1}$.

627 The value for the Gibbs energy change associated with this reaction can be converted to the 628 standard potential of the electron by making use of the solubility of the hydrogen atom:

$$
\mathrm{H}^{\bullet}(\mathrm{aq}) \rightleftharpoons \mathrm{H}^{\bullet}(\mathrm{g})
$$

$$
\Delta_{\text {solv }} G^{\mathrm{o}}=-19.99 \pm 2.22 \mathrm{~kJ} \mathrm{~mol}^{-1} \text { (see Data Sheet }
$$

\section{$1.2 \mathrm{p} K_{\mathrm{a}}$ of $\mathrm{H}^{\bullet}$}

\section{List of reports:}

\section{Forward reaction}

Alcorn et al. 2014 [15].

656 Reaction of muonium with water studied from $200{ }^{\circ} \mathrm{C}$ to $425^{\circ} \mathrm{C}$ as a surrogate for the hydrogen 657 atom. DFT calculations augmented with single-point MP4 energy calculations, were used to 658 model the reaction, particularly the abstraction channel, $\mathrm{H}^{\bullet}+\mathrm{H}_{2} \mathrm{O} \rightleftharpoons \mathrm{H}_{2}+{ }^{\bullet} \mathrm{OH}$. These were 
659 combined with higher-level calculations on $\mathrm{H}_{3} \mathrm{O}^{\bullet} \cdot\left(\mathrm{H}_{2} \mathrm{O}\right)_{n}$ clusters. These clusters were found to 660 be charge-separated species, corresponding to the products of reaction (1.2), separated by some 661 number of water molecules. Reaction 1.2, then, can be considered the reaction of $\mathrm{H}^{\bullet}$ with an 662 exterior water molecule to form $\mathrm{H}_{3} \mathrm{O}^{\bullet}$, which can either rapidly dissociate back to a hydrogen 663 atom and a water molecule, or ionize to an electron and a hydronium ion. (The work of 664 Sobolweski ea al.2002a,b [16a,b ] is cited, but see also Uhlig et al. 2011 [17] and Chulkov et al. $6652009[18]$.

666

667 From this analysis, Alcorn et al. concluded that the abstraction reaction only became significant 668 at $190{ }^{\circ} \mathrm{C}$, where it made up $10 \%$ of the reaction. Below that, the reaction leading to the solvated 669 proton and electron becomes more and more dominant.

\section{Reverse reaction}

673

674 Buxton et al., 1988 [6].

675

Review of the literature.

677

678

$$
k_{\mathrm{r}}=2.3 \times 10^{10} \mathrm{M}^{-1} \mathrm{~s}^{-1} \text { (selected value) }
$$

Elliot et al., 1990 [19].

682

683 Pulse radiolysis measurement of the decay of the absorption due to the hydrated electron in the 684 presence of perchloric acid. The activation energy is about the same as that for diffusion, but the 685 observed rate constant is about five times lower. $T=20-200{ }^{\circ} \mathrm{C}$.

$$
k_{\mathrm{r}}=2.3 \times 10^{10} \mathrm{M}^{-1} \mathrm{~s}^{-1}
$$

689

690

691 Chen et al., 1994 [11].

692 
693 Pulse radiolysis measurement of the decay of the absorption due to the hydrated electron in the 694 presence of $1-7 \times 10^{-5} \mathrm{~mol} \mathrm{~L}^{-1}$ perchloric acid. Measurements were made in isobutanol/water 695 solutions that containined $0-100 \%$ water.

Wu et al., 2002 [20].

702

Contains a graphical presentation over the temperature range $25^{\circ}-400^{\circ} \mathrm{C}$ of $k_{\mathrm{r}}$, the reaction of

Shiraishi et al., 1994 [12].

Value taken from graph. $E_{\mathrm{a}}=11 \mathrm{~kJ} / \mathrm{mol}$ at $298-373 \mathrm{~K}$ (linear part of curved plot, Fig. $\mathrm{K}:$

$$
\mathrm{p} K_{\mathrm{a}}=9.59 \pm 0.03 \text { at } 298 \mathrm{~K} \text {, thus } K_{1.2}=(2.6 \pm 0.2) \times 10^{-10} \mathrm{~mol} \mathrm{~kg}^{-1}
$$

Stevenson et al., 1991 [21].

721 Hovath et al., 1992 [22].

722 
Marsalek et al, 2010 [23]; Uhlig et al. 2011 [17]; Uhlig \& Jungwirth 2013 [24].

The reverse reaction was subjected to an ab initio - molecular dynamics study in a cluster of 32 water molecules. The results indicate that the reacion involves proton transfer, not electron transfer. The fact that the reaction is significantly slower than diffusion controlled is ascribed to

734 the energy required for desolvation of the two charge species. No evidence for the intermediate

735 formation of $\mathrm{H}_{3} \mathrm{O}^{\bullet}$ was found. It was also determined that when starting the calculation with

$736 \mathrm{H}_{3} \mathrm{O}^{\bullet}$, solvent-separated ions were formed with as few as three water molecules.

\section{Discussion}

Equilibrium 1.2 has only been observed above $100{ }^{\circ} \mathrm{C}[11]$. Values at room temperature can be obtained from Reaction 1.1.1:

by $K_{1.2}=K_{\mathrm{w}} / K_{1.1 .1}$, with $K_{\mathrm{w}}=10^{-14} \mathrm{M}^{2}$.

With $K_{1.1 .1}=(4.04 \pm 0.5) \times 10^{-5} \mathrm{~mol} \mathrm{~L}^{-1}$, this leads to $K_{1.2}=(2.48 \pm 0.24) \times 10^{-10} \mathrm{~mol} \mathrm{~L}^{-1}$ and $\Delta_{\mathrm{r}} G^{\mathrm{o}}=54.8 \pm 0.3 \mathrm{~kJ} \mathrm{~mol}^{-1}$.

\subsection{Gibbs energy of solvation of $\mathrm{H}^{\bullet}$}

\section{List of reports:}

There are no actual experimental determinations of the Henry's Law constant for the hydrogen atom, which would lead to the Gibbs energy of the hydrogen atom in water. This quantity has been estimated by comparison with the solubility of other gases - primarily $\mathrm{He}$, due to the similarity in size, and $\mathrm{H}_{2}$. Parker [25a,b] has expanded upon the first approach by pointing out that the $\Delta_{\text {solv }}$ values for the rare gases are correlated with their Van der Waals radii. On the other hand, RodunGer and Bartels [26a,b] have argued that $\mathrm{H}_{2}$ is a much better surrogate for $\mathrm{H}^{\bullet}$ due to

763 their similar polarizability values. 
766 The first question that arises is what set of Van der Waals radii to use for the rare gases and for

767 the hydrogen atom. Zefirov [27] has argued that a consistent set of radii must be taken from a

768 single experimental approach, for example crystallography, and not mixed with other

769 approaches, like equilibrium and gas-kinetic. Crystallographic values for the rare gases have

770 been reviewed recently [28], leading to a set showing a very good linear trend of radii with

771 atomic number (a quadratic fit is even better). This same general trend is shown in other data

772 sets, but the correlation in this set is much better.

773

774 For the hydrogen atom, the radii from 15 data sets in the literature were averaged to yield a value

775 of $(114 \pm 6) \mathrm{pm}$ in this recent review [28]. Other, non-crystallographic values not included are

776 (100 \pm 10$) \mathrm{pm}$ from an extrapolation to zero dipole moment in hydrogen halides [29] and $92 \mathrm{pm}$

777 from an analysis of the hyperfine coupling by EPR spectroscopy [30].

Taking the rare gas radii from $\mathrm{Hu}$, et al. [28] and solubility Gibbs energies from the IUPAC

780 Solubility Data Series [31-34], along with a radius value of $114 \mathrm{pm}$ for $\mathrm{H}^{\bullet}$, we derive $\Delta_{\text {solv }} G=$ $781(22.18 \pm 0.84) \mathrm{kJ} \mathrm{mol}^{-1}$ for standard states of one bar and one $\mathrm{mol} \mathrm{L}^{-1}$, where the error limit is 782 the standard error in the intercept, taking $114 \mathrm{pm}$ as the origin. With $\mathrm{H}^{\bullet}$ radii of $120 \mathrm{pm}$ and 108 $783 \mathrm{pm}$, we obtain (21.57 and 22.80) $\mathrm{kJ} \mathrm{mol}^{-1}$, respectively. For comparison, if we use a recent

784 analysis of Van der Waals radii based on gas-phase structural data, [35] we obtain $\Delta_{\text {solv }} G=21.99$ $785 \mathrm{~kJ} \mathrm{~mol}^{-1}$.

\section{$\mathrm{H}_{2}$ solubility}

788 If we assume the solubility of $\mathrm{H}_{2}$ as a surrogate for that of $\mathrm{H}^{\bullet}$ due to the similar polarizability 789 values, the calculation is straightforward. Taking the solubility from the IUPAC Solubility Data 790 Series, [36] we obtain $\Delta_{\text {solv }} G=(17.74 \pm 0.09) \mathrm{kJ} \mathrm{mol}^{-1}$, for standard states of one bar and one $791 \mathrm{~mol} \mathrm{~L}{ }^{-1}$. The error limit is from the reported standard deviation of the solubility fit.

792

793 Difference in rate constants

794 There is an alternate, somewhat more complicated, method for estimating the solubility of $\mathrm{H}^{\bullet}(\mathrm{g})$ 795 and thus the Gibbs energy of $\mathrm{H}^{\circ}(\mathrm{aq})$ introduced by Roduner and Bartels [26a,b]. This approach 796 compares the rate constant for a reaction in the gas phase with its rate constant in solution. The 797 reaction must have the same mechanism in both phases; an electron transfer reaction would be 798 ruled out, for example, as the reaction would not take place that way in the gas phase. Also the 799 rate constant should not be too close to the diffusion rate constant in either phase. The approach 
makes use of the well-known thermodynamic formulation of transition-state theory, which gives for the rate constant for a bimolecular reaction where $\mathrm{Q}$ is the ratio of the Boltzman constant to Planck's constant and $\Delta G^{\#}$ is the Gibbs energy of activation, that is the Gibbs energy change in going from the reactants to the transition state. The ratio of the rate constant in the aqueous phase, $k(\mathrm{aq})$, and that in that in the gas phase, $k(\mathrm{~g})$, is then simply

$$
k(\mathrm{aq}) / k(\mathrm{~g})=\exp \left(\left[-\Delta_{\text {solv }} G(\mathrm{TS})+\Delta_{\text {solv }} G\left(\mathrm{C}_{6} \mathrm{H}_{6}\right)+\Delta_{\text {solv }} G\left(\mathrm{H}^{\bullet}\right)\right] / \mathrm{R} T\right)
$$

The reaction of the hydrogen atom with benzene appears to be ideally suited for this purpose. In both phases, it has been studied by several groups with reasonable agreement. Taking the

814 solution results of Roduner and Bartels [26a] and the gas results of Nicovich and Ravishankara

815 [37], we obtain an enhancement of a factor of 40.

Solving the equation for the Gibbs energy of solvation of the hydrogen atom requires knowledge of $\Delta_{\text {solv }} G$ for both benzene and the transition state. A recent determination of the Henry's Law constant for benzene, $K_{\mathrm{H}}=\mathrm{C}_{\mathrm{aq}} / \mathrm{C}_{\mathrm{g}}=4.44$, [38] is in good agreement with most previous measurements. This leads to $\Delta_{\text {solv }} G\left(\mathrm{C}_{6} \mathrm{H}_{6}\right)=-3.79 \mathrm{~kJ} \mathrm{~mol}^{-1}$. (We use dimensionless units for $K_{\mathrm{H}}$ since the units used for the rate constants are the same in both phases and thus cancel.) The addition of a hydrogen atom to benzene would be expected to reduce the solubility. For example, for cyclohexene, $K_{\mathrm{H}}=0.57$ [38]. A cyclohexadiene would probably be a good surrogate for the transition state of the reaction. Unfortunately, there are no reported Henry's Law constants for these, but the value for 1,4-cyclohexadiene (cyclohexa-1,4-diene) can be estimated from its water solubility ((0.0117 $\left.\mathrm{mol} \mathrm{L}^{-1}[39]\right)$ and vapor pressure (0.089 atm [40]) to be 3.20 . Thus, we estimate $\Delta_{\text {solv }} G(1,4-\mathrm{C})=\Delta_{\text {solv }} G(\mathrm{TS})=-2.88 \mathrm{~kJ} \mathrm{~mol}^{-1}$. With the above equation, the Gibbs energy of $\mathrm{H}^{\bullet}(\mathrm{aq})$ is calculated to be $\Delta_{\text {solv }} G\left(\mathrm{H}^{\bullet}\right)=10.06 \mathrm{~kJ} \mathrm{~mol}^{-1}$, if the standard states are the same in both phases. Converting to the normal standard-state convention, one bar and one $\mathrm{M}^{-1}$, this

832 The uncertainty in the Gibbs energy value will arise from both the uncertainty in the enrichment 833 factor and the uncertainty in the Gibbs energy of the transition state. An uncertainty factor of $834 \pm 1.7 \mathrm{~kJ} \mathrm{~mol}^{-1}$ would represent a doubling or halving the enhancement factor. This uncertainty range is chosen because values for the gas phase rate constant for the reaction of the hydrogen 
atom with benzene range from half to twice the value used here [41] and some question has been raised about the possibility that the reaction is not at the high-pressure limit [42]. A more recent laser photolysis study, however, supports the rate constant chosen here [43]. The value is solution also is uncertain, having been reported as 50\% lower than the value used here [44]. An enhancement factor in this range is supported by studies on other reactions. From data taken from databases [41,44], we find ratios of 43 (benzonitrile), 22 (naphthalene), 36 (toluene), 15 (chlorobenzene), 28 (nitrobenzene), 9.5 (aniline), and 27 (methoxybenzene). (None of these molecules have been studied as thoroughly as benzene in either phase.) The uncertainty in the

844 Gibbs energy of the transition state is at least $1 \mathrm{~kJ} \mathrm{~mol}^{-1}$, the difference between the values for benzene and cyclohexa-1,4-diene. Thus, we estimate:

$$
\Delta_{\text {solv }} G\left(\mathrm{H}^{\bullet}\right)=+18.0 \pm 2.7 \mathrm{~kJ} \mathrm{~mol}^{-1}
$$

\section{Computational}

850 There has been a theoretical determination of the Helmholtz and Gibbs solvation energies of the

851 hydrogen atom employing path integral Monte Carlo methods that also should be considered.

852 [45] The procedure involved determining the equilibrium solvation in a cubic simulation cell of one solute and108 water molecules. For the Gibbs energy, the value $\Delta_{\text {solv }} G=(21.44 \pm 1.46) \mathrm{kJ}$ mol $^{-1}$ was obtained.

\section{Discussion}

858 There are four values of the Gibbs energy of solvation to chose among: $\Delta_{\text {solv }} G=(17.77 \pm 0.09)$

$859 \mathrm{~kJ} \mathrm{~mol}^{-1}$, from the solubility of $\mathrm{H}_{2} ; \Delta_{\text {solv }} G=(18.0 \pm 2.7) \mathrm{kJ} \mathrm{mol}^{-1}$ from the reaction of $\mathrm{H}^{\bullet}$ with

$860 \mathrm{C}_{6} \mathrm{H}_{6} ; \Delta_{\text {solv }} G=(21.44 \pm 1.46) \mathrm{kJ} \mathrm{mol}^{-1}$ from a theoretical calculation; and $\Delta_{\text {solv }} G=(22.21 \pm 0.84)$

$861 \mathrm{~kJ} \mathrm{~mol}^{-1}$ from the solubility of the rare gases.

The use of $\mathrm{H}_{2}$ as a surrogate for $\mathrm{H}^{\bullet}$ is supported by the observation that the Gibbs energy of solvation of a non-polar solute in water is proportional to its polarizability. Indeed, both the entropies and the enthalpies of solvation of the rare gases, along with $\mathrm{H}_{2}$ and $\mathrm{N}_{2}$ are smoothly related to this parameter [46]. On the other hand, whereas $\mathrm{O}_{2}$ is less polarizable than $\mathrm{N}_{2}$, it is

867 twice as soluble [47]. This was due to the difference in solvation enthalpy and was ascribed to 868 the energy required for cavity formation, with the observation from theoretical analysis that the 869 interaction between $\mathrm{N}_{2}$ and water was about twice that of $\mathrm{O}_{2}$. It should be pointed out that the 870 difference in polarizability between $\mathrm{N}_{2}$ and $\mathrm{O}_{2}$ is only about $20 \%$, while that between $\mathrm{H}^{\bullet}$ and $\mathrm{He}$ 871 is a factor of three [46]. 
873 The use of the Van der Waals radii of $\mathrm{H}^{\bullet}$ and the rare gases to derive a value for the solubility of

$874 \mathrm{H}^{\bullet}$ is based on the observation that the Gibbs energies of solvation of the rare gases are

875 correlated with the radii. The value obtained in this way is supported by the one theoretical

876 calculation addressing this matter. In addition, there have been a number of theoretical studies

877 which also may provide some insight into the solubility, even though they mostly deal with the

878 diffusion of $\mathrm{H}^{\bullet}$. The diffusion coefficient of $\mathrm{H}^{\bullet}$ is surprisingly high [48], close to that of the

879 proton, $\mathrm{H}^{+}$, which has a mechanism for diffusion unavailable to the uncharged atom [49]. He

880 diffuses similarly rapidly, with $\mathrm{H}_{2}$ and $\mathrm{Ne}$ a bit slower. The behavior of $\mathrm{H}^{\bullet}$ has been addressed in

881 molecular dynamics studies [49-52]. Pure water is characterized by hydrophobic cavities that are

882 spontaneously created and destroyed. These cavities have the right size to host a small solute

883 such as $\mathrm{H}^{\bullet}$. The rapid diffusion arises from an exchange of water molecules, structural diffusion,

884 which is unlike the behavior of small hydrated cations which will travel with their hydration

885 shell attached [50]. Of particular interest is that $\mathrm{H}^{\bullet}$ does not seem to exhibit any particular

886 interactions with the solvent shell, except some repulsion. The hydrogen atom also participates in

887 some intercavity hopping, essentially tunneling, which also explains the even greater diffusion

888 coefficient of muonium [52].

890 The Gibbs energies of solution derived from the solubility of $\mathrm{H}_{2}$ and from the rare gases

891 probably represent two extreme cases: one in which the solubility depends primarily on

892 interactions with the solvent, and one in which the size of the solute is the primary parameter.

893 The correct picture is probably somewhere in between. Thus, we have averaged these two values

894 and obtain $(19.99 \pm 2.22) \mathrm{kJ} \mathrm{mol}^{-1}$ where the uncertainty represents the range of the two values.

895 Of great importance is that this value is very close to that derived from the enhancement of the

896 rate constant for the addition to benzene in solution over that in the gas phase.

This value can be converted to the standard potential of $\mathrm{H}^{\bullet}$ by making use of the known enthalpy of dissociation of $\mathrm{H}_{2}$ in the gas phase and the defined Gibbs energy of the normal hydrogen

900 electrode, as follows:

901

902

903

904

905

906

$$
\begin{array}{ll}
\mathrm{H}^{+}(\mathrm{aq})+\mathrm{e}^{-} \rightleftharpoons 1 / 2 \mathrm{H}_{2}(\mathrm{~g}) & \Delta_{\mathrm{r}} G^{\mathrm{o}}=0 \\
1 / 2 \mathrm{H}_{2}(\mathrm{~g}) \rightleftharpoons \mathrm{H}^{\bullet}(\mathrm{g}) & \Delta_{\mathrm{r}} G^{\mathrm{o}}=+203.278 \mathrm{~kJ} \mathrm{~mol}^{-1}[14] \\
\mathrm{H}^{\bullet}(\mathrm{g}) \rightleftharpoons \mathrm{H}^{\bullet}(\mathrm{aq}) & \Delta_{\text {solv }} G^{\mathrm{o}}=+19.99 \mathrm{~kJ} \mathrm{~mol}^{-1}
\end{array}
$$

$$
\mathrm{H}^{\bullet}(\mathrm{g}) \rightleftharpoons \mathrm{H}^{\bullet}(\mathrm{aq})
$$

$$
\mathrm{H}^{+}(\mathrm{aq})+\mathrm{e}^{-} \rightleftharpoons \mathrm{H}^{\bullet}(\mathrm{aq}) \quad \Delta_{\mathrm{r}} G^{\mathrm{o}}=+223.27 \mathrm{~kJ} \mathrm{~mol}^{-1}, E^{\mathrm{o}}=-2.31 \mathrm{~V}
$$


908 The Gibbs energy for the dissociation of $\mathrm{H}_{2}$ decreases as the temperature is raised; the Gibbs 909 energy of solution of $\mathrm{H}^{\bullet}(\mathrm{g})$ increases. As a result, at least for $(0-70){ }^{\circ} \mathrm{C}$, the standard potential

910 for $\mathrm{H}^{\bullet}(\mathrm{aq})$ is independent of temperature, based on this derivation.

912 The range that arises from the two competing models for the Gibbs energy of solvation, $\pm 2.2 \mathrm{~kJ}$

$913 \mathrm{~mol}^{-1}$, probably best represents the uncertainty in the standard potential or the Gibbs energy of

914 the hydrogen atom. Thus, the recommended values are as follows:

915

916 Recommended values:

917

$918 \Delta_{\text {solv }} G=+20 \pm 2 \mathrm{~kJ} \mathrm{~mol}^{-1}$

$919 E^{\mathrm{o}}=-2.31 \pm 0.03 \mathrm{~V}$

$920 K_{\mathrm{h}}=0.313 \times 10^{-4} \mathrm{~mol} \mathrm{~L}^{-1} \mathrm{MPa}^{-1}\left(3.1 \times 10^{-4} \mathrm{~mol} \mathrm{~L}^{-1} \mathrm{~atm}^{-1}\right)$ with a range of $(0.131-0.778) \times 10^{-}$

$921{ }^{4} \mathrm{~mol} \mathrm{~L}^{-1} \mathrm{MPa}^{-1}\left\{(1.3-7.7) \times 10^{-4} \mathrm{~mol} \mathrm{~L}^{-1} \mathrm{~atm}^{-1}\right\}$.

924 Nomenclature

925

926 The recommended name of $\mathrm{H}^{\bullet}$ is hydrogen or, to avoid confusion, mono-hydrogen. There is no

927 recommended name for $\mathrm{e}^{-}$aq. $\mathrm{HClO}_{4}$, hydroxidotrioxidochlorine; perchloric acid is accepted.

\section{References}

931 1. E. M. Fielden, E. J. Hart. Trans. Faraday Soc. 63, 2975-2982 (1967).

932 2. A. J. Swallow. Photochem. Photobiol. 7, 683-694 (1968).

933 3. H. A. Schwarz. J. Phys. Chem. 96, 8937-8941 (1992).

934 4. M. S. Matheson, J. Rabani. J. Phys. Chem. 69, 1324-1335 (1965).

935 5. B. Hickel, J. Sehested. J. Phys. Chem. 89, 5271-5274 (1985).

936 6. G. V. Buxton, C. L. Greenstock, W. P. Helman, A. B. Ross. J. Phys. Chem. Ref. Data 17, 937 513-886 (1988).

938 7. P. Han, D. M. Bartels. J. Phys. Chem. 96, 4899-4906 (1992).

939 8. T. W. Marin, C. D. Jonah, D. M. Bartels. J. Phys. Chem. A 109, 1843-1848 (2005).

940 9. J. P. Renault, R. Vuilleumier, S. Pommeret. J. Phys. Chem. A 112, 7027-7034 (2008).

941 10. H. A. Schwarz. J. Phys. Chem. 95, 6697-6701 (1991).

942 11. R. Chen, Y. Avotinsh, G. R. Freeman. Can. J. Chem. 72, 1083-1093 (1994). 
943 12. H. Shiraishi, G. R. Sunaryo, K. Ishigure. J. Phys. Chem. 98, 5164-5173 (1994).

944 13. A. J. Read. J. Solution. Chem. 11, 649-664 (1982).

945 14. M. W. Chase, J. Phys. Chem. Ref. Data, Monograph 9 (1998).

946 15. C. D. Alcorn, J. C. Brodovitch, P. W. Percival, M. Smith, K. Ghandi, K.Chem. Phys.

947 435, 29-39 (2014).

948 16a. A. I. Sobolewski, W. Domcek, J. Phys. Chem. A 106, 4158-4167 (2002).

949 16b. A. I. Sobolewski, W. Domcek, Phys. Chem. Chem. Phys. 4, 4-10 (2002).

950 17. F. Uhlig, O. Marsalek, P. Jungwirth, Phys. Chem. Chem. Phys. 13, 14003-14009 (2011).

951 18. S. K. Chulkov, N. F. Stepanov, N. F.Y. V. Novakovskaya, Russ. J. Phys. Chem. 83, 798952808 (2009).

953 19. A. J. Elliot, D. R. McCracken, G. V. Buxton, N. D. Wood. J. Chem. Soc., Faraday Trans. 954 86, 1539-1547 (1990).

955 20. G. Wu, Y. Katsumura, M. Lin, T. Morioka, Y. Muroya. Phys. Chem. Chem. Phys. 4, 956 3980-3988 (2002).

957 21. K. L. Stevenson, R. M. Berger, M. M. Grush, J. C. Stayanoff. J. Photochem. Photobiol. 958 A:Chem. 60, 215-227 (1991).

959 22. A. Horváth, O. Horváth, K. L. Stevenson. J. Photochem. Photobiol. A:Chem. 68, 155-163 960 (1992).

961 23. O. Marsalek, T. Frigato, J. VandeVondele, S. E. Bradforth, B. Schmidt, C. Schütte, P. 962 Jungwirth, J. Phys. Chem. B 114, 915-920 \{2010).

963 24. F. Uhlig, P. Jungwirth, Z. Phys. Chem. 2013, 9-11 (2013).

964 25a. V. D. Parker. J. Am. Chem. Soc. 114, 7458-7462 (1992).

965 25b. V. D. Parker. Acta Chem. Scand. 46, 692-694 (1992).

966 26a. E. Roduner, D. M. Bartels. Ber. Bunsenges. physik. Chem. 96, 1037-1042 (1992);

$96726 b \quad$ E. Roduner, Rad. Phys. Chem. 72, 201-201 (2005).

968 27. Y. V. Zefirov Rus. J. Inorg. Chem. 2001, 46, 646-650.

969 28. S. Z. Hu, Z. H. Zhou, Z. X. Xie, B. E. Robertson Z. Kristallogr. 2014; 229: 517-523.

970 29. P. K. Mandal, E. Arunan J. Chem. Phys. 2001, 114, 3880-3882.

971 30. K. Nuzhdin, D. M. Bartels J. Chem. Phys. 2013, 138, 124503.

972 31. R. Battino. In Helium and Neon - Gas Solubilities, (H. L. Clever, ed.), IUPAC. Solubility 973 Data Series, Vol. 1, p. 1-5. Pergamon Press, Oxford (1979).

974 32. R. Battino. In Helium and Neon - Gas Solubilities, (H. L. Clever, ed.), IUPAC. Solubility 975 Data Series. Vol. 1, p. 124-126. Pergamon, Oxford (1979).

976 33. R. Battino. In Argon, (H. L. Clever, ed.), IUPAC. Solubility Data Series, Vol. 4, p. 1-3. 977 Pergamon Press, Oxford (1980). 
978 34. R. Battino. In Kypton, Xenon and Radon - Gas Solubilities, (H. L. Clever, ed.), IUPAC.

979 Solubility Data Series, Vol. 2, p. 1-3. Pergamon Press, Oxford (1979).

$980 \quad 35 . \quad$ J. Vogt, S. Alvarez Inorg. Chem. 2014, 53, 9260-9266.

981 36. R. Battino and E. Wilhelm. In Hydrogen and Deuterium, (C. L. Young, ed.), IUPAC.

982 Solubility Data Series, Vol. 5/6, p. 1-3. Pergamon Press, Oxford (1981).

983 37. J. M. Nicovich, A. R. Ravishankara. J. Phys. Chem. 88, 2534-2541 (1984).

984 38. A. M. Bakierowska, J. Trzeszczynski. Fluid Phase Eq. 213, 139-146 (2003).

985 39. A. Maczynski, D. G. Shaw. J. Phys. Chem. Ref. Data 34, 657-708 (2005).

986 40. T. M. Letcher, F. Marsicano. J. Chem. Thermodynamicdyn. 6, 509-514 (1974).

987 41. NIST Chemical Kinetics Database, Standard Reference Database 17, Version 7.0,

988 Release 1.4.3 http://kinetics.nist.gov/kinetics/index.jsp. 2009. National Institute of Standards 989 and Technology.

990 42. A. M. Mebel, M. C. Lin, T. Yu, K. Morokuma. J. Phys. Chem. A 101, 3189-3196 (1997).

991 43. Y. Gao, N. J. DeYonker, E. C. Garret III, A. K. Wilson, T. R. Cundari, P. Marshall. J. 992 Phys. Chem. A 113, 6955-6963 (2009).

993 44. NDRL/NIST Solution kinetics database on the web. NIST standard reference database

994 40. A compilation of kinetics data on solution-phase reactions.

995 http://kinetics.nist.gov/solution/. http://kinetics.nist.gov/solution/ . 2002. National Institute of 996 Standards and Technology.

997 45. H. Gai, B. C. Garrett, J. Phys. Chem. 98, 9642-9648 (1994).

998 46. E. Roduner, Rad. Phys. Chem. 72, 201-206 (2005).

999 47. R. Battino, P. Seybold. J. Chem. Eng. Data 56, 5036-5044 (2011).

1000 48. V. A. Benderskii, A. G. Krivenko Russ. J. Electrochem. 32 663-669 (1996).

1001 49. A. Pomogaeva, D. M. Chipman J. Phys. Chem. B 117, 16530-16541 (2013).

1002 50. B. Kirchner, J. Stubbs, D. Marx Phys. Rev. Lett. 89, 215901 (2002)

1003 51. J. P. Renault, R. Vuilleumier, S. Pommeret J. Phys. Chem. A 112, 7027-7034 (2008).

1004 52. T. E. Markland, S. Habershon, D. E. Manolopoulos J. Chem. Phys. 128, 194506 (2008).

1005

$1006 \quad 1.4$ Hydration Gibbs energies for the electron and the proton

1007

1008 The electrode potential of the electron is connected to well-known gas-phase dissociation and

1009 photoionization values through the hydration Gibbs energies of the electron and the proton.

1010

1011

1012

1013

$$
\begin{array}{ll}
1 / 2 \mathrm{H}_{2}(\mathrm{~g}) \rightleftharpoons \mathrm{H}^{\bullet}(\mathrm{g}) & \Delta_{\mathrm{r}} G^{\circ}=+203.278 \mathrm{~kJ} \mathrm{~mol}^{-1}[1] \\
\mathrm{H}^{\bullet}(\mathrm{g}) \rightleftharpoons \mathrm{e}^{-}(\mathrm{g})+\mathrm{H}^{+}(\mathrm{g}) & \Delta_{\mathrm{r}} G^{\circ}=+1310.075 \mathrm{~kJ} \mathrm{~mol}^{-1}[2] \\
\mathrm{H}^{+}(\mathrm{g}) \rightleftharpoons \mathrm{H}^{+}(\mathrm{aq}) & \Delta_{\mathrm{r}} G^{\circ}=\mathrm{X}
\end{array}
$$




$$
\mathrm{e}^{-}(\mathrm{g}) \rightleftharpoons \mathrm{e}^{-}(\mathrm{aq}) \quad \Delta_{\mathrm{r}} G^{\circ}=\mathrm{Y}
$$

$$
\mathrm{e}^{-}(\mathrm{aq})+\mathrm{H}^{+}(\mathrm{aq}) \rightleftharpoons 1 / 2 \mathrm{H}_{2}(\mathrm{~g}) \quad \Delta_{\mathrm{r}} G^{\circ}=-278.1 \mathrm{~kJ} \mathrm{~mol}^{-1} E^{\mathrm{o}}=-2.88 \mathrm{~V}
$$

From these equations, $\mathrm{X}+\mathrm{Y}=-1235.2 \mathrm{~kJ} \mathrm{~mol}^{-1}$ for a standard state of 1 bar in the gas phase and $1 \mathrm{~mol} \mathrm{~L}^{-1}$ in solution. High-level solvent-induced electronic structure calculations by Zhan \& Dixon have resulted in values of $\mathrm{X}=-1097.9 \mathrm{~kJ} \mathrm{~mol}^{-1}[3]$ and $\mathrm{Y}=-140.6 \mathrm{~kJ} \mathrm{~mol}^{-1}$ [4] which yields $\mathrm{X}+\mathrm{Y}=-1238.5 \mathrm{~kJ} \mathrm{~mol}^{-1}$, in excellent agreement. Note that $\mathrm{X}$ and $\mathrm{Y}$ refer to reactions that violate charge conservation in the individual phases and, hence, the $\mathrm{X}$ and $\mathrm{Y}$ values are "absolute" rather than conventional thermodynamicchemical quantities.

Unfortunately, even though there has been a great deal of interest in the value of the hydration energy of the proton, its value is still contentious [5-17]. Bryantsev, et al. [18] argue that the Zhan \& Dixon [3] calculation for the proton should have included concentration corrections for the water clusters. This would lower their value by about $-5.4 \mathrm{~kJ} \mathrm{~mol}^{-1}$. It is not clear what iMPact this correction would have on the electron hydration energy.

The value for the proton hydration Gibbs energy obtained from an analysis of cluster-ion solvation data is $\Delta_{\mathrm{r}} G^{\circ}=-1104.5 \mathrm{~kJ} \mathrm{~mol}^{-1}$ [19]. This value has been widly accepted. A more recient cluster correlation method has led to a "best" value of $\Delta_{\mathrm{r}} G^{\circ}=-1102.1 \mathrm{~kJ} \mathrm{~mol}^{-1}$, even closer to the theoretical value [20]. This more recient cluster correlation value for the proton hydration Gibbs energy [20] leads to a value for the hydration Gibbs energy of the electron of $\Delta_{\mathrm{r}} G^{\circ}=-136.4 \mathrm{~kJ} \mathrm{~mol}^{-1}$. This is about $4.2 \mathrm{~kJ} \mathrm{~mol}^{-1}$ higher than the theoretical value, without including any concentration corrections for clusters. That correction, applied only to the calculation for the proton, suggests an agreement to within $1.2 \mathrm{~kJ} \mathrm{~mol}^{-1}$.

1042 Thus, the sum of the electron and proton hydration Gibbs energies, $\mathrm{X}+\mathrm{Y}$, that results from

1043 theoretical and experimental studies is very close to the sum derived from the hydration Gibbs

1044 energies recommended here. This clearly supports the electrode potential for the hydrated

1045 electron recommended here, $E^{\mathrm{o}}=-2.88 \mathrm{~V}$.

\section{References}


1049 1. M. W. Chase, J. Phys. Chem. Ref. Data, Monograph 9 (1998).

1050 2. J. E. Bartmess. J. Phys. Chem. 98, 6420-6424, (1994).

1051 3. C. G. Zhan, D. A. Dixon. J. Phys. Chem. A. 105, 11534-11540, (2001).

1052 4. C. G. Zhan, D. A. Dixon. J. Phys. Chem. B 107, 4403-4417, (2003).

1053 5. J. Llano, L. A. Eriksson. J. Chem. Phys. 117, 10193, (2002).

1054 6. T. R. Tuttle, S. Malaxos, J. V. Coe. J. Phys. Chem. A. 106, 925-932, (2002).

1055 7. M. W. Palascak, G. C. Shields. J. Phys. Chem. A. 108, 3692-3694, (2004).

1056 8. D. M. Camaioni, C. A. Schwerdtfeger. J. Phys. Chem. A. 109, 10795-10797, (2005).

1057 9. J. Llano, L. A. Eriksson. J. Chem. Phys. 122, 087104, (2005).

1058 10. A. L. Rockwood. J. Chem. Phys. 122, 087103, (2005).

1059 11. C. P. Kelly, C. J. Cramer, D. G. Truhlar. J. Phys. Chem. B 110, 16066-16081, (2006).

1060 12. C. A. Kelly, C. J. Cramer, D. G. Truhlar. J. Phys. Chem. B 111, 408-422, (2007).

1061 13. W. A. Donald, R. D. Leib, J. T. O'Brien, M. F. Bush, E. R. Williams. J. Am. Chem. Soc.

1062 130, 3371-3381, (2008).

1063 14. W. R. Fawcett. Langmuir 24, 9868-9875, (2008).

1064 15. W. A. Donald, R. D. Leib, J. T. O'Brien, E. R. Williams. Chemistry - A European

1065 Journal 15, 5926-5934, (2009).

1066 16. A. A. Isse, A. Gennaro. J. Phys. Chem. B 114, 7894-7899, (2010).

1067 17. M. M. Reif, P. H. Hünenberger. J. Chem. Phys. 134, 144104, (2011).

1068 18. V. S. Bryantsev, M. S. Diallo, W. A. Goddard. J. Phys. Chem. B 112, 9709-9719, 1069 (2008).

1070 19. M. D. Tissandier, K. A. Cowen, W. Y. Feng, E. Gundlach, M. H. Cohen, A. D. Earhart, J.

1071 V. Coe, T. R. Tuttle. J. Phys. Chem. A. 102, 7787-7794, (1998).

1072 20. W. A. Donald, E. R. Williams. J. Phys. Chem. B 114, 13189-13200, (2010).

1073

1074

1075 
Data Sheet 2

1077

1078

\section{$E^{\circ}\left(\mathrm{O} / \mathrm{O}^{\circ-}\right)$}

1079

1080

\section{List of reports:}

1081

1082 No direct determinations of this standard potential have been made.

1083

1084 Henglein, 1980 [1].

1085 Henglein used $\Delta_{\mathrm{f}} G^{\circ}\left(\mathrm{O}^{\bullet-}\right)=+103 \mathrm{~kJ} \mathrm{~mol}^{-1}$, an estimated $\Delta_{\mathrm{s}} G^{\circ}(\mathrm{O})$ of $+10 \mathrm{~kJ} \mathrm{~mol}^{-1}$, and $\Delta_{\mathrm{f}} G^{\circ}(\mathrm{O}) \mathrm{g}$ $1086=+232 \mathrm{~kJ} \mathrm{~mol}^{-1}[2]$ and arrived at $E^{\circ}\left(\mathrm{O} / \mathrm{O}^{\bullet-}\right)=+1.4 \mathrm{~V}$.

1088 Stanbury, 1989 [3].

1089 Use of more recent values, $\Delta_{\mathrm{f}} G^{\circ}\left(\mathrm{O}^{\bullet-}\right)=+94 \mathrm{~kJ} \mathrm{~mol}^{-1}$ and $\Delta_{\mathrm{s}} G^{\circ}(\mathrm{O})=+19 \mathrm{~kJ} \mathrm{~mol}^{-1}$ yielded $1090 E^{\circ}\left(\mathrm{O} / \mathrm{O}^{\bullet-}\right)=+1.63 \mathrm{~V}$.

1091

1092

\section{Discussion}

1093

A Gibbs energy of formation of $251 \mathrm{~kJ} \mathrm{~mol}^{-1}$ has been estimated for $\mathrm{O}\left({ }^{3} P\right)$ in water[3]. The standard potentials $E^{\circ}\left(\mathrm{O} / \mathrm{O}^{\bullet-}\right)$ and $E^{\circ}\left(\mathrm{O}, \mathrm{H}^{+} / \mathrm{HO}^{\bullet}\right)$ are calculated from this value and $\Delta_{\mathrm{f}} G^{\circ}\left(\mathrm{O}^{\bullet-}\right)=$ $+(93.1 \pm 1.7 \mathrm{~kJ}) \mathrm{mol}^{-1}$, which follows from $\Delta_{\mathrm{f}} G^{\circ}\left(\mathrm{HO}^{\bullet}\right)=+(26.3 \pm 1.7) \mathrm{kJ} \mathrm{mol}^{-1}$ (Data Sheet 7), and a $\mathrm{p} K_{\mathrm{a}}$ of $(11.7 \pm 0.1)$ [4-12] (see Data Sheet 116 for a discussion of this $\mathrm{p} K_{\mathrm{a}}$ ).

\section{Recommended values:}

$E^{\circ}\left(\mathrm{O} / \mathrm{O}^{\bullet-}\right)=+(1.6 \pm 0.1) \mathrm{V}$ $E^{\circ}\left(\mathrm{O}, \mathrm{H}^{+} / \mathrm{HO}^{\bullet}\right)=+(2.3 \pm 0.1) \mathrm{V}$. The errors are conservative estimates.

\section{Nomenclature}

The recommended name of $\mathrm{O}$ is oxygen or, to avoid confusion, mono-oxygen, of $\mathrm{O}^{\bullet-}$ oxide $(\bullet 1-)$ or oxidanidyl, that of $\mathrm{HO}^{\bullet}$ is hydridooxygen $(\bullet)$ or oxidanyl, while hydroxyl is allowed.

\section{References}

1. A. Henglein. Radiat. Phys. Chem. 15, 151-157 (1980). 
1112 2. J. P. Hoare. In Standard Potentials in Aqueous Solution, (A. J. Bard, R. Parsons and J. 1113 Jordan, eds.), p. 49-66. Marcel Dekker, Inc., New York (1985).

1114 3. D. M. Stanbury. Adv. Inorg. Chem. 33, 69-138 (1989).

1115 4. J. Rabani, M. S. Matheson. J. Am. Chem. Soc. 86, 3175-3176 (1964).

1116 5. J. Rabani, M. S. Matheson. J. Phys. Chem. 70, 761-769 (1966).

1117 6. J. L. Weeks, J. Rabani. J. Phys. Chem. 70, 2100-2106 (1966).

1118 7. J. H. Baxendale, M. D. Ward, P. Wardman. Trans. Faraday Soc. 67, 2532-2537 (1971).

1119 8. F. Barat, L. Gilles, B. Hickel, B. Lesigne. J. Phys. Chem. 76, 302-307 (1972).

1120 9. G. V. Buxton, N. D. Wood, S. Dyster. J. Chem. Soc. ,Faraday Trans. 1 84, 1113-1121 1121 (1988).

1122 10. A. J. Elliot, D. R. McCracken. Radiat. Phys. Chem. 33, 69-74 (1989).

1123 11. B. Hickel, H. Corfitzen, K. Sehested. J. Phys. Chem. 100, 17186-17190 (1996).

1124 12. G. A. Poskrebyshev, P. Neta, R. E. Huie. J. Phys. Chem. A 106, 11488-11491 (2002).

1125

1126

1127 


\section{$1128 \quad$ Data Sheet 3}

\section{$E^{\circ}\left(\mathrm{O}_{2} / \mathrm{O}_{2}{ }^{\circ-}\right)$}

\section{List of reports:}

Chemical equilibrium: $\mathrm{DQ}+\mathrm{O}_{2}^{\bullet-} \rightleftharpoons \mathrm{O}_{2}+\mathrm{DQ}^{\bullet-}$

Wood, 1974 [1].

Review, value based on $E^{\circ}\left(\mathrm{DQ} / \mathrm{DQ}^{\bullet-}\right)=-0.25 \mathrm{~V}$, calculated, and $K(3.1)=2.3 \times 10^{-2}[2]$.

$E^{\circ}\left(\mathrm{O}_{2} / \mathrm{O}_{2}^{\bullet-}\right)=-0.15 \mathrm{~V}$ or $-0.32 \mathrm{~V}\left(\mathrm{pO}_{2}=0.100 \mathrm{MPa}\right)$

Meisel and Czapski, 1975 [3].

1143 Based on $E^{\circ}\left(\mathrm{DQ} / \mathrm{DQ}^{\bullet-}\right)=-0.235 \mathrm{~V}$, calculated, and $K(3.1)=4.6 \times 10^{-2}$, determined. Conditions:

$1144 \mathrm{pH} \mathrm{7, \mu}=25 \mathrm{mM}$ (5 mM phosphate and $10 \mathrm{mM}$ formate) or $15 \mathrm{mM}$ (5 mM phosphate with 10 $\mathrm{mM}$ 2-propanol as $\mathrm{HO}^{\bullet}$ scavenger), ambient temperature. $E^{\circ}\left(\mathrm{O}_{2} / \mathrm{O}_{2}{ }^{\bullet-}\right)=-0.16 \mathrm{~V}$ or $-0.33 \mathrm{~V}\left(p \mathrm{O}_{2}=0.100 \mathrm{MPa}\right)$

Wardman, 1991 [4].

Based on $E^{\circ}\left(\mathrm{DQ} / \mathrm{DQ}^{\bullet-}\right)=-264 \pm 5 \mathrm{mV}$, determined against a revised value for $E^{\circ}\left(\mathrm{MV}^{2+} / \mathrm{MV}^{\bullet+}\right)$, $-0.450 \mathrm{~V}$, and the average of the two $K(3.1)$ 's given above. $\mathrm{MV}^{2+}$ is the 1,1 '-dimethyl-4,4'bipyridinium(2+) cation (paraquat). Conditions: $\mathrm{pH} 7.7, \mu=0.12 \mathrm{M}, T=296 \mathrm{~K}$. $E^{\circ}\left(\mathrm{O}_{2} / \mathrm{O}_{2}{ }^{\bullet-}\right)=-(0.179 \pm 0.011)$ or $-(0.350 \pm 0.011) \mathrm{V}\left(p \mathrm{O}_{2}=0.100 \mathrm{MPa}\right)$

Chemical equilibrium: $\mathrm{DMBQ}+\mathrm{O}_{2}^{\bullet-} \rightleftharpoons \mathrm{O}_{2}+\mathrm{DMBQ}^{\bullet-}$

$1160 K(3.2)=54$, determined at $\mu \approx 105 \mathrm{mM}, T$ not stated. $E^{\circ}\left(\mathrm{DMBQ} / \mathrm{DMBQ}^{\bullet-}\right)$ is calculated from the energetics of the comproportionation reaction, $E^{\circ}\left(\mathrm{DMBQ} / \mathrm{DMBQ}^{2-}\right)$ and the dissociation

1163 that $E^{\circ}\left(\mathrm{O}_{2} / \mathrm{O}_{2}{ }^{\bullet-}\right)=-0.33 \mathrm{~V}\left(p \mathrm{O}_{2}=0.100 \mathrm{MPa}\right)$. 
Ilan, Czapski and Meisel, 1976 [6].

1166 Based on $E^{\circ}\left(\mathrm{DMBQ} / \mathrm{DMBQ}^{\bullet-}\right)=-67 \mathrm{mV}$, calculated as described above, and $K(3.2)$ values of

116756 and 53, based on equilibrium measurements, and $K(3.2)=37$ based on the ratio of the forward 1168 and backward rate constants of Reaction 3.2. The latter value is considered less reliable by the 1169 authors. The error in $E^{\circ}\left(\mathrm{DMBQ} / \mathrm{DMBQ}^{\circ-}\right)$ is not given; we estimate $10 \mathrm{mV}$.

$1170 E^{\circ}\left(\mathrm{O}_{2} / \mathrm{O}_{2}{ }^{\bullet-}\right)=-(0.169 \pm 0.011)$ or $-(0.340 \pm 0.011) \mathrm{V}\left(\mathrm{pO}_{2}=0.100 \mathrm{MPa}\right)$. The authors list -0.33 $1171 \mathrm{~V}$ for $E^{\circ}\left(\mathrm{O}_{2} / \mathrm{O}_{2}{ }^{\bullet-}\right)$.

Chemical equilibrium: $\mathrm{MQ}+\mathrm{O}_{2}{ }^{\bullet-} \rightleftharpoons \mathrm{O}_{2}+\mathrm{MQ}^{\bullet-}$

Meisel and Czapski, 1975 [3].

Based on $E^{\circ}\left(\mathrm{MQ} / \mathrm{MQ}^{\bullet-}\right)=-0.203 \mathrm{~V}$, determined against $\mathrm{DQ}$, and $K(3.3)=0.16$, determined.

1180 Conditions, see above.

$E^{\circ}\left(\mathrm{O}_{2} / \mathrm{O}_{2}{ }^{\circ-}\right)=-0.16 \mathrm{~V}$ or $-0.33 \mathrm{~V}\left(p \mathrm{O}_{2}=0.100 \mathrm{MPa}\right)$

Chemical equilibrium: IDS $+\mathrm{O}_{2}{ }^{\bullet-} \rightleftharpoons \mathrm{O}_{2}+\mathrm{IDS}^{\bullet-}$

Meisel and Czapski, 1975 [3].

Based on $E^{\circ}\left(\operatorname{IDS} / \operatorname{IDS}^{\bullet-}\right)=-0.247 \mathrm{~V}$ [7], and $K(3.4)=2.9 \times 10^{-2}$, determined. Conditions, see 1190 above.

$$
E^{\circ}\left(\mathrm{O}_{2} / \mathrm{O}_{2}{ }^{\bullet-}\right)=-0.16 \mathrm{~V} \text { or }-0.33 \mathrm{~V}\left(p \mathrm{O}_{2}=0.100 \mathrm{MPa}\right) \text {. }
$$


1199 Based on $E^{\circ}\left(\mathrm{BQ} / \mathrm{BQ}^{\bullet-}\right)=+0.10 \mathrm{~V}$.[9], $k$ (forward) $9.8 \times 10^{8} \mathrm{M}^{-1} \mathrm{~s}^{-1}$ [10] and $k($ backward $)=4.5 \times$ $120010^{4} \mathrm{M}^{-1} \mathrm{~s}^{-1}$, determined indirectly. Conditions: $\mathrm{pH}$ 5.0, $0.05 \mathrm{M}$ acetate buffer, $\mu=0.05 \mathrm{M}$, and $1201 \mathrm{pH} 7,0.05 \mathrm{M}$ phosphate buffer, $\mu=0.13 \mathrm{M}, T=298 \mathrm{~K}$.

$1202 E^{\circ}\left(\mathrm{O}_{2} / \mathrm{O}_{2}{ }^{\bullet-}\right)=+0.10-0.257=-0.16 \mathrm{~V}$ or $-0.33 \mathrm{~V}\left(p \mathrm{O}_{2}=0.100 \mathrm{MPa}\right)$

1203

1204

1205

Chemical equilibrium: iron(III)cytochrome $c+\mathrm{O}_{2}{ }^{\bullet-} \rightleftharpoons$ iron(II)cytochrome $c+\mathrm{O}_{2}$

1206

1207

Sawada et al., 1975 [8].

1208

Based on $E^{\circ}($ iron(III)-/iron(II)-cytochrome $c)=+0.255 \mathrm{~V}, k$ (forward $)=2.5 \times 10^{4} \mathrm{M}^{-1} \mathrm{~s}^{-1}$ and

1209 $k($ backward $)=0.03 \mathrm{M}^{-1} \mathrm{~s}^{-1}$, estimated. Conditions: $\mathrm{pH} 7.0,(25 \pm 2){ }^{\circ} \mathrm{C}, 0.05 \mathrm{M}$ phosphate, $\mu=$ $0.13 \mathrm{M}, T=298 \mathrm{~K}$.

1211 $E^{\circ}\left(\mathrm{O}_{2} / \mathrm{O}_{2}{ }^{\bullet-}\right)=+0.255-0.35=-0.095 \mathrm{~V}$ or $-0.27 \mathrm{~V}\left(p \mathrm{O}_{2}=0.100 \mathrm{MPa}\right)$.

1212

1213

1214

Chemical equilibrium:

1215

1216

$\left[\mathrm{Ru}\left(\mathrm{NH}_{3}\right)_{5} \text { isonicotinamide }\right]^{3+}+\mathrm{O}_{2}{ }^{\bullet-} \rightleftharpoons \mathrm{O}_{2}+\left[\mathrm{Ru}\left(\mathrm{NH}_{3}\right)_{5} \text { isonicotinamide }\right]^{2+}$

1217

1218

1219

1220

1221

1222

1223 Isonicotinamide (isn) is pyridine-4-carboxamide.

1224

1225

1226

Chemical equilibrium: $\mathrm{TBQ}+\mathrm{O}_{2}^{\bullet-} \rightleftharpoons \mathrm{TBQ}^{\bullet-}+\mathrm{O}_{2}$

1227

1228 TBQ is 2-tert-butyl-1,4-benzosemiquinone IUPAC PIN: 2-tert-butyl-4-hydroxyphenoxyl or 3-tert-butyl-4-hydroxyphenoxyl

1229

1230

Dohrmann and Bergmann, 1995 [13].

1231

Based on $E^{\circ}\left(\mathrm{TBQ} / \mathrm{TBQ}^{\bullet-}\right)=-(0.032 \pm 0.006) \mathrm{V}, k($ forward $)=(1.1 \pm 0.2) \times 10^{8} \mathrm{M}^{-1} \mathrm{~s}^{-1}$ and

1232

1233 Conditions: $22^{\circ} \mathrm{C}$ and $\mu=0.1 \mathrm{M}$

$1234 E^{\circ}\left(\mathrm{O}_{2} / \mathrm{O}_{2}{ }^{\bullet-}\right)=-(0.140 \pm 0.012) \mathrm{V}$, or $-(0.31 \pm 0.01) \mathrm{V}\left(p \mathrm{O}_{2}=0.100 \mathrm{MPa}\right)$. 


\section{Discussion}

Due to the high content of organic solvents, the concentration of dioxygen in the studies of Patel and Willson [2] is likely to be much higher than the $1.25 \mathrm{mM}$ they assumed. Based on the literature [14] the concentration may have been twice as high. Indeed, we determined $2.01 \mathrm{mM}$ $\mathrm{O}_{2}$ in $6 \mathrm{M}$ 2-propanol (Latal, Kissner, Koppenol, 2002, unpublished). This leads to a larger equilibrium constant, and the value determined by Meisel and Czapski[3] should be used. When

1243 combined with the revised value for the $\mathrm{DQ} / \mathrm{DQ}^{\bullet-}$ electrode potential from Wardman [4], one arrives at $-264+79=-185 \mathrm{mV}\left(-357 \mathrm{mV}, p \mathrm{O}_{2}=0.100 \mathrm{MPa}\right)$.

The revised value of the electrode potential of $\mathrm{DQ} / \mathrm{DQ}^{\bullet-}, 29 \mathrm{mV}$ more negative than that used by Meisel and Czapski [3], has consequences for the determination based on menadione, eq. 3.3. The corrected value for $E^{\circ}\left(\mathrm{O}_{2} / \mathrm{O}_{2}{ }^{\bullet-}\right)$ is $-0.356 \mathrm{~V}\left(\mathrm{pO}_{2}=0.100 \mathrm{MPa}\right)$.

A value of $0.078 \mathrm{~V}$ for $E^{\circ}\left(\mathrm{BQ} / \mathrm{BQ}^{\bullet-}\right)$ has been recommended by Wardman [15]. Applied to the determination based on eq. 3.5 by Sawada et al. [8] one arrives at $E^{\circ}\left(\mathrm{O}_{2} / \mathrm{O}_{2}{ }^{\bullet-}\right)=$ $+0.078-0.257=-0.179 \mathrm{~V}$ or $-0.350 \mathrm{~V}\left(p \mathrm{O}_{2}=0.100 \mathrm{MPa}\right)$.

$E^{\circ}\left(\mathrm{DMBQ} / \mathrm{DMBQ}^{\bullet-}\right),-0.067 \mathrm{~V}$ at $\mu=0.1 \mathrm{M}[6]$, can be corrected for ionic strength

1253 strength dependent, even when the difference in radii of the reactants and products are taken into 1254 account. Thus, at $\mu=0, E^{\circ}\left(\mathrm{O}_{2} / \mathrm{O}_{2}{ }^{\bullet-}\right)=-(0.35 \pm 0.02) \mathrm{V}$.

The value obtained by Sawada et al. [8] from eq. 3.6 can also be corrected. The rate constant $k$ (forward) is $(5.6 \pm 0.5) \times 10^{5} \mathrm{M}^{-1} \mathrm{~s}^{-1}$ [16] under conditions similar to those of Sawada et al. [8] (except in $0.15 \mathrm{M}$ formate). Combined with their $k$ (backward) of $0.03 \mathrm{M}^{-1} \mathrm{~s}^{-1}$, and an electrode potential of $0.26 \pm 0.01 \mathrm{~V}[17,18]$, one arrives at $-0.17 \mathrm{~V}$, or $-0.34 \mathrm{~V}\left(p \mathrm{O}_{2}=0.100\right.$ $\mathrm{MPa}$ ). Given the unknown quality of the cytochrome $c$ used, more weight is given to the values obtained with the quinones.

The determination of the electrode potential of the couple TBQ/TBQ ${ }^{\bullet-}$ has been evaluated (Data Sheet S-1), which led to a correction and increased uncertainties: $E^{\circ}\left(\mathrm{TBQ} / \mathrm{TBQ}^{\bullet-}\right)=-(0.014 \pm 0.016) \mathrm{V}$. Based on this value $E^{\circ}\left(\mathrm{O}_{2} / \mathrm{O}_{2}^{\bullet-}\right)=-(0.122 \pm 0.016) \mathrm{V}$, or $-(0.29 \pm 0.02) \mathrm{V}\left(p \mathrm{O}_{2}=0.100 \mathrm{MPa}\right)$. Given the increased uncertainties, this value is of limited use and is not used in the recommendation.

Overall, the large majority of the values cited above are in reasonable agreement.

1267 Because of the various weaknesses noted above in several of the reports, we place greatest 1268 confidence in the results derived from the DMBQ and BQ reactions. These two reports yield 1269 identical values for $E^{\circ}$. The uncertainty in the DMBQ result is suggested to be $\pm 20 \mathrm{mV}$, while 1270 none is specified for the BQ. 


\section{Recommended values:}

1273

1274

$E^{\circ}\left(\mathrm{O}_{2} / \mathrm{O}_{2}{ }^{\bullet-}\right)$ is $-(0.18 \pm 0.02) \mathrm{V}$, or $-(0.35 \pm 0.02) \mathrm{V}\left(p \mathrm{O}_{2}=0.100 \mathrm{MPa}\right)$.

1275 $\Delta_{\mathrm{f}} G^{\circ}\left(\mathrm{O}_{2}{ }^{\bullet-}\right)=+(8.1 \pm 0.5) \mathrm{kcal} \mathrm{mol}^{-1}$, or $+(33.8 \pm 1.9) \mathrm{kJ} \mathrm{mol}^{-1}$. Given a $\mathrm{p} K_{\mathrm{a}}$ of $(4.8 \pm 0.1)$ for $\mathrm{HO}_{2}{ }^{\bullet}[19], E^{\circ}\left(\mathrm{O}_{2}, \mathrm{H}^{+} / \mathrm{HO}_{2}{ }^{\bullet}\right)$ is $+(0.10 \pm 0.02) \mathrm{V}$, or $-(0.07 \pm 0.02)$ $\mathrm{V}\left(p \mathrm{O}_{2}=0.100 \mathrm{MPa}\right)$. $\Delta_{\mathrm{f}} G^{\circ}\left(\mathrm{HO}_{2}^{\bullet}\right)=+(1.7 \pm 0.5) \mathrm{kcal} \mathrm{mol}^{-1}$, or $+(7 \pm 2) \mathrm{kJ} \mathrm{mol}^{-1}$

List of auxiliary thermodynamic data:

Baxendale et al. [20] derived a value of $+8.2 \mathrm{kcal} \mathrm{mol}^{-1}$, or $+34.3 \mathrm{~kJ} \mathrm{~mol}^{-1}$, for $\Delta_{\mathrm{f}} G^{\circ}\left(\mathrm{O}_{2}{ }^{\bullet-}\right)$ via the Gibbs energy of formation of $\mathrm{HO}_{2}{ }^{\bullet}$ in the gas phase, $+34.7 \mathrm{~kJ} \mathrm{~mol}^{-1}$, an estimate for the Gibbs energy of solvation of $-28.5 \mathrm{~kJ} \mathrm{~mol}^{-1}$ (identical to that of hydrogen peroxide) and a $\mathrm{p} K_{a}$ of 4.88 . The resulting Gibbs energy of formation is in very good agreement with the recommended value. Chevalet et al. [21] reported a value of $-0.27 \mathrm{~V}$ for $E^{\circ}\left(\mathrm{O}_{2} / \mathrm{O}_{2}{ }^{\bullet-}\right)$, determined by electrochemistry. This value has been corrected to $-0.29 \mathrm{~V}$ [22]. A very similar value, $-0.284 \mathrm{~V}$, was obtained by Divišek and Kastening [22]. There are two fundamental problems with the electrochemical determination of $E^{\circ}\left(\mathrm{O}_{2} / \mathrm{O}_{2}{ }^{\bullet-}\right)$. On a metal surface, catalysis of the dismutation of superoxide proceeds vigorously, and when surfactants are used to suppress this catalysis, one may not achieve an equilibrium. For that reason we prefer the data obtained by pulse radiolysis.

Zhuravleva and Berdnikov [23] calculated a electrode potential of $-0.33 \mathrm{~V}$ from the equilibrium between iron(II) and hydrogen peroxide.

The electrode potential of $0.15 \mathrm{~V}$ reported by Rao and Hayon[10] is in error, as discussed by Wood [1] and Ilan et al. [6].

Petlicki and Van de Ven [24] have argued that the electrode potential of the $\mathrm{O}_{2} / \mathrm{O}_{2}{ }^{\bullet-}$ couple is $-0.14 \mathrm{~V}$, instead of $-0.33 \mathrm{~V}$. They drew attention to the fact that there is a discrepancy between the electrode potential of the $\mathrm{O}_{2} / \mathrm{H}_{2} \mathrm{O}_{2}$ couple derived from the NBS compilation [25] and that determined experimentally. They argue that this discrepancy proves that there is an equilibrium between superoxide on one side and dioxygen and hydrogen peroxide on the other side, which requires a substantial increase in the electrode potential of the $\mathrm{O}_{2} / \mathrm{O}_{2}{ }^{--}$couple. Given the many consistent determinations of $E^{\circ}\left(\mathrm{O}_{2} / \mathrm{O}_{2}{ }^{\bullet-}\right)$ we dismiss the value reported by these 1303 authors. 
1307 The systematic name of $\mathrm{O}_{2}{ }^{\bullet-}$ is dioxide( $\left.\bullet 1-\right)$ or dioxidanidyl, of $\mathrm{HO}_{2} \bullet$ hydrogen dioxide or

1308 dioxidanyl, and of $\mathrm{O}_{2}$, dioxygen or dioxidanediyl. The venerable name superoxide is allowed.

\section{References}

1312

1. P. M. Wood. FEBS Lett. 44, 22-24 (1974).

2. K. B. Patel, R. L. Willson. J. Chem. Soc. Faraday Trans. I 69, 814-825 (1973).

3. D. Meisel, G. Czapski. J. Phys. Chem. 79, 1503-1509 (1975).

4. P. Wardman. Free Radical Res. Commun. 14, 57-67 (1991).

5. Y. A. Ilan, D. Meisel, G. Czapski. Isr. J. Chem. 12, 891-895 (1974).

6. Y. A. Ilan, G. Czapski, D. Meisel. Biochim. Biophys. Acta 430, 209-225 (1976).

7. P. W. Preisler, E. S. Hill, R. G. Loeffel, P. A. Shaffer. J. Am. Chem. Soc. 81, 1991(1959).

8. Y. Sawada, T. Iyanagi, I. Yamazaki. Biochemistry 14, 3761-3764 (1975).

9. I. Yamazaki, T. Ohnishi. Biochim. Biophys. Acta 112, 469-481 (1966).

10. P. S. Rao, E. Hayon. Biochem. Biophys. Res. Commun. 51, 468-473 (1973).

11. D. M. Stanbury, O. Haas, H. Taube. Inorg. Chem. 19, 518-524 (1980).

12. D. M. Stanbury, W. A. Mulac, J. C. Sullivan, H. Taube. Inorg. Chem. 19, 3735-3740 (1980).

13. J. K. Dohrmann, B. Bergmann. J. Phys. Chem. 99, 1218-1227 (1995).

14. J. Tokunaka. J. Chem. Eng. Data 20, 41-46 (1975).

15. P. Wardman. J. Phys. Chem. Ref. Data 18, 1637-1755 (1989).

16. W. H. Koppenol, K. J. H. van Buuren, J. Butler, R. Braams. Biochim. Biophys. Acta 449, 157-168 (1976).

17. P. Bertrand, O. Mbarki, M. Asso, L. Blanchard, F. Guerlesquin, M. Tegoni. Biochemistry 34, 11071-11079 (1995).

18. Hock, G. J. M.Sc. Thesis, University of Wisconsin-Milwaukee. 1998.

19. B. H. J. Bielski, D. E. Cabelli, R. L. Arudi, A. B. Ross. J. Phys. Chem. Ref. Data 14, 1041-1100 (1985).

20. J. H. Baxendale, M. D. Ward, P. Wardman. Trans. Faraday Soc. 67, 2532-2537 (1971).

21. J. Chevalet, F. Rouelle, L. Gierst, J. P. Lambert. J. Electroanal. Chem. 39, 201-216 (1972).

22. J. Divisek, B. Kastening. J. Electroanal. Chem. 65, 603-621 (1975).

23. V. M. Berdnikov, O. S. Zhuravleva. Russ. J. Phys. Chem. 46, 1521-1523 (1972).

24. J. Petlicki, T. G. M. van de Ven. J. Chem. Soc., Faraday Trans. 94, $2763-2767$ (1998). 


\section{Data Sheet 4}

\section{$E^{\circ}\left({ }^{1} \Delta_{\mathrm{g}} \mathbf{O}_{2} / \mathbf{O}_{2}{ }^{\bullet-}\right)$}

1349

\section{List of reports:}

1351

1352

No direct determinations of this standard potential have been made.

1353

1354 Koppenol, 1976 [1].

1355 A value of $0.65 \mathrm{~V}$ is calculated for $E^{\circ}\left({ }^{1} \Delta_{\mathrm{g}} \mathrm{O}_{2} / \mathrm{O}_{2}{ }^{\bullet-}\right)$ relative to a $p^{1} \Delta_{\mathrm{g}} \mathrm{O}_{2}=0.100 \mathrm{MPa}$. It is based 1356 on $E^{\circ}\left(\mathrm{O}_{2} / \mathrm{O}_{2}{ }^{\bullet-}\right)=-0.33 \mathrm{~V}$, a difference in energy of $22.6 \mathrm{kcal}$ between ${ }^{3} \sum_{\mathrm{g}}{ }^{-} \mathrm{O}_{2}$ and ${ }^{1} \Delta_{\mathrm{g}} \mathrm{O}_{2}$, and a 1357 Gibbs energy of solution of singlet dioxygen identical to that of triplet dioxygen.

$1358 E^{\circ}\left({ }^{1} \Delta_{\mathrm{g}} \mathrm{O}_{2} / \mathrm{O}_{2}{ }^{\bullet-}\right)$ is $+0.82 \mathrm{~V}$, or $+0.65 \mathrm{~V}\left(p^{1} \Delta_{\mathrm{g}} \mathrm{O}_{2}=0.100 \mathrm{MPa}\right) . \Delta_{\mathrm{f}} G^{\circ}\left({ }^{1} \Delta_{\mathrm{g}} \mathrm{O}_{2}\right)=+111 \mathrm{~kJ} \mathrm{~mol}^{-1}$ or $1359+26.5 \mathrm{kcal} \mathrm{mol}^{-1}$.

1360

Stanbury, 1989 [2].

1362 A Gibbs energy of formation of $+112 \mathrm{~kJ} \mathrm{~mol}^{-1}$ for $1 \mathrm{~m}^{1} \Delta_{\mathrm{g}} \mathrm{O}_{2}$ is derived from a quantum-

1363 chemically derived Gibbs energy of formation of ${ }^{1} \Delta_{\mathrm{g}} \mathrm{O}_{2}$ in the gas phase and a Gibbs energy of 1364 solution of singlet dioxygen identical to that of triplet dioxygen.

$1365 E^{\circ}\left({ }^{1} \Delta_{\mathrm{g}} \mathrm{O}_{2} / \mathrm{O}_{2}{ }^{\bullet-}\right)$ is $+0.83 \mathrm{~V}$, or $+0.66 \mathrm{~V}\left(p^{1} \Delta_{\mathrm{g}} \mathrm{O}_{2}=0.100 \mathrm{MPa}\right) . \Delta_{\mathrm{f}} G^{\circ}\left({ }^{1} \Delta_{\mathrm{g}} \mathrm{O}_{2}\right)=+112 \mathrm{~kJ} \mathrm{~mol}^{-1}$ or $1366+26.8 \mathrm{kcal} \mathrm{mol}^{-1}$.

\section{Discussion}

A reliable standard potential can be calculated from the recommended $\Delta_{\mathrm{f}} G^{\circ}\left(\mathrm{O}_{2}{ }^{\bullet-}\right)=+(33.8 \pm$ $0.8) \mathrm{kJ} \mathrm{mol}^{-1}$ (Data Sheet 3 ) and $\Delta_{\mathrm{f}} G^{\circ}\left({ }^{1} \Delta_{\mathrm{g}} \mathrm{O}_{2}\right)=+112 \mathrm{~kJ} \mathrm{~mol}^{-1}$ or $+26.8 \mathrm{kcal} \mathrm{mol}^{-1}$.

\section{Recommended values:}

$E^{\circ}\left({ }^{1} \Delta_{\mathrm{g}} \mathrm{O}_{2} / \mathrm{O}_{2}{ }^{\bullet-}\right)$ is $+(0.81 \pm 0.01) \mathrm{V}$, or $+(0.64 \pm 0.01) \mathrm{V}\left(p^{1} \Delta_{\mathrm{g}} \mathrm{O}_{2}=0.100 \mathrm{MPa}\right)$.

1377 $\Delta_{\mathrm{f}} G^{\circ}\left({ }^{1} \Delta_{\mathrm{g}} \mathrm{O}_{2}\right)=+(112 \pm 1) \mathrm{kJ} \mathrm{mol}^{-1}$.

Nomenclature

The systematic name of $\mathrm{O}_{2}^{\bullet-}$ is dioxide $(\bullet 1-)$ or dioxidanidyl, of $\mathrm{HO}_{2} \bullet$ hydrogen dioxide or dioxidanyl, and of $\mathrm{O}_{2}$, dioxygen or dioxidanediyl. The venerable name superoxide is allowed. 
1382

1383 References

1384

1385 1. W. H. Koppenol. Nature 262, 420-421 (1976).

1386 2. D. M. Stanbury. Adv. Inorg. Chem. 33, 69-138 (1989).

1387

1388

1389 


\section{Data Sheet 5}

\section{$\boldsymbol{E}^{\circ}\left(\mathrm{HO}_{2}^{\bullet}, \mathbf{H}^{+} / \mathbf{H}_{2} \mathbf{O}_{2}\right)$}

1393

\section{List of reports:}

1396 No direct determinations of this standard potential have been made.

\section{Discussion}

1400 A value can be calculated from the Gibbs energy of formation of hydrogen dioxide $\left(\mathrm{HO}_{2}\right)^{\bullet},+(7 \pm$ 1401 2) $\mathrm{kJ} \mathrm{mol}^{-1}$ (see Data Sheet 3), and that of hydrogen peroxide. The Gibbs energies of formation 1402 of hydrogen peroxide are summarized in Table 1. The present recommendation from the 1403 National Institute of Standards and Technology [1], is the value obtained by Kern [2], -134.1 kJ $1404 \mathrm{~mol}^{-1}$, which dates from 1963; a value also found in the compilation by Hoare in Standard 1405 Potentials in Aqueous Solution [3]. The standard potentials derived from this value are $1406 E^{\circ}\left(\mathrm{HO}_{2} \cdot \mathrm{H}_{2} \mathrm{O}_{2}\right)=+1.461 \mathrm{~V}, E^{\circ}\left(\mathrm{O}_{2} / \mathrm{H}_{2} \mathrm{O}_{2}\right)=0.695 \mathrm{~V}\left(p \mathrm{O}_{2}=0.100 \mathrm{MPa}\right)$ and $E^{\circ}\left(\mathrm{H}_{2} \mathrm{O}_{2} / \mathrm{H}_{2} \mathrm{O}\right)=$ $14071.763 \mathrm{~V}$.

1408 There appears to be a distinct difference between the thermodynamic estimates and the 1409 electrochemical determinations, the latter yielding more negative values than the former, see 1410 Table 1. Given the perceived uncertainties of the electrochemical determinations, it was decided 1411 to stay with the existing recommendation. 
Table 1 Gibbs energies of formation of $\mathrm{H}_{2} \mathrm{O}_{2}$

1415

\begin{tabular}{|c|c|c|c|}
\hline Authors & Year & Value / $\left(\mathrm{kJ} \mathrm{mol}^{-1}\right)$ & Remarks \\
\hline Lewis and Randall [4] & 1914 & -129.6 & $\begin{array}{l}\text { sum of } 9 \text { Gibbs energies involving barium oxide and } \\
\text { peroxide }^{\text {a }}\end{array}$ \\
\hline Lewis and Randall [5] & 1923 & -131.7 & $\begin{array}{l}\text { sum of } 8 \text { Gibbs energies involving barium oxide and } \\
\text { peroxide }^{\text {a }}\end{array}$ \\
\hline Berl [6] & 1943 & -138.3 & $\begin{array}{l}\text { electrochemistry, } \mathrm{C}\left|\mathrm{O}_{2}, \mathrm{HO}_{2}^{-}, \mathrm{HO}^{-}\right| \text {calomel. } E^{\circ}\left(\mathrm{O}_{2} / \mathrm{HO}_{2}^{-}\right)= \\
-0.0416 \mathrm{~V}\end{array}$ \\
\hline $\begin{array}{l}\text { Yablokova and Bagotskii } \\
\text { [7] }\end{array}$ & 1952 & -137.7 & $\begin{array}{l}\text { electrochemistry, } \mathrm{Hg}\left|\mathrm{O}_{2}, \mathrm{HO}_{2}^{-}, \mathrm{HO}^{-}\right| \mathrm{HgO} E^{\circ}\left(\mathrm{O}_{2} / \mathrm{HO}_{2}^{-}\right)= \\
-0.045 \mathrm{~V}\end{array}$ \\
\hline Kern [2] & 1954 & -134.1 & $\begin{array}{l}\text { electrochemistry, } \mathrm{Hg}\left|\mathrm{O}_{2}, \mathrm{HO}_{2}{ }^{-}, \mathrm{HO}^{-}\right| \text {calomel. } E^{\circ}\left(\mathrm{O}_{2} / \mathrm{H}_{2} \mathrm{O}_{2}\right)= \\
+0.695 \text { V. Expts. pH 6-14 }\end{array}$ \\
\hline Schumb et al. [8] & 1955 & -133.7 & $\begin{array}{l}\text { calculated from } \Delta_{\mathrm{f}} \mathrm{G}^{\circ} \text { of } \mathrm{H}_{2} \mathrm{O}_{2}(\mathrm{l}) \text { and } \mathrm{H}_{2} \mathrm{O}_{2}(\mathrm{~g}) \text { and dissolution } \\
\text { in } \mathrm{H}_{2} \mathrm{O}\end{array}$ \\
\hline Yeager et al. [9] & 1964 & -137.0 & $\begin{array}{l}\text { electrochemistry, } \mathrm{C}\left|\mathrm{O}_{2}, \mathrm{HO}_{2}{ }^{-}, \mathrm{HO}^{-}\right| \mathrm{HgO} \mid \mathrm{Hg} . E^{\circ}\left(\mathrm{O}_{2} / \mathrm{HO}_{2}{ }^{-}\right)= \\
-0.048 \mathrm{~V} . \mathrm{pO}_{2} \text {-range }\end{array}$ \\
\hline Tikhomirova et al. [10] & 1965 & -137.0 & $\begin{array}{l}\text { electrochemistry, } \mathrm{Pt}\left|\mathrm{O}_{2}, \mathrm{H}_{2} \mathrm{O}_{2}, \mathrm{H}^{+}\right| \mathrm{H}_{2} \mid \mathrm{Pt} . E^{\circ}\left(\mathrm{O}_{2} / \mathrm{H}_{2} \mathrm{O}_{2}\right)=+0.71 \\
\text { V }\end{array}$ \\
\hline Rotinyan [11] & 1969 & -141.0 & $\begin{array}{l}\text { electrochemistry, } \mathrm{C}\left|\mathrm{O}_{2}, \mathrm{H}_{2} \mathrm{O}_{2}, \mathrm{H}^{+}\right| \mathrm{SO}_{4}{ }^{2-} \mid \mathrm{Hg}_{2} \mathrm{SO}_{4}, \mathrm{Hg} \text {. } \\
E^{\circ}\left(\mathrm{O}_{2} / \mathrm{H}_{2} \mathrm{O}_{2}\right)=+0.73 \mathrm{~V}\end{array}$ \\
\hline
\end{tabular}

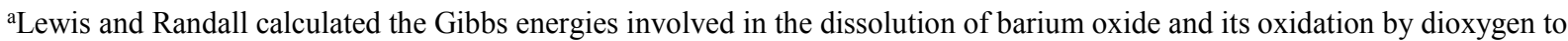
barium peroxide. When added to the formation of water from dihydrogen and dioxygen, the formation of hydrogen peroxide results. The slight difference between the calculations from 1914 and 1923 results from a better approximation of the activity coefficients involved; furthermodynamicre, one reaction was eliminated.

\section{Recommended value:}

$E^{\circ}\left(\mathrm{HO}_{2}{ }^{\bullet}, \mathrm{H}^{+} / \mathrm{H}_{2} \mathrm{O}_{2}\right)=(1.46 \pm 0.02) \mathrm{V}$.

Nomenclature dioxidane, and of $\mathrm{O}_{2}$, dioxygen or dioxidanediyl. The name hydrogen peroxide is allowed.

\section{References} Churney, R. L. Nuttal. J. Phys. Chem. Ref. Data 11 (Suppl. 2), 37-38 (1982).

2. D. M. H. Kern. J. Am. Chem. Soc. 76, 4208-4214 (1954). 
3. J. P. Hoare. In Standard Potentials in Aqueous Solution, (A. J. Bard, R. Parsons and J. Jordan, eds.), p. 49-66. Marcel Dekker, Inc., New York (1985).

4. G. M. Lewis, M. Randall. J. Am. Chem. Soc. 10, 1969-1993 (1914).

5. G. N. Lewis, M. Randall. Thermodynamics and the Free Energy of Chemical Substances, p. 487-496. McGraw-Hill Book Company, Inc., New York. (1923).

6. W. G. Berl. Trans. Electrochem. Soc. 83, 253-271 (1943).

7. I. E. Yablokova, V. S. Bagotskii. Dokl. Akad. Nauk. 85, 599-602 (1952).

8. Schumb, W. C., Satterfield, C. N., and Wentworth, R. L. Hydrogen Peroxide. (164). 1955. New York, Reinhold. ACS Monograph Series.

1444 9. E. Yeager, P. Krouse, K. V. Rao. Electrochim. Acta 9, 1057-1070 (1964).

1445

10. V. I. Tikhomirova, V. I. Luk'yanycheva, V. S. Bagotskii. Élektrokhimya 1, 645-650 (Engl. transl. pp. 568-572) (1965).

11. A. L. Rotinyan, A. I. Anurova, N. B. Dobrozrakova. Élektrokhimya 5, 1352-1354 (Engl. 


\section{Data Sheet 6}

1453

\section{$E^{\circ}\left(\mathrm{HO}^{*}, \mathrm{H}^{+} / \mathrm{H}_{2} \mathrm{O}\right)$}

1455

\section{Discussion}

The calculation of $E^{\circ}\left(\mathrm{HO}^{*}, \mathrm{H}^{+} / \mathrm{H}_{2} \mathrm{O}\right)$ is based on evaluations presented in Data Sheets 19-21.

Chemical equilibria

1460

1461

1462

1463

1464

$$
\begin{aligned}
& \mathrm{HO}{ }^{\bullet}+\mathrm{Tl}^{+} \rightleftharpoons \mathrm{TlOH}^{+} \\
& \mathrm{TlOH}^{+}+\mathrm{H}^{+} \rightleftharpoons \mathrm{Tl}^{2+}+\mathrm{H}_{2} \mathrm{O} \\
& \mathrm{Tl}^{2+}+\mathrm{e}^{-} \rightleftharpoons \mathrm{Tl}^{+}
\end{aligned}
$$

Use of the $K_{\text {eq }}$ for the Equilibrium 19.1, $K_{\text {eq }}=(5.8 \pm 1.0) \times 10^{3} \mathrm{M}^{-1}$ at $25^{\circ} \mathrm{C}$, the $K_{\mathrm{a}}$ of $\mathrm{Tl}^{2+}$ from reaction 20.1, $(1.7 \pm 0.3) \times 10^{-5} \mathrm{M}, E^{\circ}=+(2.221 \pm 0.003) \mathrm{V}$ for $\mathrm{Tl}^{2+} / \mathrm{Tl}^{+}$(Equilibrium 21.9), and the NBS value [1] of $\Delta_{\mathrm{f}} G^{\circ}$ for $\mathrm{H}_{2} \mathrm{O}(l)\left(=-237.129 \pm 0.08 \mathrm{~kJ} \mathrm{~mol}^{-1}\right)$ leads to $\Delta_{\mathrm{f}} G^{\circ}=+(25.9 \pm 0.5)$ $\mathrm{kJ} \mathrm{mol}^{-1}$ for $\mathrm{HO}^{\bullet}$. Use of the NBS value [1] of $\Delta_{\mathrm{f}} G^{\circ}$ for $\mathrm{OH}^{-}(a q)\left(=-157.244 \pm 0.08 \mathrm{~kJ} \mathrm{~mol}^{-1}\right)$ leads to $E^{\circ}=+(1.898 \pm 0.005) \mathrm{V}$ for the $\mathrm{HO}^{*} / \mathrm{HO}^{-}$redox couple.

Chemical equilibria

Kläning, Sehested and Holcman, 1985 [2].

The calculation of the standard potential involves $K(2.07)=(22 \pm 6)$ at low ionic strength (from

1478 determinations of the forward and backward rate constants at $\left.22^{\circ} \mathrm{C}\right), K(-6.02)=1.1 \times 10^{-6} \mathrm{M}$

1479 (from published forward and backward rate constants [3,4]), the ionization constant of $\mathrm{HO}^{\bullet}, 11.9$ 1480 [5], and a new determination of $E^{\circ}\left(\mathrm{ClO}_{2}{ }^{\circ} / \mathrm{ClO}_{2}^{-}\right)=+(0.934 \pm 0.002) \mathrm{V}$. No explicit error in $E^{\circ}$ is given. Note: the authors refer to $E^{\circ}\left(\mathrm{HO}^{\bullet}, \mathrm{H}^{+} / \mathrm{H}_{2} \mathrm{O}\right)$ incorrectly as an oxidation potential.

1482 These workers reported the following results: $E^{\circ}\left(\mathrm{HO}^{\bullet}, \mathrm{H}^{+} / \mathrm{H}_{2} \mathrm{O}\right)=+2.74 \mathrm{~V} . E^{\circ}\left(\mathrm{HO}^{\bullet} / \mathrm{HO}^{-}\right)=$ $1483+1.91 \mathrm{~V} . \Delta_{\mathrm{f}} G^{\circ}\left(\mathrm{HO}^{\bullet}\right)=+(26.8 \pm 1.0) \mathrm{kJ} \mathrm{mol}^{-1}$.

\section{Recommended values:}

1486 
$\left.E^{\circ}\left(\mathrm{HO}^{\bullet}, \mathrm{HO}^{-}\right)=+1.89 \pm 0.01\right) \mathrm{V}$.

$1489 E^{\circ}\left(\mathrm{H}_{2} \mathrm{O}_{2}, \mathrm{H}^{+} / \mathrm{HO}^{\bullet}, \mathrm{H}_{2} \mathrm{O}\right)=+(0.80 \pm 0.01) \mathrm{V}$ (based on the NIST Gibbs energy of $-134.1 \mathrm{~kJ} \mathrm{~mol}^{-1}$

1490 for hydrogen peroxide).

$1491 \Delta_{\mathrm{f}} G^{\circ}\left(\mathrm{HO}^{\bullet}\right)=+26 \pm 1 \mathrm{~kJ} \mathrm{~mol}^{-1}$, and $\Delta_{\mathrm{f}} G^{\circ}\left(\mathrm{O}^{\bullet-}\right)=+(92 \pm 3) \mathrm{kJ} \mathrm{mol}^{-1}$.

1492

1493

\section{List of auxiliary thermodynamic data}

1494

1495

Gibbs energies of formation of $+(6.2$ and +22.3$) \mathrm{kcal} \mathrm{mol}\left(+25.9\right.$ and $\left.+93.3 \mathrm{~kJ} \mathrm{~mol}^{-1}\right)$ were derived for $\mathrm{HO}^{\bullet}$ and $\mathrm{O}^{\bullet}$, respectively, from the gas phase Gibbs energy of formation of $\mathrm{HO}^{\bullet}$, $+34.7 \mathrm{~kJ} \mathrm{~mol}^{-1}\left(+8.3 \mathrm{kcal} \mathrm{mol}^{-1}\right)$, an assumed Gibbs solvation energy of $+\left(8.8 \mathrm{~kJ} \mathrm{~mol}^{-1}\right)(-2.1$

$1498 \mathrm{kcal} \mathrm{mol}^{-1}$ ) for $\mathrm{HO}^{\bullet}$ and a $\mathrm{p} K_{\mathrm{a}}$ of 11.8 [6].

An estimate of $E^{\circ}\left(\mathrm{HO}^{\bullet} / \mathrm{HO}^{-}\right)=+1.77 \mathrm{~V}$, and a brief discussion of earlier standard potentials are

1501 found in Koppenol and Liebman [7].

1502

\section{Nomenclature}

1504 The systematic name of $\mathrm{HO}^{\bullet}$ is hydridooxygen $(\bullet)$ or oxidanyl, of $\mathrm{O}^{\bullet-}$ oxide( $\bullet-$ ) or oxidanidyl, and of $\mathrm{H}_{2} \mathrm{O}$ oxidane. The venerable names hydroxyl and water are allowed.

\section{References}

1. D. D. Wagman, W. H. Evans, V. B. Parker, R. H. Schumm, I. Halow, S. M. Bailey, K. L. Churney, R. L. Nuttal. J. Phys. Chem. Ref. Data 11 (Suppl. 2), 37-38 (1982).

4. Farhataziz, A. B. Ross. Selected Specific Rates of Reactions of Transients from Water in 1514 Aqueous Solution. III. Hydroxyl Radical and Perhydroxyl Radical and Their Radical ions. 1515 NSRDS-NBS 59, National Bureau of Standards, Washington D.C. (1977).

1516 5. J. Rabani, M. S. Matheson. J. Am. Chem. Soc. 86, 3175-3176 (1964).

1517 6. J. H. Baxendale, M. D. Ward, P. Wardman. Trans. Faraday Soc. 67, 2532-2537 (1971).

1518 7. W. H. Koppenol, J. Liebman. J. Phys. Chem. 88, 99-101 (1984). 
1520 


\section{$1521 \quad$ Data Sheet 7}

1522 An optimization of a subset of the radical equilibria was performed using the Active

1523 Thermodynamicchemical Tables approach (see main document, section 6). It is based on the 1524 following evaluated data.

Table 7.1. Input equilibrium data for optimization

\begin{tabular}{|c|c|c|c|c|}
\hline $\begin{array}{l}\text { rxn } \\
\#\end{array}$ & reaction & $\begin{array}{l}\text { equilibrium } \\
\text { constant }\end{array}$ & uncertainty & $\begin{array}{l}\text { Data } \\
\text { Sheet \# }\end{array}$ \\
\hline 8.1 & $\mathrm{HO}^{\bullet}+\mathrm{Cl}^{-}+\mathrm{H}^{+} \rightleftharpoons \mathrm{Cl}^{\bullet}+\mathrm{H}_{2} \mathrm{O}$ & $9 \times 10^{4} \mathrm{M}^{-2}$ & within a factor of 2 & 8 \\
\hline 9.1 & $\mathrm{Cl}_{2}{ }^{-}+\mathrm{H}_{2} \mathrm{O} \rightleftharpoons \mathrm{HO}^{\bullet}+\mathrm{H}^{+}+2 \mathrm{Cl}^{-}$ & $6.1 \times 10^{-11} \mathrm{M}^{3}$ & $\pm 10 \%$ & 9 \\
\hline $\begin{array}{l}10 . \\
1\end{array}$ & $\mathrm{Cl}^{\bullet}+\mathrm{Cl}^{-} \rightleftharpoons \mathrm{Cl}_{2}^{\bullet-}$ & $1.4 \times 10^{5} \mathrm{M}^{-1}$ & $\pm 15 \%$ & 10 \\
\hline $\begin{array}{l}11 . \\
1\end{array}$ & $\mathrm{Cl}^{\bullet}+\mathrm{H}_{2} \mathrm{O} \rightleftharpoons \mathrm{HOCl}^{\bullet-}+\mathrm{H}^{+}$ & $5 \times 10^{-6} \mathrm{M}$ & within a factor of 2 & 11 \\
\hline $\begin{array}{l}12 . \\
1\end{array}$ & $\mathrm{HO}^{\bullet}+\mathrm{Cl}^{-} \rightleftharpoons \mathrm{HOCl}^{\bullet-}$ & $0.70 \mathrm{M}^{-1}$ & \pm 0.13 & 12 \\
\hline $\begin{array}{l}13 . \\
1\end{array}$ & $\mathrm{SO}_{4}^{*^{-}}+\mathrm{Cl}^{-} \rightleftharpoons \mathrm{SO}_{4}^{2-}+\mathrm{Cl}^{\bullet}(a q)$ & 1.2 & $\pm 17 \%$ & 13 \\
\hline $\begin{array}{l}14 . \\
1\end{array}$ & $\mathrm{SO}_{4}{ }^{--}+\mathrm{NO}_{3}^{-} \rightleftharpoons \mathrm{SO}_{4}^{2-}+\mathrm{NO}_{3}{ }^{\bullet}$ & 0.3 & $\pm 36 \%$ & 14 \\
\hline $\begin{array}{l}15 . \\
1\end{array}$ & $\mathrm{SO}_{4}^{\bullet-}+\mathrm{HNO}_{3} \rightleftharpoons \mathrm{HSO}_{4}^{-}+\mathrm{NO}_{3}^{\bullet}$ & $5 \times 10^{2}$ & $\pm 40 \%$ & 15 \\
\hline $\begin{array}{l}16 . \\
1\end{array}$ & $\mathrm{NO}_{3}{ }^{\bullet}+\mathrm{Cl}^{-} \rightleftharpoons \mathrm{NO}_{3}^{-}+\mathrm{Cl}^{\bullet}$ & 3.3 & $\pm 7 \%$ & 16 \\
\hline $\begin{array}{l}17 . \\
1\end{array}$ & $\mathrm{NO}_{3}{ }^{\bullet}+\mathrm{ClO}_{3}^{-} \rightleftharpoons \mathrm{NO}_{3}^{-}+\mathrm{ClO}_{3}{ }^{-}$ & $3 \times 10$ & $\pm 67 \%$ & 17 \\
\hline $\begin{array}{l}18 . \\
1\end{array}$ & $\mathrm{SO}_{4}{ }^{-}+\mathrm{H}_{2} \mathrm{O} \rightleftharpoons \mathrm{HSO}_{4}^{-}+\mathrm{HO}^{\bullet}$ & $1.4 \times 10^{-3} \mathrm{M}$ & $\pm 29 \%$ & 18 \\
\hline $\begin{array}{l}19 . \\
1\end{array}$ & $\mathrm{HO}^{\bullet}(a q)+\mathrm{Tl}^{+}(a q) \rightleftharpoons \mathrm{TlOH}^{+}(a q)$ & $5.8 \times 10^{3} \mathrm{M}^{-1}$ & $\pm 15 \%$ & 19 \\
\hline $\begin{array}{l}20 . \\
1\end{array}$ & $\begin{array}{l}\mathrm{Tl}^{2+}(a q)+\mathrm{H}_{2} \mathrm{O}(l) \rightleftharpoons \mathrm{TlOH}^{+}(a q)+ \\
\mathrm{H}^{+}(a q)\end{array}$ & $1.7 \times 10^{-5} \mathrm{M}$ & $\pm 15 \%$ & 20 \\
\hline $\begin{array}{l}21 . \\
1\end{array}$ & $\begin{array}{l}\mathrm{Tl}^{2+}(a q)+1 / 2 \mathrm{H}_{2}(g) \rightleftharpoons \mathrm{Tl}^{+}(a q)+ \\
\mathrm{H}^{+}(a q)\end{array}$ & $2.225 \mathrm{~V}$ & $\pm 0.007 \mathrm{~V}$ & 21 \\
\hline
\end{tabular}




\begin{tabular}{|l|l|l|l|l|}
\hline & $\mathrm{HNO}_{3}(a q) \rightleftharpoons \mathrm{NO}_{3}{ }^{-}(a q)+\mathrm{H}^{+}(a q)$ & $20 \mathrm{M}$ & $\pm 20 \%$ & 15 \\
\hline
\end{tabular}

1528 The above equilibrium constants were supplemented with the standard data in Table 7.2, all of

1529 which come from the NIST tables except for $\mathrm{NO}_{3}{ }^{-}$; the value for $\mathrm{NO}_{3}{ }^{-}$in the NBS tables is

1530 incorrect, and the correct value is the value given for dissociated $\mathrm{HNO}_{3}$, as explained in Data

1531 Sheet 103. Data Sheet 103 also includes an evaluation of the $\mathrm{NO}_{3}{ }^{\bullet}$ radical that is independent of

1532 the Active Thermodynamicchemical Tables optimization.

1534 Nomenclature (venerable names in italics): $\mathrm{Cl}^{\bullet}$, chlorine atom; $\mathrm{Cl}_{2}{ }^{\bullet}$, dichloride( $\bullet 1-$ ); $\mathrm{ClO}_{3}{ }^{\bullet}$,

1535 trioxidochlorine $(\bullet)$; $\mathrm{HO}^{\bullet}$, hydroxyl, oxidanyl or hydridooxygen $(\bullet)$; $\mathrm{HOCl}^{\bullet-}$,

1536 hydroxidochlorate $(\bullet 1-)$; $\mathrm{NO}_{3}{ }^{\bullet}$, trioxidonitrogen $(\bullet) ; \mathrm{SO}_{4}{ }^{\bullet}$, tetraoxidosulfate $(\bullet 1-)$; $\mathrm{TlOH}^{+}$,

1537 hydroxidothallium $(\bullet 1+)$

1539 Table 7.2. Input standard Gibbs energies for optimization

\begin{tabular}{|l|r|l|}
\hline species & $\Delta_{\mathrm{f}} G^{\circ} / \mathrm{kJ} \mathrm{mol}^{-1}$ & uncertainty $/ \mathrm{kJ} \mathrm{mol}^{-1}$ \\
\hline $\mathrm{H}^{+}(a q)$ & 0 & \\
\hline $\mathrm{H}_{2} \mathrm{O}(l)$ & -237.13 & \pm 0.080 \\
\hline $\mathrm{Cl}^{-}(a q)$ & -131.23 & \pm 0.080 \\
\hline $\mathrm{SO}_{4}^{2-}(a q)$ & -744.53 & \pm 0.80 \\
\hline $\mathrm{NO}_{3}^{-}(a q)$ & -111.25 & \pm 0.80 \\
\hline $\mathrm{HSO}_{4}^{-}(a q)$ & -755.91 & \pm 0.80 \\
\hline $\mathrm{ClO}_{3}^{-}(a q)$ & -7.95 & \pm 0.80 \\
\hline $\mathrm{Tl}^{+}(a q)$ & -32.40 & \pm 0.80 \\
\hline
\end{tabular}

1541 The result of the optimization is

1543 Table 7.3. Optimized Gibbs energies

\begin{tabular}{|l|r|l|}
\hline species & $\Delta_{\mathrm{f}} G^{\circ} \mathrm{kJ} \mathrm{mol}^{-1}$ & Uncertainty $/ \mathrm{kJ} \mathrm{mol}^{-1}$ \\
\hline $\mathrm{HO}{ }^{\bullet}(a q)$ & +26.3 & \pm 1.6 \\
\hline $\mathrm{Cl}(a q)$ & +103.4 & \pm 1.7 \\
\hline $\mathrm{Cl}_{2}^{\bullet}(a q)$ & -57.3 & \pm 1.6 \\
\hline $\mathrm{HOCl}^{\bullet}(a q)$ & -104 & \pm 1.7 \\
\hline $\mathrm{SO}_{4}^{\bullet}(a q)$ & -509.4 & \pm 1.8 \\
\hline $\mathrm{NO}_{3} \cdot(a q)$ & +126.7 & \pm 1.8 \\
\hline $\mathrm{ClO}_{3}(a q)$ & +222 & \pm 3 \\
\hline
\end{tabular}




\begin{tabular}{|l|r|l|}
\hline $\mathrm{Tl}(\mathrm{OH})^{+}(a q)$ & -27.6 & \pm 1.3 \\
\hline $\mathrm{Tl}^{2+}(a q)$ & +182.3 & \pm 1.2 \\
\hline $\mathrm{HNO}_{3}(a q)$ & -104.1 & \pm 0.9 \\
\hline
\end{tabular}

1544

1545 Standard potentials can be derived from these optimized $\Delta_{\mathrm{f}} G^{\circ}$ data by combining them with the 1546 standard Gibbs energies of formation given above plus the following additional standard Gibbs 1547 energies of formation:

1548

1549 
1550 Table 7.4. Auxiliary Gibbs energies

\begin{tabular}{|l|r|l|}
\hline species & $\Delta_{\mathrm{f}} G^{\circ} / \mathrm{kJ} \mathrm{mol}^{-1}$ & Uncertainty $/ \mathrm{kJ} \mathrm{mol}^{-1}$ \\
\hline $\mathrm{Cl}_{2}(a q)$ & +6.9 & \pm 0.8 \\
\hline $\mathrm{HOCl}(a q)$ & -80 & \pm 8 \\
\hline$\left(\mathrm{S}_{2} \mathrm{O}_{8}\right)^{2-}(a q)$ & -1115 & \pm 8 \\
\hline $\mathrm{Tl}^{3+}(a q)$ & +215 & \pm 8 \\
\hline $\mathrm{TlOH}^{2+}(a q)$ & -16 & \pm 8 \\
\hline
\end{tabular}

$1551{ }^{a}$ Data at $25^{\circ} \mathrm{C}$ and from NBS.

1553 Table 7.5. Derived standard potentials

\begin{tabular}{|c|c|c|}
\hline Reaction & $\begin{array}{l}E^{\circ} / \mathrm{V} \text { vs } \\
\mathrm{NHE}\end{array}$ & Uncertainty / V \\
\hline $\mathrm{HO}^{\bullet}(a q)+\mathrm{e}^{-} \rightleftharpoons \mathrm{HO}^{-}(a q)$ & +1.902 & \pm 0.017 \\
\hline $\mathrm{HO}^{\bullet}(a q)+\mathrm{e}^{-}+\mathrm{H}^{+}(a q) \rightleftharpoons \mathrm{H}_{2} \mathrm{O}(l)$ & +2.730 & \pm 0.017 \\
\hline $\mathrm{Cl}^{\bullet}(a q)+\mathrm{e}^{-} \rightleftharpoons \mathrm{Cl}^{-}(a q)$ & +2.432 & \pm 0.018 \\
\hline $\mathrm{Cl}_{2}{ }^{\bullet-}(a q)+\mathrm{e}^{-} \rightleftharpoons 2 \mathrm{Cl}^{-}(a q)$ & +2.126 & \pm 0.017 \\
\hline $\mathrm{Cl}_{2}(a q)+\mathrm{e}^{-} \rightleftharpoons \mathrm{Cl}_{2}^{\bullet-}(a q)$ & +0.666 & \pm 0.017 \\
\hline $\mathrm{ClOH}^{\bullet}(a q)+\mathrm{e}^{-} \rightleftharpoons \mathrm{Cl}^{-}(a q)+\mathrm{HOH}(a q)$ & +1.912 & \pm 0.018 \\
\hline $\mathrm{HOCl}^{\bullet^{-}}(a q)+\mathrm{e}^{-}+\mathrm{H}^{+}(a q) \rightleftharpoons \mathrm{Cl}^{-}(a q)+\mathrm{H}_{2} \mathrm{O}(l)$ & +2.740 & \pm 0.018 \\
\hline $\mathrm{HOCl}(a q)+\mathrm{e}^{-} \rightleftharpoons \mathrm{HOCl}^{\bullet-}(a q)$ & +0.25 & \pm 0.08 \\
\hline $\mathrm{SO}_{4}{ }^{\bullet-}(a q)+\mathrm{e}^{-} \rightleftharpoons \mathrm{SO}_{4}^{2-}(a q)$ & +2.437 & \pm 0.019 \\
\hline $\mathrm{S}_{2} \mathrm{O}_{8}^{2-}(a q)+\mathrm{e}^{-} \rightleftharpoons \mathrm{SO}_{4}^{\bullet-}(a q)+\mathrm{SO}_{4}^{2-}(a q)$ & +1.44 & \pm 0.08 \\
\hline $\mathrm{NO}_{3} \cdot(a q)+\mathrm{e}^{-} \rightleftharpoons \mathrm{NO}_{3}^{-}(a q)$ & +2.466 & \pm 0.019 \\
\hline $\mathrm{ClO}_{3}{ }^{\bullet}(a q)+\mathrm{e}^{-} \rightleftharpoons \mathrm{ClO}_{3}^{-}(a q)$ & +2.38 & \pm 0.03 \\
\hline $\mathrm{Tl}^{3+}(a q)+\mathrm{e}^{-} \rightleftharpoons \mathrm{Tl}^{2+}(a q)$ & +0.34 & \pm 0.08 \\
\hline $\mathrm{Tl}^{2+}(a q)+\mathrm{e}^{-} \rightleftharpoons \mathrm{Tl}^{+}(a q)$ & +2.225 & \pm 0.012 \\
\hline $\mathrm{TlOH}^{+}(a q)+\mathrm{e}^{-}+\mathrm{H}^{+}(a q) \rightleftharpoons \mathrm{Tl}^{+}(a q)+\mathrm{H}_{2} \mathrm{O}(l)$ & +2.507 & \pm 0.013 \\
\hline $\mathrm{TlOH}^{2+}(a q)+\mathrm{e}^{-} \rightleftharpoons \mathrm{TlOH}^{+}(a q)$ & +0.12 & \pm 0.08 \\
\hline $\mathrm{TlOH}^{2+}(a q)+\mathrm{e}^{-}+\mathrm{H}^{+}(a q) \rightleftharpoons \mathrm{Tl}^{2+}(a q)+\mathrm{H}_{2} \mathrm{O}(l)$ & +0.40 & \pm 0.08 \\
\hline
\end{tabular}




\section{Data Sheet 8}

1558 Chemical equilibrium: $\mathrm{HO}^{\bullet}+\mathrm{Cl}^{-}+\mathrm{H}^{+} \rightleftharpoons \mathrm{Cl}^{\bullet}+\mathrm{H}_{2} \mathrm{O}$

\section{List of reports:}

$K_{\text {eq }}=(2.0 \pm 1.0) \times 10^{5} \mathrm{M}^{-2}, \mu=0.01 \mathrm{M}$ [1]. Result obtained from UV/vis data on the equilibrium attained during pulse-radiolysis. The reported value includes the concentration of water; the value given here has been corrected to reflect water having unit activity. Kläning to Stanbury (21 Feb 1990) states that the result was obtained by recalulation from the optical/pulse-radiolysis data of Jayson et al. [1] with a correction for the optical density due to chlorine atoms.

\section{Discussion}

1575

McElroy [3] has argued that the decay of chlorine atoms is more complex than indicated by the models of Jayson et al. [1] and Kläning et al. [2], and he has specifically introduced the equilibrium hydration of chlorine atoms: $\mathrm{Cl}^{\bullet}(a q)+\mathrm{H}_{2} \mathrm{O}(l) \rightleftharpoons \mathrm{HOClH}^{\bullet}$ [3]. However, Buxton et been checked directly, and that it is likely to be dependent on ionic strength.

\section{Recommended value:}

$$
K_{\text {eq }}=9.1 \times 10^{4} \mathrm{M}^{-2} \text { within a factor of two at } \mu=0.01 \mathrm{M} \text {. }
$$

List of auxiliary thermodynamic data: none

\section{References} 1607 (1973). 
$1592 \quad$ 2. U. K. Kläning, T. Wolff. Ber. Bunsenges. Phys. Chem. 89, 243-245 (1985).

1593 3. W. J. McElroy. J. Phys. Chem. 94, 2435-2441 (1990).

1594 4. G. V. Buxton, M. Bydder, G. A. Salmon, J. E. Williams. Phys. Chem. Chem. Phys. 2, $1595 \quad 237-245$ (2000).

1596

1597 


\section{Data Sheet 9}

\section{List of reports:}

$K_{\text {eq }}=3.6 \times 10^{-8} \mathrm{M}^{3}$, no specified uncertainty, $\mu$ unspecified, but apparently less than $0.1 \mathrm{M}[1]$. Data obtained from flash photolysis with conductivity detection. Result obtained from ratio of forward and reverse rate constants $\left(k(19)\right.$ and $k\left(19^{\prime}\right)$ in Table 2, p. 865) given in the paper.

$K_{\mathrm{eq}}=(7.7 \pm 0.8) \times 10^{-11} \mathrm{M}^{3}, \mu \sim 0.01 \mathrm{M}$. Result obtained from ratio of forward and reverse rate constants, which were obtained from flash photolysis with optical detection [2]. The forward rate constant used is $k_{-4}^{\mathrm{I}} / K_{5}$ given on the bottom left of p. 1321 (also in Table 4), and the reverse rate constant is $k_{4} K_{3}$ from Table 2 (note that the dimensions in the paper are incorrect).

\section{Discussion}

Given the gross discrepancy between the two reports, careful evaluation is required. Note that the forward and reverse rate constants given in the two papers have different dimensions and apparently pertain to systems having different rate-limiting steps. The first report, by Wagner et al. [1], gives a forward first-order rate constant $k(19)$ of $7.2 \times 10^{3} \mathrm{~s}^{-1}$ for the direct reaction of $\mathrm{Cl}_{2}{ }^{\bullet-}$ with water. The second report, by $\mathrm{Yu}$ and Barker [2], gives a forward rate constant of $1.4 \mathrm{M}$ $\mathrm{s}^{-1}$, the dimensions reflecting an inverse dependence on $[\mathrm{Cl}]$ and thus implying a mechanism proceeding via dissociation of $\mathrm{Cl}_{2}{ }^{\bullet-}$ followed by hydrolysis of $\mathrm{Cl}$ atoms. $\mathrm{Yu}$ and Barker claim that their data set an upper limit of $\left(100 \mathrm{~s}^{-1}\right)$ for the direct reaction of $\mathrm{Cl}_{2}{ }^{\bullet-}$ with water. They cite several prior reports in support of their slow rate constant. They also cite good literature support for their measured value for the forward rate constant. In view of the great difficulty in measuring the very slow rate constant for the direct reaction of $\mathrm{Cl}_{2}{ }^{\bullet-}$ with water and the apparently incorrect value obtained by Wagner et al. [1], we recommend the result of Yu and

1627 Barker [2].

$1628 \quad \mathrm{Yu}$ and Barker [2] note that their rate constant $k_{4}$ can be corrected to zero ionic strength

1629 by applying a factor of $1 / 0.8$. As the other components of $K_{\text {eq }}\left(K_{5}, K_{3}\right.$, and $\left.k_{-4}^{\mathrm{I}}\right)$ are expected to be 1630 independent of ionic strength, we can correct $K_{\text {eq }}$ to $6.1 \times 10^{-11} \mathrm{M}^{3}$ at zero ionic strength.

\section{Recommended value:}


$1634 \quad K_{\mathrm{eq}}=(6.1 \pm 0.7) \times 10^{-11} \mathrm{M}^{3}, \mu=0 \mathrm{M}$.

1635

1636 List of auxiliary thermodynamic data: none.

1637

1638 References

1639

1640 1. I. Wagner, J. Karthauser, H. Strehlow. Ber. Bunsen-Ges. Phys. Chem. 90, 861-867 1641 (1986).

$1642 \quad 2 . \quad$ X.-Y. Yu, J. R. Barker. J. Phys. Chem. A 107, 1313-1324 (2003).

1643

1644 


\section{Data Sheet 10}

\section{List of reports:}

$K_{\text {eq }}=(1.9 \pm 0.5) \times 10^{5} \mathrm{M}^{-1}, \mu=0.01 \mathrm{M}$ [1]. Result obtained from UV/vis data of equilibrium observed during pulse-radiolysis. flash photolysis.

$K_{\text {eq }}=(4.7 \pm 0.4) \times 10^{3} \mathrm{M}^{-1}, \mu=? \mathrm{M}[3]$. Data obtained by pulse radiolysis. data on the forward and reverse rate constants determined by pulse-radiolysis. from the ratio of forward and reverse rate constants, the forward one being a literature value and the reverse being measured by Yu et al. [5].

\section{Discussion}

The low value of Wu et al. [2] is discounted because of internal inconsistency of the data, as pointed out by Wagner et al. [6] The low value of Adams et al. [3] is discounted because of an incorrect approximation, as pointed out by Buxton et al. [4]. Deviations of the values of Buxton et al. [4] and Yu et al. [5] from the result of Jayson et al. are attributed to neglect of the absorption due to chlorine atoms by Jayson et al. [1]. Thus, we recommend the averaged results of Buxton et al. [4] and Yu et al. [5].

\section{Recommended value:}

$K_{\mathrm{eq}}=(1.4 \pm 0.2) \times 10^{5} \mathrm{M}^{-1}, \mu$ unspecified and presumed to be unimportant. 


\section{References}

1682

1683 1. G. G. Jayson, B. J. Parsons, A. J. Swallow. J. Chem. Soc., Faraday Trans. I 69, 159716841607 (1973).

1685 2. D. Wu, D. Wong, B. Di Bartolo. J. Photochem. 14, 303-310 (1980).

$16863 . \quad$ D. J. Adams, S. Barlow, G. V. Buxton, T. M. Malone, G. A. Salmon. J. Chem. Soc., 1687 Faraday Trans. 91, 3303-3305 (1995).

1688 4. G. V. Buxton, M. Bydder, G. A. Salmon. J. Chem. Soc., Faraday Trans. 94, 653-657 1689 (1998).

$1690 \quad 5 . \quad$ X.-Y. Yu, J. R. Barker. J. Phys. Chem. A 107, 1313-1324 (2003).

1691 6. I. Wagner, J. Karthauser, H. Strehlow. Ber. Bunsen-Ges. Phys. Chem. 90, 861-867 1692 (1986).

1693

1694 


\section{Data Sheet 11}

\section{List of reports:}

$K_{\mathrm{eq}}=3.4 \times 10^{-6} \mathrm{M}$, within a factor of 2 [1]. Actually, Jayson et al. did not really measure this equilibrium constant but rather derived it from their measured equilibrium constants for reactions 8.1 and 12.1 (electron transfer from $\mathrm{Cl}^{-}$to $\mathrm{HO}^{\circ}$, and addition of $\mathrm{HO}^{\circ}$ to $\mathrm{Cl}^{-}$). Moreover, the value they calculate takes the concentration of water into account; the value given here has been corrected to reflect water having unit activity.

$\mathrm{p} K_{\mathrm{a}}=5.1$ [2]. The basis for this result is unclear from the published paper, but a letter from Kläning to Stanbury (21 Feb 1990) states that the result was obtained by recalculation from the optical/pulse-radiolysis data of Jayson et al. [1] with a correction for the optical density due to chlorine atoms. Thus, the actual equilibria measured directly are reactions 8.1 and 12.1.

$K_{\mathrm{a}}=5 \times 10^{-6} \mathrm{M}$, ionic strength unspecified but quite low, uncertainty unspecified [3]. Forward rate constant obtained from flash photolysis of aqueous chloroacetone. Reverse rate constant taken as the usual value for protonation reactions; Buxton (private communication) cites the reaction of $\mathrm{H}^{+}+\mathrm{O}_{2}{ }^{--}$[4] and a host of similar rate constants tabulated in Table 12.1 of Caldin's book [5].

$K_{\text {eq }}=(6.3 \pm 1.6) \times 10^{-6} \mathrm{M}$, extrapolated to zero ionic strength [6]. Result obtained by flash

1719 photolysis. It is obtained from a ratio of measured rate constants and is directly dependent on the value of the equilibrium constant for reaction 12.1 ; they actually obtained the equilibrium constant for reaction 9.1 .

\section{Discussion}

As all of the literature reports, except from Buxton et al. [3], actually present results derived from other equilibrium constants, we make no recommendation based on these.

The report from Buxton et al. [3] is based on an assumed diffusion-controlled reverse rate constant, and thus is not highly accurate; we assign an uncertainty of a factor of 2 . As the forward rate constant was obtained at quite low ionic strength and the reverse rate constant was 
1730 appropriate for zero ionic strength, the derived equilibrium constant reasonably approximates the 1731 value at zero ionic strength.

1732

\section{Recommended value:}

1734

$1735 K_{\mathrm{a}}=5 \times 10^{-6} \mathrm{M} \pm$ factor of 2 , at low ionic strength.

1736

1737 List of auxiliary thermodynamic data: none

1738

1739

\section{References}

1740

1741 1. G. G. Jayson, B. J. Parsons, A. J. Swallow. J. Chem. Soc., Faraday Trans. I 69, $1597-$ $17421607(1973)$.

1743 2. U. K. Kläning, T. Wolff. Ber. Bunsenges. Phys. Chem. 89, $243-245$ (1985).

1744 3. G. V. Buxton, M. Bydder, G. A. Salmon, J. E. Williams. Phys. Chem. Chem. Phys. 2, $1745 \quad 237-245(2000)$.

1746 4. Y. Ilan, J. Rabani. Int. J. Radiat. Phys. Chem. 8, 609-611 (1976).

1747 5. E. F. Caldin. Fast Reactions in Solution, John Wiley \& Sons Inc., New York 263 (1964).

1748 6. X.-Y. Yu, J. R. Barker. J. Phys. Chem. A 107, 1313-1324 (2003).

1749

1750 


\section{Data Sheet 12}

1752

1753 Chemical equilibrium: $\mathrm{HO}^{\bullet}+\mathrm{Cl}^{-} \rightleftharpoons \mathrm{HOCl}^{\bullet-}$

1754

1755

\section{List of reports:}

1756

$1757 K_{\text {eq }}=0.70 \pm 0.13 \mathrm{M}^{-1}, \mu=1.0 \mathrm{M}[1]$. Result obtained from optical data on the equilibrium

1758 position in pulse radiolysis experiments.

1759

1760

Discussion

1761

1762 The experiments appear to have been done quite well, and there are no conflicting data. Thus, we 1763 accept the result. It is to be expected that the equilibrium constant is not substantially affected by 1764 ionic strength.

1765

1766

Recommended value:

1767

1768

$$
K_{\text {eq }}=0.70 \pm 0.13 \mathrm{M}^{-1}
$$

1769

1770

List of auxiliary thermodynamic data: none

1771

1772

\section{References}

1773

1774 1. G. G. Jayson, B. J. Parsons, A. J. Swallow. J. Chem. Soc., Faraday Trans. I 69, 1597-

17751607 (1973).

1776

1777 


\section{Data Sheet 13}

1779

1780 Chemical equilibrium: $\mathrm{SO}_{4}{ }^{--}+\mathrm{Cl}^{-} \rightleftharpoons \mathrm{SO}_{4}{ }^{2-}+\mathrm{Cl}^{\bullet}(a q)$

1781

1782 List of reports:

1783

$1784 K_{\text {eq }}=1.9$ at $\mu=0.1 \mathrm{M}$. No uncertainty specified. Result obtained from ratio of forward and 1785 reverse rate constants [1].

1786

1787

$K_{\text {eq }}=2.9 \pm 0.2$ at $\mu=0.3 \mathrm{M}$, and $K_{\text {eq }}=1.2$ at $\mu=0 \mathrm{M}$. Results obtained from ratio of forward

1788 and reverse rate constants, with extrapolation of the ionic-strength dependent data to get the result at $\mu=0$ [2].

\section{Discussion}

The good agreement between the two determinations of this equilibrium constant gives confidence in its value. We recommend the more recent result of Buxton et al. [2], because of its experimental extrapolation to $\mu=0 \mathrm{M}$.

1796

Recommended value:

1798

1799

$K_{\mathrm{eq}}=1.2 \pm 0.2$ at $\mu=0 \mathrm{M}$

1800

1801 List of auxiliary thermodynamic data: none

1802

1803

\section{References}

1804

1805 1. R. E. Huie, C. L. Clifton, P. Neta. Radiat. Phys. Chem. 38, 477-481 (1991).

1806

2. G. V. Buxton, M. Bydder, G. A. Salmon. Phys. Chem. Chem. Phys. 1, 269-273 (1999). 


\section{Data Sheet 14}

1811 Chemical equilibrium: $\mathrm{SO}_{4}{ }^{--}+\mathrm{NO}_{3}{ }^{-} \rightleftharpoons \mathrm{SO}_{4}{ }^{2-}+\mathrm{NO}_{3}{ }^{\bullet}(a q)$

\section{List of reports:}

$1815 K_{\text {eq }}=(0.5 \pm 0.1)$ at ionic strength of $0.1 \mathrm{M}$ to $0.2 \mathrm{M}$ was determined directly from the 1816 equilibrium absorbance measurements by Løgager $e t$ al. [1]. They employed the same correction 1817 as Exner et al. [2] to extrapolate to zero ionic strength, which resulted in $K_{\mathrm{eq}}=0.28$ at $\mu=0 \mathrm{M}$.

\section{Discussion}

The determination of $K_{\mathrm{eq}}$ from the equilibrium absorbance relies upon the knowledge of spectra of the radicals. Although significant, the uncertainties in molar absorptivity are unlikely to bring the errors in $K_{\text {eq }}$ outside the stated uncertainty for this value. For the extrapolated $K_{\text {eq }}$, Løgager $e t$

1824 al. [1] have not indicated the error margins. However, error margins of no more than $30 \%$ appear 1825 reasonable in this type of extrapolations.

\section{Recommended value:}

1828

$K_{\mathrm{eq}}=(0.28 \pm 0.1)$, at $\mu=0 \mathrm{M}$.

List of auxiliary thermodynamic data: none

1835 1. T. Løgager, K. Sehested, J. Holcman. Radiat. Phys. Chem. 41, 539-543 (1993).

1836 2. M. Exner, H. Herrmann, R. Zellner. Ber. Bunsen-Ges. Phys. Chem. 96, 470-477 (1992). 


\section{Data Sheet 15}

\section{List of reports:}

1844 Løgager et al. [1] measured the ratio $\left[\mathrm{SO}_{4}{ }^{--}\right] /\left[\mathrm{NO}_{3}{ }^{\bullet}\right]$ as a function of $\left[\mathrm{HSO}_{4}^{-}\right] /\left(\left[\mathrm{NO}_{3}{ }^{-}+\left[\mathrm{HNO}_{3}\right]\right)\right.$ 1845 at three different $\mathrm{H}_{2} \mathrm{SO}_{4}$ concentrations, namely $\left(0.5,1.0\right.$, and 2.0) M. By taking $K_{\mathrm{a}}\left(\mathrm{HNO}_{3}\right)=20$ $1846 \mathrm{M}$, reportedly from the work of Hood and Reilly [2], they calculated the apparent $K_{\text {eq }}$ to be 492 , 1847462 , and 440 at $(0.5,1.0$, and 2.0$) \mathrm{M} \mathrm{H}^{+}$, respectively.

\section{Discussion}

The $K_{\mathrm{a}}$ of $\mathrm{HNO}_{3}$ is somewhat uncertain. The work of Hood and Reilly [2] actually does not report $K_{\mathrm{a}}\left(\mathrm{HNO}_{3}\right)=20 \mathrm{M}$; instead it reports two $K_{\mathrm{a}}$ values of 27.5 and 25 obtained with slightly different assumptions, both values are dimensionless and expressed through activities. Recalculation of the data from Løgager et al. [1] with the former number gives $K_{\mathrm{eq}}=670,630$, and 590 at $\left(0.5,1.0\right.$, and 2.0) $\mathrm{M}\left[\mathrm{H}^{+}\right]$, respectively. However, the $K_{\mathrm{a}}$ value of 20 has indeed been reported by Redlich et al. [3]. With such an uncertainty in $K_{\mathrm{a}}\left(\mathrm{HNO}_{3}\right)$, the equilibrium constant of reaction 15.1 is probably not better known than within $\pm 2 \times 10^{2}$. Combining $K_{\mathrm{a}}\left(\mathrm{HNO}_{3}\right)=20$ with $K_{\mathrm{a}}\left(\mathrm{HSO}_{4}^{-}\right)=1.99$ and $\left(K_{\text {eq }}\right)_{14.1}=0.28$, one obtains $\left(K_{\text {eq }}\right)_{15.1}=5.5 \times 10^{2}$, which is about the average of all the values above.

\section{Recommended value:}

1862

1863

$$
K_{\text {eq }}=(5 \pm 2) \times 10^{2}
$$

1864

List of auxiliary thermodynamic data: none

\section{References}

1869 1. T. Løgager, K. Sehested, J. Holcman. Radiat. Phys. Chem. 41, 539-543 (1993).

$1870 \quad 2 . \quad$ G. C. Hood, C. A. Reilly. J. Chem. Phys. 32, 127-130 (1960).

1871 3. O. Redlich, R. W. Duerst, A. Merbach. J. Chem. Phys. 49, 2986-2994 (1968). 


\section{Data Sheet 16}

\section{List of reports:}

$K_{\text {eq }}=(3.3 \pm 0.2)$ at $\mu=0 \mathrm{M}$, calculated from the ratio of the rate constants; $k_{\mathrm{f}}=(3.40 \pm 0.11) \times$ $10^{8} \mathrm{M}^{-1} \mathrm{~s}^{-1}$ was obtained by Buxton et al. from pulse radiolysis, and $k_{\mathrm{r}}=(1.02 \pm 0.04) \times 10^{8} \mathrm{M}^{-1}$ zero ionic strength [1]. The reported uncertainty in $K_{\text {eq }}$ is conservative, as \pm 0.17 for $K_{\text {eq }}$ follows from the propagation of uncertainties in $k_{\mathrm{f}}$ and $k_{\mathrm{r}}$. $K_{\mathrm{eq}}=(3.5 \pm 0.5)$ at $\mu=0.1-1 \mathrm{M}$, obtained from the ratio of the rate constants. Only $k_{\mathrm{f}}=(3.5 \pm$ $0.5) \times 10^{8} \mathrm{M}^{-1} \mathrm{~s}^{-1}$ was measured; the value is obtained by fitting pulse radiolysis kinetic data to a complex mechanism [2]. The literature value [1] used for $k_{\mathrm{r}}$ was rounded up to $1 \times 10^{8} \mathrm{M}^{-1} \mathrm{~s}^{-1}$; without the round-up, $K_{\mathrm{eq}}=(3.43 \pm 0.51)$.

\section{Discussion}

Only one measurement of $k_{\mathrm{r}}$ has been reported [1]. However, this measurement is straightforward (obtained from linear dependence of $\mathrm{Cl}^{\bullet}$ decay upon $\left[\mathrm{NO}_{3}{ }^{-}\right]$in chloride-free

1895 solution) and appears to be reliable. In contrast, several earlier $k_{\mathrm{f}}$ evaluations that have been 1896 reported $\left(1 \times 10^{8}[3], 8.8 \times 10^{6}[4], 7.1 \times 10^{7}[5]\right.$, and $\left.9.1 \times 10^{6} \mathrm{M}^{-1} \mathrm{~s}^{-1}[6]\right)$ are most likely in

1897 error. The probable reasons for errors in the first two of these measurements have been discussed

1898 [1]. The last two values are not accompanied by sufficient details to assess their reliability.

1899 Nearly perfect agreement between $k_{\mathrm{f}}$ in the two most recent reports $[1,2]$ and the explanations

1900 for the complex kinetic concentration dependencies (upon $\left[\mathrm{NO}_{3}{ }^{-}\right]$and $\left[\mathrm{Cl}^{-}\right]$) provide good 1901 confidence in the results. We select the data of Buxton et al. [1] because of the smaller error, 1902 simultaneous determination of both $k_{\mathrm{f}}$ and $k_{\mathrm{r}}$, transparent data analysis, and careful extrapolation 1903 to zero ionic strengths.

1904

\section{Recommended value:}

$$
K_{\text {eq }}=(3.3 \pm 0.2) \text { at } \mu=0 \mathrm{M} \text {. }
$$

1908

1909 List of auxiliary thermodynamic data: none 
1910

1911 References

1912

1913 1. G. V. Buxton, G. A. Salmon, J. Wang. Phys. Chem. Chem. Phys. 1, 3589-3593 (1999).

1914 2. G. A. Poskrebyshev, R. E. Huie, P. Neta. J. Phys. Chem. A 107, 1964-1970 (2003).

1915 3. K.-J. Kim, W. H. Hamill. J. Phys. Chem. 80, 2320-2325 (1976).

1916 4. M. Exner, H. Herrmann, R. Zellner. Ber. Bunsen-Ges. Phys. Chem. 96, 470-477 (1992).

1917 5. P. Neta, R. E. Huie. J. Phys. Chem. 90, 4644-4648 (1986).

1918 6. Z. Zuo, Y. Katsumura, K. Ueda, K. Ishigure. J. Chem. Soc., Faraday Trans. 93, 1885$19191891(1997)$.

1920

1921 


\section{$1922 \quad$ Data Sheet 17}

1924 Chemical equilibrium: $\mathrm{NO}_{3}{ }^{\circ}(a q)+\mathrm{ClO}_{3}{ }^{-} \rightleftharpoons \mathrm{NO}_{3}{ }^{-}+\mathrm{ClO}_{3}{ }^{\circ}(a q)$

\section{List of reports:}

$K_{\text {eq }}=(42 \pm 6)$ at $\mu=(1-1.4) \mathrm{M}\left(1 \mathrm{M} \mathrm{HNO}_{3}+0.02-0.4 \mathrm{M} \mathrm{NaClO}_{3}\right)$, obtained from the measurements of absorption at equilibrium as a function of $\left[\mathrm{ClO}_{3}{ }^{-}\right] /\left[\mathrm{NO}_{3}{ }^{-}\right]$by Katsumura and co-workers [1]. The $\mathrm{NO}_{3}{ }^{\bullet}$ radical has been generated by flash photolysis of cerium nitrate. The forward and reversed rate constants are reported as $k_{\mathrm{f}}=(9.0 \pm 1.2) \times 10^{3} \mathrm{M}^{-1} \mathrm{~s}^{-1}$ and $k_{\mathrm{r}}=(8.3 \pm$ $1.0) \times 10^{2} \mathrm{M}^{-1} \mathrm{~s}^{-1}$, which corresponds to $K_{\mathrm{eq}}=11 \pm 2$ from the ratio of the rate constants. The medium effects (high ionic strength) have not been considered.

\section{Discussion}

The authors are of the opinion that the value of $K_{\mathrm{eq}}$ obtained from the equilibrium position is more reliable than that obtained from the rate constants. However, this may not be the case because the equilibration is slow (milliseconds) and there is likely to be a significant net loss of radicals during that time. Such a possibility is of particular concern because of the occurrence of an unexplained first-order decay of $\mathrm{NO}_{3}{ }^{\circ}$ in the absence of added $\mathrm{ClO}_{3}{ }^{-}$that is observed on this timescale [1,2], and because of the fast second-order self-recombination $\left(2 \mathrm{k} \approx 9 \times 10^{8} \mathrm{M}^{-1} \mathrm{~s}^{-1}\right)$

1943 observed for $\mathrm{ClO}_{3}{ }^{\bullet}$ [1]. The latter should be very significant with the large concentration of

1944 radicals $(\mathrm{ca} .15 \mu \mathrm{M})$ present. Furthermore, the dose dependence of $K_{\text {eq }}$ obtained from the

1945 equilibrium position was not investigated. The net loss of radicals would tend to increase the

1946 apparent $K_{\text {eq }}$ value, such that $K_{\text {eq }}=42$ is probably close to an upper limit.

1947 The determination of $K_{\text {eq }}$ from the ratio of the rate constants is also somewhat worrisome,

1948 because the first-order decay of $\mathrm{NO}_{3}{ }^{\circ}$ was ignored and because of the possibility that the reverse reaction is actually not with $\mathrm{NO}_{3}{ }^{-}$, but with undissociated $\mathrm{HNO}_{3}$ present at (20-30) $\mathrm{mM}$ in $1 \mathrm{M}$ nitric acid. By analogy with the oxidation of $\mathrm{HNO}_{3} / \mathrm{NO}_{3}{ }^{-}$by $\mathrm{SO}_{4}{ }^{--}$[3], the oxidation of $\mathrm{HNO}_{3}$ could occur much more rapidly than that of $\mathrm{NO}_{3}{ }^{-}$. Although this possibility has not been

1952 considered, it is not unlikely that the observed equilibration (by both methods) was applied to 1953 reaction 17.2 , instead of 17.1.

$$
\mathrm{NO}_{3} \cdot(a q)+\mathrm{ClO}_{3}{ }^{-}+\mathrm{H}^{+} \rightleftharpoons \mathrm{HNO}_{3}+\mathrm{ClO}_{3}{ }^{\bullet}(a q)
$$

Recommended value: 
$1959 K_{\text {eq }}=10-50$, in $1 \mathrm{M} \mathrm{HNO}_{3}$ (can be approx. 20 times larger, if the reverse reaction is with $\mathrm{HNO}_{3}$ ) 1960

1961 List of auxiliary thermodynamic data: none

1962

1963 References

1964

1965 1. Z. Zuo, Y. Katsumura, K. Ueda, K. Ishigure. J. Chem. Soc., Faraday Trans. 93, 533-536 1966 (1997).

1967 2. P. H. Wine, R. L. Mauldin, R. P. Thorn. J. Phys. Chem. 92, 1156-1162 (1988).

1968 3. T. Løgager, K. Sehested, J. Holcman. Radiat. Phys. Chem. 41, 539-543 (1993).

1969

1970 


\section{$1971 \quad$ Data Sheet 18}

\section{List of reports:}

No $K$ has been reported,, but Wine and co-workers [1] report measurements of both forward, (3.6 $\pm 0.9) \times 10^{2} \mathrm{~s}^{-1}$, and reverse, $(3.5 \pm 0.5) \times 10^{5} \mathrm{M}^{-1} \mathrm{~s}^{-1}$, rate constants, from which $K_{\mathrm{eq}}=(1.0 \pm$ $0.3) \times 10^{-3} \mathrm{M}$ is calculated.

Four laboratories have determined the rate constant of the forward reaction, $k$, with good internal consistency. In all cases, very similar rate constants were obtained by producing the $\mathrm{SO}_{4}{ }^{--}$radical from $\mathrm{S}_{2} \mathrm{O}_{8}{ }^{2-}$ and by measuring the disappearance of the characteristic absorption of

$1986 \mathrm{SO}_{4}^{-}$around $450 \mathrm{~nm}$. The reported values are as follows: $(360 \pm 90) \mathrm{s}^{-1}$ [1], $(500 \pm 60) \mathrm{s}^{-1}$ [2], $1987(660 \pm 40) \mathrm{s}^{-1}$ [3], and $(440 \pm 50) \mathrm{s}^{-1}$ [4]. Bao and Barker have found that simulations with the 1988 last value together with the rate constant for self-recombination of $\mathrm{SO}_{4}{ }^{\circ-}$ reproduce very well the experimental traces at low ionic strength [4]. They also report low impurity contents. A much higher value for $k_{\text {f, namely }}(9.4 \pm 3.7) \times 10^{3} \mathrm{~s}^{-1}$, is reported by Ivanov et al. [5]. However, as the primary aim of the authors was not the determination of this value, they did not take special 1992 precautions to avoid impurities. In fact, they attribute their high $k_{\mathrm{f}}$ value to impurities and to the 1993 high ionic strengths of about $1 \mathrm{M}$ employed. Excluding this value, the average of $k_{\mathrm{f}}$ comes out as $1994(4.9 \pm 1.3) \times 10^{2} \mathrm{~s}^{-1}$ and this number is selected.

1995 Three direct determinations for the reverse reaction rate constant, $k_{\mathrm{r}}$, are known: $6.9 \times 10^{5}$ 1996 [6], $(3.5 \pm 0.5) \times 10^{5}[1]$, and $4.7 \times 10^{5} \mathrm{M}^{-1} \mathrm{~s}^{-1}$ [7]. The agreement is satisfactory. The first and 1997 last values are obtained by pulse radiolysis under conditions where radical-radical reactions may play a role. In addition, the last determination has been made in concentrated $\mathrm{H}_{2} \mathrm{SO}_{4}$, where the reaction $\mathrm{HO}^{\bullet}+\mathrm{H}_{2} \mathrm{SO}_{4}$ dominated the $\mathrm{HO}^{\bullet}$ decay. The second value, obtained by Tang et al. [1] using flash photolysis of $\mathrm{H}_{2} \mathrm{O}_{2}$ to generate $\mathrm{HO}^{\bullet}$, appears to be more accurate and is selected, because of the special care taken to minimize radical-radical and other interfering reactions.

\section{Recommended value:}


$2005 K_{\text {eq }}=(1.4 \pm 0.4) \times 10^{-3} \mathrm{M}$, from the selected $k_{\mathrm{f}}=(4.9 \pm 1.3) \times 10^{2} \mathrm{~s}^{-1}$ and $k_{\mathrm{r}}=(3.5 \pm 0.5) \times 10^{5}$ $2006 \mathrm{M}^{-1} \mathrm{~s}^{-1}$

2008 List of auxiliary thermodynamic data: none

2009

\section{References}

2012 1. Y. Tang, R. P. Thorn, R. L. Maudlin, P. H. Wine. J. Photochem. Photobiol., A 44, 2432013258 (1988).

2014 2. W. J. McElroy, S. J. Waygood. J. Chem. Soc., Faraday Trans. 86, 2557-2564 (1990).

2015 3. H. Herrmann, A. Reese, R. Zellner. J. Mol. Struct. 348, 183-186 (1995).

2016 4. Z.-C. Bao, J. R. Barker. J. Phys. Chem. 100, 9780-9787 (1996).

2017 5. K. L. Ivanov, E. M. Glebov, V. F. Plyusin, Y. V. Ivanov, V. P. Grivin, N. M. Bazhin. J. 2018 Photochem. Photobiol. A 133, 99-104 (2000).

2019 6. E. Heckel, A. Henglein, G. Beck. Ber. Bunsen-Ges. Phys. Chem. 70, 149-154 (1966).

2020 7. P.-Y. Jiang, Y. Katsumura, R. Nagaishi, M. Domae, K. Ishikawa, K. Ishigure, Y.

2021 Yoshida. J. Chem. Soc., Faraday Trans. 88, 1653-1658 (1992). 


\section{Data Sheet 19}

\section{List of reports:}

$K_{\text {eq }}=(5.8 \pm 1.0) \times 10^{3} \mathrm{M}^{-1}$ at $25{ }^{\circ} \mathrm{C}$ and $\mu=0.01 \mathrm{M} ; K_{\text {eq }}=(3.4 \pm 0.5) \times 10^{3} \mathrm{M}^{-1}$ at $25^{\circ} \mathrm{C}$ and $\mu=$ $1.00 \mathrm{M}\left(\mathrm{LiClO}_{4}\right)$ [1]. Data obtained by pulse radiolysis with optical detection. Result obtained from the ratio of the forward and reverse rate constants and also from the position of the equilibrium. Data analysis required the simultaneous determination of the $\mathrm{p} K_{\mathrm{a}}$ of $\mathrm{Tl}^{2+}$ (reaction 20.1).

\section{Discussion}

These sole determinations of the equilibrium constant appear to be reliable and accurate. It is not expected to be significantly dependent on ionic strength, and this expectation is supported by the data of Schwarz and Dodson at $\mu=1.0$ and $0.01 \mathrm{M}$ [1].

Indiscriminate use of this equilibrium constant with the $\mathrm{p} K_{\mathrm{a}}$ of $\mathrm{Tl}^{2+}$ can lead to a flawed value for $E^{\circ}\left(\mathrm{HO}^{\bullet} / \mathrm{HO}^{-}\right)$if it is assumed that the $\mathrm{p} K_{\mathrm{a}}$ of $\mathrm{Tl}^{2+}$ is independent of ionic strength. To avoid this problem we follow Schwarz et al. and use $E^{\circ \prime}=+(2.217 \pm 0.003) \mathrm{V}$ for the $\mathrm{Tl}^{2+} / \mathrm{Tl}^{+}$ couple in $1 \mathrm{M}$ ionic strength (see data sheet for reaction 21.1), combine it with the $K_{\mathrm{a}}=(1.2 \pm$ $0.2) \times 10^{-5} \mathrm{M}_{\text {of }} \mathrm{Tl}^{2+}$ in the same medium (reaction 20.1) and the above $K_{\text {eq }}$ in the same medium

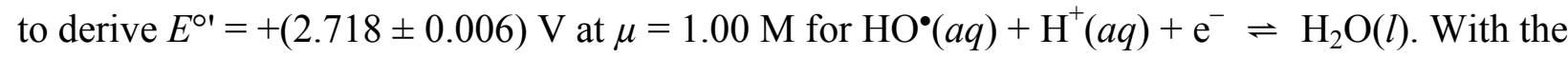
approximation that $\mathrm{HO}^{\bullet}(a q)$ and $\mathrm{H}_{2} \mathrm{O}(l)$ have activity coefficients of unity while $\mathrm{H}^{+}(a q)$ has an activity coefficient of 0.85 , we then derive $E^{\circ}=+(2.722 \pm 0.006) \mathrm{V}$ for $\mathrm{HO}^{\bullet}(a q)+\mathrm{H}^{+}(a q)+\mathrm{e}^{-}$ $\rightleftharpoons \mathrm{H}_{2} \mathrm{O}(l)$. Use of the NBS value for $\Delta_{\mathrm{f}} G^{\circ}\left(\mathrm{H}_{2} \mathrm{O}(l)\right)$ then yields $\Delta_{\mathrm{f}} G^{\circ}=+(25.5 \pm 0.6) \mathrm{kJ} \mathrm{mol}^{-1}$ for $\mathrm{HO}^{\circ}(a q)$. Use of the NBS value [2] of $\Delta_{\mathrm{f}} G^{\circ}$ for $\mathrm{OH}^{-}(a q)\left(=-157.244 \pm 0.08 \mathrm{~kJ} \mathrm{~mol}^{-1}\right)$ leads to $E^{\circ}$ $=+(1.894 \pm 0.006) \mathrm{V}$ for the $\mathrm{OH} / \mathrm{OH}^{-}$redox couple. We view the approximations and uncertainties introduced by this method to be superior to those involved in methods that use $E^{\circ}\left(\mathrm{Tl}^{2+/+}\right)$ and equilibrium constants extrapolated to zero ionic strength.

\section{Recommended values:}

$$
\begin{array}{ll}
\mathrm{HO}^{\bullet}(a q)+\mathrm{Tl}^{+}(a q) \rightleftharpoons \mathrm{TlOH}^{+}(a q) & K_{\mathrm{eq}}=(5.8 \pm 1.0) \times 10^{3} \mathrm{M}^{-1} \\
\mathrm{HO}(a q)+\mathrm{Tl}^{+}(a q) \rightleftharpoons \mathrm{TlOH}^{+}(a q) & K_{\mathrm{eq}}=(3.4 \pm 0.5) \times 10^{3} \mathrm{M}^{-1} \text { at } \mu=1.00 \mathrm{M}
\end{array}
$$




$$
\begin{array}{lll}
2059 & \mathrm{HO}^{\bullet}(a q)+\mathrm{H}^{+}(a q)+\mathrm{e}^{-} \rightleftharpoons \mathrm{H}_{2} \mathrm{O}(l) & E^{\circ \prime}=+(2.718 \pm 0.006) \mathrm{V} \text { at } \mu=1.00 \mathrm{M} \\
2060 & \mathrm{HO}^{\bullet}(a q)+\mathrm{H}^{+}(a q)+\mathrm{e}^{-} \rightleftharpoons \mathrm{H}_{2} \mathrm{O}(l) & E^{\circ}=+(2.722 \pm 0.006) \mathrm{V} \\
2061 & \mathrm{HO}^{\bullet}(a q)+\mathrm{e}^{-} \rightleftharpoons \mathrm{HO}^{-}(a q) & E^{\circ}=+(1.894 \pm 0.006) \mathrm{V} \\
2062 & \mathrm{HO}^{\bullet}(a q) & \Delta_{\mathrm{f}} G^{\circ}=+(25.5 \pm 0.6) \mathrm{kJ} \mathrm{mol}^{-1}
\end{array}
$$

2063

2064 List of auxiliary thermodynamic data: $\Delta_{\mathrm{f}} G^{\circ}$ for $\mathrm{HO}^{-}(a q)$ and $\mathrm{H}_{2} \mathrm{O}(l), K_{\text {eq }}$ for reactions 20.1 2065 and 21.1.

2066

2067 References

2068

2069 1. H. A. Schwarz, R. W. Dodson. J. Phys. Chem. 88, 3643-3647 (1984).

2070 2. D. D. Wagman, W. H. Evans, V. B. Parker, R. H. Schumm, I. Halow, S. M. Bailey, K. L.

2071 Churney, R. L. Nuttall. J. Phys. Chem. Ref. Data 11, Suppl. No. 2 (1982).

2072

2073 


\section{Data Sheet 20}

2075 Chemical equilibrium: $\mathrm{Tl}^{2+}(a q)+\mathrm{H}_{2} \mathrm{O}(l) \rightleftharpoons \mathrm{TlOH}^{+}(a q)+\mathrm{H}^{+}(a q)$

\section{List of reports:}

$\mathrm{p} K_{\mathrm{a}}=(4.7 \pm 0.2)$ at $21{ }^{\circ} \mathrm{C}$, indeterminate ionic strength [1]. The result was obtained from pulse radiolysis, using both conductivity and optical detection.

$\mathrm{p} K_{\mathrm{a}}=4.65$ probably at room temperature, unspecified ionic strength [2]. Result obtained from pulse radiolysis with conductivity detection. $K_{\mathrm{a}}=(1.7 \pm 0.3) \times 10^{-5} \mathrm{M}$ at $\mu=0.01 \mathrm{M}\left(\mathrm{p} K_{\mathrm{a}}=4.70\right)$ at $25^{\circ} \mathrm{C} ; K_{\mathrm{a}}=(1.2 \pm 0.2) \times 10^{-5} \mathrm{M}$ at $\mu=$ $1.00 \mathrm{M}\left(\mathrm{p} K_{\mathrm{a}}=4.93\right)$ at $25^{\circ} \mathrm{C}$ [3]. Data obtained from pulse radiolysis with optical detection. Results obtained from both the ratio of forward and reverse rate constants and also from the equilibrium change in optical density. Both of the methods relied on analyses that adjusted the observed data by functions of the equilibrium constant for $\mathrm{Tl}^{+}+\mathrm{HO}^{\bullet} \rightleftharpoons \mathrm{TlOH}^{+}$(reaction 19.1).

\section{Discussion}

The two earlier determinations neglected the effects of reaction 19.1 and thus the result of Schwarz and Dodson [3] is to be preferred. By comparison with the ionic strength dependence of the $\mathrm{p} K_{\mathrm{a}}$ of $\mathrm{Ni}^{2+}$, the reaction is expected to be significantly affected by ionic strength [4]. In combination with the $\mathrm{p} K_{\mathrm{a}}$ at $0.01 \mathrm{M}$, use of the NIST value [5] of $\Delta_{\mathrm{f}} G^{\circ}$ for $\mathrm{H}_{2} \mathrm{O}$ and the $\Delta_{\mathrm{f}} G^{\circ}$ value $\left(=183.1 \pm 0.7 \mathrm{~kJ} \mathrm{~mol}^{-1}\right.$ from Longhi's $\mathrm{Tl}^{+}$data [6]) for $\mathrm{Tl}^{2+}$ that we have recommended in the evaluation of reaction 21.1 (reaction of $\mathrm{Tl}^{2+}$ with $\mathrm{Fe}^{\mathrm{n}+}$ ) leads to $\Delta_{\mathrm{f}} G^{\circ}=-$ $(26.8 \pm 0.8) \mathrm{kJ} \mathrm{mol}^{-1}$ for $\mathrm{TlOH}^{+}(a q)$ at $\mu=0.01 \mathrm{M}$; this result is somewhat incorrect because it combines an ionic-strength dependent formal $\mathrm{p} K_{\mathrm{a}}$ with an ideal Gibbs energy for $\mathrm{Tl}^{2+}$. Use of the NBS value of $\Delta_{\mathrm{f}} G^{\circ}$ for $\mathrm{TlOH}^{2+}(a q)$ leads to $E^{\circ}=+0.113 \pm 0.008 \mathrm{~V}$ for the $\mathrm{TlOH}^{2+} / \mathrm{TlOH}^{+}$ couple. Use of the NBS value of $\Delta_{\mathrm{f}} G^{\circ}$ for $\mathrm{TlOH}(a q)$ leads to $E^{\circ}=+(1.690 \pm 0.008) \mathrm{V}$ for the $\mathrm{TlOH}^{+} / \mathrm{TlOH}$ couple.

\section{Recommended values:}


$2110 \quad \mathrm{TlOH}^{2+}(a q)+\mathrm{e}^{-} \rightleftharpoons \mathrm{TlOH}^{+}(a q)$

$2111 \mathrm{TlOH}^{+}(a q)+\mathrm{e}^{-} \rightleftharpoons \mathrm{TlOH}(a q)$

2113 List of auxiliary thermodynamic data: $\mathrm{NBS} \Delta_{\mathrm{f}} G^{\circ}$ for $\mathrm{H}_{2} \mathrm{O}(l), \mathrm{TlOH}^{2+}(a q)$, and $\mathrm{TlOH}(a q) ; \Delta_{\mathrm{f}} G^{\circ}$

2114 for $\mathrm{Tl}^{2+}(a q)$ (reaction 21.1).

2115

2116 References

2117

2118 1. P. O'Neill, D. Schulte-Frohlinde. J. Chem. Soc., Chem. Commun. 387-388 (1975).

2119 2. M. Bonifacic, K.-D. Asmus. J. Chem. Soc., Dalton Trans. 2074-2076 (1976).

2120 3. H. A. Schwarz, R. W. Dodson. J. Phys. Chem. 88, 3643-3647 (1984).

$2121 \quad 4 . \quad$ D. D. Perrin. J. Chem. Soc. 3644-3648 (1964).

2122 5. D. D. Wagman, W. H. Evans, V. B. Parker, R. H. Schumm, I. Halow, S. M. Bailey, K. L.

2123 Churney, R. L. Nuttall. J. Phys. Chem. Ref. Data 11, Suppl. No. 2 (1982).

2124 6. P. Longhi, T. Mussini, S. Rondinini, B. Sala. J. Chem. Thermodynamicdynam. 11, 73-81

2125 (1979).

2126 


\section{Data Sheet 21}

$2128 \quad \boldsymbol{E}^{\circ}\left(\mathrm{Tl}^{2+} / \mathrm{Tl}^{+}\right)$

Chemical equilibrium: $\mathrm{Tl}^{3+}+\mathrm{Fe}^{2+} \rightleftharpoons \mathrm{Tl}^{2+}+\mathrm{Fe}^{3+}$

\section{List of reports:}

As all determinations of this equilibrium constant are based on the kinetics of the reaction of $\mathrm{Fe}^{2+}$ with $\mathrm{Tl}^{3+}$, we present the mechanism of that reaction in order to define the rate constants involved. According to Ashurst and Higginson [1], the mechanism is

As written, the reactions pertain to unhydrolyzed aqua ions. Ashurst and Higginson report that the apparent second-order forward rate constant is sensitive to $\left[\mathrm{H}^{+}\right]$, and the overall rate law has two terms: one indicating a transition state having the composition $\mathrm{Fe}^{2+} / \mathrm{Tl}^{3+} / \mathrm{HO}^{-}$and the other being $\mathrm{Fe}^{2+} / \mathrm{Tl}^{3+} / 2 \mathrm{HO}^{-}$. Thus, the use of forward and reverse rate constants obtained at different values of $\mathrm{pH}$ introduces a degree of error, as does the use of rate constants at different ionic strengths (see Discussion below). We will thus refer to the reported equilibrium constants as "apparent" $K_{\text {app }}$.

$$
\begin{aligned}
& \mathrm{Tl}^{3+}+\mathrm{Fe}^{2+} \rightleftharpoons \mathrm{Tl}^{2+}+\mathrm{Fe}^{3+} \\
& \mathrm{Tl}^{2+}+\mathrm{Fe}^{2+} \rightarrow \mathrm{Tl}^{+}+\mathrm{Fe}^{3+}
\end{aligned}
$$$$
k_{1}, k_{-1}, K_{\mathrm{eq}}
$$$$
k_{2}
$$
2153 was from the kinetic study by Ashurst and Higginson on the overall $\mathrm{Tl}^{3+}$ reaction with $\mathrm{Fe}^{2+}[1]$.

2154 Falcinella et al. selected from Ashurst and Higginson a value for $k_{1}$ of $4.60 \times 10^{-2} \mathrm{M}^{-1} \mathrm{~s}^{-1}$ at $\mu=$ $21553.0 \mathrm{M}$ and $\left[\mathrm{H}^{+}\right]=0.40 \mathrm{M}$.

$$
K_{\text {app }}=4.2 \times 10^{-8} \text { at undefined ionic strength and } \mathrm{pH} \text { was reported by Falcinella et al., }
$$
who obtained it from the ratio of the forward and reverse rate constants [2]. Flash photolysis was used to generate $\mathrm{Tl}^{2+}$ and observe the reverse reaction, for which a rate constant $k-1=(1.1 \pm$ $0.15) \times 10^{6} \mathrm{M}^{-1} \mathrm{~s}^{-1}$ at $\mu=0.30 \mathrm{M}$ and $\left[\mathrm{H}^{+}\right]=0.25 \mathrm{M}$ was obtained. The forward rate constant $k_{1}$ determine a rate constant $k_{2}=(6.7 \pm 0.7) \times 10^{6} \mathrm{M}^{-1} \mathrm{~s}^{-1}$. The work of Ashurst and Higginson on the overall reaction of $\mathrm{Tl}^{3+}$ with $\mathrm{Fe}^{2+}$ was repeated, but in $1.1 \mathrm{M} \mathrm{HClO}_{4}$; under these conditions, the values $k_{1}=(1.39 \pm 0.02) \times 10^{-2} \mathrm{M}^{-1} \mathrm{~s}^{-1}$ and $k_{-1} / k_{2}=(0.051 \pm 0.005)$ were obtained from the $\mathrm{Fe}^{3+}$ inhibition of the kinetics. These measurements led to a value $k_{-1}=(3.4 \pm 0.5) \times 10^{5} \mathrm{M}^{-1} \mathrm{~s}^{-1}$, 
2162 where we have inferred the indicated uncertainty from their data; hence, $K_{\text {app }}=k_{-1} / k_{1}=(4.1 \pm 0$. $21636) \times 10^{-8}$.

$K_{\text {app }}=1.8 \times 10^{-7}$ at mixed ionic strength [4]. Falcinella et al. used flash photolysis to

2166 measure the rate constant of $(2.6 \pm 0.1) \times 10^{6} \mathrm{M}^{-1} \mathrm{~s}^{-1}$ for $k_{2}$ at $\mu=0.30 \mathrm{M},\left[\mathrm{H}^{+}\right]=0.25 \mathrm{M}$. Then

2167 the $\mathrm{pH}$-dependent data of Ashurst and Higginson were extrapolated to obtain $k_{-1} / k_{2}=0.10$ at

$21680.25 \mathrm{M}\left[\mathrm{H}^{+}\right]$. These two pieces of data yielded $k_{-1}=2.6 \times 10^{5} \mathrm{M}^{-1} \mathrm{~s}^{-1}$ at $\mu=0.30 \mathrm{M}$ and $\left[\mathrm{H}^{+}\right]=$

$21690.25 \mathrm{M}$. Combination of this $k_{-1}$ with Ashurst and Higginson's value for $k_{1}$ (at $\mu=3.0 \mathrm{M}$ and

$2170\left[\mathrm{H}^{+}\right]=0.40 \mathrm{M}$ ) then yielded the indicated equilibrium constant; obviously, this equilibrium

2171 constant is based on two rate constants obtained under conditions of different ionic strength and

$2172\left[\mathrm{H}^{+}\right]$. Despite the four-fold discrepancy between $k_{-1}$ determined in this way and that determined

2173 directly by Falcinella et al. [2], the two values were deemed "in reasonable agreement".

$K_{\text {app }}=8 \times 10^{-8}$ in $1 \mathrm{M} \mathrm{HClO}_{4}$ was obtained by Dodson from the ratio of the forward and reverse rate constants [5], the forward rate constant being the one determined by Schwarz et al. [3], and the reverse being obtained from the study of Fe(II)-induced radioactive label exchange between $\mathrm{Tl}(\mathrm{III})$ and $* \mathrm{Tl}(\mathrm{I})$. results in the literature [6]. Nord intended this value for equilibrium between purely aqua ions, hence $K_{\text {eq }}$ notation. The reanalysis showed that in the actual reaction mechanism an important reaction pathway involves the hydrolyzed species, i.e., the reaction smaller than for reaction 1. We note that: (i) Nord's interpretation of the acid dependence differs from that of Ashurst and Higginson and (ii) Nord's treatment entailed the use of literature values for the $\mathrm{p} K_{\mathrm{a}}$ of $\mathrm{Fe}^{3+}$ and $\mathrm{Tl}^{3+}$ as well as difficult assumptions concerning their change with ionic strength in the $1.5 \mathrm{M}$ to $3 \mathrm{M}$ region.

\section{Discussion}

All experimental evaluations of the equilibrium constant have three features in common. under conditions of partial $\mathrm{Tl}^{3+}$ and $\mathrm{Fe}^{3+}$ hydrolysis to $\mathrm{TlOH}^{2+}$ and $\mathrm{FeOH}^{2+}$; (3) pertain to 
solutions with very high ionic strengths in excess of $1 \mathrm{M}$. The first and the second features imply that the estimated equilibrium constants are, in fact, the apparent parameters based on analytical concentrations of the reactants and products

$$
K_{\text {app }}=[\mathrm{Tl}(\mathrm{II})][\mathrm{Fe}(\mathrm{III})] /[\mathrm{Tl}(\mathrm{III})][\mathrm{Fe}(\mathrm{II})]
$$

Only when forward and reverse rate constants are both measured in the same medium, will $K_{\text {app }}$ be equal to their ratio, as both rate constants are strongly medium-dependent. The $K_{\text {app }}$ value is related to the thermodynamic equilibrium constant, $K_{\mathrm{eq}}{ }^{0}$, through activity coefficients $(\gamma)$ and fractions $(F)$ of unhydrolyzed trivalent ions

$$
K_{\text {eq }}{ }^{0}=K_{\text {app }} \times\left[F\left(\mathrm{Fe}^{3+}\right) / F\left(\mathrm{Tl}^{3+}\right)\right] \times\left[\gamma\left(\mathrm{Tl}^{2+}\right) \gamma\left(\mathrm{Fe}^{3+}\right) / \gamma\left(\mathrm{Tl}^{3+}\right) \gamma\left(\mathrm{Fe}^{2+}\right)\right]
$$

Hydrolysis of divalent ions is negligible under all reported conditions. The fractions $F$ are also medium-dependent; for example, $F\left(\mathrm{Tl}^{3+}\right)=\left[\mathrm{H}^{+}\right] /\left(K_{\mathrm{a}}\left(\mathrm{Tl}^{3+}\right)+\left[\mathrm{H}^{+}\right]\right)$, where $K_{\mathrm{a}}\left(\mathrm{Tl}^{3+}\right)$ is the $\mathrm{Tl}^{3+}$ hydrolysis constant under prevailing medium conditions $K_{\mathrm{a}}\left(\mathrm{Tl}^{3+}\right)=K_{\mathrm{a}}{ }^{0} \chi\left(\mathrm{Tl}^{3+}\right) / \chi\left(\mathrm{TlOH}^{2+}\right) \chi\left(\mathrm{H}^{+}\right)$.

2214 The very high ionic strengths used in all studies makes rigorous derivation of $K_{\text {eq }}{ }^{0}$ for reaction 1 under standard conditions unfeasible, because the activity coefficients at these ionic strengths are dependent upon specific ion interactions and are unavailable for all the ions involved. A useful estimate can, however, be made assuming that the activity coefficients ratio $\chi\left(\mathrm{Tl}^{2+}\right) \chi\left(\mathrm{Fe}^{3+}\right) / \chi\left(\mathrm{Tl}^{3+}\right) \chi\left(\mathrm{Fe}^{2+}\right)$ is close to unity; implicit in this assumption is the similarity between $\mathrm{Fe}$ and $\mathrm{Tl}$ cations with respect to their interactions with anions. Then $K_{\text {eq }}{ }^{0}=K_{\text {app }} F\left(\mathrm{Fe}^{3+}\right) / F\left(\mathrm{Tl}^{3+}\right)$. The only experimental study in which both forward and reverse rate constant have been measured in the same medium $\left(1 \mathrm{M} \mathrm{HClO}_{4}\right)$ is that by Schwarz et al. [3]. The hydrolysis constants are available at $\mu=3.0 \mathrm{M}, K_{\mathrm{a}}\left(\mathrm{Fe}^{3+}\right) \approx 0.001$ and $K_{\mathrm{a}}\left(\mathrm{Tl}^{3+}\right) \approx 0.073 \mathrm{M}$. Assuming no significant change when the ionic strength is changed to $\mu=1.0 \mathrm{M}$, we compute $F\left(\mathrm{Fe}^{3+}\right) \approx 0.999$ and $F\left(\mathrm{Tl}^{3+}\right) \approx 0.932$ under the conditions of Schwarz et al. and using their $K_{\text {app }}=4.1 \times 10^{-8}$, we calculate $K_{\text {eq }}{ }^{0} \approx 4.4 \times 10^{-8}$, which is identical to the value derived by Nord through a somewhat different and more involved procedure. An uncertainty of $\pm 1.0 \times 10^{-8}$ for $K_{\mathrm{eq}}{ }^{0}$ appears reasonable under the assumptions made.

Although Dodson's induced-exchange study [5] was done in $1 \mathrm{M} \mathrm{HClO}_{4}$, as had been the earlier work from the same group, it yielded an about 2 times larger $K_{\text {app. }}$. However, this result depended upon both the detailed knowledge of mechanism for the exchange and the value of the quantum yield for photo induced exchange that was reported by Stranks and Yandell [7]. In the light of a subsequent work by Schwarz and Dodson [8], both the mechanism and the quantum yield require a revision. Specifically, it is now understood that the $\mathrm{HO}^{\bullet}$ radical is generated from 
$2234 \mathrm{Tl}(\mathrm{II})$, which sets up a chain reaction of radiolabel exchange [9]. This effect renders the 2235 exchange quantum yield by Stranks and Yandell [7] highly uncertain. This uncertainty 2236 propagates into Dodson's study [5], making the reported value of $K_{\text {app }}$ much more uncertain than 2237 that in the previous study of Schwarz et al. [3] in the same medium.

By means of $K_{\text {app }}=(4.1 \pm 0.6) \times 10^{-8}$ in $1 \mathrm{M} \mathrm{HClO}_{4}$ and the standard potential of +0.738 $2239 \pm 0.001 \mathrm{~V}$ for the $\mathrm{Fe}(\mathrm{III}) / \mathrm{Fe}$ (II) couple in the same medium [10], Schwarz et al. derived a value 2240 of $+0.301 \pm 0.003 \mathrm{~V}$ for the formal potential of Tl(III)/Tl(II) couple in $1 \mathrm{M} \mathrm{HClO}_{4}$ [3]. Schwarz 2241 et al. then used the formal Tl(III)/Tl(I) potential $(+1.259 \pm 0.001 \mathrm{~V})$ in the same medium from 2242 Stonehill [11] and from Sherrill and Hass [12] to derive $E^{\circ \prime}=+(2.217 \pm 0.003) \mathrm{V}$ for the $\mathrm{Tl}^{2+} / \mathrm{Tl}^{+}$ 2243 potential in $1 \mathrm{M} \mathrm{HClO}_{4}$.

By using $K_{\text {eq }}{ }^{0}=(4.4 \pm 1.0) \times 10^{-8}$ and the accurate $E^{\circ}\left(\mathrm{Fe}^{3+} / \mathrm{Fe}^{2+}\right)=+0.770 \pm 0.002 \mathrm{~V}$ $2245 \quad[13]$, we obtain $E^{\circ}\left(\mathrm{Tl}^{3+} / \mathrm{Tl}^{2+}\right)=+0.335 \pm 0.006 \mathrm{~V}$.

The two-electron potential $E^{\circ}\left(\mathrm{Tl}^{3+} / \mathrm{Tl}^{+}\right)=+(1.280 \pm 0.002) \mathrm{V}$ has been reported by

2247 Biedermann [14]; this is actually the formal potential in $3 \mathrm{M} \mathrm{NaClO}_{4}$. Stonehill used

2248 extrapolations to zero ionic strength and reported that the true standard potential is $+1.280 \mathrm{~V}$; we 2249 infer an uncertainty of $\pm 0.003 \mathrm{~V}$ from his data [11]. Apparently, the formal potential and 2250 standard potential are fortuitously identical. With this potential and $E^{\circ}\left(\mathrm{Tl}^{3+} / \mathrm{Tl}^{2+}\right)$ as selected above we calculate $E^{\circ}\left(\mathrm{Tl}^{2+} / \mathrm{Tl}^{+}\right)=+2.225 \pm 0.007 \mathrm{~V}$. The NIST tables [15] give $-(32.40 \pm 0.4) \mathrm{kJ}$ $\mathrm{mol}^{-1}$ for $\Delta_{\mathrm{f}} G^{\circ}$ of $\mathrm{Tl}^{+}$that lead to $\Delta_{\mathrm{f}} G^{\circ}\left(\mathrm{Tl}^{2+}\right)=(182.3 \pm 0.8) \mathrm{kJ} \mathrm{mol}^{-1}$. This value is $6.6 \mathrm{~kJ} \mathrm{~mol}^{-1}$ higher than $\Delta_{\mathrm{f}} G^{\circ}\left(\mathrm{Tl}^{2+}\right)$ given by Schwarz et al. [3] mainly because these authors used older $\Delta_{\mathrm{f}} G^{\circ}$ values for $\mathrm{Tl}^{3+}, \mathrm{Fe}^{3+}$, and $\mathrm{Fe}^{2+}$ taken from Latimer [16] to arrive at $\Delta_{\mathrm{f}} G^{\circ}\left(\mathrm{Tl}^{2+}\right)$ from their $K_{\text {app }}=$ $4.1 \times 10^{-8}$. Longhi et al. claim that the NBS value for $\Delta_{\mathrm{f}} G^{\circ}$ of $\mathrm{Tl}^{+}$is significantly in error and should be corrected to $-(31.56 \pm 0.03) \mathrm{kJ} \mathrm{mol}^{-1}$ [17]. Use of the result of Longhi et al. in combination with our recommended value for $E^{\circ}\left(\mathrm{Tl}^{2+} / \mathrm{Tl}^{+}\right)(2.225 \pm 0.007 \mathrm{~V})$ leads to $\Delta_{\mathrm{f}} G^{\circ}\left(\mathrm{Tl}^{+}\right)$ $=+(183.1 \pm 0.7) \mathrm{kJ} \mathrm{mol}^{-1}$; we are unsure whether to recommend this revised Gibbs energy because it depends on non-NIST data [15] and it is unclear to what extent other NIST data [15] are dependent on the $\Delta_{\mathrm{f}} G^{\circ}$ of $\mathrm{Tl}^{+}$.

Recommended values:

2263

2264

2265

2266

2267

2268

2269

$K_{\text {app }}=(4.1 \pm 0.6) \times 10^{-8}\left(1 \mathrm{M} \mathrm{HClO}_{4}\right)$

$K_{\text {eq }}^{\circ}=(4.4 \pm 1.0) \times 10^{-8}$

$E^{\circ}=+0.335 \pm 0.006 \mathrm{~V}$

$E^{\circ}=+2.225 \pm 0.007 \mathrm{~V}$

$E^{\circ \prime}=+0.301 \pm 0.003 \mathrm{~V}$ at $\mu=1.00 \mathrm{M}\left(\mathrm{HClO}_{4}\right)(21.10)$

$E^{\circ \mathrm{O}}=+2.217 \pm 0.003 \mathrm{~V}$ at $\mu=1.00 \mathrm{M}\left(\mathrm{HClO}_{4}\right)(21.11)$ 
List of auxiliary thermodynamic data: $K_{\mathrm{a}}$ of $\mathrm{Fe}^{3+}(\sim 0.001 \mathrm{M}$ at $\mu=3.0 \mathrm{M})$ and $\mathrm{Tl}^{3+}(\sim 0.073 \mathrm{M}$ at $\mu=3.0 \mathrm{M}) ; E^{\circ}\left(\mathrm{Fe}^{3+} / \mathrm{Fe}^{2+}\right)=+(0.770 \pm 0.002) \mathrm{V} ; E^{\circ}\left(\mathrm{Tl}^{3+} / \mathrm{Tl}^{+}\right)=+(1.280 \pm 0.002) \mathrm{V} ; \Delta_{\mathrm{f}} G^{\circ}\left(\mathrm{Tl}^{+}\right)$ $2275=-(32.40 \pm 0.4) \mathrm{kJ} \mathrm{mol}^{-1}$.

\section{References}

2278

2279 1. K. G. Ashurst, W. C. E. Higginson. J. Chem. Soc. 3044-3049 (1953).

$2280 \quad$ 2. $\quad$ B. Falcinella, P. D. Felgate, G. S. Laurence. J. Chem. Soc., Dalton Trans. 1367-1373

2281 (1974).

2282 3. H. A. Schwarz, D. Comstock, J. K. Yandell, R. W. Dodson. J. Phys. Chem. 78, 488-493 2283 (1974).

2284 4. B. Falcinella, P. D. Felgate, G. S. Laurence. J. Chem. Soc., Dalton Trans. 1-9 (1975).

2285 5. R. W. Dodson. J. Radioanal. Chem. 30, 245-261 (1976).

2286 6. G. Nord. Inorg. Chem. 16, 201-202 (1977).

2287 7. D. R. Stranks, J. K. Yandell. J. Phys. Chem. 73, 840-849 (1969).

2288 8. H. A. Schwarz, R. W. Dodson. J. Phys. Chem. 80, 2543-2548 (1976).

2289 9. H. A. Schwarz, personal communication to Lymar, S. V and Stanbury, D. M. (2003).

2290 10. L. B. Magnusson, J. R. Huizenga. J. Am. Chem. Soc. 75, 2242-2246 (1953).

2291 11. H. I. Stonehill. Trans. Faraday Soc. 39, 72-79 (1943).

2292 12. M. S. Sherrill, A. J. Haas. J. Am. Chem. Soc. 58, 952-959 (1936).

2293 13. D. O. Whittemore, D. Langmuir. J. Chem. Eng. Data 17, 288-290 (1972).

2294 14. G. Biedermann. Arkiv Kemi 5, 441-455 (1953).

2295 15. D. D. Wagman, W. H. Evans, V. B. Parker, R. H. Schumm, I. Halow, S. M. Bailey, K. L. 2296 Churney, R. L. Nuttall. J. Phys. Chem. Ref. Data 11, Suppl. No. 2 (1982).

2297 16. W. M. Latimer. Oxidation Potentials, Prentice-Hall, Englewood Cliffs, New Jersey 2298 (1952).

2299 17. P. Longhi, T. Mussini, S. Rondinini, B. Sala. J. Chem. Thermodynamicdynam. 11, 73-81 2300 (1979). 


\section{Data Sheet 22}

$\mathrm{HNO}$ and $\mathrm{NO}^{\bullet}$

\section{List of reports:}

$\Delta_{\mathrm{h}} G^{\circ}=-14 \mathrm{~kJ} \mathrm{~mol}^{-1}$, obtained from equating hydration Gibbs energy of $\mathrm{HNO}$ to that of $\mathrm{HOCl}$ [1].

$\Delta_{\mathrm{h}} G^{\circ}=-5.0 \mathrm{~kJ} \mathrm{~mol}^{-1}$, obtained from equating hydration Gibbs energy of $\mathrm{HNO}$ to that of $\mathrm{HCN}$ [2].

\section{Discussion}

Here we consider the $\mathrm{HNO}$ tautomer in its singlet ground state with the $\mathrm{H}$ atom attached to the $\mathrm{N}$ atom. Although the $\mathrm{NOH}$ tautomer with the $\mathrm{H}$ atom bound to the $\mathrm{O}$ atom, whose ground state is triplet, does exist, at least in the gas phase [3], this species is not evaluated here.

The enthalpy of HNO formation in the gas phase has been reviewed and the value of +107.1 $\mathrm{kJ} \mathrm{mol}^{-1}$ has been recommended [4]. The uncertainty in the statistical sense was not given, but the "conservative" error limits were $+(2.5$ and -0.4$) \mathrm{kJ} \mathrm{mol}^{-1}$. Taking these limits into account, we will use $\Delta_{\mathrm{f}} H^{\circ}(\mathrm{HNO})_{\mathrm{g}}=+(107.8 \pm 1.6) \mathrm{kJ} \mathrm{mol}^{-1}$ for the purposes of this evaluation. From this value and the tabulated entropy $S^{\circ}(\mathrm{HNO})_{\mathrm{g}}=220.72 \mathrm{~J} \mathrm{~K}^{-1} \mathrm{~mol}^{-1}[5]$, we calculate $\Delta_{\mathrm{f}} G^{\circ}(\mathrm{HNO})_{\mathrm{g}}=$ $+120.6 \pm 1.6 \mathrm{~kJ} \mathrm{~mol}^{-1}$.

Due to substantial instability of $\mathrm{HNO}$ toward recombination $\mathrm{HNO}+\mathrm{HNO}=\mathrm{N}_{2} \mathrm{O}+\mathrm{H}_{2} \mathrm{O}$ [68], its hydration energetics could not yet be evaluated experimentally, so that both reported values are analogy-based estimates. While Stanbury suggested $\mathrm{HOCl}$ as a proxy for HNO [1], Shafirovich and Lymar preferred HCN [2]. The latter appears to be a somewhat better choice because, unlike $\mathrm{HOCl}$, both $\mathrm{HNO}$ and $\mathrm{HCN}$ do not contain an $\mathrm{OH}$ group that participates in three hydrogen bonds with water and thereby dominates the enthalpy of hydration $[9,10]$. From this perspective, the unhydrolyzed formaldehyde, $\mathrm{H}_{2} \mathrm{CO}$, or acetaldehyde, $\mathrm{CH}_{3} \mathrm{CHO}$, appear to be as good of a model for HNO hydration as does HCN. From the overall hydration Gibbs energies that pertain to the equilibrium mixtures of hydrolyzed and unhydrolyzed forms of aldehydes in water $\Delta_{\mathrm{h}} G^{\circ}$ (formaldehyde) $=-20.5$ and $\Delta_{\mathrm{h}} G^{\circ}$ (acetaldehyde) $=-6.69 \mathrm{~kJ} \mathrm{~mol}^{-1}$ [11], and the aldehyde hydrolysis $\mathrm{RCHO}+\mathrm{H}_{2} \mathrm{O}=\mathrm{RCH}(\mathrm{OH})_{2}$ equilibrium constants $K_{\text {hyd }}\left(\mathrm{H}_{2} \mathrm{CO}\right)=1270$ [12] and $K_{\text {hyd }}\left(\mathrm{CH}_{3} \mathrm{CHO}\right)=1.4[13]$ at $25^{\circ} \mathrm{C}$, we obtain $\Delta_{\mathrm{h}} G^{\circ}=-2.8 \mathrm{~kJ} \mathrm{~mol}^{-1}$ for $\mathrm{H}_{2} \mathrm{CO}$ and $\Delta_{\mathrm{h}} G^{\circ}=-$ 

$2344 \mathrm{~kJ} \mathrm{~mol}^{-1}$.

2345

$4.5 \mathrm{~kJ} \mathrm{~mol}^{-1}$ for $\mathrm{CH}_{3} \mathrm{CHO}$. From the NBS Tables [14] $\Delta_{\mathrm{f}} G^{\circ}(\mathrm{HCN})_{\mathrm{g}}=124.7 \mathrm{~kJ} \mathrm{~mol}^{-1}$ and $\Delta_{\mathrm{f}} G^{\circ}(\mathrm{HCN})_{\mathrm{aq}}=119.7 \mathrm{~kJ} \mathrm{~mol}^{-1}$, it follows that $\Delta_{\mathrm{h}} G^{\circ}(\mathrm{HCN})=-5.0 \mathrm{~kJ} \mathrm{~mol}^{-1}$.

We thus adopt the average of hydration Gibbs energies for $\mathrm{HCN}, \mathrm{H}_{2} \mathrm{CO}$ and $\mathrm{CH}_{3} \mathrm{CHO}$; that is, $-(4.1 \pm 1.2) \mathrm{kJ} \mathrm{mol}^{-1}$ at $25^{\circ} \mathrm{C}$ as the best estimate for $\Delta_{\mathrm{h}} G^{\circ}(\mathrm{HNO})$. With this value and using $\Delta_{\mathrm{f}} G^{\circ}(\mathrm{HNO})_{\mathrm{g}}=+(120.6 \pm 1.6) \mathrm{kJ} \mathrm{mol}^{-1}$ derived above, we calculate $\Delta_{\mathrm{f}} G^{\circ}(\mathrm{HNO})_{\mathrm{aq}}=(116.5 \pm 2.0)$

\section{Recommended values:}

Electrode reaction: $\mathrm{NO}^{\bullet}+\mathrm{H}^{+}+\mathrm{e}^{-} \rightleftharpoons \mathrm{HNO}$

\section{List of reports:}

$E^{\circ}\left(\mathrm{NO}^{\circ}, \mathrm{H}^{+} / \mathrm{HNO}\right)=-0.14 \mathrm{~V}$, obtained from an analogy-based estimate of the Gibbs energy of hydration of $\mathrm{HNO}$ [2].

\section{Discussion}

Here we consider the $\mathrm{NO}^{\bullet}$ reduction to nitroxyl $(\mathrm{HNO})$ in its singlet ground state with the $\mathrm{H}$ atom attached to the $\mathrm{N}$ atom.

At present, no redox equilibria involving $\mathrm{HNO}$ have been experimentally investigated. This potential can only be evaluated from the Gibbs energies of aqueous $\mathrm{NO}^{\bullet}$ and $\mathrm{HNO}$ which are: $\Delta_{\mathrm{f}} G^{\circ}\left(\mathrm{NO}^{\circ}\right)_{\mathrm{aq}}=+(102.0 \pm 0.2) \mathrm{kJ} \mathrm{mol}^{-1}$ (see Data Sheet 90) and $\Delta_{\mathrm{f}} G^{\circ}(\mathrm{HNO})_{\mathrm{aq}}=(116.5 \pm 2.0) \mathrm{kJ}$ $\mathrm{mol}^{-1}$ (see above). Using these values, we obtain $E^{\circ}\left(\mathrm{NO}^{\bullet}, \mathrm{H}^{+} / \mathrm{HNO}\right)=-(0.145 \pm 0.021) \mathrm{V}$.

\section{Recommended value:}

$$
E^{\circ}\left(\mathrm{NO}^{\bullet}, \mathrm{H}^{+} / \mathrm{HNO}\right)=-(0.15 \pm 0.02) \mathrm{V} \text {. }
$$

Nomenclature: $\mathrm{NO}^{\bullet}$, oxidonitrogen( $\bullet$ ), oxoazanyl or nitrogen monoxide, nitric oxide is outdated. HNO, hydridooxidonitrogen, or azanone, nitrosyl hydride is outdated. 
References

2378 1. D. M. Stanbury. Adv. Inorg. Chem. 33, 69-138 (1989).

2379 2. V. Shafirovich, S. V. Lymar. Proc. Nat. Acad. Sci. USA 99, 7340-7345 (2002).

$2380 \quad 3$. H. B. Ellis, G. B. Ellison. J. Chem. Phys. 78, 6541-6558 (1983).

2381 4. W. R. Anderson. Comb. Flame 117, 394-403 (1999).

2382 5. M. W. Chase. NIST-JANAF Thermodynamicchemical Tables, 4th ed, American Institute 2383 of Physics, Woodbury, NY (1998).

2384 6. D. A. Bazylinski, T. C. Hollocher. Inorg. Chem. 24, 4285-4288 (1985).

2385 7. F. T. Bonner, M. N. Hughes. Comments Inorg. Chem. 7, 215-234 (1988).

$2386 \quad 8 . \quad$ Bonner, F. T., Stedman, G. In Methods in Nitric Oxide Research, (Feelisch, M., Stamler, 2387 J. S., eds.), p. 3-27. John Wiley and Sons, New York (1996).

2388 9. G. A. Poskrebyshev, V. Shafirovich, S. V. Lymar. J. Am. Chem. Soc. 126, 891-899 2389 (2004).

2390 10. H. A. Schwarz, R. W. Dodson. J. Phys. Chem. 88, 3643-3647 (1984).

2391 11. H. A. Schwarz, R. W. Dodson. J. Phys. Chem. 93, 409-414 (1989).

2392 12. J. G. M. Winkelman, O. K. Voorwinde, M. Ottens, A. A. C. M. Beenackers, L. P. B. M. 2393 Janssen. Chem. Eng. Sci. 57, 4067-4076 (2002).

2394 13. Bell, R. P. In Advances in Physical Organic Chemistry, (Gold, V., ed.), p. Vol. 4, 1-29. 2395 Academic Press, London (1966).

2396 14. D. D. Wagman, W. H. Evans, V. B. Parker, R. H. Schumm, I. Halow, S. M. Bailey, K. L. 2397 Churney, R. L. Nuttall. J. Phys. Chem. Ref. Data 11, Suppl. No. 2 (1982). 


\section{Data Sheet 23}

\section{Ozone/Ozonide}

Chemical equilibrium: $\mathrm{O}_{2}(\mathrm{aq})+\mathrm{O}^{\bullet-} \rightleftharpoons \mathrm{O}_{3}^{\bullet}$

Gzapski (1971) [1]

Review, $k_{1}=(3.0 \pm 0.5) \times 10^{9} \mathrm{M}^{-1} \mathrm{~s}^{-1}[2], k_{-1}=(5.0 \pm 0.5) 10^{3} \mathrm{~s}^{-1}, K=(0.6 \pm 0.1) \times 10^{6} \mathrm{M}^{-1}$.

Elliot and McCracken (1989) [3]

Determination of $K$ as a function of temperature from forward and backward rate constants, interpolated for $25^{\circ} \mathrm{C} . K=(1.4 \pm 0.1) \times 10^{6} \mathrm{M}^{-1}$.

Chemical equilibrium: $\mathrm{O}_{3}(\mathrm{aq})+\mathrm{ClO}_{2}^{-} \rightleftharpoons \mathrm{O}_{3}{ }^{--}+\mathrm{ClO}_{2}{ }^{\bullet}(\mathrm{aq})$

Kläning, Sehested and Holcman (1985) [4]

The calculation of the standard potential involves (i) $K(23.2)=(22 \pm 6)$, determined at low ionic strength and at $(22 \pm 1){ }^{\circ} \mathrm{C}$ from the forward and backward rate constants of $(4 \pm 1) \times 10^{6}$ $\mathrm{M}^{-1} \mathrm{~s}^{-1}$ and $(1.8 \pm 0.2) \times 10^{5} \mathrm{M}^{-1} \mathrm{~s}^{-1}$, respectively, (ii) a new determination of $E^{\circ}\left(\mathrm{ClO}_{2}{ }^{\bullet} / \mathrm{ClO}_{2}^{-}\right)=$ $+(0.934 \pm 0.002) \mathrm{V}$ at $25^{\circ} \mathrm{C}$, and (iii) is based on $\Delta_{\mathrm{f}} G^{\circ}\left(\mathrm{O}_{3}\right) \mathrm{aq}=+174.9 \mathrm{~kJ} \mathrm{~mol}^{-1}$.

$E^{\circ}\left(\mathrm{O}_{3 \mathrm{aq}} / \mathrm{O}_{3}{ }^{\bullet-}\right)=+(1.01 \pm 0.02) \mathrm{V} \cdot \Delta_{\mathrm{f}} G^{\circ}\left(\mathrm{O}_{3}{ }^{\bullet-}\right)=+77.1 \mathrm{~kJ} \mathrm{~mol}^{-1}$

\section{Discussion}

The first estimate of $E^{\circ}\left(\mathrm{O}_{3 \mathrm{aq}} / \mathrm{O}_{3}{ }^{--}\right)$[5] was based on the rate constants given in Ref. 1 and the following Gibbs energies: $\Delta_{\mathrm{f}} G^{\circ}\left(\mathrm{O}_{2}\right) \mathrm{aq}=+3.8 \mathrm{kcal} \mathrm{mol}^{-1}\left(+15.9 \mathrm{~kJ} \mathrm{~mol}^{-1}\right), \Delta_{\mathrm{f}} G^{\circ}\left(\mathrm{O}^{\bullet-}\right)=+22.4 \mathrm{kcal}$ $\mathrm{mol}^{-1}\left(+93.7 \mathrm{~kJ} \mathrm{~mol}^{-1}\right)$, and $\Delta_{f} G^{\circ}\left(\mathrm{O}_{3}\right) \mathrm{aq}=+41.6 \mathrm{kcal} \mathrm{mol}^{-1}\left(+174.1 \mathrm{~kJ} \mathrm{~mol}^{-1}\right)$, and resulted in a value of $+1.00 \mathrm{~V}$, and a standard Gibbs energy of formation of $\mathrm{O}_{3}{ }^{-}$of $+18.5 \mathrm{kcal} \mathrm{mol}^{-1}(+77.4$ $\mathrm{kJ} / \mathrm{mol})$.

$2432 \Delta_{\mathrm{f}} G^{\circ}\left(\mathrm{O}_{3}\right) \mathrm{g}$ is $+163.2 \mathrm{~kJ} / \mathrm{mol}^{-1}$ [6], and Henry's constant of $\mathrm{O}_{3}$ is $1.03 \times 10^{-2} \mathrm{M} / 0.100 \mathrm{MPa}$ [7], 2433 from which a $\Delta_{\mathrm{s}} G^{\circ}$ of $+11.3 \mathrm{~kJ} \mathrm{~mol}^{-1}$ follows; $\Delta_{\mathrm{f}} G^{\circ}\left(\mathrm{O}_{3}\right)$ aq is therefore $+174.5 \mathrm{~kJ} \mathrm{~mol}^{-1}$. Given a 2434 Gibbs energy change of $-35.1 \mathrm{~kJ} \mathrm{~mol}^{-1}$ for Reaction 23.1, see above [3] and a $\Delta_{\mathrm{f}} G^{\circ}\left(\mathrm{O}^{\bullet-}\right)$ of +93.1 $24351.7 \mathrm{~kJ} \mathrm{~mol}^{-1}$ (see Data sheet 2$), E^{\circ}\left(\mathrm{O}_{3} / \mathrm{O}_{3}{ }^{\bullet}\right)=+(1.036 \pm 0.020) \mathrm{V}$ and $\Delta_{\mathrm{f}} G^{\circ}\left(\mathrm{O}_{3^{\circ}}\right)=+74.6 \mathrm{~kJ} \mathrm{~mol}^{-}$ 
${ }^{1}$. The error is determined mainly by that of $\Delta_{\mathrm{f}} G^{\circ}\left(\mathrm{O}^{\bullet-}\right)$. This result is in good agreement with that of Kläning et al. ${ }^{4}$, which has an estimated error in $E^{\circ}\left(\mathrm{O}_{3 a q} / \mathrm{O}_{3}{ }^{\circ}\right)$ of $0.02 \mathrm{~V}$.

The $\mathrm{p} K_{\mathrm{a}}$ of $\mathrm{HO}_{3}{ }^{\bullet}$ is not known with certainty, and an accurate determination may be precluded by rapid dissociation into $\mathrm{HO}^{\bullet}$ and $\mathrm{O}_{2}$. Values of 6.15 [8] and 8.2 [9] are found in the literature, while a value of -2 is expected on the basis of a rule that relates the $\mathrm{p} K_{\mathrm{a}}$ to the ratio of $\mathrm{O}-\mathrm{to} \mathrm{H}-$ atoms $\left(\mathrm{p} K_{a}=19-7[\mathrm{O}] /[\mathrm{H}]\right)$ [1]. Computational studies also support a $\mathrm{p} K_{\mathrm{a}}$ near -2 [10]. No

2443 recommendation can be made.

\section{Recommended values:}

$K(23.1)=(1.4 \pm 0.1) \times 10^{6} \mathrm{M}^{-1}$.

$$
\Delta_{\mathrm{f}} G^{\circ}\left(\mathrm{O}_{3}{ }^{\bullet-}\right)=+(75 \pm 2) \mathrm{kJ} / \mathrm{mol}^{-1} \text {. }
$$

$E^{\circ}\left(\mathrm{O}_{3} / \mathrm{O}^{\bullet}\right)=+(1.03 \pm 0.02) \mathrm{V}$, or $+(0.91 \pm 0.02) \mathrm{V}\left(p \mathrm{O}_{2}=0.100 \mathrm{MPa}\right)$.

Nomenclature

The systematic name of $\mathrm{O}_{3}$ is trioxygen or trioxidanediyl, of $\mathrm{O}_{3}{ }^{\bullet-}$ trioxide $(\bullet 1-)$ or trioxidanidyl, and of $\mathrm{HO}_{3}{ }^{\bullet}$ hydrogen trioxide or trioxidanyl. The trivial name ozone is allowed.

\section{References}

1. G. Czapski, Ann. Rev. Phys. Chem. 22, 171-208 (1971).

B. L. Gall, L. M. Dorfman, J. Am. Chem. Soc. 91, 2199-2204 (1969).

A. J. Elliot, D. R. McCracken, Rad. Phys. Chem. 33, 69-74 (1989).

5. W. H. Koppenol, FEBS Lett. 140, 169-172 (1982).

24657 7. Sander, R., In NIST Chemistry WebBook, NIST Standard Reference Database Number 2466 69, (Lindstrom, P. J., Mallard, W. G., eds.), p. National Institute of Standards and Technology, 2467 Gaithersburg, MD 20899 (2003).

2468 8. R. E. Bühler, J. Staehelin, J. Hoigné, J. Phys. Chem. 88, 2560-2564 (1984).

2469 9. J. Staehelin, R. E. Bühler, J. Hoigné, J. Phys. Chem. 88, 5999-6004 (1984).

2470 10. S. Naumov, C. von Sonntag, J. Phys. Org. Chem. 24, 600-602 (2011). 


\section{Data Sheet 24}

Reaction: $\mathrm{ClO}_{2}^{\bullet}(a q)+\mathrm{e}^{-} \rightleftharpoons \mathrm{ClO}_{2}^{-}(a q)$

\section{List of reports:}

$E^{\circ}=+(0.936 \pm 0.003) \mathrm{V}$ vs NHE at $298 \mathrm{~K}$ [1]. Determined by potentiometry vs SCE. Measurements were performed as a function of temperature and ionic strength. Analysis of the data in terms of Debye-Hückel theory led to a standard potential (at $\mu=0$ ).

$E^{\circ}=+(0.934 \pm 0.002) \mathrm{V}$ vs NHE at $298 \mathrm{~K}$ [2]. Determined by potentiometry vs SCE. Measurements were performed as a function of temperature. Analysis of the data in terms of Debye-Hückel theory led to a standard potential (at $\mu=0$ ).

\section{Discussion}

The agreement between the two detailed reports of $E^{\circ}$ cited above is excellent. A more recent detailed kinetic study of the electrode process [3] confirms the fundamental electrochemical reversibility assumed in these two studies. We recommend the average of the two results for $E^{\circ}$.

As noted in Standard Potentials [4], by Kläning et al. [2], and discussed by Stanbury [5], the measured $E^{\circ}$ values differ (by $\sim 130 \mathrm{mV}$ ) from that $(+1.067 \mathrm{~V}$ ) calculated from the values of $\Delta_{\mathrm{f}} G^{\circ}$ given in the NIST tables [6]: $\Delta_{\mathrm{f}} G^{\circ}=+120.1 \mathrm{~kJ} \mathrm{~mol}^{-1}$ for $\mathrm{ClO}_{2}(a q)$ and $\Delta_{\mathrm{f}} G^{\circ}=+17.2 \mathrm{~kJ}$ $\mathrm{mol}^{-1}$ for $\mathrm{ClO}_{2}^{-}(a q)$. It has been opined that the measured $E^{\circ}$ values are less reliable than the value calculated from the NBS $\Delta_{\mathrm{f}} G^{\circ}$ values [7]; however, independent support for the potentiometric results comes from spectrophotometric determinations of the equilibrium constant for the reaction $\left[\mathrm{Fe}(\text { phen })_{3}\right]^{2+}+\mathrm{ClO}_{2}{ }^{\bullet} \rightleftharpoons\left[\mathrm{Fe}(\text { phen })_{3}\right]^{3+}+\mathrm{ClO}_{2}^{-}[8]$.

One approach to resolving this discrepancy is to recalculate $\Delta_{\mathrm{f}} G^{\circ}$ for $\mathrm{ClO}_{2}{ }^{\bullet}(a q)$ from the well-established solubility of $\mathrm{ClO}_{2}{ }^{\bullet}$ and $\Delta_{\mathrm{f}} G^{\circ}$ for $\mathrm{ClO}_{2}{ }^{\bullet}(\mathrm{g})$. This is essentially the method that was used to obtain the NBS value for $\Delta_{\mathrm{f}} G^{\circ}$ for $\mathrm{ClO}_{2}{ }^{\bullet}(a q)$ [7]. The NIST Chemistry WebBook (March 2003 release) recommends a Henry's law constant (derived from direct solubility measurements) of $1.0 \mathrm{~mol} \mathrm{~kg}^{-1} \mathrm{bar}^{-1}$ for $\mathrm{ClO}_{2}{ }^{\bullet}$, which corresponds to $\Delta G^{\circ}=0.0 \mathrm{~kJ} \mathrm{~mol}^{-1}$ for dissolution of $\mathrm{ClO}_{2}{ }^{\bullet}$. This solubility parameter is consistent with the $0.4 \mathrm{~kJ} \mathrm{~mol}^{-1}$ difference between the NBS data for $\mathrm{ClO}_{2}(g)\left(\Delta_{\mathrm{f}} G^{\circ}=+120.5 \mathrm{~kJ} \mathrm{~mol}^{-1}\right)$ and $\mathrm{ClO}_{2}{ }^{\circ}(a q)\left(\Delta_{\mathrm{f}} G^{\circ}=+120.1 \mathrm{~kJ}\right.$ $\mathrm{mol}^{-1}$ ), which implies that the Henry's law constant used in the NIST evaluation [6] is in agreement with more recent evaluations. The NIST value for $\Delta_{\mathrm{f}} G^{\circ}$ of $\mathrm{ClO}_{2}{ }^{\circ}(g)$ is based on $\Delta_{\mathrm{f}} H^{\circ}$ 
$2508=+102.5 \mathrm{~kJ} \mathrm{~mol}^{-1}$ for $\mathrm{ClO}_{2}{ }^{\circ}(\mathrm{g})$, and several lines of evidence were cited in support of this 2509 enthalpy value [7]. On the other hand, the NIST-JANAF tables (prepared in 1992) cite a value of $2510+115 \pm 8 \mathrm{~kJ} \mathrm{~mol}^{-1}$ for $\Delta_{\mathrm{f}} G^{\circ}$ of $\mathrm{ClO}_{2}^{\circ}(\mathrm{g})$, which is based on a value of $\Delta_{\mathrm{f}} H^{\circ}(298 \mathrm{~K})$ of $+99.7 \pm 8$ $2511 \mathrm{~kJ} \mathrm{~mol}^{-1}$ [9]. Gurvich et al. cite $\Delta_{\mathrm{f}} H^{\circ}(298 \mathrm{~K})=+105 \pm 6 \mathrm{~kJ} \mathrm{~mol}^{-1}$ for $\mathrm{ClO}_{2}{ }^{\circ}(g)$ [10]. More 2512 recently, the IUPAC Atmospheric Chemistry group has recommended a value of $\Delta_{\mathrm{f}} H^{\circ}(298 \mathrm{~K})=$ $2513+95.6 \pm 1.3 \mathrm{~kJ} \mathrm{~mol}^{-1}[11]$, based on reports of $+96.7 \pm 4$ by Flesch et al. and $+94.6 \pm 1.3 \mathrm{~kJ} \mathrm{~mol}^{-1}$ 2514 by Nickolaisen et al. for this quantity $[12,13]$. The latest NASA evaluation recommends a value 2515 of $+94.6 \pm 1.2 \mathrm{~kJ} \mathrm{~mol}^{-1}$ based on the kinetic result of Nickolaisen et al., apparently electing to 2516 regard the result of Flesch et al. as merely supporting that of Nickolaisen et al. [14]. Most 2517 recently $\mathrm{Xu}$ and Lin report a value of $+(100.8 \pm 0.6) \mathrm{kJ} \mathrm{mol}^{-1}$ for $\Delta_{\mathrm{f}} H^{\circ}$ (at $0 \mathrm{~K}$ ) as calculated 2518 from the dissociation energy of $\mathrm{ClO}_{2}{ }^{\circ}[15]$; correction (assuming the same correction as reported 2519 in the NIST-JANAF Tables) to $298 \mathrm{~K}$ gives $\Delta_{\mathrm{f}} H^{\circ} \sim+(98.8 \pm 0.6) \mathrm{kJ} \mathrm{mol}^{-1}$. It is clear that a wide 2520 range of values has been reported for $\Delta_{\mathrm{f}} H^{\circ}(298 \mathrm{~K})$ of $\mathrm{ClO}_{2}{ }^{\circ}(\mathrm{g})$, but the result of Nickolaisen $e t$ 2521 al. seems to be quite robust. If this result is accepted, then the NIST-JANAF recommendation is 2522 corrected to $\Delta_{\mathrm{f}} G^{\circ}=+(109.9 \pm 1.2) \mathrm{kJ} \mathrm{mol}^{-1}$ for $\mathrm{ClO}_{2}{ }^{\circ}(g)$. The NIST-recommended Henry's-law 2523 constant then leads to $\Delta_{\mathrm{f}} G^{\circ}=+(109.9 \pm 1.2) \mathrm{kJ} \mathrm{mol}^{-1}$ for $\mathrm{ClO}_{2}{ }^{\circ}(a q)$. Combination of this value 2524 with the NBS value for $\mathrm{ClO}_{2}{ }^{-}(a q)\left(\Delta_{\mathrm{f}} G^{\circ}=+17.2 \mathrm{~kJ} \mathrm{~mol}^{-1}\right)$ leads to $E^{\circ}=+(0.961 \pm 0.013) \mathrm{V}$ for 2525 the $\mathrm{ClO}_{2}{ }^{\circ}(a q) / \mathrm{ClO}_{2}{ }^{-}(a q)$ standard potential. The agreement of this corrected derived result with 2526 the experimental standard potential is much improved. On the other hand, there is no published 2527 discussion of the reliability of the more recent determinations of $\Delta_{\mathrm{f}} H^{\circ}$ for $\mathrm{ClO}_{2}{ }^{\circ}(\mathrm{g})$ vis-a-vis the 2528 older determinations mentioned by Gurvich et al., so we view the uncertainty selected in the 2529 NASA evaluation to be overly optimistic. For example, early direct calorimetric measurements 2530 of the decomposition of $\mathrm{ClO}_{2}{ }^{\circ}(g)$ appear to have been ignored. We thus favor a larger 2531 uncertainty, perhaps as much as $\pm 10 \mathrm{~kJ} \mathrm{~mol}^{-1}$. Within this uncertainty there is no need to 2532 question the NBS value of $\Delta_{\mathrm{f}} G^{\circ}$ for $\mathrm{ClO}_{2}^{-}(a q)$.

2533 Schmitz reviewed the thermodynamic chemistry of the aqueous $\mathrm{ClO}_{2}{ }^{\circ} / \mathrm{ClO}_{2}{ }^{-}$system in 25341979 [16]. He concluded that the value of $\Delta_{\mathrm{f}} G^{\circ}$ for $\mathrm{ClO}_{2}{ }^{\circ}(a q)$ is essentially as given by NBS but 2535 that the corresponding value for $\mathrm{ClO}_{2}{ }^{-}(a q)$ differs quite substantially from the NBS value. His 2536 results were obtained by deciding on the value for $\mathrm{ClO}_{2}{ }^{\circ}(a q)$ and then using the measured $E^{\circ}$ for 2537 the $\mathrm{ClO}_{2}{ }^{\circ}(a q) / \mathrm{ClO}_{2}{ }^{-}(a q)$ couple to derive $\Delta_{\mathrm{f}} G^{\circ}$ for $\mathrm{ClO}_{2}{ }^{-}(a q)$. In view of the unsettled status of $2538 \Delta_{\mathrm{f}} G^{\circ}$ for $\mathrm{ClO}_{2}{ }^{\circ}(a q)$ as described above, Schmitz's conclusions should not be considered 2539 definitive. On the other hand, there is much in his discussion that merits attention.

2540 At present we differ from the NIST tables [6] in recommending a value of $\Delta_{\mathrm{f}} G^{\circ}=+110 \pm$ $254110 \mathrm{~kJ} \mathrm{~mol}^{-1}$ for $\mathrm{ClO}_{2}{ }^{\circ}(a q)$; we consider that the potentiometric determination of $E^{\circ}$ for the $2542 \mathrm{ClO}_{2} / \mathrm{ClO}_{2}^{-}$couple is substantially more reliable than the individual values for $\Delta_{\mathrm{f}} G^{\circ}$. This 2543 recommendation for $\Delta_{\mathrm{f}} G^{\circ}$ of $\mathrm{ClO}_{2}{ }^{\circ}(a q)$ makes the NBS value $\Delta_{\mathrm{f}} G^{\circ}$ of $\mathrm{ClO}_{2}{ }^{-}(a q)$ reasonably 
2544 consistent with our recommended value for $E^{\circ}$ for $\mathrm{ClO}_{2}{ }^{\bullet}(a q) / \mathrm{ClO}_{2}^{-}(a q)$. It leads to inconsistency 2545 between the measured Henry's law constant for $\mathrm{ClO}_{2}{ }^{\bullet}$ and the NBS value for $\Delta_{\mathrm{f}} G^{\circ}$ of $\mathrm{ClO}_{2}{ }^{\bullet}(g)$, 2546 but that is probably the only such issue raised by this alteration to the NIST data [6].

\section{Recommended values:}

$$
\begin{aligned}
& E^{\circ}\left(\mathrm{ClO}_{2}{ }^{\bullet}(a q) / \mathrm{ClO}_{2}{ }^{-}\right)=+(0.935 \pm 0.003) \mathrm{V} \\
& \Delta_{\mathrm{f}} G^{\circ}\left(\mathrm{ClO}_{2}{ }^{\bullet} a q\right)=+(110 \pm 10) \mathrm{kJ} \mathrm{mol}^{-1}
\end{aligned}
$$

Nomenclature: $\mathrm{ClO}_{2}{ }^{\bullet}$, dioxidochlorine $(\bullet)$, or chlorinedioxide; $\mathrm{ClO}_{2}^{-}$, dioxidochlorate(1) or chlorite.

\section{References}

1. N. V. Troitskaya, K. P. Mishchenko, I. E. Flis. Russ. J. Phys. Chem. 33, 77-79 (1959).

2. U. K. Kläning, K. Sehested, J. Holcman. J. Phys. Chem. 89, 760-763 (1985).

3. N. Sinkaset, A. M. Nishimura, J. A. Pihl, W. C. Trogler. J. Phys. Chem. A 103, 10461256110469 (1999).

2562 4. A. J. Bard, R. Parsons, J. Jordan. Standard Potentials in Aqueous Solution, Marcel 2563 Dekker, Inc., New York 834 (1985).

2564 5. D. M. Stanbury. Adv. Inorg. Chem. 33, 69-138 (1989).

2565 6. D. D. Wagman, W. H. Evans, V. B. Parker, R. H. Schumm, I. Halow, S. M. Bailey, K. L. 2566 Churney, R. L. Nuttall. J. Phys. Chem. Ref. Data 11, Suppl. No. 2 (1982).

2567 7. D. G. Archer, personal communication to D. M. Stanbury on the origin of NBS data on $2568 \mathrm{Tl}(\mathrm{III}), \mathrm{ClO}_{2}, \mathrm{ClO}_{2}^{-}$(2003).

2569 8. $\quad$ L. A. Lednicky, D. M. Stanbury. J. Am. Chem. Soc. 105, 3098-3101 (1983).

2570 9. M. W. Chase. NIST-JANAF Thermodynamicchemical Tables, 4th ed, American Institute 2571 of Physics, Woodbury, NY (1998).

2572 10. L. V. Gurvich, I. V. Veyts, C. B. Alcock. Thermodynamic Properties of Individual 2573 Substances, Hemisphere Publishing Corp., New York (1989).

2574 11. R. Atkinson, D. L. Baulch, R. A. Cox, R. F. Hampson, J. A. Kerr, M. J. Rossi, J. Troe. J. 2575 Phys. Chem. Ref. Data 29, 167-266 (2000).

2576 12. R. Flesch, E. Rühl, K. Hottmann, H. Baumgärtel. J. Phys. Chem. 97, 837-844 (1993).

2577 13. S. L. Nickolaisen, R. R. Friedl, S. P. Sander. J. Phys. Chem. 98, 155-169 (1994).

2578 14. S. P. Sander, B. J. Finlayson-Pitts, R. R. Friedl, D. M. Golden, R. E. Huie, C. E. Kolb, M. 2579 J. Kurylo, M. J. Molina, G. K. Moortgat, V. L. Orkin, A. R. Ravishankara. Chemical Kinetics 
2580 and Photochemical Data for Use in Atmospheric Studies, Evaluation Number 14, Jet Propulsion 2581 Laboratory, Pasadena, CA (2002).

2582 15. Z. F. Xu, M. C. Lin. J. Chem. Phys. 119, 8897-8904 (2003).

2583 16. G. Schmitz. J. Chim. Phys. 76, 209-211 (1979).

2584

2585 


\section{Data Sheet 25}

Summary of the $\mathrm{ClO}^{\bullet}$ System

$\mathrm{CO}_{3}{ }^{-}+\mathrm{ClO}^{-} \rightleftharpoons \mathrm{CO}_{3}^{2-}+\mathrm{ClO}^{\bullet}$.

The equilibrium constant for this reaction, $(9.5 \pm 3.0) \times 10^{2}$ was determined at $\mu=3.0 \mathrm{M}, \mathrm{pH}=$ 12.2 , at $22.2{ }^{\circ} \mathrm{C}$. Because of the high ionic strength and charge asymmetry of the reaction, it is difficult to make a safe extrapolation to zero ionic strength. Given a recommended value for $E^{\circ \prime}\left(\mathrm{CO}_{3}{ }^{--} / \mathrm{CO}_{3}{ }^{2-}\right)$ of $+(1.57 \pm 0.03) \mathrm{V}$ at $0.5 \mathrm{M}$ to $3 \mathrm{M}$ ionic strength (Data Sheet 99$)$, we derive $E^{\text {or }}=+(1.39 \pm 0.03) \mathrm{V}$ for $\mathrm{ClO}^{\bullet} / \mathrm{ClO}^{-}$. Although the $\mathrm{CO}_{3}{ }^{-} / \mathrm{CO}_{3}{ }^{2-}$ formal potential should be strongly dependent on ionic strength, the $\mathrm{ClO}^{*} / \mathrm{ClO}^{-}$formal potential should be considerably less dependent.

A value for $\Delta_{\mathrm{f}} G^{\circ}\left(\mathrm{ClO}^{\circ}\right)$ can be derived from $E^{\circ}$ and $\Delta_{\mathrm{f}} G^{\circ}\left(\mathrm{ClO}^{-}\right)$. The NIST value for this latter quantity is $-(36.8 \pm 8) \mathrm{kJ} \mathrm{mol}^{-1}$ [2]. This seems like an unreasonably large uncertainty. NIST also gives $\Delta_{\mathrm{f}} G^{\circ}=+(6.94 \pm 0.8) \mathrm{kJ} \mathrm{mol}^{-1}$ for $\mathrm{Cl}_{2}(a q)$. The equilibrium constant for $\mathrm{Cl}_{2}$ hydrolysis $\left(\mathrm{Cl}_{2}(a q)+\mathrm{H}_{2} \mathrm{O}(l)=\mathrm{HOCl}(a q)+\mathrm{Cl}^{-}+\mathrm{H}^{+}\right)$is well defined as $(5.1 \pm 0.1) \times 10^{-4} \mathrm{M}^{2}$ at $25{ }^{\circ} \mathrm{C}$ and $\mu=0.0 \mathrm{M}$ [3]. $\mathrm{HOCl}$ has a $K_{\mathrm{a}}=(7.53 \pm 0.02)$ at $\mu=0.0 \mathrm{M}$ and $25^{\circ} \mathrm{C}$ [4]. These data, along with NIST data for $\mathrm{H}_{2} \mathrm{O}$ and $\mathrm{Cl}^{-}$lead to $\Delta_{\mathrm{f}} G^{\circ}=-(37.16 \pm 0.8) \mathrm{kJ} \mathrm{mol}^{-1}$ for $\mathrm{ClO}^{-}(a q)$, which is in excellent agreement with the NIST value. We thus derive $\Delta_{\mathrm{f}} G^{\circ}=+(97 \pm 3) \mathrm{kJ} \mathrm{mol}^{-1}$ 2608 for $\mathrm{ClO}^{*}(a q)$.

\section{Recommended values:}

$E^{\text {of }}=+(1.39 \pm 0.03) \mathrm{V}$ at $\mu=3 \mathrm{M}$.

$\Delta_{\mathrm{f}} G^{\circ}=+(97 \pm 3) \mathrm{kJ} \mathrm{mol}^{-1}$ for $\mathrm{ClO}^{\circ}(a q)$

\section{References}

1. R. E. Huie, C. L. Clifton, P. Neta. Radiat. Phys. Chem. 38, 477-481 (1991).

2. D. D. Wagman, W. H. Evans, V. B. Parker, R. H. Schumm, I. Halow, S. M. Bailey, K. L. Churney, R. L. Nuttall. J. Phys. Chem. Ref. Data 11, Suppl. No. 2 (1982).

26203 3. T. X. Wang, D. W. Margerum. Inorg. Chem. 33, 1050-1055 (1994). 


\section{Data Sheet 26}

2624 Summary of the $\mathrm{Br}^{\bullet} / \mathrm{Br}_{2}{ }^{-} / \mathrm{BrOH}^{-}$System

Tabulated below are the presently recommended equilibrium constants involving this related group of bromine radicals. The values are as given in the individual evaluations, keyed by reaction number. Uncertainties are expressed as $\pm 1 \sigma$; in many cases the value of $\sigma$ is merely a subjective guess.

rxn \# Reaction $K_{\mathrm{eq}} \quad$ dim. uncertainty $\mu / \mathrm{M}$ Data

\begin{tabular}{|c|c|c|c|c|c|c|}
\hline & & & & & & $\begin{array}{l}\text { Sheet } \\
\#\end{array}$ \\
\hline 27.1 & $2 \mathrm{Br}^{-}+\mathrm{Mn}^{3+} \rightleftharpoons \mathrm{Br}_{2}^{--}+\mathrm{Mn}^{2+}$ & $1.0 \times 10^{-1}$ & $\mathrm{M}^{-1}$ & \pm factor of 2 & 2 & 27 \\
\hline 28.1 & $\mathrm{Br}_{2}^{--}+\mathrm{ClO}_{2}^{\bullet} \rightleftharpoons \mathrm{Br}_{2}+\mathrm{ClO}_{2}^{-}$ & $7.4 \times 10^{5}$ & & \pm factor of 2 & low & 28 \\
\hline 29.1 & $\mathrm{Br}_{2}^{-}+\mathrm{N}_{3}^{-} \rightleftharpoons \mathrm{N}_{3} \cdot+2 \mathrm{Br}^{-}$ & $5.5 \times 10^{4}$ & M & \pm factor of 2 & 0 & 29 \\
\hline 30.1 & $\mathrm{Br}_{2}^{\bullet^{-}}+\mathrm{CO}_{3}^{2-} \rightleftharpoons 2 \mathrm{Br}^{-}+\mathrm{CO}_{3}^{\bullet^{-}}$ & 3.2 & M & $\pm 22 \%$ & 3 & 30 \\
\hline 31.1 & $\mathrm{Br}^{\bullet}(\mathrm{aq})+\mathrm{H}_{2} \mathrm{O} \rightleftharpoons \mathrm{BrOH}^{\bullet^{-}}+\mathrm{H}^{+}$ & none & & & & 31 \\
\hline 32.1 & $\mathrm{BrOH}^{-} \rightleftharpoons \mathrm{Br}^{\bullet}(\mathrm{aq})+\mathrm{HO}^{-}$ & $3.2 \times 10^{-4}$ & $\mathrm{M}$ & $\pm 15 \%$ & low & 32 \\
\hline 33.1 & $\mathrm{Br}^{\bullet}(\mathrm{aq})+\mathrm{Br}^{-} \rightleftharpoons \mathrm{Br}_{2}^{-}$ & $3.9 \times 10^{5}$ & $\mathrm{M}^{-1}$ & $\pm 30 \%$ & low & 33 \\
\hline 34.1 & $\mathrm{HO}^{\bullet}+\mathrm{Br}^{-} \rightleftharpoons \mathrm{BrOH}^{\bullet-}$ & $3.2 \times 10^{2}$ & $\mathrm{M}^{-1}$ & \pm factor of 2 & low & 34 \\
\hline 35.1 & $\mathrm{BrOH}^{\bullet^{-}}+\mathrm{Br}^{-} \rightleftharpoons \mathrm{Br}_{2}^{\bullet^{-}}+\mathrm{HO}^{-}$ & $7 \times 10^{1}$ & & $\pm 43 \%$ & low & 35 \\
\hline 36.1 & $\mathrm{BrSCN}^{\bullet^{-}}+\mathrm{Br}^{-} \rightleftharpoons \mathrm{Br}_{2}^{\bullet^{-}}+\mathrm{SCN}^{-}$ & $1 \times 10^{-3}$ & & \pm factor of 3 & low & 36 \\
\hline 37.1 & $\mathrm{BrSCN}^{\bullet^{-}}+\mathrm{SCN}^{-} \rightleftharpoons(\mathrm{SCN}) 2^{\bullet^{-}}+\mathrm{Br}^{-}$ & $1.1 \times 10^{2}$ & & $\pm 50 \%$ & low & 37 \\
\hline 38.1 & $\mathrm{Br}_{2}^{\bullet^{-}}+\mathrm{DMS} \rightleftharpoons \mathrm{DMS}-\mathrm{Br}^{\bullet}+\mathrm{Br}^{-}$ & $1.1 \times 10^{4}$ & & \pm factor of 2 & low & 38 \\
\hline 39.2 & $\mathrm{DMS}-\mathrm{Br}^{\bullet}+\mathrm{DMS} \rightleftharpoons(\mathrm{DMS})_{2}^{+}+\mathrm{Br}^{-}$ & 1.6 & & \pm factor of 2 & low & 39 \\
\hline
\end{tabular}

2631 DMS $=$ dimethylsulfide.

Reactions 32.1, 33.1, and 35.1 form a closed thermodynamicchemical cycle, which requires the 2634 following: $K(32.1)=K(35.1) / K(33.1)$. We obtain $3.2 \times 10^{-4} \approx 1.8 \times 10^{-4}$ which is quite satisfactory.

\section{Derived $\mathrm{Br}_{2}{ }^{-}-/ 2 \mathrm{Br}^{-}$Standard Potentials:}

Reaction 27.1 leads directly to $E^{\circ \prime}$ for $\mathrm{Br}_{2}{ }^{\circ-}+\mathrm{e}^{-} \rightleftharpoons 2 \mathrm{Br}^{-}$at $\mu=2 \mathrm{M}$ through combination with $E^{\circ \prime}$ for $\mathrm{Mn}^{3+} / \mathrm{Mn}^{2+}$. We use the value of $+(1.535 \pm 0.003) \mathrm{V}$ given by

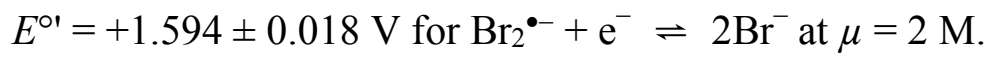


Reaction 28.1 leads directly to $E^{\circ}$ for $\mathrm{Br}_{2}+\mathrm{e}^{-} \rightleftharpoons \mathrm{Br}_{2}{ }^{--}$through use of $E^{\circ}\left(\mathrm{ClO}_{2}{ }^{\circ} / \mathrm{ClO}_{2}{ }^{-}\right)$.

2646

2647

2648

2649

2650

2651

2652

2653

2654

2655

2656

2657

2658

2659

2660

2661

2662

2663

2664

2665

2666

2667

2668

2669

2670

2671

2672

2673

2674

2675

2676

2677

2678

2679

For $E^{\circ}\left(\mathrm{ClO}_{2}{ }^{\circ} / \mathrm{ClO}_{2}{ }^{-}\right)$we use $+(0.935 \pm 0.003) \mathrm{V}$ as evaluated in Data Sheet 24 . This leads to $E^{\circ}$ $=+0.588 \pm 0.017$ for $\mathrm{Br}_{2}+\mathrm{e}^{-}=\mathrm{Br}_{2}{ }^{\circ}$. Use of $E^{\circ}=1.0874 \mathrm{~V}$ for $E^{\circ}\left(\mathrm{Br}_{2}(a q) / 2 \mathrm{Br}^{-}\right)$[2] leads to

$$
E^{\circ}=+(1.587 \pm 0.017) \mathrm{V} \text { for } \mathrm{Br}_{2}{ }^{-}+\mathrm{e}^{-} \rightleftharpoons 2 \mathrm{Br}^{-}
$$

Reaction 29.1 in combination with a value of $+(1.33 \pm 0.010) \mathrm{V}$ for $E^{\circ}\left(\mathrm{N}_{3}{ }^{\bullet} / \mathrm{N}_{3}{ }^{-}\right.$) (Data sheet 80 ) yields

$$
E^{\circ}=+(1.610 \pm 0.020) \mathrm{V} \text { for } \mathrm{Br}_{2}{ }^{--}+\mathrm{e}^{-} \rightleftharpoons 2 \mathrm{Br}^{-}
$$

Reaction 35.1 combined with reaction 34.1 leads to $\ln K=(10.12 \pm 0.78)$ for $\mathrm{HO}^{\bullet}+2 \mathrm{Br}^{-}$ $\rightleftharpoons \mathrm{Br}_{2}{ }^{\circ-}+\mathrm{HO}^{-}$. Use of $E^{\circ}=(1.902 \pm 0.017) \mathrm{V}$ for $\mathrm{HO}^{\bullet} / \mathrm{HO}^{-}$(Data sheet 7) leads to

$$
E^{\circ}=+(1.645 \pm 0.021) \mathrm{V} \text { for } \mathrm{Br}_{2}{ }^{-}+\mathrm{e}^{-} \rightleftharpoons 2 \mathrm{Br}^{-}
$$

The agreement among the above derivations of $E^{\circ}$ is not very satisfactory, spanning a range of $50 \mathrm{mV}$. The result based on reaction 28.1 is particularly suspect: it is based on a kinetic analysis of the $\mathrm{ClO}_{2} \% \mathrm{Br}_{2}{ }^{-}{ }^{-}$system that involves a complex mechanism; Toth and Fabian used a simulation that required simultaneous optimization of several rate constants. Thus, we exclude the result from reaction 28.1 from the final estimate. The Taube result (reaction 27.1) can also be excluded because of the mechanistic complexities and the high ionic strength employed. This leaves the results from reactions 29.1 and 35.1, which agree within their uncertainties; they yield an average of $E^{\circ}=+1.624 \mathrm{~V}$. An uncertainty of $\pm 0.020 \mathrm{~V}$ is inferred from the uncertainties in each the two component results and the difference between them.

\section{Recommended value:}

$$
E^{\circ}\left(\mathrm{Br}_{2}{ }^{\bullet-} / 2 \mathrm{Br}\right)=+(1.627 \pm 0.020) \mathrm{V} \text {. }
$$

\section{Other derived quantities}

From the recommended $E^{\circ}\left(\mathrm{Br}_{2}{ }^{-} / 2 \mathrm{Br}\right)$ and the $E^{\circ}\left(\mathrm{Br}_{2} / 2 \mathrm{Br}^{-}\right)$cited above we derive $E^{\circ}=+(0.55 \pm 0.02) \mathrm{V}$ for $\mathrm{Br}_{2}+\mathrm{e}^{-} \rightleftharpoons \mathrm{Br}_{2}{ }^{--}$. 
From the recommended $E^{\circ}\left(\mathrm{Br}_{2}{ }^{\bullet-} / 2 \mathrm{Br}\right)$ and $K_{\text {eq }}$ for reaction 33.1 we derive $E^{\circ}=+(1.96 \pm 0.02) \mathrm{V}$ for $\mathrm{Br}^{\bullet}+\mathrm{e}^{-} \rightleftharpoons \mathrm{Br}^{-}$. $\Delta_{\mathrm{f}} G^{\circ}\left(\mathrm{Br}^{\top}\right)$ and $\Delta_{\mathrm{f}} G^{\circ}\left(\mathrm{SCN}^{-}\right)\left(=+92.71 \mathrm{~kJ} \mathrm{~mol}^{-1}\right)$ we obtain

$$
\begin{aligned}
& \text { From the recommended } E^{\circ}\left(\mathrm{Br}^{\bullet} / \mathrm{Br}^{-}\right) \text {and the NIST value for } \Delta_{\mathrm{f}} G^{\circ} \text { of } \mathrm{Br}^{-} \text {we derive } \\
& \Delta_{\mathrm{f}} G^{\circ}=(85 \pm 2) \mathrm{kJ} \mathrm{mol}^{-1} \text { for } \mathrm{Br}^{\bullet} .
\end{aligned}
$$

$\mathrm{HO}^{-}\left(-157.244 \mathrm{~kJ} \mathrm{~mol}^{-1}\right)$ we obtain $\Delta_{\mathrm{f}} G^{\circ}=-(92.5 \pm 2) \mathrm{kJ} \mathrm{mol}^{-1}$ for $\mathrm{BrOH}^{\bullet^{-}}$. From reaction 34.1, NIST value for $\Delta_{\mathrm{f}} G^{\circ}$ of $\mathrm{Br}^{-}$, and the Task Group recommendation for $\Delta_{\mathrm{f}} G^{\circ}\left(\mathrm{HO}^{\bullet}\right)(=+26.3 \pm 1.6$ $\left.\mathrm{kJ} \mathrm{mol}^{-1}\right)$ we obtain $\Delta_{\mathrm{f}} G^{\circ}=-(92.0 \pm 1.8) \mathrm{kJ} \mathrm{mol}^{-1}$ for $\mathrm{BrOH}^{{ }^{-}}$. From $K_{\text {eq }}$ for reaction 35.1, the value for $\Delta_{\mathrm{f}} G^{\circ}\left(\mathrm{Br}_{2}{ }^{-}\right)$derived above, and the NIST values of $\Delta_{\mathrm{f}} G^{\circ}$ for $\mathrm{Br}^{-}$and $\mathrm{HO}^{-}$we obtain $\Delta_{\mathrm{f}} G^{\circ}=-(93.8 \pm 2.2) \mathrm{kJ} \mathrm{mol}^{-1}$ for $\mathrm{BrOH}^{{ }^{-}}$. These three derivations are in excellent agreement and yield an average value of $-(93 \pm 2) \mathrm{kJ} \mathrm{mol}^{-1}$ for $\Delta_{\mathrm{f}} G^{\circ}$ of $\mathrm{BrOH}^{\bullet-}$.

$$
\Delta_{\mathrm{f}} G^{\circ}=+(129 \pm 3) \mathrm{kJ} \mathrm{mol}^{-1} \text { for } \mathrm{BrSCN}^{\bullet-} \text {. }
$$

From $K_{\text {eq }}$ for reaction 32.1 and a value of $1 \times 10^{-14} \mathrm{M}^{2}$ for $K_{\mathrm{w}}$ we derive $\mathrm{p} K_{\mathrm{a}}=(10.50 \pm$ 0.07) for $\mathrm{Br}^{\bullet}$ (reaction 31.1).

From $\Delta_{\mathrm{f}} G^{\circ}\left(\mathrm{Br}^{\bullet}, a q\right)$ as derived above and the NIST value for $\Delta_{\mathrm{f}} G^{\circ}$ for $\operatorname{Br}^{\bullet}(g)(=+82.396$ $\left.\mathrm{kJ} \mathrm{mol}^{-1}\right)$ we derive $\Delta G_{\mathrm{hyd}}=+(2.3 \pm 2) \mathrm{kJ} \mathrm{mol}^{-1}$ for $\mathrm{Br}^{\bullet}$.

2715 Dekker, Inc., New York 834 (1985). 
2716 3. D. D. Wagman, W. H. Evans, V. B. Parker, R. H. Schumm, I. Halow, S. M. Bailey, K. L. 2717 Churney, R. L. Nuttall. J. Phys. Chem. Ref. Data 11, Suppl. No. 2 (1982). 2718

2719 


\section{Data Sheet 27}

Chemical equilibrium: $2 \mathrm{Br}^{-}+\mathrm{Mn}^{3+} \rightleftharpoons \mathrm{Br}^{-\bullet}+\mathrm{Mn}^{2+}$

\section{List of reports:}

$$
K_{\text {eq }}=1 /(16 \mathrm{M})\left(=6.3 \times 10^{-2} \mathrm{M}^{-1}\right) \text { at } 25.2^{\circ} \mathrm{C} \text { and } \mu=(2-2.15) \mathrm{M} \text { [1]. Obtained from the }
$$
kinetics of $\mathrm{Mn}(\mathrm{III})$ catalysis of the reaction of bromine with oxalic acid. determination of the reverse rate constant and a conventional kinetic determination of the forward rate constant.

\section{Discussion}

Taube's early (1948) determination [1] of this radical equilibrium constant is remarkably prescient. His data yield a value of 0.27 (time in minutes) for $2 k_{5} / K_{\mathrm{d}}{ }^{2}$, where these parameters refer to the reactions

Taube's assumption for the value of $2 k_{5}$ seems somewhat high; although there are no direct determinations of $2 k_{5}$ at such high ionic strengths, it is reported that $2 k_{5}$ is $(4.8 \pm 0.6) \times 10^{9} \mathrm{M}^{-1}$ $\mathrm{s}^{-1}$ at $1 \mathrm{M}$ ionic strength [3]. With $2 k_{5}$ taken as $(4.8 \pm 0.6) \times 10^{9} \mathrm{M}^{-1} \mathrm{~s}^{-1}$ we obtain $K_{\mathrm{d}}=(1.0 \pm$ $0.3) \times 10^{6} \mathrm{M}^{2}$, which is quite close to the value reported by Taube; presumably he made a computational or typographical error that has been largely compensated for by our 20 -fold adjustment to $2 k_{5}$. This leads to a corrected value of $(0.10 \pm 0.3) \mathrm{M}^{-1}$ for $K_{\text {eq }}$ at $\mu=2 \mathrm{M}$.

$$
\mathrm{Mn}^{3+}+\mathrm{Br}^{-} \rightleftharpoons \mathrm{MnBr}^{2+} \quad K_{22}
$$




$$
\mathrm{MnBr}^{2+}+\mathrm{Br}^{-} \rightleftharpoons \mathrm{Mn}^{2+}+\mathrm{Br}_{2}^{\bullet-} \quad k_{23}, k_{-23}
$$

2758 They used flash photolysis of solutions that contained $\mathrm{Mn}^{2+}$ and $\mathrm{Br}_{3}{ }^{-}$to generate $\mathrm{Br}_{2}{ }^{-{ }^{-}}$and

2759 measure $k_{-23}\left(=9.0 \times 10^{6} \mathrm{M}^{-1} \mathrm{~s}^{-1}\right.$ [2]. These flash photolysis experiments were performed at 25

$2760{ }^{\circ} \mathrm{C}$ and ionic strength ranging from $0.21 \mathrm{M}$ to $0.25 \mathrm{M}$. They then used Wells and Mays' data for 2761 the value of $K_{22} k_{23}\left(=3.6 \times 10^{5} \mathrm{M}^{-2} \mathrm{~s}^{-1}\right)$ at $4 \mathrm{M}$ ionic strength [4]. Combining these two values 2762 led to $K_{\mathrm{eq}}=4 \times 10^{-2} \mathrm{M}^{-1}$.

2763 Given the high ionic strength dependence expected for the rate constants in Laurence and 2764 Thornton's determination [2], the result can only be approximate. We thus prefer Taube's

2765 determination [1]. Given the agreement between the two reports and the overall complexity of 2766 the determinations we assume an uncertainty in $K_{\text {eq }}$ of a factor of 2.

\section{Recommended value:}

$$
K_{\text {eq }}=1.0 \times 10^{-1} \mathrm{M}^{-1} \text { at } 25.2^{\circ} \mathrm{C} \text { and } \mu=(2-2.15) \mathrm{M} \text { within a factor of two. }
$$

List of auxiliary thermodynamic data: none.

Nomenclature: see Data Sheet 26.

\section{References}

2778 1. H. Taube. J. Am. Chem. Soc. 70, 3928-3935 (1948).

2779 2. G. S. Laurence, A. T. Thornton. J. Chem. Soc., Dalton Trans. 1637-1644 (1973).

2780 3. M. D'Angelantonio, M. Venturi, Q. G. Milazzani. Radiat. Phys. Chem. 32, 319-324 2781 (1988).

27824 4. C. F. Wells, D. Mays. J. Chem. Soc. A 577-583 (1968). 


\section{Data Sheet 28}

Chemical equilibrium: $\mathrm{ClO}_{2}{ }^{\bullet}+\mathrm{Br}_{2}^{\bullet-} \rightleftharpoons \mathrm{ClO}_{2}^{-}+\mathrm{Br}_{2}$

\section{List of reports:}

$K_{\text {eq }}=(2.7 \pm 1.4) \times 10^{6}$. This value has not been published, but it can be calculated from

\section{Discussion} published values for the forward and reverse rate constants. A value of $(3.56 \pm 0.06) \times 10^{9} \mathrm{M}^{-1} \mathrm{~s}^{-}$ ${ }^{1}$ at $\mu=1.0 \mathrm{M}$ (and presumably at room temperature) for $k_{\mathrm{f}}$ was reported by Tóth et al. from a flash photolysis study [1]. Experiments at $\mu=0.10$ and $0.05 \mathrm{M}$ show the rate constant to be essentially independent of ionic strength. Tóth and Fábián reported $k_{r}=(1.3 \pm 0.2) \times 10^{3} \mathrm{M}^{-1} \mathrm{~s}^{-1}$ at $25.0^{\circ} \mathrm{C}$ and $\mu=1.0 \mathrm{M}$; this result was obtained from stopped-flow experiments, with the rate constants being evaluated by numerical fitting of a complex model [2]. The value obtained for $k_{\mathrm{r}}$ varied over a factor of $\sim 3$ depending on the details of the model, and the indicated uncertainty is merely a statistical result for one of the models. Thus, we assign a larger uncertainty of a factor of 2 in $K_{\text {eq. }}$

The value of $K_{\text {eq }}$ presented above is the only experimental result available. It seems to be fairly reliable, although there is a large uncertainty because of the complex mechanism used to derive it. Some degree of skepticism in the value of $k_{\mathrm{r}}$ arises from a recent report on the reaction of $\mathrm{HOBr}$ with $\mathrm{Cl}(\mathrm{III})$ [3]. This new paper gives a significantly revised value for the rate constant of the reaction of $\mathrm{HOBr}+\mathrm{HClO}_{2}$, which also figured in the mechanism of the reaction that led to the value for $k_{\mathrm{r}}$. This paper provides no information as to how this new information affects the fits from which $k_{\mathrm{r}}$ is derived.

As described in Tóth's Ph.D. dissertation [4], the revised data on the $\mathrm{HOBr} / \mathrm{Cl}(\mathrm{III})$ reaction lead to an adjustment in the value for $k_{\mathrm{r}}$ to $(4.84 \pm 0.02) \times 10^{3} \mathrm{M}^{-1} \mathrm{~s}^{-1}$. This latest 
2821 Recommended value:

2822

$2823 \quad K_{\text {eq }}=7.4 \times 10^{5}$ within a factor of 2.

2824

2825 List of auxiliary thermodynamic data: none

2826

2827 Nomenclature: See Data Sheet 26. $\mathrm{ClO}_{2}^{\bullet}$, dioxidochlorine(•).

2828

2829 References

2830

2831 1. Z. Tóth, I. Fábián, A. Bakac. Inorg. React. Mech. 3, 147-152 (2001).

2832 2. Z. Tóth, I. Fabian. Inorg. Chem. 39, 4608-4614 (2000).

2833 3. Z. Tóth, I. Fábián. Inorg. Chem. 43, 2717-2723 (2004).

2834 4. Z. Tóth. (Ph. D. dissertation: The reactions of chlorine(III) with bromine and

2835 hypobromous acid: kinetics and mechanism); University of Debrecen: Debrecen, Hungary, 2003.

2836

2837 


\section{Data Sheet 29}

\section{List of reports:}

$K_{\text {eq }}=5.5 \times 10^{4} \mathrm{M}$, presumably at room temperature, with $\mu=2$ or $3 \mathrm{M}$ [1]. Results were obtained by pulse radiolysis of $\mathrm{Br}^{-} / \mathrm{N}_{3}{ }^{-}$mixtures, and by measuring $k_{\text {obs }}$ for the above reaction; a plot of $k_{\text {obs }} /\left[\mathrm{Br}^{-}\right]^{2}$ vs $\left[\mathrm{N}_{3}\right] /\left[\mathrm{Br}^{-}\right]^{2}$ yields $k_{\mathrm{f}}$ and $k_{\mathrm{r}}$ from the slope and intercept, and $K_{\text {eq }}$ from the ratio of $k_{\mathrm{f}} / k_{\mathrm{r}}$. A "similar" equilibrium constant was obtained from the equilibrium concentration of $\mathrm{Br}_{2}{ }^{--}$determined at $360 \mathrm{~nm}$.

While we have no reason to doubt the quality of this work, the very high ionic strength of the solutions makes the result of limited value in determining the equilibrium constant at $\mu=0$. The reaction is electrostatically balanced, in that there are two product anions and two reactant anions, so the equilibrium constant should not vary too much with ionic strength. We tentatively assign an uncertainty of a factor of 2 .

$K_{\mathrm{eq}}{ }^{0}=5.5 \times 10^{4} \mathrm{M}$ within a factor of 2.

2862 List of auxiliary thermodynamic data: none

2863

Nomenclature: See Data Sheet 26. $\mathrm{N}_{3}{ }^{\bullet}$, trinitrogen $(2 N-N)(\bullet)$

\section{References}

2868 1. Z. B. Alfassi, A. Harriman, R. E. Huie, S. Mosseri, P. Neta. J. Phys. Chem. 91, $2120-$ 28692122 (1987). 


\section{Data Sheet 30}

2873 Trioxidocarbonate $(\cdot 1-) /$ trioxidocarbonate $(2-)$

2874

List of reported equilibrium constants:

2876

Chemical equilibrium $\mathrm{Br}_{2}{ }^{--}+\mathrm{CO}_{3}{ }^{2-} \rightleftharpoons 2 \mathrm{Br}^{-}+\mathrm{CO}_{3}{ }^{-}$

2878

Huie et al. [1].

$K=3.2 \pm 0.7(\mathrm{I}=3 \mathrm{M}, \mathrm{pH} 12.0), \Delta E=(0.030 \pm 0.006) \mathrm{V}$.

Based on reaction 30.1 and $E^{\circ}\left(\mathrm{Br}_{2}{ }^{\bullet} / \mathrm{Br}^{-}\right)=+1.625 \mathrm{~V}$ [2], (see Data Sheet 26) $E^{\circ}\left(\mathrm{CO}_{3}{ }^{\bullet} / \mathrm{CO}_{3}{ }^{2-}\right)=$ $2884+(1.59 \pm 0.02) \mathrm{V}$.

Lymar et al., 2000 [3].

$K=(1.5 \pm 0.3) \times 10^{4} \mathrm{M}^{-1}$ and $(2.1 \pm 0.2) \times 10^{4} \mathrm{M}^{-1}$ at $0.5 \mathrm{M}$ and $1.5 \mathrm{M}$ ionic strength, $E^{\circ}\left((\mathrm{SCN})_{2}{ }^{-} / 2 \mathrm{SCN}^{-}\right)$. The authors have noted that this difference can be somewhat smaller at low ionic strength, as the electrolyte would tend to stabilize $\mathrm{CO}_{3}{ }^{2-}$ the most. Given $E^{\circ}\left((\mathrm{SCN}) 2^{\circ}\right.$ $\left./ 2 \mathrm{SCN}^{-}\right)=1.30 \mathrm{~V}($ see Data Sheet 101$), E^{\circ}\left(\mathrm{CO}_{3}{ }^{-} / \mathrm{CO}_{3}{ }^{2-}\right)=+1.55 \mathrm{~V}$.

$$
K=(9.5 \pm 3.0) \times 10^{2}\left(\mu=3.0 \mathrm{M}, \mathrm{pH} 12.2,22.2{ }^{\circ} \mathrm{C}\right), \Delta E=(0.176 \pm 0.010) \mathrm{V} .
$$

\section{Discussion} absorbance at $360 \mathrm{~nm}\left(\mathrm{Br}_{2}{ }^{\circ-}\right)$ at equilibrium and of $3.1 \pm 0.5$ from the rate constants for the decay 
2908 electrode potential determines that in $E^{\circ}\left(\mathrm{CO}_{3}{ }^{\bullet-} / \mathrm{CO}_{3}{ }^{2-}\right)$. The difference of $0.04 \mathrm{~V}$ between two 2909 careful measurements may be due to medium effects.

2911 The standard electrode potential of the $\mathrm{ClO}^{\bullet} / \mathrm{ClO}^{-}$couple is not known precisely enough to 2912 determine $E^{\circ}\left(\mathrm{CO}_{3}{ }^{--} / \mathrm{CO}_{3}{ }^{2-}\right)$; in fact the value of $+1.59 \mathrm{~V}$ is used to estimate $E^{\circ}\left(\mathrm{ClO}^{\bullet} / \mathrm{ClO}^{-}\right)[1]$.

\section{Recommended values:}

$E^{\circ}\left(\mathrm{CO}_{3}{ }^{--} / \mathrm{CO}_{3}{ }^{2-}\right)=+(1.57 \pm 0.03) \mathrm{V}$

$\Delta_{\mathrm{f}} G^{\circ}\left(\mathrm{CO}_{3}^{\bullet-}\right)=-(89.1 \pm 0.8) \mathrm{kcal} / \mathrm{mol}$, or $-(373 \pm 3) \mathrm{kJ} \mathrm{mol}^{-1}$;

List of auxiliary thermodynamic data

Based on a review of earlier literature, Stanbury proposed a value of $1.5 \mathrm{~V}$ [2]. In an ab initio experimentally derived values, this result is impressive for an ab initio calculation.

Chemical equilibrium $\mathrm{HCO}_{3}^{\bullet} \rightleftharpoons \mathrm{H}^{+}+\mathrm{CO}_{3}^{\bullet-}$

2928

Czapski et al. [5].

A $\mathrm{p} K_{\mathrm{a}}$ smaller than 0 has been determined [5], as expected for a $\mathrm{HOXO}_{2}$ acid.

\section{Recommended value:}

\section{References}

2943 1. R. E. Huie, C. L. Clifton, P. Neta. Radiat. Phys. Chem. 38, 477-481 (1991). 
2944 2. D. M. Stanbury. Adv. Inorg. Chem. 33, 69-138 (1989).

2945 3. S. V. Lymar, H. A. Schwarz, G. Czapski. Rad. Phys. Chem. 59, 387-392 (2000).

2946 4. D. A. Armstrong, W. L. Waltz, A. Rauk. Can. J. Chem. 84, 1614-1619 (2006).

2947 5. G. Czapski, S. V. Lymar, H. A. Schwarz. J. Phys. Chem. A 103, 3447-3450 (1999).

2948 6. Z. Zuo, Z. Cai, Y. Katsumura, N. Chitose, Y. Muroya. Radiat. Phys. Chem. 55, 15-23 2949 (1999).

2950

2951 


\section{$2952 \quad$ Data Sheet 31}

2954 Chemical equilibrium: $\mathrm{Br}^{\bullet}(a q)+\mathrm{H}_{2} \mathrm{O} \rightleftharpoons \mathrm{BrOH}^{\bullet^{-}}+\mathrm{H}^{+}$

\section{List of reports:}

$K_{\text {eq }}=3.09 \times 10^{-11} \mathrm{M}$. We derive this result from the forward rate constant $\left(k_{\mathrm{f}}=1.36 \mathrm{~s}^{-1}\right)$ reported by Kläning and Wolff and the reverse rate constant $\left(k_{\mathrm{r}}=(4.4 \pm 0.8) \times 10^{10} \mathrm{M}^{-1} \mathrm{~s}^{-1}\right)$

\section{Discussion}

Note that Kläning and Wolff erroneously cite Mamou et al. for $k_{\mathrm{r}}$. [3]. The Kläning and 2966 However, it appears that the method used was laser flash photolysis, which means that the value 2967 for $k_{\mathrm{f}}$ is too small to have been measured in this way. In fact, it was calculated from a 2968 thermodynamic cycle; the actual measurement by Kläning and Wolff must have been for the 2969 corresponding reaction in alkaline media: $\mathrm{Br}^{\bullet}+\mathrm{HO}^{-} \rightleftharpoons \mathrm{BrOH}^{-}$.

Recommended value: None. We can derive a value from the corresponding alkaline equilibrium, but there is no direct

2976 List of auxiliary thermodynamic data: none.

\section{References}

2980 1. U. K. Kläning, T. Wolff. Ber. Bunsenges. Phys. Chem. 89, 243-245 (1985).

2981 2. D. Zehavi, J. Rabani. J. Phys. Chem. 76, 312-319 (1972).

2982 3. A. Mamou, J. Rabani, D. Behar. J. Phys. Chem. 81, 1447-1448 (1977). 


\section{Data Sheet 32}

\section{List of reports:}

$$
K_{\text {eq }}=3.2 \times 10^{-4} \mathrm{M} \text {. This value calculated from } k_{\mathrm{f}} / k_{\mathrm{r}} \cdot k_{\mathrm{f}}=(4.2 \pm 0.6) \times 10^{6} \mathrm{~s}^{-1} \text { was }
$$

reported by Zehavi and Rabani from pulse radiolysis measurements.at $25 \pm 2{ }^{\circ} \mathrm{C}$ [1]. Zehavi and Rabani obtained $k_{\mathrm{f}}$ by combining various measured quantities as described below. The value for $k_{\mathrm{r}}\left(k_{\mathrm{r}}=1.3 \times 10^{10} \mathrm{M}^{-1} \mathrm{~s}^{-1}\right)$ was measured by Kläning and Wolff with flash photolysis of $\mathrm{HOBr}$ [2]. Due to the preliminary nature of Kläning and Wolff's report [2], the actual conditions of the experiment are unknown, but we can assume they were at room temperature and at $\mathrm{pH} 12$. Note that Kläning and Wolff [2] eroneously cited Mamou et al. [3] for the value of $k_{\mathrm{f}}$.

\section{Discussion}

Zehavi and Rabani's [1] determination of $k_{\mathrm{f}}$ is complex and is described here in outline. They assumed that the mechanism includes the steps

$$
\mathrm{Br}^{-}+\mathrm{HO}^{\bullet} \rightleftharpoons \mathrm{Br}^{\bullet}+\mathrm{HO}^{-}
$$

Note that $k_{1}$ is a pseudo-second-order rate constant that varies at high [Br ${ }^{-}$. Thus, the yield of $\mathrm{Br}_{2}{ }^{--}$depends on the alcohol concentration. By determining the $\mathrm{Br}_{2}{ }^{\bullet-}$ yield as a function of alcohol they obtained $k_{3} / k_{-2}=(0.127 \pm 0.007)$ at neutral $\mathrm{pH}$. In acidic ethanolic media, similar competition experiments yielded $k_{5} / k_{2}=(0.172 \pm 0.013)$. Use of the literature value for $k_{5}(=1.83$ $\times 10^{9} \mathrm{M}^{-1} \mathrm{~s}^{-1}$ ) then gave $k_{2}=1.06 \times 10^{10} \mathrm{M}^{-1} \mathrm{~s}^{-1}$. In a series of experiments they measured $k_{1}$ at various bromide concentrations up to $2 \mathrm{M}$, they plotted a graph of $\left(\left(k_{2}\right)\left(k_{3} / k_{-2}\right)-k_{1}\right) /[\mathrm{Br}]$ vs. $k_{1}$, and obtained a value of $k_{2} / k_{-2}=3.2 \times 10^{2} \mathrm{M}^{-1}$ from the slope. A value of $3.3 \times 10^{7} \mathrm{M}^{-1} \mathrm{~s}^{-1}$ was derived for $k_{-2}$ from the values for $k_{2}$ and $k_{2} / k_{-2}$. Finally, combining the values for $k_{-2}$ and $k_{3} / k_{-2}$ led to $k_{3}=4.2 \times 10^{6} \mathrm{~s}^{-1}$, which is $k_{\mathrm{f}}$.

We thus see that the value for $k_{\mathrm{f}}$ was obtained from data at various ionic strengths, some as high as $2 \mathrm{M}$. On the other hand, the value for $k_{\mathrm{r}}$ was determined at low ionic strength.

However, neither rate constant should be particularly sensitive to ionic strength, so the derived equilibrium constant can be reasonably described as an ideal one. 
$3021 \quad$ We estimate the uncertainty as $\pm 15 \%$ by combining the published uncertainty in $k_{\mathrm{f}}$ and 3022 our estimated uncertainty for $k_{\mathrm{r}}$.

3023 A strongly conflicting value for $K_{\text {eq }}$ of $2 \times 10^{-5}$ was calculated by Mamou et al. [3] from 3024 prior literature data of Behar [4]. Mamou et al. [3] then performed experiments that 3025 demonstrated an error in the results of Behar [4].

3026

3027 Recommended value:

3028

3029

$$
K_{\text {eq }}=(3.2 \pm 0.5) \times 10^{-4} \mathrm{M}
$$

3030

3031 List of auxiliary thermodynamic data: none.

3032

3033 Nomenclature: See Data Sheet 26

3034

3035

\section{References}

3036

3037 1. D. Zehavi, J. Rabani. J. Phys. Chem. 76, 312-319 (1972).

3038 2. U. K. Kläning, T. Wolff. Ber. Bunsenges. Phys. Chem. 89, 243-245 (1985).

3039 3. A. Mamou, J. Rabani, D. Behar. J. Phys. Chem. 81, 1447-1448 (1977).

3040 4. D. Behar. J. Phys. Chem. 76, 1815-1818 (1972). 


\section{Data Sheet 33}

\section{List of reports:}

$K_{\mathrm{eq}}=3.3 \times 10^{3} \mathrm{M}^{-1}$, presumably at room temperature at ionic strength ranging from quite

\section{Discussion} order rate constant for decay of $\mathrm{Br}_{2}{ }^{\bullet-}$.

$$
K_{\mathrm{eq}}=(1.7 \pm 0.7) \times 10^{4} \mathrm{M}^{-1} \text { at } 25^{\circ} \mathrm{C} \text { and various ionic strengths [2], from the kinetics of }
$$
formation of $\mathrm{Br}_{2}{ }^{\bullet-}$ as a function of $\left[\mathrm{Br}^{-}\right]$in the flash photolysis of solutions of $\mathrm{Br}_{2}$ in $0.12 \mathrm{M}$ $\mathrm{HClO}_{4}$ and of $1.4 \mathrm{mM} \mathrm{C}_{6} \mathrm{H}_{5} \mathrm{Br}$.

$K_{\text {eq }}=(1.1 \pm 0.3) \times 10^{5} \mathrm{M}^{-1}$, at $(24 \pm 2){ }^{\circ} \mathrm{C}$ and low ionic strength [3]. Result obtained by pulse radiolysis determination of the equilibrium absorbance of $\mathrm{Br}_{2}{ }^{\bullet-}$ as a function of [Br ${ }^{-}$.

$$
K_{\mathrm{eq}}=3.1 \times 10^{3} \mathrm{M}^{-1} \text {, at } 288 \mathrm{~K} \text { and low ionic strength [4]. Result obtained by a flash }
$$
photolysis of $\mathrm{Br}^{-}$with conductivity detection. They obtained the rate of dissociation of $\mathrm{Br}_{2}{ }^{--}$by fitting the kinetic traces with a complex mechanism. We calculate the equilibrium constant here from the ratio of the forward and reverse rate constants given in the paper.

$$
K_{\text {eq }}=2.2 \times 10^{5} \mathrm{M}^{-1} \text {, presumably at room temperature and low ionic strength [5]. }
$$

\section{Obtained by pulse radiolysis of $N$-bromosuccinimide [IUPAC PIN: 1-bromopyrrolidine-2,5-} dione], from the ratio of $k_{\mathrm{f}}$ and $k_{\mathrm{r}}$ for formation of $\mathrm{Br}_{2}{ }^{\bullet-}$.

$$
K_{\mathrm{eq}}=6 \times 10^{5} \mathrm{M}^{-1} \text { at } 25^{\circ} \mathrm{C} \text { and } \mu \sim 0.1 \mathrm{M} \text { [6]. Obtained from by pulse radiolysis of } \mathrm{Br}^{-}
$$
solutions, measuring the equilibrium $\mathrm{Br}_{2}{ }^{\bullet-}$ concentration. Also obtained from steady-state gamma radiolysis of $\mathrm{Br}^{-}$/oxalic acid solutions, by measuring the $\mathrm{CO}_{2}$ yield. The equilibrium constant inferred here was obtained by interpolation of a graph of $K_{\text {eq }}$ vs $T$.

$$
K_{\text {eq }}=6 \times 10^{5} \mathrm{M}^{-1} \text { at room temperature [7]. Pulse radiolysis of 1,2-dibromoethane was }
$$
used to generate $\mathrm{Br}_{2}{ }^{--}$through the direct reaction of $\mathrm{e}^{-}(a q)$ with $\mathrm{C}_{2} \mathrm{Br}_{2} \mathrm{H}_{4}$; the decay of $\mathrm{Br}_{2}{ }^{\bullet-}$ in the presence of 1-2 M propan-2-ol yielded $k_{\mathrm{r}}=1.9 \times 10^{4} \mathrm{~s}^{-1}$. A value for $k_{\mathrm{f}}$ of $1.2 \times 10^{10} \mathrm{M}^{-1} \mathrm{~s}^{-1}$ was then used to determine $K_{\text {eq }}$ from $k_{\mathrm{f}} / k_{\mathrm{r}}$.

$$
K_{\text {eq }}=(3.9 \pm 1.2) \times 10^{5} \mathrm{M}^{-1} \text { at } 298 \mathrm{~K} \text { and low ionic strength [8]. Flash photolysis of }
$$
aqueous 1,2-dibromoethane in $\mathrm{Br}^{-}$solutions was used to generate $\mathrm{Br}^{\bullet}$ atoms. The equilibrium constant was obtained from the ratio of $k_{\mathrm{f}}$ to $k_{\mathrm{r}}$, the two rate constants being obtained from the kinetics of formation of $\mathrm{Br}_{2}{ }^{\bullet-}$ as a function of $\left[\mathrm{Br}^{-}\right]$. 
A wide range of values has been reported for $K_{\text {eq. }}$. In the earlier studies the results seemed to cluster with low values for the flash-photolysis experiments and high values for the pulse radiolysis experiments. However, the latest flash photolysis result is in the range of the pulse radiolysis results, which leads us to believe that the early low results of Wong et al. [1] and 3083 Treinin et al. [2] may be disregarded.

3084 Wagner and Strehlow [4] have pointed out that the result of Wong et al. [1] is probably the consequence of neglecting reactions of the solvated electron [4]. On the other hand, the result from Wagner and Strehlow [4] is rather similar to that of Wong et al. [1] and is also likely incorrect. The lower temperature in this study is unlikely to be the source of the discrepancy, in view of the temperature dependence reported by Kosanic [6]. In a personal communication from John Barker to Stanbury (Jan. 2005) is was suggested that the results reported by Wagner and Strehlow [4] might be incorrect because Runga Kutta integration was used to fit the data, while a more robust integrator should have been used. He also mentions the greater complexity of the Wagner and Strehlow mechanism, which is a consequence of the solvated electrons generated by bromide photolysis. Also, the high radical concentrations generated $\left(\mathrm{ca} \cdot 10^{-6}-10^{-4} \mathrm{M}\right)$ mean that second-order processes will affect the results more strongly.

Kosanic's result is notable in providing the temperature dependence of $K_{\text {eq }}$, from which $\Delta H^{\circ}$ for the reaction was derived.

The most recent result, from Barker's group, appears to be the most carefully conducted and analyzed, and accordingly we select it for recommendation. Their stated uncertainty comes close to encoMPasing the other reports.

\section{Recommended value:}

List of auxiliary thermodynamic data: none.

Nomenclature: see Data Sheet 26.

$$
K_{\text {eq }}=(3.9 \pm 1.2) \times 10^{5} \mathrm{M}^{-1}
$$

3111 1. D. Wong, B. Di Bartolo. J. Photochem. 4, 249-268 (1975).

3112 2. A. Treinin, E. Hayon. J. Am. Chem. Soc. 97, 1716-1721 (1975).

3113 3. A. Mamou, J. Rabani, D. Behar. J. Phys. Chem. 81, 1447-1448 (1977).

3114 4. I. Wagner, H. Strehlow. Ber. Bunsenges. Phys. Chem. 91, 1317-1321 (1987). 
3115 5. J. Lind, X. Sen, T. E. Eriksen, G. Merényi, L. Eberson. J. Am. Chem. Soc. 113, 4629$31164633(1991)$.

3117 6. M. M. Kosanic. J. Serb. Chem. Soc. 58, 55-62 (1993).

3118 7. G. Merényi, J. Lind. J. Am. Chem. Soc. 116, 7872-7876 (1994).

3119 8. Y. Liu, A. S. Pimentel, Y. Antoku, B. J. Giles, J. R. Barker. J. Phys. Chem. A 106, $3120 \quad 11075-11082(2002)$.

3121

3122 


\section{$3123 \quad$ Data Sheet 34}

3125 Chemical equilibrium: $\mathrm{HO}^{\bullet}+\mathrm{Br}^{-} \rightleftharpoons \mathrm{BrOH}^{\bullet}$

\section{List of reports:} pulse radiolysis with a combination of competition yields and kinetics as described in the evaluation of reaction $5.02\left(\mathrm{BrOH}^{\bullet^{-}} \rightleftharpoons \mathrm{Br}^{\bullet}(a q)+\mathrm{OH}^{-}\right)$. strength [2]. Obtained by pulse radiolysis of $\mathrm{Br}^{-}$solutions from the absorbance of $\mathrm{Br}_{2}{ }^{\bullet-}$ as a

3134 function of $\left[\mathrm{Br}^{-}\right]$and $\left[\mathrm{HO}^{-}\right]$.

\section{Discussion}

Given the major disagreement between the first two determinations of $K_{\text {eq }}$, Mamou et al. measured two related equilibrium constants to calculate a value for $K_{\text {eq }}$ [3]; their results supports the original result of Zehavi et al.

The magnitude of $K_{\mathrm{eq}}$ is not expected to depend significantly on ionic strength. Although $K_{\text {eq }}$ was measured by Zehavi and Rabani in solutions having a wide range of ionic strengths, this should not be a serious consideration.

\section{Recommended value:}

$$
\log K_{\text {eq }}=(2.5 \pm 0.3)
$$

List of auxiliary thermodynamic data: none.

Nomenclature: See Data Sheet 26.

\section{References}

3157 1. D. Zehavi, J. Rabani. J. Phys. Chem. 76, 312-319 (1972).

3158 2. D. Behar. J. Phys. Chem. 76, 1815-1818 (1972). 
3159 3. A. Mamou, J. Rabani, D. Behar. J. Phys. Chem. 81, 1447-1448 (1977).

3160

3161 


\section{Data Sheet 35}

3164 Chemical equilibrium: $\mathrm{BrOH}^{0^{-}}+\mathrm{Br}^{-} \rightleftharpoons \mathrm{Br}_{2}^{{ }^{-}}+\mathrm{OH}^{-}$

\section{List of reports:}

$K_{\mathrm{eq}}=(3.7 \pm 1.5)$ and 4.35 , presumably at room temperature and low ionic strength [1].

3169 Obtained by pulse radiolysis of $\mathrm{Br}^{-}$solutions from the equilibrium absorbance of $\mathrm{Br}_{2}{ }^{--}$as a

3170 function of $\left[\mathrm{Br}^{-}\right]$and $\left[\mathrm{HO}^{-}\right]$.

$$
K_{\text {eq }}=(70 \pm 30) \text {, at }(24 \pm 2)^{\circ} \mathrm{C} \text { and low ionic strength [2]. Obtained by pulse radiolysis of }
$$

$3172 \mathrm{Br}^{-}$solutions from the equilibrium absorbance arising from $\mathrm{Br}_{2}{ }^{\circ}$ and $\mathrm{BrOH}^{-}$.

\section{Discussion} recommend the result of Mamou et al. [2].

\section{Recommended value:}

$$
K_{\text {eq }}=(0.7 \pm 0.3) \times 10^{2}
$$

3184 List of auxiliary thermodynamic data: none.

3186 Nomenclature: See Data Sheet 26.

\section{References}

1. D. Behar. J. Phys. Chem. 76, 1815-1818 (1972).

3191

2.

A. Mamou, J. Rabani, D.

D. Behar. J. Phys. Chem. 81, 1447-1448 (1977).

3192

3193 


\section{Data Sheet 36}

3196 Chemical equilibrium: $\mathrm{BrSCN}^{-}+\mathrm{Br}^{-} \rightleftharpoons \mathrm{Br}_{2}{ }^{--}+\mathrm{SCN}^{-}$

\section{List of reports:}

$K_{\text {eq }}=1 \times 10^{-3}$, presumably at room temperature with ionic strength ranging from low up 3202 to $2 \mathrm{M}$ [1]. Obtained by pulse radiolysis with optical detection, measuring the position of

\section{Discussion}

The experiments appear to be well performed, and we see no reason to object to the results. The authors do not specify any range of uncertainty, but we suggest a factor of three, 3208 given the nature of the data.

\section{Recommended value:}

$$
K_{\text {eq }}=1 \times 10^{-3} \text { within the range of } 03 \text { to } 3 \text {. }
$$

3214 List of auxiliary thermodynamic data: none.

3215

3216 Nomenclature: See Data Sheet 26.

\section{References}




\section{$3223 \quad$ Data Sheet 37}

3225 Chemical equilibrium: $\mathrm{BrSCN}^{\bullet^{-}}+\mathrm{SCN}^{-} \rightleftharpoons(\mathrm{SCN})_{2}{ }^{--}+\mathrm{Br}^{-}$

\section{List of reports:} equilibrium.

\section{Discussion} results. The authors do not specify any range of uncertainty, but we suggest $\pm 50 \%$, given the 3237 nature of the data.

\section{Recommended value:}

$$
K_{\text {eq }}=(1.1 \pm 0.6) \times 10^{2} \text {. }
$$

3243 List of auxiliary thermodynamic data: none.

3245 Nomenclature: See Data Sheet 26. $(\mathrm{SCN})_{2}{ }^{\bullet-}$, bis(nitridosulfidocarbonate $)(S-S)(\bullet 1-)$.

\section{References}

3249 1. M. Schöneshöfer, A. Henglein. Ber. Bunsen-Ges. Phys. Chem. 73, 289-293 (1969). 


\section{$3252 \quad$ Data Sheet 38}

3253 Subject: Bromidodimethylsulfur $(\bullet)$ (Dimethyl sulfide radical cation-bromide complex)

3254 Couple type: $\mathrm{R}_{2} \mathrm{~S}-\mathrm{Br} / \mathrm{R}_{2} \mathrm{~S}, \mathrm{Br}^{-},\left(\mathrm{R}=-\mathrm{CH}_{3}\right)$.

3255 Solvent: Water

3256

3257

3258

3259

3260

3261

3262

3263

3264

3265

3266

3267

3268

3269

3270

3271

3272

3273

3274

3275

3276

3277

Method: Calculation in reference [1] from pulse radiolysis data in reference [2] and $E^{\mathrm{O}}\left(\mathrm{Br}_{2}{ }^{-}\right.$ $\left./ 2 \mathrm{Br}^{-}\right)$:

Equilibria: (i) $\mathrm{R}_{2} \mathrm{~S}+\mathrm{Br}_{2}{ }^{--} \rightleftharpoons \mathrm{R}_{2} \mathrm{~S} \bullet \cdot \mathrm{Br}+\mathrm{Br}^{-}$;

$K=1.1 \times 10^{4} . \quad$ Error limit in $K$ stated $\leq 2 \times$.

(ii) $\mathrm{Br}_{2}{ }^{--}+\mathrm{e}^{-} \rightleftharpoons 2 \mathrm{Br}^{-}$; $\quad E^{0}=+(1.63 \pm 0.02) \mathrm{V}$

(ii) - (i) $\mathrm{R}_{2} \mathrm{~S} \bullet \bullet \mathrm{Br}+\mathrm{e}^{-} \rightleftharpoons \mathrm{R}_{2} \mathrm{~S}+\mathrm{Br}^{-} ; \quad E^{\mathrm{o}}=+(1.39 \pm 0.03) \mathrm{V}$

Reference: $E^{\mathrm{o}}\left(\mathrm{Br}_{2}{ }^{--} / 2 \mathrm{Br}^{-}\right)$.

Temperature: $(293 \pm 2) \mathrm{K}$. Ionic strength effects estimated: No.

Corrected equilibrium constant given: No.

Reference standard potential assumed: $E^{0}=+(1.63 \pm 0.03) \mathrm{V}$

\section{Discussion}

No correction needed for ionic strength. Equilibrium (i) has charge symmetry and therefore the Debye-Hückel corrections will cancel. (ii) is a standard potential.

Recalculation under the assumption of a $100 \%$ error limit in $K$ gives: $(1.39 \pm 0.03) \mathrm{V}$ vs NHE.

\section{Recommended value:}

$E^{\circ}\left(\mathrm{R}_{2} \mathrm{~S}-\mathrm{Br} / \mathrm{R}_{2} \mathrm{~S}, \mathrm{Br}^{-}\right),\left(\mathrm{R}=-\mathrm{CH}_{3}\right)=+(1.39 \pm 0.03) \mathrm{V}$ vs NHE.

3278

3279

Nomenclature: See Data Sheet 26.

3280

3281

3282

3283

3284

1. Armstrong, D. A. In S-Centered Radicals, (Alfassi, Z. B., ed.), p. 27-61. John Wiley \&

References 


\section{Data Sheet 39}

Subject: Bromidodimethylsulfur( $\bullet$ ) (Dimethyl sulfide dimer radical cation).

Couple type: $\mathrm{R}_{2} \mathrm{~S} \bullet \bullet \mathrm{R}_{2} \mathrm{~S}^{+} / 2 \mathrm{R}_{2} \mathrm{~S},\left(\mathrm{R}=-\mathrm{CH}_{3}\right)$

Solvent: Water

Method 1: Pulse radiolysis

$$
K=1.1 \times 10^{4}
$$

(ii) $\mathrm{R}_{2} \mathrm{~S} \bullet \bullet \mathrm{Br}+\mathrm{R}_{2} \mathrm{~S} \rightleftharpoons \mathrm{R}_{2} \mathrm{~S} \bullet \bullet \mathrm{R}_{2} \mathrm{~S}^{+}+\mathrm{Br}^{-}$;

$$
K=1.64
$$

Error limit in $K \mathrm{~s} \leq$ factor of 2 .

Calculated in reference [2] :

$$
\begin{gathered}
\text { (i) }+ \text { (ii) } 2 \mathrm{R}_{2} \mathrm{~S}+\mathrm{Br}_{2}{ }^{--} \rightleftharpoons \mathrm{R}_{2} \mathrm{~S} \bullet \bullet \mathrm{R}_{2} \mathrm{~S}^{+}+2 \mathrm{Br}^{-} ; \\
K=1.8 \times 10^{4}
\end{gathered}
$$

Reference: $\mathrm{Br}_{2}{ }^{--}+\mathrm{e}^{-} \rightleftharpoons 2 \mathrm{Br}^{-}$;

Other solutes: Bromide salt.

Gas: $\mathrm{N}_{2} \mathrm{O} \quad$ Buffer: Not stated in [1].

pH $=$ Not stated. Temperature: $293 \pm 2 \mathrm{~K}$. Ionic strength: ?? M

Uncorrected equilibrium constant from concentrations: $1.8 \times 10^{4}$

Ionic strength effects estimated: No.

Observed equilibrium constant/measurement corresponds to $\Delta E=(0.249 \pm 0.03) \mathrm{V}$

Reference standard potential assumed: $E^{\mathrm{o}}=+1.62 \mathrm{~V}$

Standard potential of couple indicated in reference [2]: $+1.37 \mathrm{~V}$ vs NHE

Method 2: Pulse radiolysis

Solvent: Water

Measurements by electron transfer equilibria in reference [2] :

Equilibrium: $\mathrm{R}_{2} \mathrm{~S} \bullet \bullet \mathrm{R}_{2} \mathrm{~S}^{\bullet+}+\mathrm{N}_{3}^{-} \rightleftharpoons 2 \mathrm{R}_{2} \mathrm{~S}+\mathrm{N}_{3} \bullet$

$$
K=16.4 \mathrm{~mol} \mathrm{dm}^{-3} \text {. }
$$

$3320 \quad \mathbf{p H}=$ Not stated Temperature: $\sim 295 \mathrm{~K}$. Ionic strength: 0.1 ??M

3321 Ionic strength effects estimated: No.

3322 Observed equilibrium constant/measurement corresponds to $\Delta \boldsymbol{E}=\left(0.07_{1} \pm 0.03\right) \mathrm{V}$

3323 Reference standard potential assumed: $E^{\mathrm{o}}=+(1.33 \pm 0.03) \mathrm{V}$ 
3324 Standard potential of couple indicated in reference [2]: $+1.40 \mathrm{~V} v \mathrm{~s}$ NHE

3325

\section{Discussion}

3328 There are sufficient experimental details available to evaluate the data.

3329 Calculation from method 1: (1.37 V $\pm \mathbf{0 . 0 4})$ (Error in $K$ s taken as $\pm 100 \%)$.

3330 Calculation from method 2: $(1.40 \mathrm{~V} \pm \mathbf{0 . 0 2})$ (Error in $K$ s taken as $\pm 50 \%$; probably

3331 generous as $\left.K_{(\mathrm{Kin})}=\mathbf{1 2 . 5}\right)$. Method 2 is more direct and therefore weighted more heavily.

3332 Correction desirable for ionic strength effects: The magnitude of the errors should be checked

3333 for both methods, but exact corrections are probably impractical due to lack of data.

$E^{\circ}\left(\mathrm{R}_{2} \mathrm{~S} \bullet \bullet \mathrm{R}_{2} \mathrm{~S}^{+} / 2 \mathrm{R}_{2} \mathrm{~S}\right),\left(\mathrm{R}=-\mathrm{CH}_{3}\right)=+1.39 \mathrm{~V} \pm 0.03 \mathrm{~V}$

3339 Nomenclature: See Data Sheet 26.

\section{References}

3343 1. M. Bonifacic, K.-D. Asmus. J. Chem. Soc., Perkin Trans. II 758-762 (1980).

3344 2. G. Merényi, J. Lind, L. Engman. J. Phys. Chem. 100, 8875-8881 (1996). 


\section{Data Sheet 40}

\section{Summary of the $\mathrm{BrO}_{2}{ }^{\bullet}$ System}

Tabulated below are the presently recommended equilibrium constants involving the $\mathrm{BrO}_{2}{ }^{\bullet}$ radical. Uncertainties are expressed as $\pm 1 \sigma$; in many cases the value of $\sigma$ is merely a subjective guess.

\begin{tabular}{|c|c|c|c|c|c|}
\hline reaction & $K_{\mathrm{eq}}$ & dim. & uncertainty & $\mu, \mathrm{M}$ & Data Sheet \# \\
\hline $\mathrm{ClO}_{2}{ }^{\bullet}+\mathrm{BrO}_{2}^{-} \rightleftharpoons \mathrm{ClO}_{2}^{-}+\mathrm{BrO}_{2}^{\bullet}$ & $1.0 \times 10^{-6}$ & & $0.1 \times 10^{-6}$ & 0 & 41 \\
\hline $\mathrm{HBrO}_{2}+\mathrm{BrO}_{3}^{-}+\mathrm{H}^{+} \rightleftharpoons 2 \mathrm{BrO}_{2}{ }^{-}+$ & $1 \times 10^{-6}$ & $\mathrm{M}^{-1}$ & $(0.5-2) \times$ & 0 & 42 \\
\hline $\mathrm{H}_{2} \mathrm{O}$ & & & $10^{-6}$ & & \\
\hline $\mathrm{Br}_{2} \mathrm{O}_{4} \rightleftharpoons 2 \mathrm{BrO}_{2}$ & $5.3 \times 10^{-5}$ & $\mathrm{M}$ & $1.1 \times 10^{-5}$ & 0.01 & 43 \\
\hline $\begin{array}{l}\mathrm{Ce}(\mathrm{III})+\mathrm{BrO}_{2}^{\bullet}(a q)+\mathrm{H}^{+} \rightleftharpoons \mathrm{Ce}(\mathrm{IV}) \\
+\mathrm{HBrO}_{2}(a q)\end{array}$ & 7 & $\mathbf{M}^{-1}$ & 2 & 1 & 44 \\
\hline
\end{tabular}

From reaction 41.1 (see below) and our recommended $E^{\circ}$ for $\mathrm{ClO}_{2}{ }^{\bullet}$ we derive $E^{\circ}=+(1.290 \pm$ 0.005) $\mathrm{V}$ for $\mathrm{BrO}_{2} \bullet / \mathrm{BrO}_{2}^{-}$. From reaction 42.1 and other data we derive $E^{\circ}=+(1.260 \pm 0.024) \mathrm{V}$ 3357 for the $\mathrm{BrO}_{2}{ }^{\bullet} / \mathrm{BrO}_{2}^{-}$couple These two completely independent determinations of $E^{\circ}$ agree within 3358 their uncertainties. Overall, we recommend the value derived from reaction 41.1 because of its 3359 smaller uncertainty and because the result from reaction 42.1 was derived with a large extrapolation from data at high $(1.0 \mathrm{M})$ ionic strength. This result leads to $\Delta_{\mathrm{f}} G^{\circ}=+(152 \pm 4) \mathrm{kJ}$ $\mathrm{mol}^{-1}$ for $\mathrm{BrO}_{2}{ }^{\bullet}(a q)$. Formal potentials at $\mu=1 \mathrm{M}$ are derived from reaction 44.1 and are in good agreement with that derived from reaction 41.1 .

\section{Recommended values:}

$$
\mathrm{BrO}_{2} \cdot(a q)+\mathrm{e}^{-} \rightleftharpoons \mathrm{BrO}_{2}^{-}(a q) \quad E^{\circ}=+(1.290 \pm 0.005) \mathrm{V}
$$

$$
\mathrm{BrO}_{2}{ }^{\circ}(a q)+\mathrm{H}^{+}+\mathrm{e}^{-} \rightleftharpoons \mathrm{HBrO}_{2} \quad E^{\circ \prime}=+(1.49 \pm 0.01) \mathrm{V} \text { at } 20^{\circ} \mathrm{C} \text { in } 1 \mathrm{M} \mathrm{H}_{2} \mathrm{SO}_{4}
$$

$\Delta_{\mathrm{f}} G^{\circ}\left(\mathrm{BrO}_{2}^{\bullet}(a q)\right)=+(152 \pm 4) \mathrm{kJ} \mathrm{mol}^{-1}$ 


\section{Data Sheet 41}

Chemical equilibrium: $\mathrm{ClO}_{2}{ }^{\bullet}+\mathrm{BrO}_{2}^{-} \rightleftharpoons \mathrm{ClO}_{2}^{-}+\mathrm{BrO}_{2}{ }^{\bullet}$

\section{List of reports:}

$K_{\text {eq }}=1.0 \times 10^{-6}[1]$. Result obtained from the ratio of the forward and reverse rate constants. The forward rate constant was obtained from a stopped-flow study of the reaction of $\mathrm{ClO}_{2}{ }^{\circ}$ with $\mathrm{BrO}_{2}{ }^{-}$at $25.0^{\circ} \mathrm{C}$ and $\mu=1.0 \mathrm{M}$ [1]. The reverse rate constant was obtained by pulse radiolysis, presumably at room temperature at an unspecified ionic strength [2].

\section{Discussion}

As the reverse rate constant is expected to be independent of ionic strength, the calculation of $K_{\text {eq }}$ is not seriously compromised. $K_{\text {eq }}$ should also be independent of ionic strength. The reverse rate constant is rather large $\left(3.6 \times 10^{7} \mathrm{M}^{-1} \mathrm{~s}^{-1}\right)$ and hence should not be very temperature dependent. A $6 \%$ uncertainty was assigned to the forward rate constant. We suggest a $10 \%$ uncertainty for the reverse rate constant. Thus, the uncertainty in $K_{\text {eq }}$ is about $10 \%$.

Given our recommended value of $E^{\circ}=+(0.935 \pm 0.003) \mathrm{V}$ for $\mathrm{ClO}_{2}{ }^{\bullet} \mathrm{ClO}_{2}{ }^{-}$, we thus derive $E^{\circ}=+(1.290 \pm 0.005) \mathrm{V}$ for the couple $\mathrm{BrO}_{2}{ }^{\bullet} / \mathrm{BrO}_{2}{ }^{-}$. Prior estimates of this quantity are considered to be much less reliable.

Although not given in the NIST tables [3], the value for $\Delta_{\mathrm{f}} G^{\circ}\left(=+27.2 \mathrm{~kJ} \mathrm{~mol}^{-1}\right)$ for $\mathrm{BrO}_{2}^{-}$given by Lee and Lister seems widely accepted $[4,5]$. We suggest that the uncertainty in Lee and Lister's result is $\pm 4 \mathrm{~kJ}$. Thus we derive $\Delta_{\mathrm{f}} G^{\circ}=+(152 \pm 4) \mathrm{kJ} \mathrm{mol}^{-1}$ for $\mathrm{BrO}_{2}{ }^{\bullet}$.

\section{Recommended values:}

$K_{\text {eq }}=(1.0 \pm 0.1) \times 10^{-6}$ at $25^{\circ} \mathrm{C}$ and $\mu=0.0 \mathrm{M}$.

3401

$E^{\circ}\left(\mathrm{BrO}_{2} \bullet / \mathrm{BrO}_{2}^{-}\right)=+(1.290 \pm 0.005) \mathrm{V}$

$\Delta_{\mathrm{f}} G^{\circ}\left(\mathrm{BrO}_{2}^{\bullet}\right)=+(152 \pm 4) \mathrm{kJ} \mathrm{mol}^{-1}$

Nomenclature: see Data Sheet 40. 


\section{References}

3409

$3410 \quad$ 1. $\quad$ L. Wang, J. S. Nicoson, K. E. H. Hartz, J. S. Francisco, D. W. Margerum. Inorg. Chem.

3411 41, 108-113 (2002).

3412 2. R. E. Huie, P. Neta. J. Phys. Chem. 90, 1193-1198 (1986).

3413 3. D. D. Wagman, W. H. Evans, V. B. Parker, R. H. Schumm, I. Halow, S. M. Bailey, K. L.

3414 Churney, R. L. Nuttall. J. Phys. Chem. Ref. Data 11, Suppl. No. 2 (1982).

3415 4. C. L. Lee, M. W. Lister. Can. J. Chem. 49, 2822-2826 (1971).

3416 5. D. M. Stanbury. Adv. Inorg. Chem. 33, 69-138 (1989). 


\section{Data Sheet 42}

3422 Chemical equilibrium: $\mathrm{HBrO}_{2}+\mathrm{BrO}_{3}^{-}+\mathrm{H}^{+} \rightleftharpoons 2 \mathrm{BrO}_{2}{ }^{\bullet}+\mathrm{H}_{2} \mathrm{O}$

\section{List of reports:}

1) $K_{\text {eq }}=5 \times 10^{-4} \mathrm{M}^{-1}[1]$. We calculate this from the forward and reverse rate constants selected by Field et al. (1972). The forward rate was assumed to be twice the rate of isotopic exchange between $\mathrm{Br}_{2}$ and $\mathrm{BrO}_{3}{ }^{-}$as reported by Betts and MacKenzie (1951) [2], and the rate constant was calculated by assuming a mechanism with rate-limiting exchange between $\mathrm{HBrO}_{2}$ and $\mathrm{BrO}_{3}{ }^{-}$; the concentration of $\mathrm{HBrO}_{2}$ used in this calculation was based on a $\mathrm{p} K_{\mathrm{a}}$ for $\mathrm{HBrO}_{2}$ that is now known to be in error [3]. The reverse rate constant was from the pulse radiolysis study of Buxton and Dainton [4].

2) $K_{\text {eq }}=1 \times 10^{-6} \mathrm{M}^{-1}$, in $1 \mathrm{M} \mathrm{H}_{2} \mathrm{SO}_{4}$ at $20.0^{\circ} \mathrm{C}$ [5]. Calculated by Field and Försterling [5] from the data of Försterling et al. (1980), originally thought to refer to the dimerization equilibrium of $\mathrm{BrO}_{2}{ }^{\bullet}$ [6]. The experimental data were the equilibrium absorbances due to $\mathrm{BrO}_{2}{ }^{\bullet}$ in acidic mixtures of $\mathrm{HBrO}_{2}$ and $\mathrm{BrO}_{3}^{-}$.

3) $K_{\text {eq }}=0.9 \times 10^{-6} \mathrm{M}^{-1}$, in $1 \mathrm{M} \mathrm{H}_{2} \mathrm{SO}_{4}$ at $20.0^{\circ} \mathrm{C}$ [5]. Obtained from the kinetics of decay of $\mathrm{BrO}_{2}{ }^{\bullet}$ in an acidic $\mathrm{HBrO}_{2} / \mathrm{BrO}_{3}{ }^{-}$mixture; the calculation is directly dependent on the value for the $k$ of $\mathrm{HBrO}_{2}$ disproportionation, which was reported by other workers.

4) $K_{\text {eq }}=8.0 \times 10^{-7} \mathrm{M}^{-1}[7]$. We calculate this equilibrium constant from the forward and reverse rate constants of the two component reactions as summarized by Gao and Försterling [7]:

$$
\begin{array}{ll}
\mathrm{HBrO}_{2}+\mathrm{BrO}_{3}{ }^{-}+\mathrm{H}^{+} \rightleftharpoons \mathrm{Br}_{2} \mathrm{O}_{4}+\mathrm{H}_{2} \mathrm{O} & k_{5}, k_{-5}, K_{5}, \\
\mathrm{Br}_{2} \mathrm{O}_{4} \rightleftharpoons 2 \mathrm{BrO}_{2}{ }^{\bullet} & k_{5},, k_{-5}, K_{5},
\end{array}
$$

3446 We use here the authors' rate constant numbering scheme. Gao and Försterling [7] measured the value for $k_{5}$, and used values for the other three rate constants as recommended by Field and

3448 Försterling (1986) [5]. These authors obtained their values for $k_{5}$ " and $k_{-5}$ " from the pulse radiolysis results of Buxton and Dainton (1968) [4]. They obtained the value for $k_{-5}$ by

3450 combining their values for $K_{\text {eq }}, k_{5}$ ", $k_{-5}$ " and $k_{5}$. Their value for $k_{5}$, was obtained from the kinetics 3451 of the oxidation of $\mathrm{Ce}(\mathrm{III})$ with $\mathrm{BrO}_{3}{ }^{-}$and from an assumed value for $k_{4}\left(\mathrm{HBrO}_{2}\right.$

3452 disproportionation). We conclude that this procedure leads to circularity in the argument, since 3453 there is no independent determination of $k-5$. 
5) $\quad K_{\mathrm{eq}}=2.2 \times 10^{-6} \mathrm{M}^{-1}$. We calculate this result from the value for $2 k_{-5^{\circ}} / K_{5^{\prime \prime}}\left(=4.3 \times 10^{7} \mathrm{M}^{-}\right.$ ${ }^{1} \mathrm{~s}^{-1}$ at room temperature and $\mu=0.01 \mathrm{M}$ ) reported by Buxton and Dainton [4] and the value for $k_{5},\left(=48 \mathrm{M}^{-2} \mathrm{~s}^{-1}\right.$ in $1 \mathrm{M} \mathrm{H}_{2} \mathrm{SO}_{4}$ at $\left.20.0{ }^{\circ} \mathrm{C}\right)$ measured by Gao and Försterling [7].

\section{Discussion}

We exclude determinations $\# 1$ and \#4 for the reasons mentioned above. The remaining three determinations of $K_{\mathrm{eq}}(\# 2,3$, and 5) are based on fundamentally different methods and yield essentially the same result. However, as many of the experiments were conducted in $1 \mathrm{M} \mathrm{H}_{2} \mathrm{SO}_{4}$ and at $20^{\circ} \mathrm{C}$, it is difficult to specify an accurate value for $K_{\text {eq }}$ at $25^{\circ} \mathrm{C}$ and $\mu=0 \mathrm{M}$. We tentatively recommend a value of $K_{\mathrm{eq}}=1 \times 10^{-6} \mathrm{M}^{-1}$ with an uncertainty of a factor of 2 at $25^{\circ} \mathrm{C}$ and $\mu=0 \mathrm{M}$.

NIST values [8] are lacking for $\Delta_{\mathrm{f}} G^{\circ}$ for $\mathrm{BrO}_{2}{ }^{\bullet}, \mathrm{HBrO}_{2}$ and $\mathrm{BrO}_{2}{ }^{-}$, while the corresponding values are $-(237.13 \pm 0.08)$ for $\mathrm{H}_{2} \mathrm{O}$ and $+(18.6 \pm 0.8) \mathrm{kJ} \mathrm{mol}^{-1}$ for $\mathrm{BrO}_{3}{ }^{-}$[8].

From the title reaction we derive

$$
2 \Delta_{\mathrm{f}} G^{\circ}\left(\mathrm{BrO}_{2}{ }^{\bullet}\right)-\Delta_{\mathrm{f}} G^{\circ}\left(\mathrm{HBrO}_{2}\right)=-R T \ln K_{\mathrm{eq}}-\Delta_{\mathrm{f}} G^{\circ}\left(\mathrm{H}_{2} \mathrm{O}\right)+\Delta_{\mathrm{f}} G^{\circ}\left(\mathrm{BrO}_{3}{ }^{-}\right)
$$

and with our recomended value for $K_{\text {eq }}$ we obtain

$$
2 \Delta_{\mathrm{f}} G^{\circ}\left(\mathrm{BrO}_{2}{ }^{\circ}\right)-\Delta_{\mathrm{f}} G^{\circ}\left(\mathrm{HBrO}_{2}\right)=(290.0 \pm 2.3) \mathrm{kJ} \mathrm{mol}^{-1}
$$

The value for $\Delta_{\mathrm{f}} G^{\circ}\left(=+27.2 \mathrm{~kJ} \mathrm{~mol}^{-1}\right)$ for $\mathrm{BrO}_{2}^{-}$given by Lee and Lister [9] seems widely accepted, and we suggest that the uncertainty is $\pm 4 \mathrm{~kJ}[9,10]$. The $K_{\mathrm{a}}$ of $\mathrm{HBrO}_{2}$ is now believed to be $(3.7 \pm 0.9) \times 10^{-4} \mathrm{M}$ at $25.0^{\circ} \mathrm{C}$ and $\mu=0.06 \mathrm{M}$ [3], and thus we derive $\Delta_{\mathrm{f}} G^{\circ}\left(\mathrm{HBrO}_{2}\right)=$ $+(6.8 \pm 4) \mathrm{kJ} \mathrm{mol}^{-1}$. We then derive from the above that $\Delta_{\mathrm{f}} G^{\circ}\left(\mathrm{BrO}_{2}{ }^{\circ}\right)=+(148 \pm 2) \mathrm{kJ} \mathrm{mol}^{-1}$, $E^{\circ}\left(\mathrm{BrO}_{2}{ }^{\bullet}, \mathrm{H}^{+} / \mathrm{HBrO}_{2}\right)=+(1.468 \pm 0.024) \mathrm{V}$, and $E^{\circ}\left(\mathrm{BrO}_{2} \cdot \mathrm{BrO}_{2}{ }^{-}\right)=+(1.260 \pm 0.024) \mathrm{V}$.

\section{Recommended values:}

$K_{\text {eq }}=1 \times 10^{-6} \mathrm{M}^{-1}$ with an uncertainty of a factor of 2 at $25^{\circ} \mathrm{C}$ and $\mu=0 \mathrm{M}$

$$
\Delta_{\mathrm{f}} G^{\circ}\left(\mathrm{BrO}_{2}{ }^{\bullet}\right)=+(148 \pm 2) \mathrm{kJ} \mathrm{mol}^{-1}
$$

$$
\begin{array}{ll}
\mathrm{BrO}_{2}+\mathrm{H}^{+}+\mathrm{e}^{-} \rightleftharpoons \mathrm{HBrO}_{2} & E^{\circ}=+(1.47 \pm 0.02) \mathrm{V} \\
\mathrm{BrO}_{2}+\mathrm{e}^{-} \rightleftharpoons \mathrm{BrO}_{2}^{-} & E^{\circ}=+(1.26 \pm 0.02) \mathrm{V}
\end{array}
$$




\section{$3491 \quad$ References}

3492

3493 1. R. J. Field, E. Körös, R. M. Noyes. J. Am. Chem. Soc. 94, 8649-8664 (1972).

3494 2. R. H. Betts, A. N. MacKenzie. Can. J. Chem. 29, 655-665 (1951).

3495 3. R. B. Faria, I. R. Epstein, K. Kustin. J. Phys. Chem. 98, 1363-1367 (1994).

3496 4. G. V. Buxton, F. S. Dainton. Proc. Roy. Soc. A (London) 304, 427-439 (1968).

3497 5. R. J. Field, H.-D. Försterling. J. Phys. Chem. 90, 5400-5407 (1986).

3498 6. H.-D. Försterling, H. J. Lamberz, H. Schreiber. Z. Naturforsch. 35a, 1354-1360 (1980).

3499 7. Y. Gao, H.-D. Försterling. J. Phys. Chem. 99, 8638-8644 (1995).

35008 8. D. Wagman, W. H. Evans, V. B. Parker, R. H. Schumm, I. Halow, S. M. Bailey, K. L.

3501 Churney, R. L. Nuttall. J. Phys. Chem. Ref. Data 11, Suppl. No. 2 (1982).

3502 9. C. L. Lee, M. W. Lister. Can. J. Chem. 49, 2822-2826 (1971).

3503 10. D. M. Stanbury. Adv. Inorg. Chem. 33, 69-138 (1989).

3504

3505 


\section{Data Sheet 43}

3508 Chemical equilibrium: $\mathrm{Br}_{2} \mathrm{O}_{4} \rightleftharpoons 2 \mathrm{BrO}_{2}$ •

Nomenclature: see Data sheet 42.

List of auxiliary thermodynamic data: none.

\section{References}

1. G. V. Buxton, F. S. Dainton. Proc. Roy. Soc. A (London) 304, 427-439 (1968).

3539 2. H.-D. Försterling, H. J. Lamberz, H. Schreiber. Z. Naturforsch. 35a, 1354-1360 (1980).

$35403 . \quad$ R. J. Field, H.-D. Försterling. J. Phys. Chem. 90, 5400-5407 (1986).

3541 4. L. Kuhnert, H.-J. Krug, L. Pohlmann. J. Phys. Chem. 89, 2022-2026 (1985). 


\section{Data Sheet 44}

Chemical equilibrium: $\mathrm{Ce}(\mathrm{III})+\mathrm{BrO}_{2}^{\bullet}(a q)+\mathrm{H}^{+} \rightleftharpoons \mathrm{Ce}(\mathrm{IV})+\mathrm{HBrO}_{2}(a q)$

\section{List of reports:}

$$
K_{\text {eq }}=1.5 \mathrm{M}^{-1} \text { at } \mu \sim 1 \mathrm{M} \text { and } \sim 25^{\circ} \mathrm{C} \text {. Calculated here from the ratio of the forward and }
$$
reverse rate constants as summarized by Field and Försterling [1]. The forward reaction was investigated by Försterling et al. at $20{ }^{\circ} \mathrm{C}$ in $1 \mathrm{M} \mathrm{H}_{2} \mathrm{SO}_{4}$ by conventional spectrophotometry [2]; they obtained a rate constant of $(1.0 \pm 0.05) \times 10^{5} \mathrm{M}^{-1} \mathrm{~s}^{-1}$. Note that the rate constant was reported as a second order one: the $\mathrm{pH}$ dependence was not investigated. Field and Forsterling subsequently converted the rate constant to third-order dimensions on the assumption of a firstorder dependence on $\left[\mathrm{H}^{+}\right]$, and they corrected for the effects of the reversibility of the reaction to obtain a forward rate constant of $8 \times 10^{4} \mathrm{M}^{-2} \mathrm{~s}^{-1}$ [1]. The reverse reaction was studied by Sullivan and Thompson at $25{ }^{\circ} \mathrm{C}$ with $0.3 \mathrm{M} \mathrm{NaClO}_{4}$ and $0.3 \mathrm{M} \mathrm{H}_{2} \mathrm{SO}_{4}$ by stopped-flow spectrophotometry; they obtained a reverse rate constant of $5.5 \times 10^{4} \mathrm{M}^{-1} \mathrm{~s}^{-1}$ [3]. However, they [3] were unable to obtain meaningful kinetic results at higher acidities because the reaction did not proceed.

\section{Discussion}

Försterling and Varga [4] reinvestigated the reverse reaction, using a special reactor 3565 Sullivan and Thompson [3]. Försterling and Varga [4] noted a strong dependence of the rate constant on ionic strength, which was attributed to the medium dependence of the distribution between the various $\mathrm{Ce}(\mathrm{IV}) / \mathrm{SO}_{4}{ }^{2-}$ species. At $20^{\circ} \mathrm{C}$ and $1 \mathrm{M} \mathrm{H}_{2} \mathrm{SO}_{4}$ they obtained a reverse rate constant of $1.2 \times 10^{4} \mathrm{M}^{-2} \mathrm{~s}^{-1}$. If we combine this rate constant with the forward rate constant recommended by Field and Försterling [1] $\left(8 \times 10^{4} \mathrm{M}^{-2} \mathrm{~s}^{-1}\right)$, we obtain an equilibrium constant of 6.7 for reaction 44.1 at $20{ }^{\circ} \mathrm{C}$ in $1 \mathrm{M} \mathrm{H}_{2} \mathrm{SO}_{4}$. Given the strong medium effects and other complications we suggest an uncertainty of $\pm 30 \%$ for this result.

Field and Försterling interpreted the $\mathrm{Ce}(\mathrm{III}) / \mathrm{BrO}_{2}{ }^{\bullet}$ reaction by use of $E^{\circ \prime}=1.44 \mathrm{~V}$ for

3574 in $1 \mathrm{M} \mathrm{H}_{2} \mathrm{SO}_{4}$ is recommended in Standard Potentials in Aqueous Solution [5]. We assume an 3575 uncertainty of $\pm 10 \mathrm{mV}$ in this formal potential. This leads to $E^{\circ \prime}=(1.49 \pm 0.01) \mathrm{V}$ for the couple $3576 \quad\left(\mathrm{BrO}_{2}{ }^{\bullet}(a q), \mathrm{H}^{+}\right) / \mathrm{HBrO}_{2}$. 
The $\mathrm{p} K_{\mathrm{a}}$ of $\mathrm{HBrO}_{2}$ is $(3.43 \pm 0.05)$ at $25^{\circ} \mathrm{C}$ and $\mu=0.06 \mathrm{M}$ [6]. No doubt this $\mathrm{p} K_{\mathrm{a}}$

3578 depends significantly on ionic strength, but procedures to extrapolate to $\mu=1 \mathrm{M}$ are unreliable.

3579 However, by working in analogy with the $\mathrm{p} K_{\mathrm{a}}$ of $\mathrm{HClO}_{2}$, we suggest that the $\mathrm{p} K_{\mathrm{a}}$ of $\mathrm{HBrO}_{2}$ is

$3580 \quad(3.16 \pm 0.10)$ at $\mu=1.0 \mathrm{M}$. This leads to $E^{\circ \prime}=(1.30 \pm 0.01) \mathrm{V}$ for $\mathrm{BrO}_{2} \cdot \mathrm{BrO}_{2}{ }^{-}$.

3581

\section{Recommended values:}

$3584 \quad K_{\text {eq }}=(7 \pm 2)$ at $20^{\circ} \mathrm{C}$ in $1 \mathrm{M} \mathrm{H}_{2} \mathrm{SO}_{4}$.

$\mathrm{BrO}_{2}^{\bullet}(a q)+\mathrm{H}^{+}+\mathrm{e}^{-} \rightleftharpoons \mathrm{HBrO}_{2}$

$E^{\circ \prime}=+(1.49 \pm 0.01) \mathrm{V}$ at $20{ }^{\circ} \mathrm{C}$ in $1 \mathrm{M} \mathrm{H}_{2} \mathrm{SO}_{4}$

$\mathrm{BrO}_{2}^{\bullet}(a q)+\mathrm{e}^{-} \rightleftharpoons \mathrm{BrO}_{2}^{-}$

$E^{\circ \mathrm{ol}}=+(1.30 \pm 0.01) \mathrm{V}$ at $20^{\circ} \mathrm{C}$ in $1 \mathrm{M} \mathrm{H}_{2} \mathrm{SO}_{4}$

List of auxiliary thermodynamic data: $E^{\circ \prime}$ for $\mathrm{Ce}(\mathrm{IV}) / \mathrm{Ce}(\mathrm{III}), \mathrm{p} K_{\mathrm{a}}$ for $\mathrm{HBrO}_{2}$.

Nomenclature: see Data Sheet 43.

\section{References}

3594 1. R. J. Field, H.-D. Försterling. J. Phys. Chem. 90, 5400-5407 (1986).

3595 2. H. D. Försterling, H. J. Lamberz, H. Schreiber. Z. Naturforsch. 40a, 368-372 (1985).

3596 3. J. C. Sullivan, R. C. Thompson. Inorg. Chem. 18, 2375-2379 (1979).

3597 4. H.-D. Försterling, M. Varga. J. Phys. Chem. 97, 7932-7938 (1993).

3598 5. A. J. Bard, R. Parsons, J. Jordan. Standard Potentials in Aqueous Solution, Marcel 3599 Dekker, Inc., New York 834 (1985).

3600 6. R. B. Faria, I. R. Epstein, K. Kustin. J. Phys. Chem. 98, 1363-1367 (1994). 


\section{$3603 \quad$ Data Sheet 45}

3604 Summary of the $\mathrm{I} / \mathrm{I}^{\bullet}{ }^{\bullet-}$ System

3605

3606

3607

3608

Tabulated below are the presently recommended equilibrium constants involving this related

3609 group of iodine radicals. Uncertainties are expressed as $\pm 1 \sigma$; in many cases the value of $\sigma$ is merely a subjective guess.

\begin{tabular}{|c|c|c|c|c|c|c|}
\hline $\operatorname{rxn} \#$ & reaction & $K_{\text {eq }}$ & dim. & uncertainty & $\mu / \mathrm{M}$ & $\begin{array}{c}\text { Data Sheet } \\
\quad \#\end{array}$ \\
\hline 46.1 & $\begin{array}{l}2 \mathrm{I}^{-}+\left[\mathrm{Os}(\mathrm{bpy})_{3}\right]^{3+} \rightleftharpoons \\
\mathrm{I}_{2}{ }^{--}+\left[\mathrm{Os}(\mathrm{bpy})_{3}\right]^{2+}\end{array}$ & $3 \times 10^{-4}$ & $\mathrm{M}^{-1}$ & $\pm 1 \times 10^{-4}$ & 0.1 & 46 \\
\hline 47.1 & $\begin{array}{l}\mathrm{I}_{2}(a q)+\mathrm{HO}_{2}^{\bullet} \rightleftharpoons \mathrm{I}_{2}^{\bullet-}+\mathrm{H}^{+}+ \\
\mathrm{O}_{2}(a q)\end{array}$ & 30 & M & \pm 15 & 1.0 & 47 \\
\hline 48.1 & $\mathrm{I}_{2}{ }^{\bullet-}+\mathrm{DMTD}^{2-} \rightleftharpoons \mathrm{DMTD}^{\bullet-}+2 \mathrm{I}^{-}$ & $2.0 \times 10^{3}$ & M & $\pm 0.5 \times 10^{3}$ & 0.2 & 48 \\
\hline 49.1 & $\mathrm{NO}_{2}^{\bullet}+\mathrm{I}^{-} \rightleftharpoons \mathrm{NO}_{2}^{-}+\mathrm{I}^{\bullet}(a q)$ & none & & & & 49 \\
\hline 50.1 & $\mathrm{I}_{2}^{\bullet-}+\mathrm{PZH}^{+} \rightleftharpoons \mathrm{PZH}^{2+}+2 \mathrm{I}^{-}$ & 90 & M & $45-180$ & $\sim 0.1$ & 50 \\
\hline 51.1 & $\mathrm{I}^{\bullet}(a q)+\mathrm{H}_{2} \mathrm{O} \rightleftharpoons \mathrm{IOH}^{\bullet-}+\mathrm{H}^{+}$ & $5 \times 10^{-14}$ & M & $\begin{array}{l}(1.5-15) \times \\
10^{-14}\end{array}$ & 0.1 & 51 \\
\hline 52.1 & $\mathrm{I}^{\bullet}(a q)+\mathrm{I}^{-} \rightleftharpoons \mathrm{I}_{2}^{\bullet-}$ & $\begin{array}{l}1.35 \times \\
10^{5}\end{array}$ & $\mathrm{M}^{-1}$ & $\begin{array}{l} \pm 0.11 \times \\
10^{5}\end{array}$ & Low & 52 \\
\hline 53.1 & $\mathrm{HO}^{\bullet}+\mathrm{I}^{-} \rightleftharpoons \mathrm{IOH}^{\bullet-}$ & $1.2 \times 10^{4}$ & $\mathrm{M}^{-1}$ & $\begin{array}{l}(0.6-2.4) \times \\
10^{-4}\end{array}$ & 10 & 53 \\
\hline 54.1 & $\mathrm{IOH}^{\bullet-}+\mathrm{I}^{-} \rightleftharpoons \mathrm{I}_{2}^{\bullet-}+\mathrm{HO}^{-}$ & $2.5 \times 10^{4}$ & & $\pm 1.2 \times 10^{4}$ & 1.0 & 54 \\
\hline 55.1 & $\mathrm{ISCN}^{\bullet-}+\mathrm{SCN}^{-} \rightleftharpoons(\mathrm{SCN})_{2}^{\bullet-}+\mathrm{I}^{-}$ & $\begin{array}{l}2.5 \times 10^{-} \\
3\end{array}$ & & $\begin{array}{l} \pm 0.4 \times 10^{-} \\
3\end{array}$ & $0.3-1$ & 55 \\
\hline 56.1 & $\mathrm{ISCN}^{\bullet-}+\mathrm{I}^{-} \rightleftharpoons \mathrm{I}_{2}^{\bullet-}+\mathrm{SCN}^{-}$ & 55 & & \pm 19 & 0.035 & 56 \\
\hline 57.1 & $\left(\mathrm{CH}_{3}\right)_{2} \mathrm{~S}+\mathrm{I}_{2}^{\bullet-} \rightleftharpoons\left(\mathrm{CH}_{3}\right)_{2} \mathrm{~S} \therefore \mathrm{I}+\mathrm{I}^{-}$ & $2 \times 10^{-1}$ & & $\begin{array}{l}(1-4) \times \\
10^{-1}\end{array}$ & & 57 \\
\hline 58.1 & $\begin{array}{l}\left(\mathrm{CH}_{3} \mathrm{CH}_{2}\right)_{2} \mathrm{~S}+\mathrm{I}_{2}{ }^{\bullet-} \rightleftharpoons \\
\quad\left(\mathrm{CH}_{3} \mathrm{CH}_{2}\right)_{2} \mathrm{~S} \therefore \mathrm{I}+\mathrm{I}^{-}\end{array}$ & $\begin{array}{l}4.5 \times 10^{-} \\
1\end{array}$ & & $\begin{array}{l}(2-9) \times \\
10^{-1}\end{array}$ & & 58 \\
\hline
\end{tabular}


Internal consistency test.

A closed thermodynamicchemical cycle is formed from reactions 54.1, 51.1, and 52.1.

Thus we expect to find that $K(54.1)=K(52.1) K_{\mathrm{w}} / K(51.1)$. The above values give: $2.5 \times 10^{4}=\left(1.35 \times 10^{5} \mathrm{M}^{-1}\right)\left(1 \times 10^{-14} \mathrm{M}^{2}\right) /\left(10^{-13.3} \mathrm{M}\right)=2.7 \times 10^{4}$, in rather good agreement!

\section{Derived $E^{\circ}$ for $\mathrm{I}_{2}{ }^{-}+\mathrm{e}^{-} \rightleftharpoons 2 \mathrm{I}^{-}$:}

Reaction 46.1 leads directly to $E^{\circ}$ for $\mathrm{I}_{2}{ }^{\bullet-}+\mathrm{e}^{-}=2 \mathrm{I}^{-}$. Nord et al. report that $E^{\circ \prime}=+(0.857 \pm$ $0.004) \mathrm{V}$ for $\mathrm{Os}(\mathrm{III}) / \mathrm{Os}(\mathrm{II})$ in $0.10 \mathrm{M} \mathrm{NaCl}$, which thus gives $E^{\circ \prime}=+(1.063 \pm 0.011) \mathrm{V}_{\text {for }} \mathrm{I}^{\bullet-}$ $/ 2 \mathrm{I}^{-}[1]$.

Reaction 47.1 leads directly to $E^{\circ}$ for $\mathrm{I}_{2}(a q)+\mathrm{e}^{-} \rightleftharpoons \mathrm{I}_{2}{ }^{\bullet-}$. Schwarz and Bielski used $E^{\circ}=$ $-0.33 \mathrm{~V}$ for $\mathrm{O}_{2} / \mathrm{O}_{2}{ }^{\bullet}$, the $\mathrm{NIST}(68)$ value for $\Delta_{\mathrm{f}} G^{\circ}\left(\mathrm{O}_{2}(a q)\right)=+16.4 \mathrm{~kJ}$ (which is unchanged in the current NIST tabulation [2]), and $\mathrm{p} K_{\mathrm{a}}=4.8$ to derive $E^{\circ}=+0.21 \mathrm{~V}$ for $\mathrm{I}_{2}(a q) / \mathrm{I}_{2}{ }^{\bullet-}$ [3]. We now recommend $E^{\circ}=-(0.35 \pm 0.01) \mathrm{V}$ for $\mathrm{O}_{2}(g) / \mathrm{O}_{2}{ }^{\bullet-}$, which leads to $E^{\circ}=+(0.19 \pm 0.015) \mathrm{V}$ for $\mathrm{I}_{2}(a q) / \mathrm{I}_{2}{ }^{\bullet-}$. Use of the NIST values for $\Delta_{\mathrm{f}} G^{\circ}\left(\mathrm{I}_{2}(a q)\right)=+16.40 \mathrm{~kJ}$ and $\Delta_{\mathrm{f}} G^{\circ}\left(\mathrm{I}^{-}\right)=-51.57 \mathrm{~kJ}$ yields $E^{\circ}=+(1.05 \pm 0.02) \mathrm{V}$ for $\mathrm{I}_{2}{ }^{-} / 2 \mathrm{I}^{-}$.

Reaction 48.1 leads to no recommendations because the DMTD $^{\bullet-} / \mathrm{DMTD}^{2-}$ potential is presently not known independently.

Reaction 49.1 leads to no recommendation because no equilibrium constant is recommended.

Reaction 50.1 can be used to derive $E^{\circ}\left(\mathrm{I}_{2}{ }^{-} / 2 \mathrm{I}^{-}\right)$from $E^{\circ}$ for $\mathrm{PZH}^{2+} / \mathrm{PZH}^{+}$. Wardman recommends a value of $+0.865 \mathrm{~V}$ for the latter [4], which leads to $E^{\circ}=(0.981 \pm 0.021) \mathrm{V}_{\text {for } \mathrm{I}_{2}}{ }^{-}$ $/ 2 \mathrm{I}^{-}$. More recently, Madej and Wardman recommended $E^{\circ}=+0.935 \mathrm{~V}$ for PZH [5], which adjusts the derived $\mathrm{I}_{2}{ }^{\bullet-} / 2 \mathrm{I}^{-}$potential to $+1.05 \mathrm{~V}$.

The addition of reactions 53.1 and 54.1 gives $\mathrm{HO}^{\bullet}+2 \mathrm{I}^{-} \rightleftharpoons \mathrm{I}_{2}^{\bullet-}+\mathrm{HO}^{-}$, for which the recommended equilibrium constants give $K=3 \times 10^{8} \mathrm{M}^{-1}$ within a factor of 2.5. If we use the optimized potential (Data Sheet 7) for $\mathrm{HO}^{\bullet} / \mathrm{HO}^{-}\left(E^{\circ}=+1.902 \pm 0.017 \mathrm{~V}\right)$, we derive $E^{\circ}=+1.40$ $\mathrm{V}$ for $\mathrm{I}_{2}{ }^{\bullet-} / 2 \mathrm{I}^{-}$, which is absurd in the context of the above results. We suggest that reaction 53.1 is far from correct, since the other reactions are part of the consistency cycle presented above. Equilibrium constant 53.1, taken from the ratio of the forward and reverse rate constants, makes use of a very low fitted reverse rate constant of $2 \times 10^{6} \mathrm{~s}^{-1}$, and a much lower value is required in order to obtain a reasonable $E^{\circ}$. We suspect that this is the likely cause of the error.

By combining reactions 55.1 and 56.1 we obtain $\mathrm{I}_{2}{ }^{--}+2 \mathrm{SCN}^{-} \rightleftharpoons(\mathrm{SCN})_{2}{ }^{--}+2 \mathrm{I}^{-}$, for which the equilibrium constant is calculated as $4.55 \times 10^{-5} \pm 50 \%$. The presently recommended $E^{\circ}\left((\mathrm{SCN})_{2}{ }^{--} / 2 \mathrm{SCN}^{-}\right)($Data Sheet 101$)$ is $+(1.30 \pm 0.02) \mathrm{V}$, which leads to $E^{\circ}=+(1.043 \pm 0.026)$ $\mathrm{V}$ for $\mathrm{I}_{2}{ }^{-} / 2 \mathrm{I}^{-}$.

The two thioether reactions $(57.1$ and 58.1$)$ given above do not lead to a derived $E^{\circ}\left(\mathrm{I}_{2}{ }^{\bullet-}\right.$ 
$\left./ 2 \mathrm{I}^{-}\right)$because there is no independent information regarding the product, iododimethylsulfur( $\bullet$ ),

As reported by Stanbury et al. and summarized by Nord, a large group of one-electron oxidations of iodide have measured rate constants for the step $\mathrm{M}_{\mathrm{ox}}+\mathrm{I}^{-} \rightleftharpoons \mathrm{M}_{\mathrm{red}}+\mathrm{I}^{\bullet}[6,7]$. It was argued that the reverse process, in general, is diffusion controlled, with $k_{\mathrm{r}}=1.2 \times 10^{10} \mathrm{M}^{-1} \mathrm{~s}^{-1}$, which thus led to an assignment of $E^{\circ}=+(1.33 \pm 0.03) \mathrm{V}$ for $\mathrm{I}^{\bullet} / \mathrm{I}^{-}$. By combination with the above recommended value for reaction 52.1 we derive $E^{\circ}=+(1.03 \pm 0.03)$ V for $\mathrm{I}_{2}{ }^{-} / 2 \mathrm{I}^{-}$.

\section{Summary and Evaluation of Derived $E^{\circ}\left(\mathbf{I}^{\circ}{ }^{\bullet} / 2 \mathbf{I}^{-}\right)$}

With the exclusion of the result derived from reaction 53.1, the five completely independent derived results given above are in agreement that $E^{\circ}\left(\mathrm{I}_{2}{ }^{\bullet-} / 2 \mathrm{I}^{-}\right)$is within the range of +1.03 to $1.06 \mathrm{~V}$, and the individual results are completely in agreement within their uncertainties. We thus recommend an average value of $+(1.05 \pm 0.02) \mathrm{V}$ for $E^{\circ}\left(\mathrm{I}_{2}{ }^{-} / 2 \mathrm{I}^{-}\right)$. The other derived quantities given below are derived from this value with use of NIST thermodynamicchemical data [2] for the stable species and the recommended equilibrium constants given above.

\section{Recommended values:}

$\mathrm{I}_{2}{ }^{--}+\mathrm{e}^{-} \rightleftharpoons 2 \mathrm{I}^{-}$

3669

3670

3671

3672

3673

3674

3675

3676

3677

3678

3679

3680

3681

3682

3683

3684

3685

3686
$\mathrm{I}^{\bullet}+\mathrm{e}^{-} \rightleftharpoons \mathrm{I}^{-}$

$\mathrm{I}_{2}(a q)+\mathrm{e}^{-} \rightleftharpoons \mathrm{I}_{2}{ }^{\bullet}$

$\mathrm{I}_{2}{ }^{\bullet}$

$\mathrm{I}^{\circ}(a q)$

$\mathrm{IOH}^{\bullet}$

$\mathrm{ISCN}^{\bullet}$

\section{References} (1982).

$$
\begin{aligned}
& E^{\circ}=+(1.05 \pm 0.02) \mathrm{V} \\
& E^{\circ}=+(1.35 \pm 0.02) \mathrm{V} \\
& E^{\circ}=+(0.19 \pm 0.02) \mathrm{V} \\
& \Delta_{\mathrm{f}} G^{\circ}=-(2.1 \pm 1.9) \mathrm{kJ} \\
& \Delta_{\mathrm{f}} G^{\circ}=+(79 \pm 2) \mathrm{kJ} \\
& \Delta_{\mathrm{f}} G^{\circ}=-(83 \pm 2) \mathrm{kJ} \\
& \Delta_{\mathrm{f}} G^{\circ}=+(152 \pm 2) \mathrm{kJ}
\end{aligned}
$$

Nomenclature: $\mathrm{I}^{\bullet}$, iodine $(\bullet)$; $\mathrm{I}^{-}$, iodide; $\mathrm{I}_{2}$, diiodine; $\mathrm{I}_{2}{ }^{\bullet-}$, diiodide $(\bullet 1-)$; $\mathrm{IOH}^{\bullet-}$, hydroxidoiodate $(\bullet 1-)$; ISCN ${ }^{\bullet}$, (iodosulfato)nitridocarbonate $(\bullet 1-)$; $\left(\mathrm{CH}_{3}\right) \mathrm{S} \therefore \mathrm{I}$, iododimethylsulfur( $\bullet$ ).

1. G. Nord, B. Pedersen, E. Floryan-Løvborg, P. Pagsberg. Inorg. Chem. 21, 2327-2330

2. D. D. Wagman, W. H. Evans, V. B. Parker, R. H. Schumm, I. Halow, S. M. Bailey, K. L. Churney, R. L. Nuttall. J. Phys. Chem. Ref. Data 11, Suppl. No. 2 (1982).

3. H. A. Schwarz, B. H. Bielski. J. Phys. Chem. 90, 1445-1448 (1986). 
3687 4. P. Wardman. J. Phys. Chem. Ref. Data 18, 1637-1755 (1989).

3688 5. E. Madej, P. Wardman. Rad. Phys. Chem. 75, 990-1000 (2006).

3689 6. G. Nord. Comments Inorg. Chem. 13, 221-239 (1992).

36907 7. D. M. Stanbury, W. K. Wilmarth, S. Khalaf, H. N. Po, J. E. Byrd. Inorg. Chem. 19, $2715-$ $36912722(1980)$.

3692 


\section{$3693 \quad$ Data Sheet 46}

3695 Chemical equilibrium: $2 \mathrm{I}^{-}+\left[\mathrm{Os}(\mathrm{bpy})_{3}\right]^{3+} \rightleftharpoons \mathrm{I}_{2}{ }^{\bullet-}+\left[\mathrm{Os}(\mathrm{bpy})_{3}\right]^{2+}$

\section{List of reports:}

3700 ratio of the forward and reverse rate constants reported by Nord et al. The forward rate constant 3701 was obtained by stopped-flow kinetics, while the reverse was obtained by pulse radiolysis.

3702

3703

\section{Discussion}

This work appears to be reliable and is accepted as given.

\section{Recommended value:}

$$
K_{\text {eq }}=(3.1 \pm 0.9) \times 10^{-4} \mathrm{M}^{-1} \text {, at } 22^{\circ} \mathrm{C} \text { and } \mu=0.1 \mathrm{M} \text {. }
$$

3711 List of auxiliary thermodynamic data: none.

3712

3713 Nomenclature: see Data Sheet 45

3714

\section{References}

3716

3717 1. G. Nord, B. Pedersen, E. Floryan-Løvborg, P. Pagsberg. Inorg. Chem. 21, 2327-2330

3718 (1982).

3719

3720 


\section{$3721 \quad$ Data Sheet 47}

3723 Chemical equilibrium: $\mathrm{I}_{2}(a q)+\mathrm{HO}_{2} \rightleftharpoons \mathrm{I}_{2}{ }^{\bullet-}+\mathrm{H}^{+}+\mathrm{O}_{2}(a q)$

3724

3725

\section{List of reports:}

3726

3727

$$
K_{\text {eq }}=(30 \pm 15) \mathrm{M} \text { at } 25^{\circ} \mathrm{C} \text { and } \mu=1.0 \mathrm{M}\left(\mathrm{LiClO}_{4}\right)[1] \text {. From pulse radiolysis of } \mathrm{I}^{-} / \mathrm{I}_{2} / \mathrm{O}_{2}
$$

3728 solutions, measuring the equilibrium yield of $\mathrm{I}_{2}{ }^{\bullet-}$.

3729

3730

Discussion

3731

3732

As this is the sole report on this reaction, and it appears to have been conducted

3733 competently, we recommend the reported result. Note, however, that the result should depend

3734 significantly on ionic strength.

3735

3736

Recommended value:

3737

3738

$$
K_{\text {eq }}=(30 \pm 15) \mathrm{M} \text { at } 25^{\circ} \mathrm{C} \text { and } \mu=1.0 \mathrm{M}
$$

3739

3740 List of auxiliary thermodynamic data: none.

3741

3742 Nomenclature: see Data Sheet 45.

3743

\section{References}

3745

3746 1. H. A. Schwarz, B. H. Bielski. J. Phys. Chem. 90, 1445-1448 (1986).

3747

3748 


\section{Data Sheet 48}

3750

3751

Chemical equilibrium: $\mathrm{I}_{2}{ }^{\bullet-}+$ DMTD $^{2-} \rightleftharpoons$ DMTD $^{\bullet-}+2 \mathrm{I}^{-}$

3752

DMTD $^{2-}$ is the dianion of 2.5-dimercaptothiadiazole.

3753

DMTD IUPAC PIN: 1,3,4-thiadiazole-2,5-dithiol.

3754

3755

List of reports:

3756

3757

$K_{\text {eq }}=2 \times 10^{3} \mathrm{M}$, at room temperature (presumably) and $\mu=0.2 \mathrm{M}$ [1]. Kishore et al.

3758

obtained this result with pulse radiolysis, determining the equilibrium constant from the kinetics of approach to equilibrium.

\section{Discussion}

3762

3763

No uncertainty was specified in the original publication, but we suggest is should be \pm $376425 \%$.

3765

3766

Recommended value:

3767

3768

$$
K_{\text {eq }}=(2.0 \pm 0.5) \times 10^{3} \mathrm{M} \text { at } \mu=0.2 \mathrm{M} \text {. }
$$

3769

3770

List of auxiliary thermodynamic data: none.

3771

3772 Nomenclature: See Data Sheet 45.

3773

3774

\section{References}

3775

3776

1. K. Kishore, G. R. Dey, P. N. Moorthy. J. Phys. Chem. 99, 13476-13479 (1995).

3777

3778 


\section{Data Sheet 49}

\section{List of reports:}

$k_{\mathrm{f}}=1.1 \times 10^{5} \mathrm{M}^{-1} \mathrm{~s}^{-1}$ was mentioned by Willson and co-workers, stating that it was determined by pulse radiolysis [1]. This number does not contradict the upper limit $k_{\mathrm{f}}<1 \times 10^{7} \mathrm{M}^{-1} \mathrm{~s}^{-1}$ obtained earlier by Barkatt and Ottolenghi who also used pulse radiolysis [2].

$k_{\mathrm{r}}=8.8 \times 10^{9} \mathrm{M}^{-1} \mathrm{~s}^{-1}$ was obtained using flash photolysis to generate the I atom; competition with the $\mathrm{I}^{\bullet}+\mathrm{I}^{-}$reaction was measured [2]. An upper limit $K_{\text {eq }}<1.1 \times 10^{-3}$ was suggested.

\section{Discussion}

$K_{\text {eq }}=1.3 \times 10^{-5}$ can be derived from the reported $k_{\mathrm{f}}=1.1 \times 10^{5} \mathrm{M}^{-1} \mathrm{~s}^{-1}$ and $k_{\mathrm{r}}=8.8 \times 10^{9} \mathrm{M}^{-1} \mathrm{~s}^{-}$

1. The reverse rate constant appears to be fairly reliable, as it is based on $k=9.8 \times 10^{9} \mathrm{M}^{-1} \mathrm{~s}^{-1}$ for the competing $\mathrm{I}^{\bullet}+\mathrm{I}^{-}$reaction and this value agrees within some $20 \%$ with most of the other measurements that have been tabulated [3]. In contrast, the reliability of the forward rate constant is impossible to judge. Indeed, Willson and co-workers [1] refer to their own work, which has never been published, so no experimental details are available. However, the accurate measurement of such a low $k_{\mathrm{f}}$ by pulse radiolysis appears to be extremely challenging (if at all possible) experimentally due to the approximately equal rate constants of $\mathrm{HO}^{\bullet}$ with $\mathrm{NO}_{2}{ }^{-}$and $\mathrm{I}^{-}$

3802 (requiring $\left[\mathrm{NO}_{2}^{-}\right]>>\left[\mathrm{I}^{-}\right]$for selective formation of $\mathrm{NO}_{2}{ }^{\bullet}$ ) and the self-recombination of $\mathrm{NO}_{2}{ }^{\bullet}$ at 3803 low $\left[\mathrm{I}^{-}\right]$. At the same time, the very rapid reverse reaction requires $\left[\mathrm{NO}_{2}^{-}\right]<<\left[\mathrm{I}^{-}\right]$to help quickly 3804 remove the $\mathrm{I}$ atom via the $\mathrm{I}^{\bullet}+\mathrm{I}^{-}$reaction.

3805 In the absence of any experimental evidence for $k_{\mathrm{f}}$, it is prudent to refrain from evaluating $K_{\text {eq }}$.

\section{Recommended value:}

None

3813 Nomenclature: see Data Sheet 45; $\mathrm{NO}_{2}{ }^{\bullet}$, nitrogen dioxide or dioxidonitrogen( $\bullet$ () 


\section{References}

3816

3817 1. L. G. Forni, V. O. Mora-Arellano, J. E. Packer, R. L. Willson. J. Chem. Soc., Perkin 3818 Trans. II 1-6 (1986).

3819 2. A. Barkatt, M. Ottolenghi. Mol. Photochem. 6, 253-261 (1974).

3820 3. P. Neta, R. E. Huie, A. B. Ross. J. Phys. Chem. Ref. Data 17, 1027-1284 (1988).

3821

3822 


\section{$3823 \quad$ Data Sheet 50}

Chemical equilibrium: $\mathrm{I}_{2}^{\bullet-}+\mathrm{PZH}^{+} \rightleftharpoons \mathrm{PZH}^{\bullet 2+}+2 \mathrm{I}^{-}$

$\mathrm{PZH}=$ promethazine (a phenothiazine)

IUPAC PIN: $N, N$-dimethyl-1-(10H-phenazin-10-yl)propan-2-amine

\section{List of reports:}

$K_{\text {eq }}=(90 \pm 5) \mathrm{M}$, at room temperature and variable ionic strength [1]. Bahnemann et al. obtained this result with pulse radiolysis, and the reported result is the average of the kinetic result $\left(k_{\mathrm{f}} / k_{\mathrm{r}}\right)$ and the equilibrium result.

\section{Discussion}

As this equilibrium constant is expected to be sensitive to ionic strength and the ionic strength was not held constant in these studies, the reported uncertainty is an underestimate. We suggest a more reasonable estimate of the uncertainty is a factor of 2 .

Recommended value:

3845 List of auxiliary thermodynamic data: none.

3847 Nomenclature: see Data Sheet 45.

\section{References}




\section{Data Sheet 51}

Chemical equilibrium: $\mathrm{I}^{\bullet}(a q)+\mathrm{H}_{2} \mathrm{O} \rightleftharpoons \mathrm{IOH}^{\bullet-}+\mathrm{H}^{+}$

\section{List of reports:}

$\mathrm{p} K_{\mathrm{a}}=(11.7 \pm 1)$, at $296 \mathrm{~K}$ and $10 \mathrm{M}$ ionic strength [1]. Büchler and Bühler used pulse radiolysis of iodide in strongly alkaline solutions, and fitted the kinetics of $\mathrm{I}_{2}{ }^{-}$growth and decay to a complex mechanism to obtain the equilibrium constant.

$$
\mathrm{p} K_{\mathrm{a}}=13.3 \text {, no specified uncertainty, at }(22 \pm 2){ }^{\circ} \mathrm{C} \text { and } \mu=10^{-4} \text { to } 0.1 \mathrm{M} \text { [2]. Mulazzani }
$$
and Buxton used pulse radiolysis of iodide at $\mathrm{pH} 10$ and 13, monitored the kinetics at $380 \mathrm{~nm}$, and fit the complex kinetics to a complex mechanism to derive forward and reverse rate constants for the addition of $\mathrm{HO}^{-}$to $\mathrm{I}^{\bullet}$. This equilibrium constant was then converted to a $\mathrm{p} K_{\mathrm{a}}$ by use of an unspecified value for $K_{\mathrm{w}}$.

\section{Discussion}

The two reports differ quite substantially with regard to the value of $\mathrm{p} K_{\mathrm{a}}$. Both reports used essentially the same method and obtained rather similar results. The main difference 3875 between the two seems to be the absorption coefficients of $\mathrm{HOI}^{\bullet-}$ and $\mathrm{I}_{2}{ }^{--}$used in the fitting. 3876 Mullazani and Buxton argue that Büchler and Bühler erred in resolving the two spectra by 3877 neglecting the absorbance of $\mathrm{HOI}^{\bullet-}$ at $360 \mathrm{~nm}$. This seems to be a reasonable argument, and thus 3878 we accept the result of Mullazani and Buxton. Given the apparent sensitivity of the derived parameters to the model specifications, we infer that the derived $\mathrm{p} K_{\mathrm{a}}$ has an uncertainty of at least 0.2 units. Further adding to the uncertainty are unknowns relating to the conversion between $\left[\mathrm{HO}^{-}\right]$and $\mathrm{pH}$ and ionic strength effects. Overall, an uncertainty of $\pm 0.5 \mathrm{p} K_{\mathrm{a}}$ units seems appropriate.

\section{Recommended value:}

List of auxiliary thermodynamic data: none.

Nomenclature: see Data Sheet 45. 


\section{References}

3892

3893 1. H. Büchler, R. E. Bühler. Chem. Phys. 16, 9-18 (1976).

3894 2. Q. G. Mulazzani, G. V. Buxton. Chem. Phys. Lett. 421, 261-265 (2006).

3895

3896 


\section{Data Sheet 52}

\section{List of reports:}

$K_{\text {eq }}>1.2 \times 10^{4} \mathrm{M}^{-1}$. From flash photolysis of iodide solutions. A very early report (1957) from Grossweiner and Matheson [1].

$K_{\text {eq }}=1.3 \times 10^{5} \mathrm{M}^{-1}$ at $22{ }^{\circ} \mathrm{C}$ at $\mathrm{pH} 7$ in phosphate buffer of unspecified ionic strength [2]. Baxendale et al. used pulse radiolysis of iodide solutions, monitoring the kinetics of decay. $K_{\text {eq }}=1.13 \times 10^{5} \mathrm{M}^{-1}$ at $22{ }^{\circ} \mathrm{C}$ at $\mathrm{pH} 7$ in phosphate buffer of unspecified ionic strength $[2,3]$. Baxendale et al. used pulse radiolysis of iodide solutions, with spectrophotometric detection of the position of equilibrium.

$K_{\text {eq }}=8.4 \times 10^{4} \mathrm{M}^{-1}$ under unspecified conditions [4]. Thomas used pulse radiolysis of iodide solutions.

$K_{\text {eq }}=1.4 \times 10^{4} \mathrm{M}^{-1}$ at unspecified temperature and low ionic strength [5]. Fournier de Violet et al used flash photolysis of iodine solutions, monitoring the yield of $\mathrm{I}_{2}{ }^{\bullet-}$. No mention was made regarding the $\mathrm{pH}$ of the solutions or any measures to remove $\mathrm{O}_{2}$. Violet et al used flash photolysis of $\mathrm{HgI}_{2} / \mathrm{I}^{-}$solutions, monitoring the kinetics of formation of $\mathrm{I}_{2}{ }^{\bullet}$ - No mention was made regarding the $\mathrm{pH}$ of the solutions or any measures to remove $\mathrm{O}_{2}$.

$$
K_{\text {eq }}=(1.1 \pm 0.2) \times 10^{4} \mathrm{M}^{-1} \text { at }(20 \pm 2)^{\circ} \mathrm{C} \text { and low ionic strength [7]. Barkatt and }
$$
Ottolenghi used flash photolysis of $\mathrm{I}_{3}{ }^{-}$solutions, monitoring the yield of $\mathrm{I}_{2}{ }^{--}$and also the kinetics of its formation. No mention was made regarding the $\mathrm{pH}$ of the solutions or any measures to remove $\mathrm{O}_{2}$.

$K_{\text {eq }}=(3 \pm 2) \times 10^{3} \mathrm{M}^{-1}$ at $25^{\circ} \mathrm{C}$ and low ionic strength [8]. Treinin and Hayon used flash photolysis of $\mathrm{I}_{3}^{-}$solutions, monitoring the yield of $\mathrm{I}_{2}{ }^{--}$and also the kinetics of its formation. $K_{\text {eq }}=5.0 \times 10^{4} \mathrm{M}^{-1}$ at $22{ }^{\circ} \mathrm{C}$ and low ionic strength [9]. Elliot and Sopchyshyn used pulse radiolysis of $\mathrm{I}^{-}$solutions, monitoring the yield of $\mathrm{I}_{2}{ }^{\bullet-}$.

$K_{\text {eq }}=1.1 \times 10^{5} \mathrm{M}^{-1}( \pm 15 \%)$ at $25^{\circ} \mathrm{C}$ and low ionic strength [10]. Schwarz and Bielski used pulse radiolysis of $\mathrm{I}^{-}$solutions, monitoring the yield of $\mathrm{I}_{2}^{\bullet-}$.

$K_{\text {eq }}=1.28 \times 10^{5} \mathrm{M}^{-1}$ at $25^{\circ} \mathrm{C}$ and low ionic strength [11]. Elliot interpolated this result from the temperature-dependent data of Schwarz and Bielski [10].

$K_{\text {eq }}=1.0 \times 10^{5} \mathrm{M}^{-1}$ at $25^{\circ} \mathrm{C}$ and low ionic strength [12]. Merény and Lind used pulse radiolysis of $\mathrm{ICH}_{2} \mathrm{CH}_{2} \mathrm{I}$, measuring the rate of dissociation of $\mathrm{I}_{2}{ }^{\bullet-}$ produced, and obtained the 3932 equilibrium constant from the ratio of the formation and dissociation rate constants. 
3934 flash photolysis of $\mathrm{I}^{-}$, measuring the rate of formation of $\mathrm{I}_{2}{ }^{--}$to obtain the forward and reverse 3935 rate constants, from the ratio of which the equilibrium constant is derived.

\section{Discussion}

The reported equilibrium constants range from $3 \times 10^{3} \mathrm{M}$ to $1.35 \times 10^{5} \mathrm{M}^{-1}$, and in none of the reports is an explanation provided for disagreement with prior results. It was noted in 1989 that the flash-photolysis results clustered around the lower value while the pulse radiolysis results clustered around the higher value [14]; recently, however, the careful flash-photolysis study from Barker's group supports the highest value.

Another conceivable explanation for the diversity of reported values for $K_{\text {eq }}$ is the failure to remove $\mathrm{O}_{2}$ or control $\mathrm{pH} . \mathrm{O}_{2}$ could interfere in studies where the solvated electron was 3946 involved, or possibly through direct reaction with $\mathrm{I}_{2}{ }^{-}$, high $\mathrm{pH}$ could lead to the formation of $3947 \mathrm{IOH}^{-}$from $\mathrm{I}^{\bullet}$ and $\mathrm{HOI}$ from $\mathrm{I}_{2}$, and low $\mathrm{pH}$ could lead to formation of $\mathrm{HI}^{\bullet-}$ through reaction of $\mathrm{H}$ 3948 atoms with $\mathrm{I}^{-}$[15].This would exclude the results from Thomas [4], from Barkatt and Ottolenghi [7], and from Fornier de Violet [5, 6]. These exclusions would lead to values of $K_{\text {eq }}$ clustering at the high end of the range, with the notable outlier from Treinin and Hayon [8]. Note, however, that Treinin and Hayon specifically state that $\mathrm{O}_{2}$ had no effect and that $\mathrm{I}_{2}$ is insignificantly hydrolyzed at $\mathrm{pH} 6$ [8]. Treinin and Hayon found that the $\mathrm{I}_{2}{ }^{\bullet-}$ dissociation rate constant was the same at $(25$ and 75$){ }^{\circ} \mathrm{C}$, which seems quite unlikely. Apparently, the results of Treinin and Hayon are flawed, although for unknown reasons. Thus we support the results obtained with $K_{\text {eq }}$ near $10^{5} \mathrm{M}^{-1}$.

We presently recommend the most recent result from Barker's group on the basis of the values could be rationalized or tested.

Recommended value:

$$
K_{\text {eq }}=(1.35 \pm 0.10) \times 10^{5} \mathrm{M}^{-1}
$$

List of auxiliary thermodynamic data: none. 


\section{References}

3970 1. L. I. Grossweiner, M. S. Matheson. J. Phys. Chem. 61, 1089-1095 (1957).

3971 2. J. H. Baxendale, P. L. T. Bevan, D. A. Stott. Trans. Faraday Soc. 64, 2389-2397 (1968).

3972 3. J. H. Baxendale, P. L. T. Bevan. J. Chem. Soc. (A) 2240-2241 (1969).

3973 4. J. K. Thomas. Adv. Rad. Chem. 1, 103-198 (1969).

3974 5. P. Fornier de Violet, R. Bonneau, J. Joussot-Dubien. J. Chim. Phys. 70, 1404-1409 3975 (1973).

3976 6. P. Fornier de Violet, R. Bonneau, S. R. Logan. J. Phys. Chem. 78, 1698-1701 (1974).

3977 7. A. Barkatt, M. Ottolenghi. Mol. Photochem. 6, 253-261 (1974).

3978 8. A. Treinin, E. Hayon. Int. J. Radiat. Phys. Chem. 7, 387-393 (1975).

3979 9. A. J. Elliot, F. C. Sopchyshyn. Int. J. Chem. Kinet. 16, 1247-1256 (1984).

3980 10. H. A. Schwarz, B. H. Bielski. J. Phys. Chem. 90, 1445-1448 (1986).

3981 11. A. J. Elliot. Can. J. Chem. 70, 1658-1661 (1992).

3982 12. G. Merényi, J. Lind. J. Am. Chem. Soc. 116, $7872-7876$ (1994).

3983 13. Y. Liu, R. L. Sheaffer, J. R. Barker. J. Phys. Chem. A 107, 10296-10302 (2003).

3984 14. D. M. Stanbury. Adv. Inorg. Chem. 33, 69-138 (1989).

3985 15. A. J. Elliot, S. Geertsen, G. V. Buxton. J. Chem. Soc., Faraday Trans. 1 84, 1101-1112 3986 (1988). 


\section{Data Sheet 53}

Chemical equilibrium: $\mathrm{HO}^{\bullet}+\mathrm{I}^{-} \rightleftharpoons \mathrm{IOH}^{\bullet-}$

\section{List of reports:}

$K_{\mathrm{eq}}=1.2 \times 10^{4} \mathrm{M}^{-1}$, within a factor of 2 at $296 \mathrm{~K}$ and $10 \mathrm{M}$ ionic strength [1]. We obtain this result from the ratio of forward and reverse rate constants reported by Büchler and Bühler. The estimated uncertainty is derived from the reported uncertainties in the individual rate constants. They obtained their rate constants by pulse radiolysis of iodide, fitting the kinetics with a complex procedure.

\section{Discussion}

As this is the sole report and seems to have been performed competently, we accept the result. Although the experiments were conducted at very high ionic strength, the equilibrium constant is not expected to be very sensitive to this parameter. However, this result leads to an unacceptable standard potential for $\mathrm{I}_{2}{ }^{\bullet-} / 2 \mathrm{I}^{-}$, which implies that there is something fundamentally wrong with this result; see the iodine radical summary pages (Data Sheet 45) for an explanation.

\section{Recommended value:}

4013 List of auxiliary thermodynamic data: none.

4014

4015 Nomenclature: see Data Sheet 45.

4016

\section{References}

4019 1. H. Büchler, R. E. Bühler. Chem. Phys. 16, 9-18 (1976). 


\section{$4022 \quad$ Data Sheet 54}

4023

4024 Chemical equilibrium: $\mathrm{IOH}^{\bullet-}+\mathrm{I}^{-} \rightleftharpoons \mathrm{I}_{2}{ }^{--}+\mathrm{HO}^{-}$

4025

\section{List of reports:} pulse radiolysis of iodide in strongly alkaline solutions, determining the position of equilibrium

Discussion

As this is the sole report on this reaction, and it appears to have been conducted competently, we recommend the reported result. Note, however, that the result should depend 4036 significantly on ionic strength.

\section{Recommended value:}

4039

4040

$$
K_{\text {eq }}=(2.5 \pm 1.2) \times 10^{4} \text { at } 25^{\circ} \mathrm{C} \text { and } \mu=1.0 \mathrm{M}
$$

4041

4042 List of auxiliary thermodynamic data: none.

4043

4044 Nomenclature: See Data Sheet 54.

4045

4046

\section{References}

4047

4048

1. H. Büchler, R. E. Bühler. Chem. Phys. 16, 9-18 (1976).

4049

4050 


\section{Data Sheet 55}

4052

4053 Chemical equilibrium: $\mathrm{ISCN}^{\bullet-}+\mathrm{SCN}^{-} \rightleftharpoons(\mathrm{SCN}) 2^{\bullet-}+\mathrm{I}^{-}$

4054

\section{List of reports:}

4056

$K_{\text {eq }}=2.5 \times 10^{-3}$, presumably at room temperature, ionic strength varying from 0.3 to 1

$4058 \mathrm{M}, \mathrm{N}_{2} \mathrm{O}$ saturated, no $\mathrm{pH}$ control [1]. Shöneshofer and Henglein obtained this result by pulse

4059 radiolysis, monitoring the equilibrium absorbance at $550 \mathrm{~nm}$.

4060

\section{Discussion}

As this is the sole report on this reaction, and it appears to have been conducted

4064 competently, we recommend the reported result. The result should not depend significantly on 4065 ionic strength. Although no uncertainty was specified, we suggest $\pm 15 \%$ based on the quality of 4066 the data.

4067

4068 Recommended value:

4069

4070

$$
K_{\text {eq }}=(2.5 \pm 0.4) \times 10^{-3} .
$$

4071

4072 List of auxiliary thermodynamic data: none.

4073

4074 Nomenclature: see Data Sheet 45.

4075

\section{References}

4077

4078 1. M. Schöneshöfer, A. Henglein. Ber. Bunsenges. Phys. Chem. 74, 393-398 (1970).

4079 


\section{$4081 \quad$ Data Sheet 56}

4083 Chemical equilibrium: $\mathrm{ISCN}^{\bullet-}+\mathrm{I}^{-} \rightleftharpoons \mathrm{I}_{2}{ }^{\bullet-}+\mathrm{SCN}^{-}$

\section{List of reports:}

4086

$K_{\text {eq }}=55$, presumably at room temperature, ionic strength $0.03 \mathrm{M}, \mathrm{N}_{2} \mathrm{O}$ saturated, no $\mathrm{pH}$ control [1]. Shöneshofer and Henglein obtained this result by pulse radiolysis, plotting a function of the difference in the equilibrium absorbances at $420 \mathrm{~nm}$ and $550 \mathrm{~nm}$ as a function of [ $\mathrm{SCN}^{-}$], and deriving the equilibrium constant from the midpoint of the sigmoidal curve.

\section{Discussion}

As this is the sole report on this reaction, and it appears to have been conducted competently, we recommend the reported result. The result should not depend significantly on ionic strength. Although no uncertainty was specified, we suggest $\pm 35 \%$ based on the graphical method of extracting the equilibrium constant from the data.

Recommended value:

$$
K_{\text {eq }}=55 \pm 19 .
$$

4103 List of auxiliary thermodynamic data: none.

4105 Nomenclature: see Data Sheet 45.

\section{References}

4109 1. M. Schöneshöfer, A. Henglein. Ber. Bunsenges. Phys. Chem. 74, 393-398 (1970). 


\section{Data Sheet 57}

4113 Subject: Dimethyl sulfide radical cation-iodide complex (iododimethylsulfur( $\bullet$ ))

4114 Couple type: $\mathrm{R}_{2} \mathrm{~S}-\mathrm{I} / \mathrm{R}_{2} \mathrm{~S}, \mathrm{I}^{-},\left(\mathrm{R}=-\mathrm{CH}_{3}\right)$.

4115 Solvent: Water

4116

Reference: $E^{\mathrm{o}}\left(\mathrm{I}_{2}{ }^{-} / 2 \mathrm{I}^{-}\right)$.

4127 Temperature: $(293 \pm 2) \mathrm{K}$. Ionic strength effects estimated: Not needed.

\section{Discussion}

No correction needed for ionic strength. (i) is charge symmetrical and Debye-Hückel corrections

4133 will cancel. (ii) is a standard potential. Recalculation taking $\pm 100 \%$ error limit in $K$ gives: (1.07

$4134 \pm 0.03) \mathrm{V} v$ s NHE.

4135

4136 Correction desirable for reference potential used: no.

\section{Recommended value:}

$E^{\circ}\left(\mathrm{R}_{2} \mathrm{~S}-\mathrm{I} / \mathrm{R}_{2} \mathrm{~S}, \mathrm{I}^{-},\left(\mathrm{R}=-\mathrm{CH}_{3}\right)\right)=(1.07 \pm 0.03) \mathrm{V}$ vs NHE.

4142 Nomenclature: see Data Sheet 45.

\section{References}

4145 
4146 1. Armstrong, D. A. In S-Centered Radicals, (Alfassi, Z. B., ed.), p. 27-61. John Wiley \& 4147 Sons, New York (1999).

4148 2. M. Bonifacic, K.-D. Asmus. J. Chem. Soc., Perkin Trans. II 758-762 (1980). 4149 


\section{Data Sheet 58}

Subject: Diethyl sulfide radical cation-iodide complex (iododiethylsulfur( $\bullet$ ))

4152 Couple type: $\mathrm{R}_{2} \mathrm{~S}-\mathrm{I} / \mathrm{R}_{2} \mathrm{~S}, \mathrm{I}^{-},\left(\mathrm{R}=-\mathrm{CH}_{2}-\mathrm{CH}_{3}\right)$.

\section{Solvent: Water.}

Method: Calculation in reference [1] from pulse radiolysis data in reference [2] and $E^{\circ}\left(\mathrm{I}_{2}{ }^{\bullet-} / 2 \mathrm{I}^{-}\right)$:

4164 Temperature: $(293 \pm 2) \mathrm{K}$. Ionic strength effects estimated: No.

(ii) $\mathrm{I}_{2}{ }^{--}+\mathrm{e}^{-} \rightleftharpoons 2 \mathrm{I}^{-}$

$$
E^{\mathrm{o}}=(1.03 \pm 0.02) \mathrm{V}
$$$$
\text { (ii) - (i) } \mathrm{R}_{2} \mathrm{~S} \bullet \bullet \mathrm{I}+\mathrm{e}^{-} \rightleftharpoons \mathrm{R}_{2} \mathrm{~S}+\mathrm{I}^{-}
$$

$$
E^{\mathrm{o}}=(1.05 \pm 0.03) \mathrm{V}
$$

No correction needed for ionic strength. Equilibrium (i) has charge symmetry and Debye-Hückel corrections will cancel. (ii) is a standard potential.

$E^{\circ}\left(\mathrm{R}_{2} \mathrm{~S}-\mathrm{Cl} / \mathrm{R}_{2} \mathrm{~S}, \mathrm{I}^{-},\left(\mathrm{R}=-\mathrm{CH}_{2}-\mathrm{CH}_{3}\right)\right)=+(1.05 \pm 0.03) \mathrm{V}$ vs NHE

\section{References} 4180 Sons, New York (1999).

4181 2. M. Bonifacic, K.-D. Asmus. J. Chem. Soc., Perkin Trans. II 758-762 (1980). 


\section{$4184 \quad$ Data Sheet 59}

4185 Summary of the $\mathrm{SO}_{3}{ }^{-}$System

Tabulated below are the presently recommended equilibrium constants involving the trioxidosulfate $(\bullet 1-)$ (sulfite) radical. Uncertainties are expressed as \pm 1 sigma; in many cases the value of sigma is merely a subjective guess.

rxn \# reaction $\quad K_{\text {eq }} \quad$ uncertainty $\mu / \mathrm{M}$ Data

\begin{tabular}{|c|c|c|c|c|c|}
\hline \multirow{2}{*}{60.1} & & & & & Sheet \# \\
\hline & $\begin{array}{l}\mathrm{SO}_{3}^{2-}+\left[\mathrm{Ru}(\text { phen })\left(\mathrm{NH}_{3}\right)_{4}\right]^{3+} \rightleftharpoons \mathrm{SO}_{3}{ }^{--}+ \\
{\left[\mathrm{Ru}(\mathrm{phen})\left(\mathrm{NH}_{3}\right)_{4}\right]^{2+}}\end{array}$ & $\begin{array}{l}(1.8-7.4) \\
\times 10^{-4}\end{array}$ & Factor of 2 & 0.1 & 60 \\
\hline 61.1 & $\begin{array}{l}\mathrm{SO}_{3}{ }^{--}+\text {chlorpromazine }^{+} \rightleftharpoons \mathrm{S}(\mathrm{IV})+ \\
\text { chlorpromazyl }{ }^{\circ+}\end{array}$ & 11 & \pm 2 & 0.1 & 61 \\
\hline 62.1 & $\mathrm{SO}_{3}^{\bullet-}+\mathrm{ClO}_{2}^{-} \rightleftharpoons \mathrm{SO}_{3}^{2-}+\mathrm{ClO}_{2}^{\bullet}$ & 4850 & $?$ & 0 & 62 \\
\hline 63.1 & $\begin{array}{l}\mathrm{SO}_{3}{ }^{--}+\text {phenoxide } \\
\text { phenoxyl }(\bullet)\end{array}$ & 0.056 & \pm 0.008 & 0 & 63 \\
\hline 64.1 & $\mathrm{TyrO}^{\bullet}+\mathrm{SO}_{3}^{2-} \rightleftharpoons \mathrm{TyrO}^{-}+\mathrm{SO}_{3}^{\bullet-}$ & 0.61 & \pm 0.04 & 0 & 64 \\
\hline 65.1 & $\begin{array}{l}3-\mathrm{MeC}_{6} \mathrm{H}_{4} \mathrm{O}^{\bullet}+\mathrm{SO}_{3}{ }^{2-} \rightleftharpoons 3-\mathrm{MeC}_{6} \mathrm{H}_{4} \mathrm{O}^{-}+ \\
\mathrm{SO}_{3}{ }^{\bullet-}\end{array}$ & 0.88 & 0.09 & 0 & 65 \\
\hline
\end{tabular}

Reaction 60.1 with $E^{\circ}$ ' $\left[\mathrm{Ru}(\mathrm{phen})\left(\mathrm{NH}_{3}\right)_{4}\right]^{3+/ 2+}$ measured by cyclic voltammetry as $+(0.516$ $\pm 0.002) \mathrm{V}$, leads to $E^{\circ}=+(0.72 \pm 0.02) \mathrm{V}$ at $25^{\circ} \mathrm{C}$ and $\mu=0.1 \mathrm{M}$.

Reaction 61.1 leads to $E^{\circ}=+(0.71 \pm 0.01) \mathrm{V}$ for $\mathrm{SO}_{3}{ }^{-}-/ \mathrm{SO}_{3}{ }^{2-}$. Note that this result is drastically corrected from the original report.

Reaction 62.1 has $K_{\text {eq }}$ extrapolated to zero ionic strength. With use of $E^{\circ}=+0.934 \mathrm{~V}$ for $\mathrm{ClO}_{2}{ }^{\bullet} / \mathrm{ClO}_{2}{ }^{-}$, this leads to $E^{\circ}=+(0.72 \pm 0.01) \mathrm{V}$ for $\mathrm{SO}_{3}{ }^{\circ-} / \mathrm{SO}_{3}{ }^{2-}$. A recent paper by Horvath and Nagypal attempts to discredit the prior work on this reaction [1]. They claim that the prior report by Merényi, Lind and Shen [2] mistakenly observed the formation of a $\mathrm{ClO}_{2} \mathrm{SO}_{3}{ }^{-}$adduct rather than electron-transfer products. However, the experimental basis for this assertion is quite tenuous. On the other hand, it must be acknowleged that Merényi et al. performed their equilibrium measurements at only one $\mathrm{ClO}_{2}{ }^{-}$concentration, so their data do not rule out adduct formation. As is described in Data Sheet 62, the measurement of $K_{\text {eq }}$ for this reaction was also compromised by neglect of the effects of $\left(\mathrm{ClO}_{2}\right)_{2}{ }^{\bullet-}$.

Reaction 63.1 leads to $E^{\circ}=+(0.72 \pm 0.01) \mathrm{V}$ for $\mathrm{SO}_{3}{ }^{\circ-} / \mathrm{SO}_{3}{ }^{2-}$ and appears quite reliable. Reaction 64.1 leads to $E^{\circ}=+(0.723 \pm 0.01) \mathrm{V}$ for $\mathrm{SO}_{3}{ }^{-}-/ \mathrm{SO}_{3}{ }^{2-}$ and appears quite reliable. 
Reaction 65.1 leads to $E^{\circ}=+(0.737 \pm 0.01) \mathrm{V}$ for $\mathrm{SO}_{3}{ }^{\bullet-} / \mathrm{SO}_{3}{ }^{2-}$ but was studied less extensively than reactions 63.1 and 64.1 .

The broad agreement of the above determinations suggests that $E^{\circ}$ is in the neighborhood of $+0.72 \mathrm{~V}$ for $\mathrm{SO}_{3}{ }^{--} / \mathrm{SO}_{3}{ }^{2-}$. To obtain a more precise recommendation we disregard reaction 60.1 because of the difficulties in extrapolation to zero ionic strength for a reaction involving such high charges. We exclude reaction 61.1 because of the large corrections required to extrapolate from $\mathrm{pH} 3.3$ to high $\mathrm{pH}$. We also exclude reaction 62.1 because of the concerns raised by Horvath and Nagypal and because of the unknown effects of $\left(\mathrm{ClO}_{2}\right)_{2}{ }^{\bullet-}$. We also exclude reaction 65.1 because it was not studied in depth. We are then left with reactions 63.1 and 64.1. Taking the average of these two leads to $E^{\circ}=+(0.72 \pm 0.01) \mathrm{V}$.

Using the NBS value of $-(486.5 \pm 8) \mathrm{kJ} \mathrm{mol}^{-1}$ for $\Delta_{\mathrm{f}} G^{\circ}$ of $\mathrm{SO}_{3}{ }^{2-}(a q)$, the recommended value of $E^{\circ}\left(\mathrm{SO}_{3}{ }^{\bullet-} / \mathrm{SO}_{3}{ }^{2-}\right)$ leads to $\Delta_{\mathrm{f}} G^{\circ}=-(416 \pm 8) \mathrm{kJ} \mathrm{mol}^{-1}$ for $\mathrm{SO}_{3}{ }^{\bullet-}(a q)$. Note that the NBS uncertainty in $\Delta_{\mathrm{f}} G^{\circ}\left(\mathrm{SO}_{3}{ }^{2-}\right)$ seems unreasonably large. A more realistic assessment is based on $\Delta_{\mathrm{f}} H^{\circ}{ }_{298}\left(\mathrm{SO}_{2}, g\right)=-(296.84 \pm 0.21) \mathrm{kJ} \mathrm{mol}^{-1}$ as reported in the NIST Webbook and in the JANAF tables, $4^{\text {th }}$ ed. This then leads to $\Delta_{\mathrm{f}} G^{\circ}\left(\mathrm{SO}_{2}, g\right)=-(300.125 \pm 0.21) \mathrm{kJ} \mathrm{mol}^{-1}$. We then use following equilibrium constants as recommended in the Smith, Martell, and Motekaitis NIST compendium of aqueous formation constants [3]: for the Henry's law constant (M/atm) of $\mathrm{SO}_{2}$, $\log K=(0.09 \pm 0.01)$, for the first $K_{\mathrm{a}}$ of " $\mathrm{H}_{2} \mathrm{SO}_{3}$ " $\mathrm{p} K_{\mathrm{a}}=(1.85 \pm 0.01)$; for $\mathrm{HSO}_{3}{ }^{-} \mathrm{p} K_{\mathrm{a}}=(7.19 \pm$ $0.01)$. These data then lead to $\Delta G^{\circ}=+(51.11 \pm 0.11) \mathrm{kJ} \mathrm{mol}^{-1}$ for $\mathrm{SO}_{2}(g)+\mathrm{H}_{2} \mathrm{O}(l)=\mathrm{SO}_{3}{ }^{2-}(a q)$ $+2 \mathrm{H}^{+}(a q)$. Finally, using the NBS $\Delta_{\mathrm{f}} G^{\circ}$ for $\mathrm{H}_{2} \mathrm{O}(l)$ we obtain $\Delta_{\mathrm{f}} G^{\circ}=-(486.1 \pm 0.2) \mathrm{kJ} \mathrm{mol}^{-1}$, which is in excellent agreement with the NBS value except for a much smaller uncertainty. This revised uncertainty then leads to an uncertainty of $\pm 2 \mathrm{~kJ} \mathrm{~mol}^{-1}$ for $\Delta_{\mathrm{f}} G^{\circ}\left(\mathrm{SO}_{3}{ }^{\bullet-}\right)$.

\section{Recommended values:}

$E^{\circ}=+(0.72 \pm 0.01) \mathrm{V}$.

$\mathrm{SO}_{3}{ }^{\bullet-}(a q)$

$$
\Delta_{\mathrm{f}} G^{\circ}=-(416 \pm 2) \mathrm{kJ} \mathrm{mol}^{-1}
$$

Nomenclature: $\mathrm{ClO}_{2} \bullet$, dioxidochlorine $(\bullet)$; $\mathrm{SO}_{3}{ }^{\bullet-}$, trioxidosulfate $(\bullet 1-)$; chlorpromazine, IUPAC PIN 3-(2-chloro-10H-phenothiazin-10-yl)- $N, N$-dimethylpropan-1-amine

\section{References}

4241 1. A. K. Horvath, I. Nagypal. J. Phys. Chem. A 110, 4753-4758 (2006).

4242 2. G. Merényi, J. Lind, X. Shen. J. Phys. Chem. 92, 134-137 (1988). 
$4243 \quad 3 . \quad$ A. E. Martell, R. M. Smith, R. J. Motekaitis. NIST Critically Selected Stability Constants 4244 of Metal Complexes Database, 7.0, U.S. Department of Commerce, Gaithersburg, MD (2003). 4245 


\section{Data Sheet 60}

Chemical equilibrium: $\mathrm{SO}_{3}{ }^{2-}+\left[\mathrm{Ru}(\text { phen })\left(\mathrm{NH}_{3}\right)_{4}\right]^{3+} \rightleftharpoons \mathrm{SO}_{3}{ }^{--}+\left[\mathrm{Ru}(\text { phen })\left(\mathrm{NH}_{3}\right)_{4}\right]^{2+}$

\section{List of reports:}

$$
K_{\text {eq }}=3.7 \times 10^{-4} \text { at } \sim 25^{\circ} \mathrm{C} \text { and } \mu=0.1 \mathrm{M}[1] \text { obtained from the ratio of the forward and }
$$
reverse rate constants. The forward rate constant was measured by stopped-flow kinetics of the reaction of $\mathrm{SO}_{3}{ }^{2-}$ with $\left[\mathrm{Ru}(\mathrm{phen})\left(\mathrm{NH}_{3}\right)_{4}\right]^{3+}$ as a function of $\mathrm{pH}$ at $25.0^{\circ} \mathrm{C}$. The reverse was measured by pulse radiolysis at room temperature $\left(\sim 22^{\circ} \mathrm{C}\right)$. Uncertainties in $K_{\text {eq }}$ were not reported.

\section{Discussion}

An estimate of the uncertainty in $K_{\text {eq }}$ can be derived from the uncertainties in the individual rate constants. An uncertainty of $\pm 7 \%$ was reported for $k_{\mathrm{f}}$. The uncertainty in $k_{\mathrm{r}}$ was not reported but could be as large as a factor of 2 , given the effects of the competing reaction

$$
\mathrm{SO}_{3}{ }^{--}+\mathrm{Ru}^{3+} \rightarrow \mathrm{SO}_{3}+\mathrm{Ru}^{2+}
$$

Thus we assign an uncertainty of a factor of 2 to $K_{\text {eq }}$.

Cyclic voltammetry was used to determine $E^{\circ}=+(0.516 \pm 0.002) \mathrm{V}$ for $+0.72 \mathrm{~V}$ was derived for $E^{\circ \prime}$ for $\mathrm{SO}_{3}{ }^{--} / \mathrm{SO}_{3}{ }^{2-}$. The factor-of-2 uncertainty in $K_{\text {eq }}$ leads to a $20 \mathrm{mV}$ uncertainty in $E^{\circ}$.

\section{Recommended values:}

$$
\mathrm{SO}_{3}{ }^{2-}+\left[\mathrm{Ru}(\text { phen })\left(\mathrm{NH}_{3}\right)_{4}\right]^{3+} \rightleftharpoons \mathrm{SO}_{3}{ }^{\bullet-}+\left[\mathrm{Ru}(\text { phen })\left(\mathrm{NH}_{3}\right)_{4}\right]^{2+}
$$
$K_{\text {eq }}=3.7 \times 10^{-4}$ within a factor of 2 at $\sim 25^{\circ} \mathrm{C}$ and $\mu=0.1 \mathrm{M}$. $E^{\circ}=(0.72 \pm 0.02) \mathrm{V}$ at $25^{\circ} \mathrm{C}$ and $\mu=0.1 \mathrm{M}$.

Nomenclature: See Data Sheet 59

\section{References}


4282 1. R. Sarala, M. S. Islam, S. B. Rabin, D. M. Stanbury. Inorg. Chem. 29, 1133-1142 (1990). 4283

4284 


\section{Data Sheet 61}

Chemical equilibrium: $\mathrm{SO}_{3}{ }^{--}+$chlorpromazine $^{+} \rightleftharpoons \mathrm{S}(\mathrm{IV})+$ chlorpromazyl $^{\bullet+}$

Chlorpromazine IUPAC PIN: 3-(2-chloro-10H-phenothiazin-10-yl)- $N, N$-dimethylpropan-1amine

\section{List of reports:}

$K_{\text {eq }}=(11 \pm 2)$ at $\mathrm{pH} 3.6, \mu=0.1 \mathrm{M}$, unspecified temperature [1]. Result obained by pulse radiolysis, by measurement of the equilibrium optical absorbance of the chlorpromazyl radical 4295 cation.

\section{Discussion}

We presume that the work was conducted at room temperature, $22 \pm 2{ }^{\circ} \mathrm{C}$.

Huie and Neta used $E=+0.78 \mathrm{~V}$ for the chlorpromazine $(\mathrm{ClPz})$ couple to derive $E=$ $+0.84 \mathrm{~V}$ for the $\mathrm{SO}_{3}{ }^{--} / \mathrm{S}(\mathrm{IV})$ couple at $\mathrm{pH} 3.6$. The value for $E^{\circ}\left(\mathrm{ClPz}^{\bullet+} / \mathrm{ClPz}^{+}\right)$was originally reported by Pelizzetti and Mentasti [2]. The Pelizzetti and Mentasti result was obtained in $1 \mathrm{M}$ $\mathrm{HClO}_{4}$, and there is no indication as to whether it should be applicable at $\mathrm{pH}$ 3.6. Several of the phenothiazine potentials reported by Pelizzetti and Mentasti subsequently have been argued to be incorrect [3].

Huie and Neta then used their $E$ value at $\mathrm{pH} 3.6$, literature $\mathrm{p} K_{\mathrm{a}}$ values for " $\mathrm{H}_{2} \mathrm{SO}_{3}$ " and $\mathrm{HSO}_{3}{ }^{-}$, and the assumption that $\mathrm{HSO}_{3}{ }^{\bullet}$ is completely dissociated in the $\mathrm{pH}$ range considered, to derive $E^{\circ}=+0.63 \mathrm{~V}$ for the couple $\mathrm{SO}_{3}{ }^{-}-\mathrm{SO}_{3}{ }^{2-}$.

Madej and Wardman have recently revised $E^{\circ}\left(\mathrm{ClPz}^{\cdot 2+} / \mathrm{ClPz}^{+}\right)$, using both pulse radiolysis and cyclic voltammetry to confirm their result; they now recommend $E^{\circ}=+0.860 \pm$

$4312+0.92 \pm 0.01 \mathrm{~V}$ for the $\mathrm{SO}_{3}{ }^{\bullet} / \mathrm{S}(\mathrm{IV})$ couple at $\mathrm{pH}$ 3.6. Adjustment for the $\mathrm{p} K_{\mathrm{a}} \mathrm{S}$ as described above 4313 leads to $E^{\circ}=+(0.71 \pm 0.1) \mathrm{V}$ for $\mathrm{SO}_{3}{ }^{\bullet-} / \mathrm{SO}_{3}{ }^{2-}$.

Recommended values:

$$
\begin{array}{ll}
\mathrm{SO}_{3}{ }^{\bullet-}+\text { chlorpromazine }^{+} \rightleftharpoons & \mathrm{S}(\mathrm{IV})+\text { chlorpromazyl }^{{ }^{2+}} \\
& K_{\mathrm{eq}}=(11 \pm 2) \text { at } \mathrm{pH} 3.6, \mu=0.1 \mathrm{M}, 22{ }^{\circ} \mathrm{C} \\
\mathrm{SO}_{3}{ }^{\bullet-}+\mathrm{e}^{-} \rightleftharpoons \mathrm{SO}_{3}{ }^{2-} & E^{\circ}=+(0.71 \pm 0.1) \mathrm{V}
\end{array}
$$


4321 List of auxiliary thermodynamic data: $E^{\circ}$ for chlorpromazyl, $\mathrm{p} K_{\mathrm{a}} 1$ and $\mathrm{p} K_{\mathrm{a}} 2$ for $\mathrm{SO}_{2}(a q)$ 4322

4323 Nomenclature: See Data Sheet 59

4324

4325 References

4326

4327 1. R. E. Huie, P. Neta, J. Phys. Chem. 88, 5665-5669 (1984).

4328 2. E. Pelizzetti, E. Mentasti, Inorg. Chem. 18, 583-588 (1979).

4329 3. S. V. Jovanovic, S. Steenken, M. G. Simic, J. Phys. Chem. 94, 3583-3588 (1990).

4330 4. E. Madej, P. Wardman, Rad. Phys. Chem. 75, 990-1000 (2006).

4331

4332 


\section{Data Sheet 62}

4335 Chemical equilibrium: $\mathrm{ClO}_{2}{ }^{\bullet}+\mathrm{SO}_{3}^{2-} \rightleftharpoons \mathrm{ClO}_{2}{ }^{-}+\mathrm{SO}_{3}{ }^{--}$

List of reported equilibrium constants:

$K_{\mathrm{c}}=2100$ from absorbance at $360 \mathrm{~nm}$ at $\mu=c a .1 \mathrm{M}$ [1].

4340 At $\mu=1 \mathrm{M}$, the extended Debye-Huckel treatment yields the activity coefficient ratio,

$4341 K_{\gamma}=\gamma_{\mathrm{ClO} 2-\gamma \gamma_{\mathrm{SO}} .-} / \gamma_{\mathrm{ClO} 2} \gamma_{\mathrm{SO} 2-}=2.31$. The thermodynamic equilibrium constant

$4342 \quad K=K_{\mathrm{c}} \times K \gamma=2100 \times 2.31=4850$.

4343 Taking $E^{\mathrm{o}}\left(\mathrm{ClO}_{2} \% \mathrm{ClO}_{2}{ }^{-}\right)=+0.934 \mathrm{~V}$ (Data Sheet 24)

$4344 E^{\mathrm{o}}\left(\mathrm{SO}_{3}{ }^{-} / \mathrm{SO}_{3}{ }^{2-}\right)=+(0.72 \pm 0.02) \mathrm{V}$.

Discussion

In ref. [1] an erroneous calculation was made, in that $K_{\mathrm{c}}$ was divided rather than multiplied by the otherwise correctly evaluated factor $K_{\gamma}=2.31$.

Some uncertainty is introduced into the value of $K_{62.1}$ because its determination neglected the association of $\mathrm{ClO}_{2}{ }^{\bullet}$ with $\mathrm{ClO}_{2}{ }^{-}$as in eq $62.2[2,3]$ :

$$
\mathrm{ClO}_{2}{ }^{\bullet}+\mathrm{ClO}_{2}{ }^{-} \rightleftharpoons\left(\mathrm{ClO}_{2}\right)_{2}{ }^{\bullet}
$$

A value of $5.01 \mathrm{M}^{-1}$ has been reported for $K_{62.2}$, which means that at the high $(1 \mathrm{M}) \mathrm{ClO}_{2}{ }^{-}$ concentrations used in measuring $K_{62.1}$ approximately $80 \%$ of the $\mathrm{ClO}_{2}{ }^{\bullet}$ will be bound as $\left(\mathrm{ClO}_{2}\right)_{2}{ }^{\circ}$. This species contributes significantly to the absorbance at the wavelength where $\mathrm{ClO}_{2}$ was monitored, which introduces an additional complication to the interpretation of the results. While it seems likely that $K_{62.1}$ is in the neighborhood of $5 \times 10^{3}$, further analysis of the experimental results is required.

\section{Recommended value:}

\section{References}


$4370 \quad$ 1. G. Merényi, J. Lind, X. Shen, J. Phys. Chem. 92, 134-137 (1988).

$4371 \quad 2 . \quad$ Z. Körtvelyesi, G. Gordon, J. Am. Wat. Works. Assoc. 96, 81-87 (2004).

4372 3. G. Gordon, F. Emmenegger, Inorg. Nucl. Chem. Lett. 2, 395-398 (1966).

4373 


\section{Data Sheet 63}

\section{List of reports:} was obtained by pulse radiolysis, by measuring the equilibrium optical absorbance of the phenoxyl radical.

$1 / K_{\mathrm{eq}}=(9-16)$ at $\mathrm{pH} 11.6$; this value was obtained at $(21 \pm 2){ }^{\circ} \mathrm{C}[2]$ and depends on $\mu$, Result obtained by pulse radiolysis, measuring the equilibrium optical absorbance of the phenoxyl radical.

\section{Discussion}

Huie and Neta (1984) used this equilibrium constant plus their (now) questionable $E^{\circ}\left(\mathrm{SO}_{3}{ }^{-} / \mathrm{SO}_{3}{ }^{2-}\right)$ to derive $E^{\circ}($ phenoxyl $/$ phenoxide $)=+0.70 \mathrm{~V}[1]$. of the equilibrium constant, and they measured the equilibrium constant as a function of ionic strength. Das et al. then used $E^{\circ}$ (phenoxyl/phenoxide $)=(0.80 \pm 0.01) \mathrm{V}$ to derive $E^{\circ}=+0.720 \mathrm{~V}$ for $\mathrm{SO}_{3}{ }^{\bullet} / \mathrm{SO}_{3}{ }^{2-}$. challenge, because the value of $1 / K$ at lowest ionic strength $(\mu=0.067 \mathrm{M})$ is rather divergent. Inspection of their Figure 3 reveals that this is probably a typo. Recalculation of the data in Das et al.'s Figure 3 and extrapolation to $\mu=0$ yields $1 / K^{\circ}=(18 \pm 1)$. Based on our current recommendation (Data Sheet S-2) for $E^{\circ}\left(\mathrm{PhO}^{\bullet} / \mathrm{PhO}^{-}\right)=+(0.793 \pm 0.008) \mathrm{V}$ we derive $E^{\circ}\left(\mathrm{SO}_{3}{ }^{\bullet-}\right.$ $\left./ \mathrm{SO}_{3}{ }^{2-}\right)=+(0.72 \pm 0.01) \mathrm{V}$.

\section{Recommended values:}

$$
\begin{array}{ll}
\mathrm{SO}_{3}{ }^{--}+\text {phenoxide }^{-} \rightleftharpoons \mathrm{SO}_{3}{ }^{2-}+\text { phenoxyl }^{\bullet} & K_{\mathrm{eq}}=(0.056 \pm 0.003) \\
\mathrm{SO}_{3}{ }^{--}+\mathrm{e}^{-} \rightleftharpoons \mathrm{SO}_{3}{ }^{2-} & E^{\circ}=+(0.72 \pm 0.01) \mathrm{V}
\end{array}
$$

Nomenclature; See Data Sheet 59. 
4409 List of auxiliary thermodynamic data: none

4410

\section{References}

4412

4413 1. R. E. Huie, P. Neta. J. Phys. Chem. 88, 5665-5669 (1984).

4414 2. T. N. Das, R. E. Huie, P. Neta. J. Phys. Chem. A 103, 3581-3588 (1999).

4415

4416 


\section{Data Sheet 64}

Chemical equilibrium: $\mathrm{TyrO}{ }^{\bullet}+\mathrm{SO}_{3}{ }^{2-} \rightleftharpoons \mathrm{TyrO}^{-}+\mathrm{SO}_{3}{ }^{\bullet-}$

$4420 \mathrm{TyrO}^{\bullet}$ is the phenoxyl radical from tyrosine; $\mathrm{TyrO}^{-}$is the phenoxide form of tyrosine.

\section{List of reports:} obtained by pulse radiolysis, by measurement of the equilibrium optical absorbance of the tyrosyl radical.

\section{Discussion}

Das, Huie, and Neta (1999) found only a small dependence of $K_{\mathrm{eq}}$ on $\mu, \mu=(0.1-0.3)$ M). We infer a value for $K^{\circ}$ of $(0.61 \pm 0.04)$. Das et al. also determined $E^{\circ}=+0.736 \mathrm{~V}$ for the tyrosyl radical at $\mathrm{pH} 11.3$ (relative to phenoxyl), and they used this result to derive $E^{\circ}=+0.736$ $\mathrm{V}$ for $\mathrm{SO}_{3}{ }^{-} / \mathrm{SO}_{3}{ }^{2-}$. Given that they assigned an uncertainty of $\pm 0.01 \mathrm{~V}$ to $E^{\circ}$ (phenoxyl), we propagate this to give an uncertainty of $\pm 0.01 \mathrm{~V}$ for $E^{\circ}\left(\mathrm{SO}_{3}{ }^{-} / \mathrm{SO}_{3}{ }^{2-}\right)$. We note that they assign an uncertainty of only $0.003 \mathrm{~V}$ to $E^{\circ}$, but this clearly does not take the uncertainty of the reference potential into account.

We currently recommend $E^{\circ}\left(\mathrm{TyrO}^{\bullet} / \mathrm{TyrO}^{-}\right)=+(0.723 \pm 0.010) \mathrm{V}$ (Supplementary Data

4438 Sheet S4). This leads to an adjustment of the derived value to $E^{\circ}\left(\mathrm{SO}_{3}{ }^{\circ-} / \mathrm{SO}_{3}{ }^{2-}\right)=+(0.723 \pm$ $44390.010) \mathrm{V}$.

\section{Recommended values:}

4441

4442

$$
\mathrm{TyrO}{ }^{\bullet}+\mathrm{SO}_{3}{ }^{2-} \rightleftharpoons \mathrm{TyrO}^{-}+\mathrm{SO}_{3}{ }^{-}
$$$$
K_{\text {eq }}=K_{\text {eq }}{ }^{\circ}=(0.61 \pm 0.04)
$$

$\mathrm{SO}_{3}{ }^{-}+\mathrm{e}^{-} \rightleftharpoons \mathrm{SO}_{3}^{2-}$

$E^{\circ}=+(0.723 \pm 0.01) \mathrm{V}$

4445 List of auxiliary thermodynamic data: none

4447 Nomenclature: See Data Sheet 59

\section{References}




\section{Data Sheet 65}

Chemical equilibrium: 3- $\mathrm{MeC}_{6} \mathrm{H}_{4} \mathrm{O}^{\bullet}+\mathrm{SO}_{3}^{2-} \rightleftharpoons 3-\mathrm{MeC}_{6} \mathrm{H}_{4} \mathrm{O}^{-}+\mathrm{SO}_{3}{ }^{\bullet-}$

3- $\mathrm{MeC}_{6} \mathrm{H}_{4} \mathrm{OH}=3$-cresol; IUPAC PIN: 3-methylphenol

\section{List of reports:}

\section{Discussion}

It is unclear how Das et al. extrapolated to zero ionic strength, given that they have data 4467 only at $\mu=0.80 \mathrm{M}$. We assume they made no correction and that $K^{\circ}=(0.88 \pm 0.09)$. Das et al. 4468 derive $E^{\circ}=+(0.737 \pm 0.004) \mathrm{V}$ for $\mathrm{SO}_{3}{ }^{-} / \mathrm{SO}_{3}{ }^{2-}$ based on $E^{\circ}=+(0.736 \pm 0.003) \mathrm{V}$ for the cresyl 4469 radical. The later, however, was measured relative to the phenoxyl radical, so full propagation of error gives an uncertainty of $\pm 0.01 \mathrm{~V}$ for $E^{\circ}\left(\mathrm{SO}_{3}{ }^{-} / \mathrm{SO}_{3}{ }^{2-}\right)$.

4471

Recommended values:

4473

$$
3-\mathrm{MeC}_{6} \mathrm{H}_{4} \mathrm{O}^{\bullet}+\mathrm{SO}_{3}^{2-} \rightleftharpoons 3-\mathrm{MeC}_{6} \mathrm{H}_{4} \mathrm{O}^{-}+\mathrm{SO}_{3}{ }^{\bullet-}
$$$$
K_{\mathrm{eq}}{ }^{\circ}=(0.88 \pm 0.09)
$$

$4475 \mathrm{SO}_{3}{ }^{-}+\mathrm{e}^{-} \rightleftharpoons \mathrm{SO}_{3}^{2-}$ $E^{\circ}=+(0.737 \pm 0.01) \mathrm{V}$

4476

Nomenclature: See Data Sheet 59.

4478

List of auxiliary thermodynamic data: none

4480

\section{References}

4482

4483 1. T. N. Das, R. E. Huie, P. Neta. J. Phys. Chem. A 103, 3581-3588 (1999). 


\section{Data Sheet 66}

Summary of the $\mathrm{SO}_{5}{ }^{\circ-}$ System

Tabulated below are the recommended equilibrium constants involving the $\mathrm{SO}_{5}{ }^{--}$radical.

Uncertainties are expressed as $\pm 1 \sigma$; in many cases the value of $\sigma$ is merely a subjective guess.

\begin{tabular}{|c|c|c|c|c|c|}
\hline $\operatorname{rxn} \#$ & Reaction & $K_{\text {eq }}$ & Uncertainty & $\mu / \mathrm{M}$ & $\begin{array}{l}\text { Data } \\
\text { Sheet \# }\end{array}$ \\
\hline 67.1 & $\mathrm{C}_{6} \mathrm{H}_{4} \mathrm{O}^{\bullet}+\mathrm{SO}_{5}^{2-} \rightleftharpoons \mathrm{C}_{6} \mathrm{H}_{4} \mathrm{O}^{-}+\mathrm{SO}_{5}^{\bullet-}$ & 0.28 & \pm 0.03 & 0.06 & 67 \\
\hline 68.1 & $\begin{array}{l}\text { 3- } \mathrm{Me}-\mathrm{C}_{6} \mathrm{H}_{4} \mathrm{O}^{\bullet}+\mathrm{SO}_{5}^{2-} \rightleftharpoons \\
3-\mathrm{Me}_{-} \mathrm{C}_{6} \mathrm{H}_{4} \mathrm{O}^{-}+\mathrm{SO}_{5}^{\bullet-}\end{array}$ & $3.7 \times 10^{-2}$ & $\pm 0.4 \times 10^{-2}$ & 0.382 & 68 \\
\hline 69.1 & $\mathrm{TyrO}^{\bullet}+\mathrm{SO}_{5}^{2-} \rightleftharpoons \mathrm{TyrO}^{-}+\mathrm{SO}_{5}^{\bullet-}$ & $2.1 \times 10^{-2}$ & $\pm 0.2 \times 10^{-2}$ & 0.4 & 69 \\
\hline 70.1 & $\mathrm{DMA}^{\bullet+}+\mathrm{SO}_{5}^{2-} \rightleftharpoons \mathrm{DMA}^{2-} \mathrm{SO}_{5}^{\bullet-}$ & $3.7 \times 10^{-3}$ & $\pm 0.4 \times 10^{-3}$ & $\sim 0.1$ & 70 \\
\hline
\end{tabular}

(DMA $=N, N$-dimethylaniline)

Reactions 67.1, 68.1, 69.1, and 70.1 lead to $E^{\circ}=+(0.813 \pm 0.008) \mathrm{V},+(0.81 \pm 0.01) \mathrm{V}$, $+(0.804 \pm 0.01) \mathrm{V}$, and $E^{\circ}=+(0.84 \pm 0.01) \mathrm{V}$, respectively, for the $\mathrm{SO}_{5}{ }^{--} / \mathrm{SO}_{5}{ }^{2-}$ couple. Das $e t$ al. suggest that the last value (from DMA) should be excluded because of the possibility that the DMA was incompletely dissolved [1]. Exclusion of reaction 70.1 leads to excellent agreement between the three other determinations, with an average value of $E^{\circ}=+(0.81 \pm 0.01) \mathrm{V}$ for $\mathrm{SO}_{5}{ }^{--} / \mathrm{SO}_{5}{ }^{2-}$. \pm 0.2 [3] , and thus $\Delta_{\mathrm{f}} G^{\circ}\left(\mathrm{SO}_{5}{ }^{2-}\right)=-(584 \pm 3) \mathrm{kJ} \mathrm{mol}^{-1}$. In combination with the $E^{\circ}$ recommended above we then derive $\Delta_{\mathrm{f}} G^{\circ}=-(506 \pm 3) \mathrm{kJ} \mathrm{mol}^{-1}$ for $\mathrm{SO}_{5}{ }^{\bullet-}$.

\section{Recommended values:}

$$
E^{\circ}=+(0.81 \pm 0.01) \mathrm{V} \text { for } \mathrm{SO}_{5}{ }^{\bullet-} / \mathrm{SO}_{5}^{2-}
$$

Nomenclature: $\mathrm{SO}_{5}^{\bullet-},($ dioxido)trioxidosulfate $(\bullet-)$

\section{References}

4513 1. T. N. Das, R. E. Huie, P. Neta. J. Phys. Chem. A 103, 3581-3588 (1999). 
4514 2. J. Balej. J. Electroanal. Chem. 214, 481-483 (1986).

4515 3. H. Elias, U. Götz, K. J. Wannowius. Atmos. Envir. 28, 439-448 (1994).

4516 


\section{$4517 \quad$ Data Sheet 67}

4518

4519 Chemical equilibrium: $\mathrm{C}_{6} \mathrm{H}_{4} \mathrm{O}^{\bullet}+\mathrm{SO}_{5}^{2-} \rightleftharpoons \mathrm{C}_{6} \mathrm{H}_{4} \mathrm{O}^{-}+\mathrm{SO}_{5}{ }^{-}$

4520

4521

\section{List of reports:}

4522

4523

$$
K_{\mathrm{eq}}=(0.28 \pm 0.03) \text { at } \mu=0.06 \mathrm{M}, \mathrm{pH} 11.3 \text {, and }(21 \pm 2)^{\circ} \mathrm{C}[1] \text {. Das et al. obtained this }
$$

4524 result by pulse radiolysis, measuring the position of equilibrium optically.

4525

4526

4527

4528

\section{Discussion}

Das et al. extrapolated $K_{\text {eq }}$ to zero ionic strength and then used $E^{\circ}=+0.800 \pm 0.005 \mathrm{~V}$ for the phenoxyl radical to derive $E^{\circ}=+(0.820 \pm 0.005) \mathrm{V}$ for $\mathrm{SO}_{5}{ }^{--} / \mathrm{SO}_{5}{ }^{2-}$. Use of our presently recommended reference potential; $(+0.793 \pm 0.008) \mathrm{V}$ for phenoxyl, Data Sheet S-2, leads to $E^{\circ}$ $=+(0.813 \pm 0.008) \mathrm{V}$ for $\mathrm{SO}_{5}{ }^{-} / \mathrm{SO}_{5}{ }^{2-}$.

4538 List of auxiliary thermodynamic data: none.

4539

4540 Nomenclature: See Data Sheet 66.

4541

4542

\section{References}

4543

4544 1. T. N. Das, R. E. Huie, P. Neta. J. Phys. Chem. A 103, 3581-3588 (1999).

4545 


\section{DataSheet 68}

4548

4549 Chemical equilibrium: $3-\mathrm{Me}_{-} \mathrm{C}_{6} \mathrm{H}_{4} \mathrm{O}^{\bullet}+\mathrm{SO}_{5}^{2-} \rightleftharpoons 3-\mathrm{Me}^{2-} \mathrm{C}_{6} \mathrm{H}_{4} \mathrm{O}^{-}+\mathrm{SO}_{5}{ }^{\bullet-}$

4550

4551

\section{List of reports:}

4552

4553

$$
K_{\text {eq }}=(3.7 \pm 0.4) \times 10^{-2} \text { at } \mu=0.382 \mathrm{M}, \mathrm{pH} 11.4 \text {, and }(21 \pm 2){ }^{\circ} \mathrm{C} \text { [1]. Das et al. obtained }
$$

this result by pulse radiolysis, measuring the position of equilibrium optically.

4555

4556

4557

4558

Discussion

4559

Das et al. extrapolated $K_{\text {eq }}$ to zero ionic strength and then used $E^{\circ}=+(0.736 \pm 0.003) \mathrm{V}$

4560 for the 3-methylphenoxyl radical to derive $E^{\circ}=+(0.806 \pm 0.005) \mathrm{V}$ for the $\mathrm{SO}_{5}{ }^{-} / \mathrm{SO}_{5}{ }^{2-}$ couple Use of our presently recommended reference potential $(+0.74 \pm 0.01 \mathrm{~V}$ for 3-methylphenoxyl,

4562

4563 Data Sheet S-3) leads to $E^{\circ}=+(0.81 \pm 0.01) \mathrm{V}$ for $\mathrm{SO}_{5}{ }^{\bullet-} / \mathrm{SO}_{5}{ }^{2-}$.

4564

4565

$K_{\text {eq }}=(3.7 \pm 0.4) \times 10^{-2}$ at $\mu=0.382 \mathrm{M}, \mathrm{pH} 11.4$, and $21 \pm 2{ }^{\circ} \mathrm{C}$

4566

$E^{\circ}=+(0.81 \pm 0.01) \mathrm{V}$ for $\mathrm{SO}_{5}{ }^{--} / \mathrm{SO}_{5}^{2-}$

4567

4568 List of auxiliary thermodynamic data: none.

4569

4570 Nomenclature: See Data Sheet 66.

4571

4572

\section{References}

4573

4574 1. T. N. Das, R. E. Huie, P. Neta. J. Phys. Chem. A 103, 3581-3588 (1999).

4575

4576 


\section{Data Sheet 69}

4578

4579

Chemical equilibrium: $\mathrm{TyrO}^{\bullet}+\mathrm{SO}_{5}{ }^{2-} \rightleftharpoons \mathrm{TyrO}^{-}+\mathrm{SO}_{5}{ }^{\bullet-}$

$4580 \mathrm{TyrO}^{\bullet}$ is the phenoxyl radical from tyrosine; $\mathrm{TyrO}^{-}$is the phenoxide form of tyrosine.

4581

4582

4583

4584

\section{List of reports:}

$$
K_{\text {eq }}=(2.1 \pm 0.2) \times 10^{-2} \text { at } \mu=0.40 \mathrm{M}, \mathrm{pH} 11.4 \text {, and }(21 \pm 2)^{\circ} \mathrm{C}[1] \text {. Das } \text { et al. obtained }
$$
this result by pulse radiolysis, measuring the position of equilibrium optically.

\section{Discussion}

Das et al. extrapolated $K_{\text {eq }}$ to zero ionic strength and then used $E^{\circ}=+(0.737 \pm 0.004) \mathrm{V}$

$K_{\text {eq }}=(2.1 \pm 0.2) \times 10^{-2}$ at $\mu=0.40 \mathrm{M}, \mathrm{pH} 11.4$, and $(21 \pm 2)^{\circ} \mathrm{C}$

$E^{\circ}=+(0.804 \pm 0.01) \mathrm{V}$ for $\mathrm{SO}_{5}{ }^{--} / \mathrm{SO}_{5}^{2-}$ for the tyrosyl radical to derive $E^{\circ}=+(0.818 \pm 0.005) \mathrm{V}$ for $\mathrm{SO}_{5}{ }^{\bullet-} / \mathrm{SO}_{5}{ }^{2-}$. Use of our presently recommended reference potential $(+0.723 \pm 0.01 \mathrm{~V}$ for the tyrosyl/tyrosine couple, Data Sheet $\mathrm{S}-$ 4) leads to $E^{\circ}=+(0.804 \pm 0.01) \mathrm{V}$ for $\mathrm{SO}_{5}{ }^{--} / \mathrm{SO}_{5}{ }^{2-}$.

4601 Nomenclature: See Data Sheet 66.

4602

\section{References}

4604

4605 1. T. N. Das, R. E. Huie, P. Neta. J. Phys. Chem. A 103, 3581-3588 (1999). 


\section{Data Sheet 70}

Chemical equilibrium: $\mathrm{DMA}^{\bullet+}+\mathrm{SO}_{5}^{2-} \rightleftharpoons \mathrm{DMA}+\mathrm{SO}_{5}^{\bullet-}$

$4611 \quad(\mathrm{DMA}=N, N$-dimethylaniline $)$

4612

\section{List of reports:}

$$
K_{\text {eq }}=(3.7 \pm 0.4) \times 10^{-3} \text { at } \mu=(0.090-0.141) \mathrm{M}, \mathrm{pH} 11 \text {, and }(21 \pm 2){ }^{\circ} \mathrm{C}[1] \text {. Das et al. }
$$
obtained this result by pulse radiolysis, measuring the position of equilibrium optically.

\section{Discussion}

4618

Das et al. extrapolated $K_{\text {eq }}$ to zero ionic strength and then used $E^{\circ}=+(0.692 \pm 0.003) \mathrm{V}$ for the $\mathrm{DMA}^{\bullet+}$ radical to derive $E^{\circ}=+(0.836 \pm 0.005) \mathrm{V}$ for $\mathrm{SO}_{5}{ }^{\bullet-} / \mathrm{SO}_{5}{ }^{2-}$. Use of our presently recommended reference potential $(+0.69 \pm 0.01) \mathrm{V}$ for DMA, Data Sheet S-5 leads to $E^{\circ}=$ $+(0.84 \pm 0.01) \mathrm{V}$ for $\mathrm{SO}_{5} / \mathrm{SO}_{5}{ }^{2-}$. Das et al. suggest that the equilibrium constant may not be very accurate because in incomplete dissolution of DMA.

\section{Recommended values:}

$K_{\text {eq }}=(3.7 \pm 0.4) \times 10^{-3}$ at $\mu=(0.0 .090-0.141) \mathrm{M}, \mathrm{pH} 11$, and $(21 \pm 2)^{\circ} \mathrm{C}$ $E^{\circ}=+(0.84 \pm 0.01) \mathrm{V}$ for $\mathrm{SO}_{5}{ }^{--} / \mathrm{SO}_{5}^{2-}$

\section{References}

4633

4634

1. T. N. Das, R. E. Huie, P. Neta. J. Phys. Chem. A 103, 3581-3588 (1999).

4635

4636 


\section{Data Sheet 71}

4638 Summary of the $\mathrm{S}_{2} \mathrm{O}_{3}{ }^{-} / \mathrm{S}_{4} \mathrm{O}_{6}{ }^{\bullet-}$ System

Tabulated below are the presently recommended equilibrium constants involving this related 4641 group of hexaoxidodisulfate $(\bullet 3-)$ (thiosulfate and tetrathionate-derived) radicals. Uncertainties 4642 are expressed as $\pm 1 \sigma$; in many cases the value of $\sigma$ is merely a subjective guess.

4643

\begin{tabular}{|c|c|c|c|c|c|c|}
\hline rxn \# & reaction & $K_{\mathrm{eq}}$ & $\operatorname{dim}$. & uncertainty & $\mu / \mathrm{M}$ & $\begin{array}{l}\text { Data } \\
\text { Sheet \# }\end{array}$ \\
\hline 72.1 & $\begin{array}{l}\mathrm{N}_{3}^{\bullet}+2 \mathrm{~S}_{2} \mathrm{O}_{3}^{2-} \rightleftharpoons \mathrm{N}_{3}^{-}+ \\
\left(\mathrm{S}_{2} \mathrm{O}_{3}\right)_{2}{ }^{\bullet-}\end{array}$ & $1.9 \times 10^{4}$ & $\mathrm{M}^{-1}$ & $\pm 0.2 \times 10^{4}$ & 0.44 & 72 \\
\hline 73.1 & $\begin{array}{l}4-\mathrm{CNC}_{6} \mathrm{H}_{4} \mathrm{O}^{\bullet}+2 \mathrm{~S}_{2} \mathrm{O}_{3}{ }^{2-} \rightleftharpoons \\
4-\mathrm{CNC}_{6} \mathrm{H}_{4} \mathrm{O}^{-}+\left(\mathrm{S}_{2} \mathrm{O}_{3}\right)_{2}{ }^{\bullet 3-}\end{array}$ & 2.2 & $\mathrm{M}^{-1}$ & \pm 0.2 & 0.28 & 73 \\
\hline 74.1 & $\mathrm{HS}_{4} \mathrm{O}_{6} \cdot{ }^{\cdot 2-} \rightleftharpoons \mathrm{S}_{4} \mathrm{O}_{6} \cdot{ }^{\bullet-}+\mathrm{H}^{+}$ & $\mathrm{p} K_{\mathrm{a}}=6.2$ & & & & 74 \\
\hline 75.1 & $\begin{array}{r}\mathrm{S}_{2} \mathrm{O}_{3}^{\bullet-}+\mathrm{SCN}^{-} \rightleftharpoons \\
\mathrm{SCNS}_{2} \mathrm{O}_{3}^{\bullet-}\end{array}$ & $1.2 \times 10^{3}$ & $\mathrm{M}^{-1}$ & $\begin{array}{l}(2.4-0.6) \times \\
10^{3}\end{array}$ & $?$ & 75 \\
\hline 76.1 & $\begin{array}{l}(\mathrm{SCN})_{2}{ }^{\bullet-}+\mathrm{S}_{2} \mathrm{O}_{3}^{2-} \rightleftharpoons \\
\mathrm{SCNS}_{2} \mathrm{O}_{3}{ }^{\bullet-}+\mathrm{SCN}^{-}\end{array}$ & $1.6 \times 10^{2}$ & & $\pm 0.4 \times 10^{2}$ & 0.0 & 76 \\
\hline
\end{tabular}

4644

4645

4646

4647

4648

4649

4650

4651

4652

4653

4654

4655

4656

4657

4658

4659

The equilibrium constant for the reaction

$$
\mathrm{S}_{2} \mathrm{O}_{3}{ }^{\bullet-}+2 \mathrm{SCN}^{-} \rightleftharpoons \mathrm{S}_{2} \mathrm{O}_{3}{ }^{2-}+(\mathrm{SCN})_{2}{ }^{--}
$$

is obtained as the ratio of $K_{75.1} / K_{76.1}: K=7.5 \mathrm{M}^{-1}$ within a factor of 2.1. Given our recommended $E^{\circ}=+1.30 \pm 0.02 \mathrm{~V}$ for $(\mathrm{SCN}) 2^{\bullet} / 2 \mathrm{SCN}^{-}$, we derive $E^{\circ}=+(1.35 \pm 0.03) \mathrm{V}$ for $\mathrm{S}_{2} \mathrm{O}_{3}{ }^{\circ} / \mathrm{S}_{2} \mathrm{O}_{3}{ }^{2-}$.

An independent derivation of $E^{\circ}=+1.30 \mathrm{~V}$ for $\mathrm{S}_{2} \mathrm{O}_{3}{ }^{\bullet} / \mathrm{S}_{2} \mathrm{O}_{3}{ }^{2-}$ at $\mu=0.1 \mathrm{M}$ was obtained from the rate constants for oxidation of $\mathrm{S}_{2} \mathrm{O}_{3}{ }^{2-}$ by several outer-sphere metal-complex oxidants, making the assumption that the reverse reactions had diffusion-controlled rates [1].

In view of the ionic strength issues, the agreement between the two above determinations is good. We recommend the value derived from the thiocyanate equilibria because an assumed (not measured) reverse rate constant was used for the derivation from the reactions with metal complexes.The NBS Tables [2] give $\Delta_{\mathrm{f}} G^{\circ}=-(522.5 \pm 8) \mathrm{kJ} \mathrm{mol}^{-1}$ for $\mathrm{S}_{2} \mathrm{O}_{3}{ }^{2-}(a q)$. Thus, we derive $\Delta_{\mathrm{f}} G^{\circ}=-(392 \pm 8) \mathrm{kJ} \mathrm{mol}^{-1}$ for $\mathrm{S}_{2} \mathrm{O}_{3}{ }^{\circ}(a q)$. Note that Cobble et al. [2a] recommend a value of $-(544.3 \pm 7.5) \mathrm{kJ} \mathrm{mol}^{-1}$ for $\Delta_{\mathrm{f}} G^{\circ}\left(\mathrm{S}_{2} \mathrm{O}_{3}{ }^{2-}\right)$, which differs substantially from the NBS 
value; however, to maintain consistency we retain the NBS value in calculating our recommended values.

Reaction 72.1 leads to $E^{\circ}=+(1.10 \pm 0.01) \mathrm{V}$ for $\mathrm{S}_{4} \mathrm{O}_{6}{ }^{\circ-} / 2 \mathrm{~S}_{2} \mathrm{O}_{3}{ }^{2-}$, while reaction 73.1

4663 leads to $+(1.09 \pm 0.03) \mathrm{V}$ for this potential. The two results are equivalent within the specified 4664 uncertainties, and thus we recommend the more precise value derived from reaction 72.1. The 4665 corresponding $\Delta_{\mathrm{f}} G^{\circ}$ is $-(939 \pm 8) \mathrm{kJ} \mathrm{mol}^{-1}$ for $\mathrm{S}_{4} \mathrm{O}_{6}{ }^{\circ 3-}$.

$\left(\mathrm{S}_{2} \mathrm{O}_{3}\right)_{2}{ }^{\bullet-} \rightleftharpoons \mathrm{S}_{2} \mathrm{O}_{3}{ }^{\bullet}+\mathrm{S}_{2} \mathrm{O}_{3}{ }^{2-}$

Their result, $K_{71.2}=1.3 \times 10^{-4} \mathrm{M}$, is based on $E^{\circ}$ values that differ slightly from our recommended values; however, the differing $E^{\circ}$ values lead to an approximate cancellation of

4673 errors, so the final result is not much affected. Given the uncertainties in the component $E^{\circ}$

4674 values, we assign an uncertainty of a factor of 3 for $K_{71.2}$. Thus, the reverse of reaction 71.2

4675 (which is a hemicolligation reaction) has $\log K_{\mathrm{eq}}=(4.1 \pm 0.5)$.

4676

\section{Recommended values:}

4678

4679

$E^{\circ}=+(1.35 \pm 0.03) \mathrm{V}$ for $\mathrm{S}_{2} \mathrm{O}_{3}{ }^{\circ-} / \mathrm{S}_{2} \mathrm{O}_{3}{ }^{2-}$ at $25^{\circ} \mathrm{C}$ and $\mu=0 \mathrm{M}$.

4680

$\Delta_{\mathrm{f}} G^{\circ}=-(392 \pm 8) \mathrm{kJ} \mathrm{mol}^{-1}$ for $\mathrm{S}_{2} \mathrm{O}_{3}{ }^{-}$

4681

$\mathrm{p} K_{\mathrm{a}}=6.2$ for $\mathrm{HS}_{4} \mathrm{O}_{6}{ }^{\circ-}$

4682

$E^{\circ}=+(1.10 \pm 0.01) \mathrm{V}$ for $\mathrm{S}_{4} \mathrm{O}_{6}{ }^{\circ-} / 2 \mathrm{~S}_{2} \mathrm{O}_{3}{ }^{2-}$

4683

$\Delta_{\mathrm{f}} G^{\circ}$ is $-(939 \pm 8) \mathrm{kJ} \mathrm{mol}^{-1}$ for $\mathrm{S}_{4} \mathrm{O}_{6}{ }^{\circ-}$

4684

$\log K_{\text {eq }}=(4.1 \pm 0.5)$ for $\mathrm{S}_{2} \mathrm{O}_{3}{ }^{\circ-}+\mathrm{S}_{2} \mathrm{O}_{3}{ }^{2-}=\mathrm{S}_{4} \mathrm{O}_{6}{ }^{\bullet-}$

Nomenclature: $\mathrm{N}_{3}{ }^{\bullet}$, trinitrogen $(2 N-N)(\bullet) ; \mathrm{N}_{3}^{-}$, trinitride $(1-) ; \mathrm{SCN}^{-}$, nitridosulfidocarbonate $(1-)$, thiocyanate is allowed; $(\mathrm{SCN}) 2^{\bullet}$, bis(nitridosulfidocarbonate) $(S-S)(\bullet 1-) ; \mathrm{S}_{2} \mathrm{O}_{3}{ }^{\bullet-}$,

4688 trioxidosulfidosulfate $(S-S)(\bullet-)$; $\mathrm{S}_{2} \mathrm{O}_{3}{ }^{2-}$, trioxidosulfidosulfate $(S-S)(2-)$, thiosulfate is allowed;

$4689 \mathrm{~S}_{4} \mathrm{O}_{6}{ }^{\bullet-}$, bis[(trioxidosulfate)sulfate] $(\bullet 3-)$, and $\mathrm{SCNS}_{2} \mathrm{O}_{3}{ }^{\bullet 2-}$,

4690 (nitridosulfidocarbonato)trioxidosulfidosulfate $(\bullet 2-)$

\section{References}

4693

4694 1. R. Sarala, D. M. Stanbury. Inorg. Chem. 31, 2771-2777 (1992). 
$4695 \quad 2 . \quad$ D. D. Wagman, W. H. Evans, V. B. Parker, R. H. Schumm, I. Halow, S. M. Bailey, K. L. 4696 Churney, R. L. Nuttall. J. Phys. Chem. Ref. Data 11, Suppl. No. 2 (1982).

4697 2a. J. W. Cobble, H. P. Stephens, I. R. McKinnon, E. F. Westrum. Inorg. Chem. 11, 166946981674 (1972).

4699 3. T. N. Das, R. E. Huie, P. Neta. J. Phys. Chem. A 103, 3581-3588 (1999).

4700 


\section{Data Sheet 72}

Chemical equilibrium: $\mathrm{N}_{3}{ }^{\bullet}+2 \mathrm{~S}_{2} \mathrm{O}_{3}{ }^{2-} \rightleftharpoons \mathrm{N}_{3}{ }^{-}+\left(\mathrm{S}_{2} \mathrm{O}_{3}\right)_{2}{ }^{\bullet-}$

\section{List of reports:}

$$
K_{\text {eq }}=(2.0 \pm 0.2) \times 10^{4} \mathrm{M}^{-1} \text { at } \mu=0.85 \mathrm{M} \text { and }(21 \pm 2){ }^{\circ} \mathrm{C}[1] \text {. Result obtained by pulse }
$$
radiolysis with optical detection of the position of equilibrium. radiolysis with optical detection of the position of equilibrium.

\section{Discussion}

Das et al. ${ }^{1}$ argue that the species $\left(\mathrm{S}_{2} \mathrm{O}_{3}\right)_{2}{ }^{\bullet-}\left(\right.$ or $\left.\mathrm{S}_{4} \mathrm{O}_{6}{ }^{\bullet-}\right)$ on the time scale of the above measurements is not $\left(\mathrm{O}_{3} \mathrm{SSSSO}_{3}\right)^{\bullet 3-}$ but rather an isomer, such as $\left(\mathrm{O}_{3} \mathrm{SSOSO}_{2} \mathrm{~S}\right)^{\bullet{ }^{\bullet 3}}$. the equilibrium constant to zero ionic strength by use of an incorrect equation (their eq. 27) for activity coefficients. The equation used may be appropriate when all reactants are uncharged as in their eq 26, but this is not the case for reaction 72.1 .

A more correct equation can be derived as follows: first,

$\log K^{\circ}=\log K+\log \left(\gamma\left(\mathrm{N}_{3}{ }^{-}\right) \gamma\left(\mathrm{S}_{4} \mathrm{O}_{6}{ }^{\bullet-}\right) / \gamma\left(\mathrm{S}_{2} \mathrm{O}_{3}{ }^{2-}\right)^{2}\right)$

4724

Then, we use the Guggenheim eq. for single-ion activity coefficients:

4726 $\log \gamma=-A z_{i}^{2} \mu^{1 / 2} /\left(1+\mu^{1 / 2}\right)+\beta \mu$.

This leads to $\log K^{\circ}=\log K-A \mu^{1 / 2} /\left(1+\mu^{1 / 2}\right)\left(z\left(\mathrm{~N}_{3}{ }^{-}\right)^{2}+z\left(\mathrm{~S}_{4} \mathrm{O}_{6}{ }^{\bullet-}\right)^{2}-2 z\left(\mathrm{~S}_{2} \mathrm{O}_{3}{ }^{2-}\right)^{2}\right)$

Thus, $\log K^{\circ}=\log K-A \mu^{1 / 2} /\left(1+\mu^{1 / 2}\right)\left((-1)^{2}+(-3)^{2}-2(-2)^{2}\right)=\log K-A \mu^{1 / 2} /\left(1+\mu^{1 / 2}\right)(2)$ or, $\log K=\log K^{\circ}+2 A \mu^{1 / 2} /\left(1+\mu^{1 / 2}\right)$. $A=0.509$ for water at $25^{\circ} \mathrm{C}$.

4734 From the data at $\mu=0.44 \mathrm{M}$ we thus calculate $\log K^{\circ}=3.87$, and $\Delta E=0.229 \mathrm{~V}$. With our 4735 recommended $E^{\circ}=+(1.33 \pm 0.01) \mathrm{V}$ for $\mathrm{N}_{3}{ }^{\bullet} / \mathrm{N}_{3}{ }^{-}$we then obtain $E^{\circ}=+(1.10 \pm 0.01) \mathrm{V}$. 
4737 Recommended values:

4738

$4739 \quad K_{\text {eq }}=(1.9 \pm 0.2) \times 10^{4} \mathrm{M}^{-1}$ at $\mu=0.44 \mathrm{M}$ and $(21 \pm 2){ }^{\circ} \mathrm{C}$

$4740 \quad \log K^{\circ}=(3.87 \pm 0.04)$ at $\mu=0.0 \mathrm{M}$

$4741 \quad E^{\circ}=+(1.10 \pm 0.01) \mathrm{V}$ for $\mathrm{S}_{4} \mathrm{O}_{6}{ }^{\cdot 3-} / 2 \mathrm{~S}_{2} \mathrm{O}_{3}{ }^{2-}$

4742

4743 Nomenclature: see Data Sheet 71.

4744

4745 List of auxiliary thermodynamic data: none.

4746

4747 References

4748

4749 1. T. N. Das, R. E. Huie, P. Neta. J. Phys. Chem. A 103, 3581-3588 (1999).

4750

4751

4752 


\section{Data Sheet 73}

Chemical equilibrium: $4-\mathrm{CNC}_{6} \mathrm{H}_{4} \mathrm{O}^{\bullet}+2 \mathrm{~S}_{2} \mathrm{O}_{3}{ }^{2-} \rightleftharpoons 4-\mathrm{CNC}_{6} \mathrm{H}_{4} \mathrm{O}^{-}+\left(\mathrm{S}_{2} \mathrm{O}_{3}\right)_{2}{ }^{\bullet-}$

$$
\text { 4- } \mathrm{CNC}_{6} \mathrm{H}_{4} \mathrm{O}^{-}=4 \text {-cyanophenoxide }
$$

\section{List of reports:}

$$
K_{\text {eq }}=(2.2 \pm 0.2) \mathrm{M}^{-1} \text { at } \mu=0.28 \mathrm{M} \text { and }(21 \pm 2){ }^{\circ} \mathrm{C} \text { [1]. Result obtained by pulse }
$$
radiolysis with optical detection of the position of equilibrium.

\section{Discussion}

This equilibrium constant should be sensitive to ionic strength. Das et al. [1] corrected the equilibrium constant to zero ionic strength by use of an incorrect equation (their eq 27) for activity coefficients. The equation used may be appropriate when all reactants are uncharged as in their eq 26 , but this is not the case for reaction 73.1 .

A more correct eq can be derived as follows: first,

$\log K^{\circ}=\log K+\log \left(\gamma\left(4-\mathrm{CNC}_{6} \mathrm{H}_{4} \mathrm{O}^{-}\right) \gamma\left(\mathrm{S}_{4} \mathrm{O}_{6}{ }^{\cdot 3-}\right) / \gamma\left(\mathrm{S}_{2} \mathrm{O}_{3}{ }^{2-}\right)^{2}\right)$

4773

$$
=\log K+\log \gamma\left(4-\mathrm{CNC}_{6} \mathrm{H}_{4} \mathrm{O}^{-}\right)+\log \gamma\left(\mathrm{S}_{4} \mathrm{O}_{6}{ }^{\cdot 3-}\right)-2 \log \gamma\left(\mathrm{S}_{2} \mathrm{O}_{3}{ }^{2-}\right)
$$

Then, we use the Guggenheim eq. for single-ion activity coefficients:

So, $\log K^{\circ}=\log K-A \mu^{1 / 2} /\left(1+\mu^{1 / 2}\right)\left((-1)^{2}+(-3)^{2}-2(-2)^{2}\right)=\log K-A \mu^{1 / 2} /\left(1+\mu^{1 / 2}\right)(2)$ or, $\log K=\log K^{\circ}+2 A \mu^{1 / 2} /\left(1+\mu^{1 / 2}\right)$. $A=0.509$ for water at $25^{\circ} \mathrm{C}$.

From the data at $\mu=0.28 \mathrm{M}$ we thus calculate $\log K^{\circ}=-(0.010 \pm 0.020)$, and $\Delta E=-(0.001 \pm$ $0.002) \mathrm{V}$. With our recommended $E^{\circ}=+(1.09 \pm 0.03) \mathrm{V} 4-\mathrm{CNC}_{6} \mathrm{H}_{4} \mathrm{O} / 4-\mathrm{CNC}_{6} \mathrm{H}_{4} \mathrm{O}^{-}$(Data Sheet $\mathrm{S}-6)$ we then obtain $E^{\circ}=+(1.09 \pm 0.03) \mathrm{V}$ for $\mathrm{S}_{4} \mathrm{O}_{6}{ }^{\bullet-}-2 \mathrm{~S}_{2} \mathrm{O}_{3}{ }^{2-}$.

\section{Recommended values:}


$4789 \quad K_{\text {eq }}=(2.2 \pm 0.2) \mathrm{M}^{-1}$ at $\mu=0.28 \mathrm{M}$ and $(21 \pm 2){ }^{\circ} \mathrm{C}$

$4790 \quad \log K^{\circ}=-(0.01 \pm 0.02)$ at $\mu=0.0 \mathrm{M}$

$4791 E^{\circ}=+(1.09 \pm 0.03) \mathrm{V}$ for $\mathrm{S}_{4} \mathrm{O}_{6}{ }^{\cdot 3-} / 2 \mathrm{~S}_{2} \mathrm{O}_{3}{ }^{2-}$

4792

4793 Nomenclature: see Data Sheet 71.

4794

4795 List of auxiliary thermodynamic data: none.

4796

4797 References

4798

4799 1. T. N. Das, R. E. Huie, P. Neta. J. Phys. Chem. A 103, 3581-3588 (1999).

4800

4801 


\section{Data Sheet 74}

4803

4804 Chemical equilibrium: $\mathrm{HS}_{4} \mathrm{O}_{6}{ }^{\circ-} \rightleftharpoons \mathrm{S}_{4} \mathrm{O}_{6}{ }^{\bullet 3-}+\mathrm{H}^{+}$

4805

\section{List of reports:}

4807

4808

4809

$$
\mathrm{p} K_{\mathrm{a}}=6.2 \text { [1]. Determined by pulse radiolysis of } \mathrm{S}_{2} \mathrm{O}_{3}{ }^{2-} \text { solutions, with conductivity }
$$

4810

4811

4812

4813

4814 measured $25 \mu$ s after the pulse.

4815 performed at $\mathrm{pH} 8.8$ and 12 , and thus do not disagree with the reported $\mathrm{p} K_{\mathrm{a}}$.

4816

4817 Recommended value:

4818

$4819 \mathrm{p} K_{\mathrm{a}}=6.2$

4820

4821 List of auxiliary thermodynamic data: none.

4822

4823

\section{References}

4824

4825 1. M. Schöneshöfer. Int. J. Radiat. Phys. Chem. 5, 375-386 (1973).

4826 2. T. N. Das, R. E. Huie, P. Neta. J. Phys. Chem. A 103, 3581-3588 (1999).

4827

4828 


\section{Data Sheet 75}

4830

4831

Chemical equilibrium: $\mathrm{S}_{2} \mathrm{O}_{3}{ }^{\bullet-}+\mathrm{SCN}^{-} \rightleftharpoons \mathrm{SCNS}_{2} \mathrm{O}_{3}{ }^{\bullet-}$

4832

\section{List of reports:}

4834

4835

$1 / K_{\mathrm{eq}}=(8.3 \pm 2.5) \times 10^{-4} \mathrm{M}$, presumably at room temperature, with $\mu$ varying from 0.01

$4836 \mathrm{M}$ to $0.12 \mathrm{M}$ [1]. Obtained by pulse radiolysis of $\mathrm{SCN}^{-} / \mathrm{S}_{2} \mathrm{O}_{3}{ }^{2-}$ mixtures, deriving the equilibrium 4837 constant from the thiocyanate dependence of the kinetics.

4838

4839

4840

4841

The equilibrium constant is not expected to differ significantly between room

4842 temperature and $25^{\circ} \mathrm{C}$. On the other hand, $K_{\text {eq }}$ is expected to be sensitive to ionic strength, which

4843 varied drastically in these experiments. Given this concern, we expand the uncertainty to \pm a

4844 factor of 2.

4845

4846

Recommended value:

4847

$4848 \quad K_{\mathrm{eq}}=1.2 \times 10^{3} \mathrm{M}^{-1}$ within a factor of 2.

4849

4850 List of auxiliary thermodynamic data: none.

4851

4852 References

4853

4854 1. M. Schöneshöfer. Ber. Bunsen-Ges. Phys. Chem. 77, 257-262 (1973).

4855

4856 


\section{Data Sheet 76}

4858

4859

Chemical equilibrium: $(\mathrm{SCN})_{2}{ }^{\bullet-}+\mathrm{S}_{2} \mathrm{O}_{3}^{2-} \rightleftharpoons \mathrm{SCNS}_{2} \mathrm{O}_{3}{ }^{\bullet-}+\mathrm{SCN}^{-}$

4860

4861

\section{List of reports:}

4862

4863

$K_{\text {eq }}=(1.6 \pm 0.4) \times 10^{2}$, presumably at room temperature, with $\mu$ ranging from $0.01 \mathrm{M}$ to $48640.1 \mathrm{M}$ [1]. Obtained by pulse radiolysis of $\mathrm{SCN}^{-} / \mathrm{S}_{2} \mathrm{O}_{3}{ }^{2-}$ mixtures, and derivation of the 4865 equilibrium constant from the thiocyanate dependence of the kinetics.

4866

4867

4868

4869

This equilibrium constant is expected to be insensitive to ionic strength; thus, the variable

4870 ionic strength in the experiments is not a concern. The equilibrium constant is not expected to

4871 differ significantly between room temperature and $25^{\circ} \mathrm{C}$.

4872

4873

Recommended value:

4874

4875

$K_{\text {eq }}=(1.6 \pm 0.4) \times 10^{2}$ at $\mu=0.0 \mathrm{M}$ and $25^{\circ} \mathrm{C}$.

4876

4877 List of auxiliary thermodynamic data: none.

4878

4879

\section{References}

4880

4881 1. M. Schöneshöfer. Ber. Bunsen-Ges. Phys. Chem. 77, 257-262 (1973).

4882

4883 


\section{Data Sheet 77}

Chemical equilibrium:

$$
4-\mathrm{OCH}_{3}-\mathrm{C}_{6} \mathrm{H}_{4}-\mathrm{NH}_{2}{ }^{\bullet+}+\mathrm{HS}^{-} / \mathrm{H}_{2} \mathrm{~S} \rightleftharpoons 4-\mathrm{OCH}_{3}-\mathrm{C}_{6} \mathrm{H}_{4}-\mathrm{NH}_{2}+\mathrm{S}^{\bullet-} \text { at } \mathrm{pH}=7
$$

\section{List of reports:}

Only one study has been made of this system. Das et al. [1] used pulse radiolysis to measure the equilibrium quotient as $(68 \pm 10) \mathrm{M}^{-1}$ for reaction 77.2 at $\mathrm{pH} 7$ and $\mu=0.1 \mathrm{M}$ :

$$
\begin{aligned}
& 4-\mathrm{OCH}_{3}-\mathrm{C}_{6} \mathrm{H}_{4}-\mathrm{NH}_{2}^{\bullet+}+2 \mathrm{HS}^{-} / \mathrm{H}_{2} \mathrm{~S} \rightleftharpoons 4-\mathrm{OCH}_{3}-\mathrm{C}_{6} \mathrm{H}_{4}-\mathrm{NH}_{2}+\mathrm{HSS}^{\bullet 2-}+\mathrm{H}^{+} \text {at } \mathrm{pH}=7 \\
& \mathrm{~S}^{\bullet-}+\mathrm{SH}^{-} \rightleftharpoons \mathrm{HSS}^{\bullet-}
\end{aligned}
$$

4895

By combining the equilibrium quotients for reactions 77.2 and 77.3 (taken as $9 \times 10^{3} \mathrm{M}^{-1}$, see Data Sheet 117) we calculate the equilibrium constant for reaction 77.1 to be $7.55 \times 10^{-3}$ at $\mathrm{pH}=$ 7. Using $+0.79 \mathrm{~V}$ reported for the anilinium couple [2], Das et al. calculated $E^{\circ}\left(\mathrm{S}^{\bullet-} /\left(\mathrm{HS}^{-} / \mathrm{H}_{2} \mathrm{~S}\right)\right)$

The equilibrium "constant" calculated above for reaction 77.1 is obtained by combining equilibrium quotients at different ionic strengths, and hence is not well defined. Further complicating matters, the $E^{\circ}\left(\mathrm{S}^{\bullet-} /\left(\mathrm{HS}^{-} / \mathrm{H}_{2} \mathrm{~S}\right)\right)$ value is derived by using the aniline $E^{\circ}$ value, leading to a further mixing of conditions. In what follows we make the approximation that results are obtained at zero ionic strength.

The newly revised $E^{\circ}$-value for promethazine [3] raises the $E^{\circ}$ of the anilinium couple to $4909+(0.80 \pm 0.02) \mathrm{V}$ (see Supplementry Data Sheet S-11). Hence $E^{\circ}\left(\mathrm{S}^{\bullet-} /\left(\mathrm{HS}^{-} / \mathrm{H}_{2} \mathrm{~S}\right)\right)=+(0.93 \pm$ $49100.03) \mathrm{V}$ at $\mathrm{pH}=7$ and $\mu=0$. Utilizing that $\mathrm{p} K_{\mathrm{a}}\left(\mathrm{H}_{2} \mathrm{~S}\right)=6.97$ and noting that $\mathrm{p} K_{\mathrm{a}}\left(\mathrm{HS}^{\bullet}\right)<<7$, we 4911 can calculate from these data the following potentials at $\mathrm{pH}=0$ :

4916 From recently revised and apparently rather accurate gas phase data [4], we calculate $4917 \Delta_{\mathrm{f}} G^{\mathrm{o}}\left(\mathrm{HS}^{\bullet}(\mathrm{g})\right)=113.6 \mathrm{~kJ} \mathrm{~mol}^{-1}$. As is well-known, $\Delta_{\mathrm{f}} G^{\mathrm{o}}\left(\mathrm{H}_{2} \mathrm{~S}(\mathrm{~g})\right)=-35.56 \mathrm{~kJ} \mathrm{~mol}^{-1}$. The Henry's 4918 law constants, $K_{\mathrm{H}}$, of sulfides increase monotonously with increasing alkylation [5]. Thus, they 
$4920 \mathrm{MPa}^{-1}(0.54 \mathrm{M} / \mathrm{bar})$ for $\left(\mathrm{CH}_{3}\right)_{2} \mathrm{~S}$. This trend reveals that hydrogen bonding between $\mathrm{S}-\mathrm{H}$ bonds 4921 and water oxygens are of no consequence. Rather it is the hydrogen bonding between the lone 4922 pair on $\mathrm{S}$ and the water protons that matter. This suggests that $K_{\mathrm{H}}\left(\mathrm{H}_{2} \mathrm{~S}\right) / K_{\mathrm{H}}\left(\mathrm{HS}^{\bullet}\right) \leq$ $4923 K_{\mathrm{H}}\left(\mathrm{HSCH}_{3}\right) / K_{\mathrm{H}}\left(\mathrm{H}_{2} \mathrm{~S}\right)$. In fact, we assume $K_{\mathrm{H}}\left(\mathrm{H}_{2} \mathrm{~S}\right) / K_{\mathrm{H}}(\mathrm{HS} \bullet) \approx\left(K_{\mathrm{H}}\left(\mathrm{HSCH}_{3}\right) / K_{\mathrm{H}}\left(\mathrm{H}_{2} \mathrm{~S}\right)\right)^{1 / 2}=1.9$.

4924 Hence, we calculate the following aqueous potential:

4925

$\mathrm{HS}^{\bullet}+\mathrm{e}^{-}+\mathrm{H}^{+} \rightleftharpoons \mathrm{H}_{2} \mathrm{~S}$

$E^{\circ}\left(\mathrm{HS}^{\bullet}, \mathrm{H}^{+} / \mathrm{H}_{2} \mathrm{~S}\right)=+(1.54 \pm 0.03) \mathrm{V}$

The error margin assumes a maximum uncertainty factor of 3 in the Henry's constant ratios of the two species. This yields $E^{\circ}\left(\mathrm{HS}^{\bullet} / \mathrm{HS}^{-}\right)=+(1.13 \pm 0.03) \mathrm{V}$ and $\left.\mathrm{p} K_{\mathrm{a}}(\mathrm{HS})^{\bullet}\right)=(3.4 \pm 0.7)$. When combined with NBS data for $\mathrm{HS}^{-}$and $\mathrm{H}_{2} \mathrm{~S}(\mathrm{aq})$ the above $E^{\circ}$, values yield $\Delta_{\mathrm{f}} G^{\circ}=+(140$ $\pm 3) \mathrm{kJ} \mathrm{mol}^{-1}$ for $\mathrm{S}^{\bullet-}$ and $\Delta_{\mathrm{f}} G^{\circ}=+(121 \pm 3) \mathrm{kJ} \mathrm{mol}^{-1}$ for $\mathrm{HS}^{\bullet}$. Das et al. [1] also determined the equilibrium constant for reaction 77.7:

$\left[\mathrm{Mo}(\mathrm{CN})_{8}\right]^{3-}+2 \mathrm{SH}^{-} \rightleftharpoons\left[\mathrm{Mo}(\mathrm{CN})_{8}\right]^{4-}+\mathrm{HSS}^{\bullet-}+\mathrm{H}^{+}$

The result provides good support for the result obtained from the methoxyaniline reaction (eq 77.1). However, this measurement was performed at $\mu=0.1 \mathrm{M}$, and given the high ionic charges involved in this reaction we prefer to base our recommendations on eq 77.1.

Given our recommended equilibrium constant for eq $77.3\left(K=(9 \pm 2) \times 10^{3} \mathrm{M}^{-1}\right.$, see Data Sheet 117), the NBS value of $+(12.08 \pm 0.8) \mathrm{kJ} \mathrm{mol}^{-1}$ for $\Delta_{\mathrm{f}} G^{\circ}\left(\mathrm{HS}^{-}\right)$[6], and our derived value for

$4942 \Delta_{\mathrm{f}} G^{\circ}\left(\mathrm{S}^{\bullet-}\right)$, we obtain $\Delta_{\mathrm{f}} G^{\circ}\left(\mathrm{HSS}^{\bullet-}\right)=+(129 \pm 4) \mathrm{kJ} \mathrm{mol}^{-1}$. Kamyshny et al. have reported a value 4943 of $+(20.2 \pm 1.3) \mathrm{kJ} \mathrm{mol}^{-1}$ for $\Delta_{\mathrm{f}} G^{\circ}\left(\mathrm{HS}_{2}^{-}\right)$[7], which thus leads to a value of $-(1.13 \pm 0.05) \mathrm{V}$ for $4944 E^{\circ}\left(\mathrm{HS}_{2}{ }^{-} / \mathrm{HSS}^{\bullet-2-}\right)$.

4945

Recommended values:

$E^{\circ}\left(\mathrm{S}^{\bullet-}, \mathrm{H}^{+} / \mathrm{HS}^{-}\right)=+(1.33 \pm 0.03) \mathrm{V}$

$4949 \quad E^{\circ}\left(\mathrm{S}^{\bullet-}, 2 \mathrm{H}^{+} / \mathrm{H}_{2} \mathrm{~S}\right)=+(1.74 \pm 0.03) \mathrm{V}$

$4950 \quad E^{\circ}\left(\mathrm{HS}^{\bullet}, \mathrm{H}^{+} / \mathrm{H}_{2} \mathrm{~S}\right)=+(1.54 \pm 0.03) \mathrm{V}$

$4951 E^{\circ}\left(\mathrm{HS}^{\bullet} / \mathrm{HS}^{-}\right)=+(1.13 \pm 0.03) \mathrm{V}$

$4952 E^{\circ}\left(\mathrm{HS}_{2}{ }^{-} / \mathrm{HSS}^{\bullet-}{ }^{-2}\right)=-(1.13 \pm 0.05) \mathrm{V}$

$4953 \mathrm{p} K_{\mathrm{a}}\left(\mathrm{HS}^{\bullet}\right)=(3.4 \pm 0.7)$

$4954 \Delta_{\mathrm{f}} G^{\circ}=+(140 \pm 3) \mathrm{kJ} \mathrm{mol}^{-1}$ for $\mathrm{S}^{\bullet-}$

$4955 \Delta_{\mathrm{f}} G^{\circ}=+(121 \pm 3) \mathrm{kJ} \mathrm{mol}^{-1}$ for $\mathrm{HS}^{\bullet}$ 
$4956 \Delta_{\mathrm{f}} G^{\circ}\left(\mathrm{HSS}^{\bullet 2-}\right)=(129 \pm 4) \mathrm{kJ} \mathrm{mol}^{-1}$

$4957 \quad \Delta_{\mathrm{f}} G^{\circ}\left(\mathrm{HS}_{2}^{-}\right)=+(20.2 \pm 1.3) \mathrm{kJ} \mathrm{mol}^{-1}$

4958

4959 List of auxiliary thermodynamic data: none

4960

4961 Nomenclature: $\mathrm{S}^{\bullet-}$, sulfide(•-) or sulfanidyl, HS $\bullet$, hydridosulfur(•) or sulfanyl; $\mathrm{H}_{2} \mathrm{~S}$,

4962 dihydridosulfur or sulfane (hydrogen sulfide or, better, dihydrogen sulfide is acceptable); $\mathrm{HS}_{2}{ }^{-}$,

4963 hydridodisulfide $(S-S)(1-)$ or disulfanide; $\operatorname{HSS}^{\bullet 2-}$, hydridodisulfide $(S-S)(\bullet 2-)$ or disulfanudi-idyl;

$4964 \mathrm{HSSH}^{\bullet-}$, dihydridodisulfide $(S-S)(\bullet 1-)$ or disulfanuidyl.

4965

4966 References

4967

4968 1. T. N. Das, R. E. Huie, P. Neta, S. Padmaja. J. Phys. Chem. A 103, 5221-5226 (1999).

4969 2. M. Jonsson, J. Lind, T. E. Eriksen, G. Merényi. J. Am. Chem. Soc. 116, 1423-1427

4970 (1994).

4971 3. E. Madej, P. Wardman. Rad. Phys. Chem. 75, 990-1000 (2006).

4972 4. K. Lodders. J. Phys. Chem. Ref. Data 33, 357-367 (2004).

4973 5. A. Przyjazny, W. Janicki, W. Chrzanowski, R. Staszewski. J. Chromatog. 280, 249-260

4974 (1983).

$4975 \quad 6 . \quad$ D. D. Wagman, W. H. Evans, V. B. Parker, R. H. Schumm, I. Halow, S. M. Bailey, K. L. 4976 Churney, R. L. Nuttall. J. Phys. Chem. Ref. Data 11, Suppl. No. 2 (1982).

4977 7. A. Kamyshny, A. Goifman, J. Gun, D. Rizkov, O. Lev. Environ. Sci. Technol. 38, 663349786644 (2004).

4979 


\section{Data Sheet 78}

Chemical equilibria:

\section{List of reports:}

4988 There is only one report [1]. Kläning and Sehested have determined by pulse radiolysis the equilibrium constants $K_{78.1}=4.8 \times 10^{3} \mathrm{M}^{-1} ; K_{78.2}=37 ; K_{78.3}=0.78 \mathrm{M}^{-1}$, all corrected to zero ionic strength.

\section{Discussion}

Although the above constants are extracted from a somewhat complex scheme, they appear to be very carefully and professionally done. Experimentally, rate constants for forward and reverse reactions are measured separately with due allowance for ionic strength effects. As for equilibrium 78.3, the hydrolysis of the $\mathrm{SeO}_{3}{ }^{\bullet-}$ radical, the authors analyze the spectral change with varying $\left[\mathrm{HO}^{-}\right]$at constant dose, while making the appropriate corrections. From the finding of a distinct isosbestic point, the simultaneous presence of only two species, $\mathrm{SeO}_{3}{ }^{\bullet-}$ and $\mathrm{HSeO}_{4}{ }^{\circ 2-}$, is deduced. At high $\mathrm{pH}$ the radical(s) disappear in a first order process, the rate increasing with increasing $\left[\mathrm{HO}^{-}\right]$. When $\mathrm{O}_{2}$ is present in such solutions, the authors observe a

5002 first order build-up of $\mathrm{O}_{3}{ }^{\bullet-}$, at a rate that exactly matches the decay of the $\mathrm{HSeO}_{4}{ }^{\bullet-}$ radicals.

5003 Hence the occurrence of reactions -78.1 and -78.2 is inferred. From measurements of the rate of radical disappearance at varying $\left[\mathrm{HO}^{-}\right]$both $k_{-78.1}$ and $k_{-78.2}$ are obtained, while $k_{78.1}$ and $k_{78.2}$ are derived directly from the build-up of radical absorbance during $\mathrm{SeO}_{3}{ }^{2-}$ consumption by $\mathrm{HO}^{\bullet} / \mathrm{O}^{\bullet-}$. From the above equilibrium constants the authors derive a number of electrode potentials as well as Gibbs energies of formation for selenium radical species. These hinge, of course, on the 5008 correctly assumed values for the references $\mathrm{HO}^{\bullet}$ and $\mathrm{O}^{\bullet-}$. Fortunately, the authors use the same 5009 electrode potential for $\left(\mathrm{HO}^{\bullet}, \mathrm{H}^{+} / \mathrm{H}_{2} \mathrm{O}\right)=+2.73 \mathrm{~V}$, as we have agreed upon. Hence we can use 5010 their published values, which they believe to be correct within $10 \mathrm{mV}$, a value that should be 5011 doubled to include all error sources.

5012 The qualitatively interesting part in this study is the finding that $\mathrm{Se}(\mathrm{V})$ can exist in four5013 coordinate form, something S(V) cannot. This is no doubt mainly due to the size difference of 5014 the central atoms. Of further interest is the finding that both the four- and three-coordinate $5015 \mathrm{Se}(\mathrm{V})$-species can rapidly be produced by reduction of tetraoxidoselenate(2-), $\mathrm{Se}(\mathrm{VI})$, by the 
5016 hydrated electron. This is in sharp contrast to $\mathrm{SO}_{4}{ }^{2-}$, which is inert against one-electron 5017 reduction. It is also intuitively non-trivial to understand how the electrode potential of $\mathrm{SeO}_{3}{ }^{-{ }^{-}}$and 5018 the $\mathrm{H}-\mathrm{O}$ bond strength in $\mathrm{H}-\mathrm{O}-\mathrm{SeO}_{2}{ }^{-}$can exceed by $c a .1 \mathrm{eV}$ the corresponding values for $5019 \mathrm{SO}_{3}{ }^{-}$and $\mathrm{H}-\mathrm{O}-\mathrm{SO}_{2}{ }^{-}$. Be it as it may, the finding that $\mathrm{SeO}_{3}{ }^{--}$oxidizes $\mathrm{CO}_{3}{ }^{2-}$ rather fast (with $\left.5020 E^{\circ}\left(\mathrm{CO}_{3}{ }^{--} / \mathrm{CO}_{3}{ }^{2-}\right)=+1.59 \mathrm{~V}\right)$, while $\mathrm{SO}_{3}{ }^{\circ-}$ is completely unreactive towards $\mathrm{CO}_{3}{ }^{2-}$, firmly proves 5021 this ranking.

5022

\section{Recommended values:}

5024

5025

$E^{\circ}\left(\mathrm{SeO}_{3}{ }^{\bullet-} / \mathrm{SeO}_{3}{ }^{2-}\right)=+(1.68 \pm 0.03) \mathrm{V}$

5026

$E^{\circ}\left(\mathrm{SeO}_{3}{ }^{-}, \mathrm{H}^{+} / \mathrm{HSeO}_{3}{ }^{-}\right)=+(2.18 \pm 0.03) \mathrm{V}$

$5027 \Delta_{\mathrm{f}} G^{\mathrm{o}}\left(\mathrm{SeO}_{3}{ }^{\circ-}\right)=-(202 \pm 3) \mathrm{kJ} \mathrm{mol}^{-1}$

$5028 \Delta_{\mathrm{f}} G^{\mathrm{o}}\left(\mathrm{HSeO}_{4}{ }^{2-}\right)=-(358 \pm 3) \mathrm{kJ} \mathrm{mol}^{-1}$

5029

5030 Nomenclature: $\mathrm{SeO}_{3}{ }^{\bullet-}$, trioxidoselenate $(\bullet-)$; $\mathrm{SeO}_{3}{ }^{2-}$, trioxidoselenate $(2-)$;

$5031 \mathrm{HSeO}_{3}{ }^{-}$, hydroxidodioxidoselenate $(-)$, and $\mathrm{HSeO}_{4}{ }^{\bullet 2-}$, hydroxidotrioxidoselenate $(\bullet 2-)$

5032

5033 List of auxiliary thermodynamic data: none

5034

5035

\section{References}

5036

5037

1. U. K. Kläning, K. Sehested. J. Phys. Chem. 90, 5460-5464 (1986).

5038

5039 


\section{Data Sheet 79}

Chemical equilibria:

\section{List of reports:}

5049 There is only one report [1]. From the pulse radiolytic data of Kläning and Sehested the following values for the above equilibrium constants are obtained:

$K_{79.1}=(3.7 \pm 1.3) \times 10^{6} \mathrm{M}^{-1} ; K_{79.2}=(2.7 \pm 0.5) \times 10^{5} \mathrm{M}^{-1} ; \mathrm{p} K_{79.3}=(9.96 \pm 0.15) ; \mathrm{p} K_{79.4}=(13.2$ $\pm 0.2) . K_{79.1}$ should be independent of ionic strength. $K_{79.2}$ at $\mu=0.1 \mathrm{M}, K_{79.3}$ at $\mu=(0.01-0.03)$ $\mathrm{M} ; K_{79.4}$ at $\mu=(0.01-0.3) \mathrm{M}$.

\section{Discussion}

Qualitatively, tellurium behaves similarly to selenium. Thus $\mathrm{Te}(\mathrm{V})$ species are facilely obtained either by way of one-electron oxidation of $\mathrm{Te}(\mathrm{IV})$ by $\mathrm{HO}^{\bullet} / \mathrm{O}^{\bullet-}$ or by one-electron reduction of $\mathrm{Te}(\mathrm{VI})$ by the hydrated electron. Just as in the case of selenium, and in contrast to S, the four-coordinate $\mathrm{Te}(\mathrm{V})$ can exist in equilibrium with the corresponding three-coordinate $\mathrm{Te}(\mathrm{V})$ species. In the case of tellurium, the four-coordinate species is stable in a considerably

5063 larger $\mathrm{pH}$-interval than the $\mathrm{Se}(\mathrm{V})$ species. This is in agreement with the larger size of Te as 5064 coMPared to Se. Hence, the authors can observe four $\mathrm{Te}(\mathrm{V})$ species: to wit $\mathrm{TeO}_{3}{ }^{\bullet-}, \mathrm{H}_{2} \mathrm{TeO}_{4}{ }^{\bullet-}$, $5065 \mathrm{HTeO}_{4}{ }^{\bullet-}$ and $\mathrm{TeO}_{4}{ }^{\bullet-3}$. By spectral and kinetic analysis some acid -base dissociation constants can be evaluated. From the kinetics of decay at different $\mathrm{pH}$-values of the four-coordinate species the rate constants of expulsion of $\mathrm{HO}^{\bullet} / \mathrm{O}^{\bullet-}$ were determined, which in combination with

5068 the forward rates yielded the pertinent equilibrium constants. Hence, just as in the case of $\mathrm{Se}(\mathrm{V})$,

5069 the electrode potentials and Gibbs energies of formation of the $\mathrm{Te}(\mathrm{V})$ species hinge on the 5070 reference values for $\mathrm{HO}^{\bullet}$ and $\mathrm{O}^{\bullet}$. The authors happen to employ the same electrode potential for 5071 these species as was recommended by our task group. Hence their reported values can be 5072 recommended. The error margins in the potentials are probably $\pm 20 \mathrm{mV}$. Note that the Gibbs 5073 energies of formation are dependent on a non-NBS value for $\Delta_{\mathrm{f}} G^{\circ}\left(\mathrm{TeO}_{3}{ }^{2-}\right)$ as is described in the 5074 cited publication. Although the derived $E^{\circ}$ and $\Delta_{\mathrm{f}} G^{\circ}$ values are based, in part, on equiibrium 
5075 constants that have not been corrected to zero ionic strength, we consider that the errors 5076 introduced are small enough relative to the stated uncertainties.

5077

\section{Recommended values:}

5079

$5080 E^{\circ}\left(\mathrm{TeO}_{3}{ }^{\bullet} / \mathrm{TeO}_{3}{ }^{2-}\right)=+(1.74 \pm 0.03) \mathrm{V}$

$5081 E^{\circ}\left(\mathrm{TeO}_{3}{ }^{\circ}, \mathrm{H}^{+} / \mathrm{HTeO}_{3}{ }^{-}\right)=+(2.31 \pm 0.03) \mathrm{V}$

$5082 \Delta_{\mathrm{f}} G^{\mathrm{o}}\left(\mathrm{TeO}_{3}{ }^{\circ}\right)=-(214 \pm 3) \mathrm{kJ} \mathrm{mol}^{-1}$

$5083 \Delta_{\mathrm{f}} G^{\mathrm{o}}\left(\mathrm{HTeO}_{4}{ }^{\circ-}\right)=-(394 \pm 3) \mathrm{kJ} \mathrm{mol}^{-1}$

$5084 \Delta_{\mathrm{f}} G^{\mathrm{o}}\left(\mathrm{TeO}_{4}{ }^{\circ-}-\right)=-(319 \pm 3) \mathrm{kJ} \mathrm{mol}^{-1}$

5085

5086 Nomenclature: $\mathrm{TeO}_{3}{ }^{\bullet-}$, trioxidotellurate $(\bullet-) ; \mathrm{TeO}_{3}{ }^{2-}$, trioxidotelurate $(2-)$;

$5087 \mathrm{HTeO}_{3}{ }^{-}$, hydroxidodioxidotellurate $(1-) ; \mathrm{TeO}_{4}{ }^{\bullet-}-$ tetraoxidotellurate $(\bullet 3-)$, and $\mathrm{HTeO}_{4}{ }^{\bullet-}$, 5088 hydroxidotrioxidotellurate $(\bullet 2-)$

5089

5090

5091 List of auxiliary thermodynamic data: none

5092

5093

\section{References}

5094

5095 1. U. K. Kläning, K. Sehested. J. Phys. Chem. A. 105, 6637-6645 (2001). 


\section{Data Sheet 80}

5099 Summary of the $\mathrm{N}_{3}{ }^{\bullet}$ System

Tabulated below are the presently recommended equilibrium constants involving the

5102 trinitrogen $(2 N-N)(\bullet)\left(\mathrm{N}_{3}{ }^{\bullet}\right)$ radical. Uncertainties are expressed as $\pm 1 \sigma$; in many cases the value 5103 of $\sigma$ is merely a subjective guess.

5104

\begin{tabular}{|c|c|c|c|c|c|c|}
\hline rxn \# & Reaction & $K_{\mathrm{eq}}$ & $\operatorname{dim}$. & uncertainty & $\mu / \mathrm{M}$ & $\begin{array}{l}\text { Data } \\
\text { Sheet \# }\end{array}$ \\
\hline 81.1 & $\begin{array}{l}\mathrm{N}_{3}^{-}+\left[\mathrm{Ru}(\mathrm{bpy})_{3}\right]^{3+} \rightleftharpoons \mathrm{N}_{3}{ }^{\bullet}+ \\
{\left[\mathrm{Ru}(\mathrm{bpy})_{3}\right]^{2+}}\end{array}$ & 14 & & \pm 4 & 0 & 81 \\
\hline 82.1 & $\mathrm{~N}_{3}^{-}+\left[\mathrm{IrCl}_{6}\right]^{2-} \rightleftharpoons \mathrm{N}_{3}{ }^{\bullet}+\left[\mathrm{IrCl}_{6}\right]^{3-}$ & $1.7 \times 10^{-7}$ & & \pm 0.2 & 1.0 & 82 \\
\hline 83.1 & $\mathrm{ClO}_{2}^{\bullet}+\mathrm{N}_{3}^{-} \rightleftharpoons \mathrm{ClO}_{2}^{-}+\mathrm{N}_{3}^{\bullet}$ & $4 \times 10^{-7}$ & & $\pm 1 \times 10^{-7}$ & 0 & 83 \\
\hline 29.1 & $\mathrm{Br}_{2}^{\bullet-}+\mathrm{N}_{3}^{-} \rightleftharpoons \mathrm{N}_{3}^{\bullet}+2 \mathrm{Br}^{-}$ & $5.5 \times 10^{4}$ & M & factor of 2 & 0 & 29 \\
\hline 84.1 & $(\mathrm{DMS})_{2}^{\bullet+}+\mathrm{N}_{3}^{-} \rightleftharpoons 2 \mathrm{DMS}+\mathrm{N}_{3}^{\bullet}$ & 16.4 & $\mathrm{M}$ & \pm 1.0 & $?$ & 84 \\
\hline 72.1 & $\mathrm{~N}_{3}{ }^{\bullet}+2 \mathrm{~S}_{2} \mathrm{O}_{3}^{2-} \rightleftharpoons \mathrm{N}_{3}^{-}+\left(\mathrm{S}_{2} \mathrm{O}_{3}\right)_{2}^{\bullet 3-}$ & $1.9 \times 10^{4}$ & $\mathrm{M}^{-1}$ & $\pm 2 \times 10^{3}$ & 0.44 & 72 \\
\hline 85.1 & $\mathrm{~N}_{3}^{\bullet}+\mathrm{N}_{3}^{-} \rightleftharpoons \mathrm{N}_{6}^{\bullet-}$ & 0.24 & $\mathrm{M}^{-1}$ & $\pm 30 \%$ & 0 & 85 \\
\hline 86.1 & $\mathrm{~N}_{3} \cdot+\mathrm{e}^{-} \rightleftharpoons \mathrm{N}_{3}^{-}$ & 1.32 & $\mathrm{~V}$ & \pm 0.03 & 0.2 & 86 \\
\hline
\end{tabular}

DMS is dimethylsulfide, $\mathrm{CH}_{3} \mathrm{SCH}_{3}$

Reaction 81.1, in combination with the measured electrode potential of the $\mathrm{Ru}(\mathrm{III} / \mathrm{II})$ couple leads to $E^{\circ}=+(1.33 \pm 0.01) \mathrm{V}$ for $\mathrm{N}_{3}{ }^{\bullet} / \mathrm{N}_{3}{ }^{-}$at $25^{\circ} \mathrm{C}$ and $\mu=0.01 \mathrm{M}$.

Reaction 82.1, in combination with the electrode potential of the $\operatorname{Ir}(\mathrm{IV} / \mathrm{III})$ couple leads to $E^{\circ}=$ $+(1.33 \pm 0.02) \mathrm{V}$ at $25^{\circ} \mathrm{C}$ and $\mu=1.0 \mathrm{M}$.

Reaction 83.1, in combination with the standard potential of the $\mathrm{ClO}_{2}{ }^{\bullet} / \mathrm{ClO}_{2}{ }^{-}$couple leads to $E^{\circ}=$ $+(1.313 \pm 0.006) \mathrm{V}$ at $25^{\circ} \mathrm{C}$ and $\mu=0.0 \mathrm{M}$. The uncertainty here may be overly optimistic, given

5116 the wide range of reports for $k_{\mathrm{r}}$.

5118 Reaction 29.1, in combination with the standard potential of the $\mathrm{Br}_{2}{ }^{-} / 2 \mathrm{Br}^{-}$couple $(+1.625 \pm$ $51190.020) \mathrm{V}$ leads to $E^{\circ}=+(1.34 \pm 0.03) \mathrm{V}$ at $25^{\circ} \mathrm{C}$. 
5121 Reaction 84.1 is unsuitable for deriving $E^{\circ}\left(\mathrm{N}_{3}{ }^{\bullet} / \mathrm{N}_{3}{ }^{-}\right)$because it is used to derive the potential of 5122 the $(\mathrm{DMS})_{2}{ }^{\bullet+} / 2 \mathrm{DMS}$ system.

5124 Reaction 72.1 is unsuitable for deriving $E^{\circ}\left(\mathrm{N}_{3}{ }^{\bullet} \mathrm{N}_{3}{ }^{-}\right)$because it is used to derive the potential of 5125 the thiosulfate system.

Reaction 86.1 (from irreversible cyclic voltammetry) yields an electrode potential at $\mu=0.2 \mathrm{M}$.

The various routes to $E^{\circ}$ given above are essentially all in agreement within their specified uncertainties. We assign relatively low weight to the result from reaction 83.1 because of concerns about the scatter in $k_{\mathrm{r}}$. Given the consistency of the remaining results despite their varying ionic strengths, we recommend $E^{\circ}=+(1.33 \pm 0.02) \mathrm{V}$ at $25^{\circ} \mathrm{C}$.

NBS gives $\Delta_{\mathrm{f}} G^{\circ}=+(348 \pm 8) \mathrm{kJ}$ for $\mathrm{N}_{3}{ }^{-}(a q)$. The $E^{\circ}$ recommended above yields $\Delta_{\mathrm{f}} G^{\circ}\left(\mathrm{N}_{3}{ }^{-}, a q\right)-\Delta_{\mathrm{f}} G^{\circ}\left(\mathrm{N}_{3}{ }^{\bullet}, a q\right)=-(128 \pm 1) \mathrm{kJ} \mathrm{mol}^{-1}$. Thus, we obtain $\Delta_{\mathrm{f}} G^{\circ}=(476 \pm 8) \mathrm{kJ} \mathrm{mol}^{-1}$

5136 for $\mathrm{N}_{3}{ }^{\bullet}(a q)$, where most of the uncertainty reflects the uncertainty in $\mathrm{N}_{3}{ }^{-}$.

\section{Recommended values:}

$E^{\circ}\left(\mathrm{N}_{3}{ }^{\bullet} / \mathrm{N}_{3}{ }^{-}\right)=+(1.33 \pm 0.02) \mathrm{V}$ at $25^{\circ} \mathrm{C}$

5143 Nomenclature: $\mathrm{Br}_{2}{ }^{--}$, dibromide $(\bullet 1-)$; $\mathrm{Br}^{-}$, bromide $(1-)$ or bromide; $\mathrm{ClO}_{2}{ }^{\bullet}$, dioxidochlorine $(\bullet)$ or 5144 chlorine dioxide; $\left[\mathrm{IrCl}_{6}\right]^{2-}$, hexachloridoiridate $(2-) ; \mathrm{N}_{3}{ }^{\bullet}, \operatorname{trinitrogen}(2 N-N)(\bullet) ; \mathrm{N}_{3}^{-}, \operatorname{trinitride}(1-)$, 5145 azide is acceptable; $\mathrm{N}_{6}{ }^{\bullet}$, hexanitride $(\bullet 1-) ; \mathrm{S}_{2} \mathrm{O}_{3}{ }^{2-}$, trioxidosulfidosulfate $(S-S)(2-) ;\left(\mathrm{S}_{2} \mathrm{O}_{3}\right)_{2}{ }^{\bullet 3-}$,

5146 bis $[($ trioxidosulfidosulfate $)](S-S)(\bullet 3-) ;\left[\mathrm{Ru}(\text { bpy })_{3}\right]^{2+}$, tris(bipyridine)ruthenium $(2+)$. 


\section{Data Sheet 81}

\section{List of reports:}

$$
K_{\text {eq }}=(10 \pm 5) \text { at } \mu=0.01 \mathrm{M} \text { and } 25{ }^{\circ} \mathrm{C} \text { [1]. Determined from the ratio of forward and }
$$
reverse rate constants for approach to equilibrium, by pulse radiolysis experiments. The value of $K_{\text {eq }}$ was not actually reported and the value given here is derived from the reported $E^{\circ}$, values for the $\mathrm{N}_{3}{ }^{\bullet} / \mathrm{N}_{3}{ }^{-}$and $\left[\mathrm{Ru}(\mathrm{bpy})_{3}\right]^{3+} /\left[\mathrm{Ru}(\mathrm{bpy})_{3}\right]^{2+}$ couples.

$K_{\text {eq }}=(4.8 \pm 2.4)$ at $\mu=0.01 \mathrm{M}$ and $25^{\circ} \mathrm{C}[1]$. Determined from absorbance measurements at equilibrium, during pulse radiolysis experiments. The value of $K_{\text {eq }}$ was not actually reported and the value given here is derived from the reported $E^{\circ}$, values for the $\mathrm{N}_{3}{ }^{\bullet} / \mathrm{N}_{3}{ }^{-}$ and $\left.\left.\mathrm{Ru}(\mathrm{bpy})_{3}\right]^{3+} / \mathrm{Ru}(\mathrm{bpy})_{3}\right]^{2+}$ couples.

\section{Discussion}

The two determinations of the equilibrium constant are in good agreement and yield an average value of $(7.4 \pm 3.7)$ at $25{ }^{\circ} \mathrm{C}$ and $\mu=0.01 \mathrm{M}$. Given the low ionic strength of the measurements, it is reasonable to correct for activity coefficients by the eq $\log \gamma=-A z^{2} \mu^{1 / 2} /\left(1+\mu^{1 / 2}\right)$. This procedure yields $K_{\text {eq }}=(14 \pm 4)$ at $25^{\circ} \mathrm{C}$ and $\mu=0 \mathrm{M}$.

As reported by the original authors, the equilibrium constant plus the measured potential for the $\mathrm{Ru}(\mathrm{III} / \mathrm{II})$ couple $E^{\circ \prime}=+(1.28 \pm 0.01) \mathrm{V}$ at $\mu=0.1 \mathrm{M}$ leads to $E^{\circ \prime}=+(1.33 \pm 0.01) \mathrm{V}$ for $\mathrm{N}_{3} \cdot \mathrm{N}_{3}{ }^{-}$. The estimated uncertainty is probably too small, given the varying ionic strengths in the component measurements.

\section{Recommended values:}

$K_{\text {eq }}=(14 \pm 4)$ at $25^{\circ} \mathrm{C}$ and $\mu=0 \mathrm{M}$ $E^{\circ}=+(1.33 \pm 0.01) \mathrm{V}$ for the $\mathrm{N}_{3}{ }^{\bullet} / \mathrm{N}_{3}{ }^{-}$couple at $25^{\circ} \mathrm{C}$ and $\mu=0.01 \mathrm{M}$.

Nomenclature: see Data Sheet 80. 


\section{References}

5187

5188 1. M. R. DeFelippis, M. Faraggi, M. H. Klapper. J. Phys. Chem. 94, 2420-2424 (1990). 5189

5190 


\section{Data Sheet 82}

\section{List of reports:}

$$
K_{\text {eq }}=(1.45 \pm 0.23) \times 10^{-7} \text { at unspecified ionic strength and temperature [1]. Result }
$$
obtained from the ratio of the forward and reverse rate constants. The forward rate constant was obtained by stopped-flow measurements at $25^{\circ} \mathrm{C}$ and $\mu=1.0 \mathrm{M}$. The reverse rate constant was obtained by pulse radiolysis at $22{ }^{\circ} \mathrm{C}$ and $\mu=(0.01-0.1) \mathrm{M}$.

$$
K_{\text {eq }}=1.7 \times 10^{-7} \text { at } 25^{\circ} \mathrm{C} \text { and } \mu=1.0 \mathrm{M} \text { [2]. Result obtained from the ratio of the forward }
$$
and reverse rate constants. The forward rate constant was obtained by stopped-flow measurements at $25^{\circ} \mathrm{C}$ and $\mu=1.0 \mathrm{M}$. The reverse rate constant was obtained by pulse

5205 radiolysis at $22^{\circ} \mathrm{C}$ and $\mu=(0.01-0.1) \mathrm{M}$.

\section{Discussion}

The two reports of $K_{\text {eq }}$ differ because of slightly different values used for the forward rate constant; the reverse rate constant was identical in the two reports. The first report was a preliminary version of the second, and so we recommend the second with uncertainties as given in the first: $K_{\mathrm{eq}}=(1.7 \pm 0.2) \times 10^{-7}$ at $25^{\circ} \mathrm{C}$ and $\mu=1.0 \mathrm{M}$. Although the reverse rate constant

5213 was obtained under various ionic strengths, it is expected to be independent of ionic strength, and 5214 thus the derived value of $K_{\text {eq }}$ pertains to the ionic strength at which the forward rate constant was 5215 determined.

\section{Recommended values:}

$$
K_{\text {eq }}=(1.7 \pm 0.2) \times 10^{-7} \text { at } 25^{\circ} \mathrm{C} \text { and } \mu=1.0 \mathrm{M}
$$

5222 $E^{\circ}=+(1.33 \pm 0.02) \mathrm{V}$ for $\mathrm{N}_{3}{ }^{\bullet} / \mathrm{N}_{3}{ }^{-}$at $25^{\circ} \mathrm{C}$ and $\mu=1.0 \mathrm{M}$

Nomenclature: see Data Sheet 80. 
References

5229

5230 1. M. S. Ram, D. M. Stanbury. Inorg. Chem. 24, 4233-4234 (1985).

$5231 \quad 2 . \quad$ M. S. Ram, D. M. Stanbury. J. Phys. Chem. 90, 3691-3696 (1986).

5232

5233 


\section{Data Sheet 83}

\section{List of reports:}

$$
K_{\text {eq }}=(4.0 \pm 1) \times 10^{-7} \text { at } 25^{\circ} \mathrm{C} \text { and } \mu=0.1 \mathrm{M} \text {. Calculated herein from the ratio of the }
$$
forward and reverse rate constants. Awad and Stanbury determined $k_{\mathrm{f}}=(809 \pm 9) \mathrm{M}^{-1} \mathrm{~s}^{-1}$ at 25 ${ }^{\circ} \mathrm{C}$ and $\mu=0.1 \mathrm{M}$ from stopped-flow experiments [1]. The reverse rate constant was reported by DeFelippis et al. from pulse radiolysis as $7.8 \times 10^{7} \mathrm{M}^{-1} \mathrm{~s}^{-1}$ at an unspecified temperature and $\mu=$ $0.1 \mathrm{M}$ [2]. Shoute et al. reported $k_{\mathrm{r}}$ from pulse radiolysis as $1.9 \times 10^{9} \mathrm{M}^{-1} \mathrm{~s}^{-1}$ at $17^{\circ} \mathrm{C}$ and $3.2 \times$ $10^{9} \mathrm{M}^{-1} \mathrm{~s}^{-1}$ at $33{ }^{\circ} \mathrm{C}$, both at $\mu=0.1 \mathrm{M}$ [3]. These workers noted the discrepancy between their rate constant and that reported by DeFelippis et al. [2] (their ref. 25), and they also noted some other issues that undermine the credibility of $\mathrm{ClO}_{2}{ }^{-}$rate constants (with $(\mathrm{SCN})_{2}{ }^{\bullet-}$ and $\mathrm{Br}_{2}{ }^{\bullet-}$ ) reported by DeFelippis et al. Difficulties in the $(\mathrm{SCN})_{2}{ }^{\bullet-}$ and $\mathrm{Br}_{2}{ }^{--}$reactions can be understood because $\mathrm{ClO}_{2}^{-}$reacts with $\mathrm{SCN}^{-}$and $\mathrm{Br}^{-}[4,5]$; a coMParable explanation for the $\mathrm{N}_{3}^{-}$ discrepancy is presently lacking. Merényi et al. used pulse radiolysis to obtain $k_{\mathrm{r}}=1.9 \times 10^{9} \mathrm{M}^{-1}$ $\mathrm{s}^{-1}$ at an unspecified temperature and ionic strength [6]. We reject the report on $k_{\mathrm{r}}$ from DeFelippis et al. [2] on the grounds that it disagrees seriously with the two other reports, which are quite consistent with each other. The value of $k_{\mathrm{r}}$ should be rather insensitive to $\mu$ and $T$; combining the results of Shoute et al. and Merényi et al. we recommend $k_{\mathrm{r}}=(2.0 \pm 0.5) \times 10^{9}$ $\mathrm{M}^{-1} \mathrm{~s}^{-1}$ at $25^{\circ} \mathrm{C}$ and arbitrary ionic strength. The ratio of $k_{\mathrm{f}}$ and $k_{\mathrm{r}}$ is thus $(4 \pm 1) \times 10^{-7}$ at $25^{\circ} \mathrm{C}$ and $\mu=0.1 \mathrm{M}$. Note that this specified uncertainty is perhaps too optimistic, as it is based on a somewhat arbitrary rejection of the results of DeFelippis et al. [2].

\section{Discussion}

As the values of $k_{\mathrm{f}}, k_{\mathrm{r}}$, and $K_{\text {eq }}$ should be insensitive to $\mu$, we recommend $K_{\text {eq }}=(4 \pm 1) \times$ $10^{-7}$ at $25^{\circ} \mathrm{C}$ and $\mu=0.0 \mathrm{M}$.

With $E^{\circ}=+0.935 \pm 0.003 \mathrm{~V}$ for $\mathrm{ClO}_{2} \% \mathrm{ClO}_{2}{ }^{-}$as we have recommended elsewhere in this

\section{Recommended values:}

$K_{\text {eq }}=(4 \pm 1) \times 10^{-7}$ at $25^{\circ} \mathrm{C}$ and $\mu=0.0 \mathrm{M}$ 
$5270 \quad E^{\circ}=+(1.313 \pm 0.006) \mathrm{V}$ for $\mathrm{N}_{3}{ }^{\bullet} / \mathrm{N}_{3}{ }^{-}$at $25^{\circ} \mathrm{C}$

5271

5272 List of auxiliary thermodynamic data: none.

5273

5274 Nomenclature: see Data Sheet 80.

5275

5276 References

5277

5278 1. H. H. Awad, D. M. Stanbury. J. Am. Chem. Soc. 115, 3636-3642 (1993).

5279 2. M. R. DeFelippis, C. P. Murthy, M. Faraggi, M. H. Klapper. Biochemistry 28, 4847-4853 5280 (1989).

$5281 \quad 3 . \quad$ L. C. T. Shoute, Z. B. Alfassi, P. Neta, R. E. Huie. J. Phys. Chem. 95, 3238-3242 (1991).

5282 4. M. Alamgir, I. R. Epstein. J. Phys. Chem. 89, 3611-3614 (1985).

5283 5. O. Valdes-Aguilera, D. W. Boyd, I. R. Epstein, K. Kustin. J. Phys. Chem. 1986, 6702$52846708(1986)$.

5285 6. G. Merényi, J. Lind, X. Shen, T. E. Eriksen. J. Phys. Chem. 94, 748-752 (1990). 


\section{$5288 \quad$ Data Sheet 84}

5290 Chemical equilibrium:

$5291(\mathrm{DMS})_{2}{ }^{\bullet+}+\mathrm{N}_{3}{ }^{-} \rightleftharpoons 2 \mathrm{DMS}+\mathrm{N}_{3}{ }^{\bullet}$

5292 DMS is $\mathrm{CH}_{3} \mathrm{SCH}_{3}$

5293

5294 List of reports:

$K_{\text {eq }}=16.4 \mathrm{M}$ at room temperature and an unspecified ionic strength [1]. Obtained from pulse radiolysis measuring the absorbance at equilibrium.

\section{Discussion}

We assume room temperature is $22{ }^{\circ} \mathrm{C}$. An uncertainty of \pm 1 seems appropriate, given 5302 the number of significant figures specified. couple, and hence is not of much value in determining $E^{\circ}$ for the $\mathrm{N}_{3}{ }^{\bullet} \mathrm{N}_{3}{ }^{-}$couple.

\section{Recommended value:}

$5309 K_{\text {eq }}=(16.4 \pm 1.0) \mathrm{M}$ at $22{ }^{\circ} \mathrm{C}$ and unspecified ionic strength.

5311 List of auxiliary thermodynamic data: none.

5313 Nomenclature: see Data Sheet 80.

\section{References}

5317 1. G. Merényi, J. Lind, L. Engman. J. Phys. Chem. 100, 8875-8881 (1996). 


\section{Data Sheet 85}

5322 Chemical equilibrium: $\mathrm{N}_{3}{ }^{\bullet}+\mathrm{N}_{3}^{-} \rightleftharpoons \mathrm{N}_{6}{ }^{\bullet-}$

\section{List of reports:}

$K_{\text {eq }}=0.33 \mathrm{M}^{-1}$ at an unspecified temperature with $\mu=(0.1-1) \mathrm{M}$ [1]. Result obtained by pulse radiolysis, with optical measurement of the position of equilibrium. Data were probably acquired at room temperature: $22^{\circ} \mathrm{C}$.

$K_{\text {eq }}=(0.16-0.22) \mathrm{M}^{-1}$ at an unspecified temperature with $\mu=(0.5-4) \mathrm{M}$ [2]. This result was obtained by pulse radiolysis, by measuring the equilibrium absorbance of $\mathrm{N}_{6}{ }^{\bullet-}$. Data were probably acquired at room temperature: $22{ }^{\circ} \mathrm{C}$.

\section{Discussion}

There is good agreement between the two reports on $K_{\text {eq. }}$. Ionic strength considerations should not be important for this reaction. We recommend an average value of $0.24 \mathrm{M}^{-1}$ to $K_{\text {eq }}$ and assign an uncertainty of $\pm 30 \%$. The temperature effect is not likely to make $K_{\text {eq }}$ significantly different at $25{ }^{\circ} \mathrm{C}$ than at $22{ }^{\circ} \mathrm{C}$.

Recommended value:

$K_{\text {eq }}=(0.24 \pm 0.08) \mathrm{M}^{-1}$ at $25^{\circ} \mathrm{C}$ and $\mu=0 \mathrm{M}$.

5344 List of auxiliary thermodynamic data: none.

5346 Nomenclature: see Data Sheet 80.

\section{References}




\section{$5354 \quad$ Data Sheet 86}

5356 Chemical equilibrium: $\mathrm{N}_{3}{ }^{\bullet}+\mathrm{e}^{-} \rightleftharpoons \mathrm{N}_{3}{ }^{-}$

\section{List of reports:}

5361 obtained by cyclic voltammetry, based on the scan-rate dependence of the irreversible peak

5362 potential [1].

\section{Discussion}

We assume the experiments were performed at room temperature, i.e., $22{ }^{\circ} \mathrm{C}$. Although obtained

5367 from an unconventional method for determining electrode potentials, the result seems reliable.

5368 The conversion from $E_{1 / 2}$ to $E^{\circ}$ is a function of the diffusion constants, but the difference is

5369 expected to be negligible relative to the specified uncertainty.

5370

5371

Recommended value:

5372

5373

$E^{\circ}=+(1.32 \pm 0.03) \mathrm{V}$ at $\mu=0.2 \mathrm{M}$ and $22{ }^{\circ} \mathrm{C}$.

5374

5375

List of auxiliary thermodynamic data: none.

5376

5377 Nomenclature: see Data Sheet 80.

5378

5379

5380

References

5382 1. $\quad$ Z. B. Alfassi, A. Harriman, R. E. Huie, S. Mosseri, P. Neta. J. Phys. Chem. 91, $2120-$

$53832122(1987)$.

5384

5385 


\section{Data Sheet 87}

Simple 1-electron oxidation of hydroxylamine can yield the corresponding radical cation, $\mathrm{H}_{2} \mathrm{NOH}^{\bullet+}$; this cation is a strong acid as noted in Table 3. Thus, we begin with a discussion of the oxidation to the more accessible species $\mathrm{H}_{2} \mathrm{NO}^{\bullet}$ as in

$\mathrm{H}_{2} \mathrm{NO}^{\bullet}+\mathrm{H}^{+}+\mathrm{e}^{-} \rightleftharpoons \mathrm{H}_{2} \mathrm{NOH}$

$E^{\circ}$ ' values involving the $\mathrm{H}_{2} \mathrm{NO}^{\bullet}$ radical are derived from the kinetics of oxidation of hydroxylamine, as described by Lind and Merényi [1].

The oxidation of $\mathrm{H}_{2} \mathrm{NOH}$ by $\mathrm{Pu}(\mathrm{IV})$ under conditions of a large excess of hydroxylamine in nitric acid media $\left[\mathrm{H}^{+}\right]=(1.28-2.5) \mathrm{M}$ has the rate law as presented by Barney [2]:

$$
-\frac{d[\mathrm{Pu}(\mathrm{IV})]}{d t}=\frac{k[\mathrm{Pu}(\mathrm{IV})]^{2}\left[\mathrm{H}_{3} \mathrm{NOH}^{+}\right]^{2}}{[\mathrm{Pu}(\mathrm{III})]^{2}\left[\mathrm{H}^{+}\right]^{4}\left(K_{\mathrm{d}}+\left[\mathrm{NO}_{3}^{-}\right]\right)^{2}}
$$

5401

Values for $k$ of $(0.029 \pm 0.008) \mathrm{M}^{5} \mathrm{~s}^{-1}$ and $K_{\mathrm{d}}=(0.33 \pm 0.15) \mathrm{M}$ were determined at $30^{\circ} \mathrm{C}$ and 2.4 $\mathrm{M}$ ionic strength [2].

As discussed by Lind and Merényi, this rate law implies the following mechanism:

Thus, $k / K_{\mathrm{d}}^{2}=K_{\mathrm{et}}^{2}\left(2 k_{\mathrm{dim}}\right)=(0.27 \pm 0.16) \mathrm{M}^{3} \mathrm{~s}^{-1}$.

The reaction of $\mathrm{Fe}(\mathrm{III})$ with hydroxylamine studied in perchlorate media has a similar rate law but lacking the nitrate dependence [3]. Bengtsson et al. interpreted the reaction as occurring via $\mathrm{Fe}(\mathrm{OH})^{2+}$ and $\mathrm{H}_{2} \mathrm{NOH}$, but for the present purposes the alternative formulation

$5414\left(\mathrm{Fe}^{3+}+\mathrm{H}_{3} \mathrm{NOH}^{+}\right)$is equivalent. In terms of the above mechanism, the measured rate constant, $5415 K_{\mathrm{et}}^{2}\left(2 k_{\mathrm{dim}}\right)$, is $(1.5 \pm 0.4) \times 10^{-9} \mathrm{M}^{3} \mathrm{~s}^{-1}$ at $25^{\circ} \mathrm{C}$ and $\mu=1.0 \mathrm{M}$ [3]. This result is the average of 5416 measurements made both by initial rates and from the integrated rate law.

5417 Lind and Merényi used pulse radiolysis to determine $k_{\mathrm{dim}}$, obtaining $2 k_{\mathrm{dim}}=(2.8 \pm 0.5) \times$ $541810^{8} \mathrm{M}^{-1} \mathrm{~s}^{-1}$ (presumably at room temperature) [1]. This rate constant is expected to be rather 5419 independent of ionic strength. 
The above results lead to values for $K_{\text {et }}$ of $(3.1 \pm 1.7) \times 10^{-5} \mathrm{M}^{2}$ for $\mathrm{Pu}$ and $(2.3 \pm 0.8) \times$ $10^{-9} \mathrm{M}^{2}$ for $\mathrm{Fe}$.

In the calculation of $E^{\circ}\left(\mathrm{H}_{2} \mathrm{NO}^{\bullet}\right)$ from the plutonium reaction, Lind and Merényi used $+(0.982 \pm 0.001) \mathrm{V}$ as the electrode potential of the $\mathrm{Pu}^{4+} / \mathrm{Pu}^{3+}$ couple at $25^{\circ} \mathrm{C}$ in $1 \mathrm{M} \mathrm{HClO}_{4}$, which was measured by Connick and McVey [4]. A 1999 IUPAC recommendation seems to support a lower value of $(0.954 \pm 0.005) \mathrm{V}$ in $1 \mathrm{M} \mathrm{HClO}_{4}$ [5], but a more recent evaluation supports the older data [6]. According to Lemire's evaluation, the electrode potential is essentially unchanged between 1.0 and $2.0 \mathrm{M}$ ionic strength. Use of this electrode potential with the measured value of $K_{\text {et }}$ leads to $E^{\circ}\left(\mathrm{H}_{2} \mathrm{NO}^{\bullet}, 2 \mathrm{H}^{+} / \mathrm{H}_{3} \mathrm{NOH}^{+}\right)=+(1.249 \pm 0.012) \mathrm{V}$.

An electrode potential of $+(0.738 \pm 0.001) \mathrm{V}$ for the $\mathrm{Fe}^{3+/ 2+}$ redox couple in $1 \mathrm{M} \mathrm{HClO}_{4}$ at $25^{\circ} \mathrm{C}$ was selected for analysis of the $\mathrm{Fe}^{3+} / \mathrm{H}_{2} \mathrm{NOH}$ reaction [7]. The derived electrode potential for the $\mathrm{H}_{2} \mathrm{NO}, 2 \mathrm{H}^{+} / \mathrm{H}_{3} \mathrm{NOH}$ couple is $+(1.249 \pm 0.010) \mathrm{V}$ at $\mu=1 \mathrm{M}$.

In view of the excellent agreement between the potentials calculated from both the $\mathrm{Pu}^{4+}$ and $\mathrm{Fe}^{3+}$ reactions we have considerable confidence in the average result: $E^{\circ}\left(\left(\mathrm{H}_{2} \mathrm{NO}^{\bullet}, 2 \mathrm{H}^{+} /\right.\right.$ $\left.\mathrm{H}_{3} \mathrm{NOH}^{+}\right)=+(1.249 \pm 0.010) \mathrm{V}$ at $\mu=1 \mathrm{M}$.

Following Lind and Merényi [1], we apply a correction of $4 \mathrm{mV}$ for the activity coefficient of the proton in $1 \mathrm{M}$ perchlorate media, as described by Schwarz and Dodson [8]. We make the assumption that activity coefficients for $\mathrm{H}_{3} \mathrm{NOH}^{+}$and $\mathrm{H}^{+}$are equal, which is supported by the weak ionic-strength dependence of the $\mathrm{p} K_{\mathrm{a}}$ of $\mathrm{H}_{3} \mathrm{NOH}^{+}$[9]. The $4 \mathrm{mV}$ correction leads to $E^{\circ}\left(\left(\mathrm{H}_{2} \mathrm{NO} \bullet, 2 \mathrm{H}^{+} / \mathrm{H}_{3} \mathrm{NOH}^{+}\right)=+(1.253 \pm 0.010) \mathrm{V}\right.$.

The conjugate acid of hydroxylamine has a $\mathrm{p} K_{\mathrm{a}}=5.96$ at $25^{\circ} \mathrm{C}$ and $\mu=0$ [9]. Thus, $E^{\circ}\left(\mathrm{H}_{2} \mathrm{NO}^{\bullet}, \mathrm{H}^{+} / \mathrm{H}_{2} \mathrm{NOH}\right)=+(0.900 \pm 0.010) \mathrm{V}$.

No value for $\Delta_{\mathrm{f}} G^{\circ}\left(\mathrm{H}_{2} \mathrm{NOH}(a q)\right)$ is given in the NBS tables [10]. A value for this quantity 5444 essentially just Latimer's estimate. In view of the uncertainties in Latimer's estimate we refrain 5445 from deriving further results from it. On the other hand, the NBS tables do provide a value of $\Delta_{\mathrm{f}} H^{\circ}=-98.3 \mathrm{~kJ} \mathrm{~mol}^{-1}$ for $\mathrm{H}_{2} \mathrm{NOH}(a q)[10]$. We derive the entropy of aqueous $\mathrm{H}_{2} \mathrm{NOH}$ from its gas-phase entropy and its entropy of hydration. According to Gurvich et al. (Table 171), $S^{\circ}\left(\mathrm{H}_{2} \mathrm{NOH}, g\right)=236 \mathrm{~J} \mathrm{~K}^{-1} \mathrm{~mol}^{-1}[12]$. We estimate the entropy of hydration $\left(\Delta_{\text {hyd }} S^{\circ}\right)$ to be -100

$5449 \pm 5 \mathrm{~J} \mathrm{~K}^{-1} \mathrm{~mol}^{-1}$ on the basis of coMParison with a variety of monohydroxy compounds [13] and $5450 \quad \mathrm{~N}_{2} \mathrm{H}_{4}\left(\Delta_{\text {hyd }} S^{\circ}=-100 \mathrm{~J} \mathrm{~K}^{-1} \mathrm{~mol}^{-1}\right.$, NBS [10]). This leads to $S^{\circ}\left(\mathrm{H}_{2} \mathrm{NOH}, \mathrm{aq}\right)=(136 \pm 5) \mathrm{J} \mathrm{K}^{-1}$ $5451 \mathrm{~mol}^{-1}$. By combining this aqueous entropy with the value of $\Delta_{\mathrm{f}} H^{\circ}$ given above and the requisite 5452 standard NBS entropies [10] we obtain $\Delta_{\mathrm{f}} G^{\circ}=-(21 \pm 2) \mathrm{kJ} \mathrm{mol}^{-1}$ for aqueous hydroxylamine. 5453 This quantity, in combination with $E^{\circ}\left(\mathrm{H}_{2} \mathrm{NO}^{\bullet}, \mathrm{H}^{+} / \mathrm{H}_{2} \mathrm{NOH}\right)=+(0.900 \pm 0.010) \mathrm{V}$, leads to $\Delta_{\mathrm{f}} G^{\circ}=$ $5454+(66 \pm 3) \mathrm{kJ} \mathrm{mol}^{-1}$ for $\mathrm{H}_{2} \mathrm{NO}{ }^{\bullet}(a q)$. 

$\mathrm{mol}^{-1}$ from Data Sheet 22 to derive a value for $E^{\circ}\left(\mathrm{HNO}, \mathrm{H}^{+} / \mathrm{H}_{2} \mathrm{NO}^{\circ}\right)=+(0.52 \pm 0.04) \mathrm{V}$.

\section{Recommended values:}

$\mathrm{H}_{2} \mathrm{NO}^{\bullet}+2 \mathrm{H}^{+}+\mathrm{e}^{-} \rightleftharpoons \mathrm{H}_{3} \mathrm{NOH}^{+}$

$E^{\circ}=+(1.253 \pm 0.010) \mathrm{V}$ at $25^{\circ} \mathrm{C}$

5461

5462

5463

5464

5465

5466

5467

5468

5469

5470

5471

5472

5473

5474

5475

5476

5477

5478

5479

5480

5481

5482

54837.

54848.

$\mathrm{H}_{2} \mathrm{NO}^{\bullet}+\mathrm{H}^{+}+\mathrm{e}^{-} \rightleftharpoons \mathrm{H}_{2} \mathrm{NOH}$

$E^{\circ}=+(0.900 \pm 0.010) \mathrm{V}$ at $25^{\circ} \mathrm{C}$

$\mathrm{HNO}^{\bullet}+\mathrm{H}^{+}+\mathrm{e}^{-} \rightleftharpoons \mathrm{H}_{2} \mathrm{NO}^{\bullet}$

$\Delta_{\mathrm{f}} G^{\circ}=+66 \pm 3 \mathrm{~kJ} \mathrm{~mol}^{-1}$ for $\mathrm{H}_{2} \mathrm{NO}{ }^{\bullet}(a q)$

$E^{\circ}=+(0.52 \pm 0.04) \mathrm{V}$ at $25^{\circ} \mathrm{C}$

Supplementary thermodynamic data: as indicated in the discussion above.

Nomenclature: $\mathrm{ClO}_{4}^{-}$, tetraoxidochlorate, perchlorate is allowed; $\mathrm{H}_{2} \mathrm{NOH}$, dihydridohydroxidonitrogen, azanol; hydroxylamine is acceptable. $\mathrm{H}_{2} \mathrm{NOH}^{\bullet+}$, dihydridohydroxidonitrogen $(\bullet+)$; $\mathrm{H}_{2} \mathrm{NO} \bullet$, dihydridooxidonitrogen( $\bullet$ ), aminoxidanyl or hydroxyazanyl, aminoxyl is acceptable.

\section{References}

1. J. Lind, G. Merényi. J. Phys. Chem. A. 110, 192-197 (2006).

2. $\quad$ G. S. Barney. J. Inorg. Nucl. Chem. 38, 1677-1681 (1976).

3. G. Bengtsson, S. Fronaeus, L. Bengtsson-Kloo. J. Chem. Soc., Dalton Trans. 2548-2552 (2002).

54859 9. A. E. Martell, R. M. Smith, R. J. Motekaitis. NIST Critically Selected Stability Constants 5486 of Metal Complexes Database, 7.0, U.S. Department of Commerce, Gaithersburg, MD (2003).

5487 10. D. D. Wagman, W. H. Evans, V. B. Parker, R. H. Schumm, I. Halow, S. M. Bailey, K. L. 5488 Churney, R. L. Nuttall. J. Phys. Chem. Ref. Data 11, Suppl. No. 2 (1982).

5489 11. A. J. Bard, R. Parsons, J. Jordan. Standard Potentials in Aqueous Solution, Marcel 5490 Dekker, Inc., New York 834 (1985). 
5491 12. L. V. Gurvich, I. V. Veyts, C. B. Alcock. Thermodynamic Properties of Individual 5492 Substances, vol. 1, part two, Hemisphere Publishing Corp., New York (1989).

5493 13. G. A. Poskrebyshev, V. Shafirovich, S. V. Lymar. J. Am. Chem. Soc. 126, 891-899 5494 (2004).

5495

5496 


\section{Data Sheet 88}

Summary of the $\mathrm{NO}_{2} \bullet$ System

Tabulated below are the presently recommended equilibrium constants involving the nitrogen dioxide radical. Uncertainties are expressed as $\pm 1 \sigma$; in many cases the value of $\sigma$ is merely a 5502 subjective guess.

5503

\begin{tabular}{|c|c|c|c|c|c|c|}
\hline rxn \# & reaction & $K_{\mathrm{eq}}$ & $\operatorname{dim}$ & uncertainty & $\mu / \mathrm{M}$ & $\begin{array}{l}\text { Data } \\
\text { Sheet } \\
\#\end{array}$ \\
\hline 89.1 & $\mathrm{~N}_{2} \mathrm{O}_{4} \rightleftharpoons 2 \mathrm{NO}_{2}$ & $1.5 \times 10^{-5}$ & $\mathrm{M}$ & $\pm 20 \%$ & $?$ & 89 \\
\hline 91.1 & $\begin{array}{l}\mathrm{NO}_{2}^{-}+\left[\mathrm{Fe}(\mathrm{TMP})_{3}\right]^{3+} \rightleftharpoons \mathrm{NO}_{2} \\
+\left[\mathrm{Fe}(\mathrm{TMP})_{3}\right]^{2+}\end{array}$ & $3.9 \times 10^{-4}$ & & $\pm 31 \%$ & 0.3 & 91 \\
\hline 92.1 & $\begin{array}{l}\mathrm{NO}_{2}^{-}+\mathrm{RNO}^{+} \rightleftharpoons \mathrm{NO}_{2}^{\bullet}+ \\
\mathrm{RNO}^{\bullet}\left(\mathrm{RNO}^{\bullet}=\mathrm{TEMPO}\right)\end{array}$ & $1.5 \times 10^{-5}$ & & $\pm 33 \%$ & 0 & 92 \\
\hline 49.1 & $\mathrm{NO}_{2}^{\bullet}+\mathrm{I}^{-} \rightleftharpoons \mathrm{NO}_{2}^{-}+\mathrm{I}^{\bullet}(a q)$ & none & & & & 49 \\
\hline 93.1 & $\mathrm{NO}_{2}^{\bullet}(g) \rightleftharpoons \mathrm{NO}_{2}^{\bullet}(a q)$ & $1.2 \times 10^{-2}$ & $\mathrm{M} \mathrm{bar}^{-1}$ & $\pm 17 \%$ & 0 & 93 \\
\hline 94.1 & $\begin{array}{l}2 \mathrm{HNO}_{2}(a q) \rightleftharpoons \mathrm{NO}^{\bullet}(a q)+ \\
\mathrm{NO}_{2}(a q)+\mathrm{H}_{2} \mathrm{O}\end{array}$ & $1.1 \times 10^{-7}$ & & $\pm 10 \%$ & 0 & 94 \\
\hline 95.1 & $\begin{array}{l}2 \mathrm{NO}_{2} \\
\mathrm{NO}_{3}^{-}\end{array}$ & $3.8 \times 10^{9}$ & M & $\pm 39 \%$ & 0 & 95 \\
\hline
\end{tabular}

$5504 \mathrm{TMP}=$ tetramethylphenanthroline; $\mathrm{TEMPO}=$ 2,2,6,6-tetramethylpiperidine-1-oxyl

Reaction 91.1, when combined with $E^{\circ \prime}(\mathrm{Fe}(\mathrm{III}) / \mathrm{Fe}(\mathrm{II}))$, leads to $E^{\circ \prime}=+(1.04 \pm 0.01) \mathrm{V}$ at $\mu=0.3 \mathrm{M}$ for $\mathrm{NO}_{2}{ }^{\bullet}(a q) / \mathrm{NO}_{2}^{-}$.

Reaction 92.1, in combination with $E^{\circ}=+(0.750 \pm 0.005) \mathrm{V}$ for $\mathrm{TEMPO}^{+/ 0}$ as reviewed in Data Sheet S-7, yields $E^{\circ}=+(1.04 \pm 0.02) \mathrm{V}$ for $\mathrm{NO}_{2}{ }^{\circ}(a q) / \mathrm{NO}_{2}{ }^{-}$.

Reaction 94.1 can be combined with the equilibrium constant for the corresponding mixed-phase reaction $\left(2 \mathrm{HNO}_{2}(a q)=\mathrm{NO}^{\bullet}(g)+\mathrm{NO}_{2} \bullet(g)+\mathrm{H}_{2} \mathrm{O}(l)\right)$ and the Henry's law constant for $\mathrm{NO}^{\bullet}$ to obtain the Henry's law constant for $\mathrm{NO}_{2}{ }^{\bullet}$. An assumed value for $H_{\mathrm{NO} 2}$ was used in the determination of $K_{\text {eq }}$ for reaction 94.1, but the two quantities are not completely correlated because of an additional " $C$ " parameter. This mixed-phase equilibrium constant $\left(1 / K_{\mathrm{M} 2}\right.$ ' in the parlance of Schwartz and White (1981)) has a value of $1 /\left(1.26 \times 10^{2}\right) \mathrm{atm}^{2} \mathrm{M}^{-2}$ \{i.e. $1 /(1.23 \times$ $\left.\left.10^{4}\right) \mathrm{MPa}^{2} \mathrm{M}^{-2}\right\}$ as reported by Schwartz and White [1]. Schwartz and White derived this value 5517 from the equilibrium constant for the corresponding gas-phase reaction and $H_{\mathrm{HNO} 2}$. The latter has 
5518 been confirmed by Park and Lee [2]. We use $H_{\mathrm{NO}}=(1.93 \pm 0.06) \times 10^{-3} \mathrm{M} \mathrm{bar}^{-1}\left\{\right.$ i.e. $1.93 \times 10^{-2}$ $\left.5519 \mathrm{M} \mathrm{MPa}^{-1}\right\}$ as recommended in Data Sheet 90 . Thus, $H_{\mathrm{NO} 2}=K_{10.01} K_{\mathrm{M} 2} / H_{\mathrm{NO}}=7.2 \times 10^{-3} \mathrm{M} \mathrm{bar}^{-1}$ $5520 \pm 12 \%$ i.e. $\left.7.2 \times 10^{-2} \mathrm{M} \mathrm{MPa}^{-1}\right\}$. The discrepancy between this result and the value tabulated 5521 above is likely due to the number of quantities used in the calculation and correlation issue noted 5522 above.

$5523 \quad$ Reaction 95.1 can be combined with the equilibrium constant for the corresponding 5524 mixed-phase reaction $\left(2 \mathrm{NO}_{2}{ }^{\bullet}(g)=\mathrm{HNO}_{2}(a q)+\mathrm{H}^{+}(a q)+\mathrm{NO}_{3}{ }^{-}(a q)\right.$ to obtain the Henry's law 5525 constant for $\mathrm{NO}_{2}{ }^{\circ}$. This latter reaction (M 1' in the parlance of Schwartz and White (1981)) has $5526 K_{\text {eq }}=4.78 \times 10^{5} \mathrm{M}^{3}$ atm $^{-2}$ [1] \{i.e. $\left.4.66 \times 10^{7} \mathrm{M}^{3} \mathrm{MPa}^{-2}\right\}$. Schwartz and White obtained this 5527 value by combining $\mathrm{K}_{\mathrm{M} 2}$ 'and $\mathrm{K}_{\mathrm{M} 3}$, and these, respectively were obtained by combining $\left(K_{\mathrm{G} 2}\right.$ and $\left.5528 H_{\mathrm{HNO} 2}\right)$ and $\left(K_{\mathrm{G} 3}\right.$ and $\left.K_{\mathrm{V} 2}\right)$. We do not question the gas-phase equilibrium constants $K_{\mathrm{G} 2}$ and $K_{\mathrm{G} 3}$, 5529 and the values selected for $H_{\mathrm{HNO} 2}$ and $K_{\mathrm{V} 2}$ were subsequently confirmed by Park and Lee [2].

5530 Following Schwartz and White (1981) we thus obtain $H_{\mathrm{NO} 2}=1.1 \times 10^{-2} \mathrm{M} \mathrm{atm}^{-1}$ \{i.e. $10.9 \times 10^{-}$

$5531{ }^{2} \mathrm{M} \mathrm{MPa}^{-1}$ with a $39 \%$ uncertainty. In short, the tabulated equilibrium constants for reactions

553294.1 and 95.1 are in acceptable agreement with the tabulated value for $H_{\mathrm{NO} 2}$.

5533 The tabulated value for $H_{\mathrm{NO} 2}$, in combination with the NBS value for $\Delta_{\mathrm{f}} G^{\circ}\left(\mathrm{NO}_{2}{ }^{\bullet}(g)\right)(=$

$\left.5534+51.31 \pm 0.8 \mathrm{~kJ} \mathrm{~mol}^{-1}\right)[3]$ yields $\Delta_{\mathrm{f}} G^{\circ}\left(\mathrm{NO}_{2}{ }^{\bullet}(a q)\right)=+62.3 \pm 1.0 \mathrm{~kJ} \mathrm{~mol}^{-1}$. The JANAF-NIST

5535 tables give a very similar value and uncertainty for $\Delta_{\mathrm{f}} G^{\circ}\left(\mathrm{NO}_{2}{ }^{\circ}(g)\right)$ [4]. With use of the $1982 \mathrm{NBS}$

5536 value for $\Delta_{\mathrm{f}} G^{\circ}\left(\mathrm{NO}_{2}^{-}(a q)\right)\left(=-32.2 \pm 8.0 \mathrm{~kJ} \mathrm{~mol}^{-1}\right)[3]$ we derive $E^{\circ}\left(\mathrm{NO}_{2}{ }^{\circ}(a q) / \mathrm{NO}_{2}^{-}(a q)\right)=+0.98$

$5537 \pm 0.08 \mathrm{~V}$. Ram and Stanbury have commented that the $1982 \mathrm{NBS}$ value for $\Delta_{\mathrm{f}} G^{\circ}$ of $\mathrm{HNO}_{2}(a q)$ or

$5538 \mathrm{NO}_{2}^{-}(a q)$ may be incorrect [5, 6]. Further discussion of this issue appears in Park and Lee's

5539 discussion of their measurement of the solubility of $\mathrm{HNO}_{2}$ [2]; there seems to be good evidence

5540 that the NBS values for $\Delta_{\mathrm{f}} G^{\circ}$ of $\mathrm{HNO}_{2}(a q)$ and $\mathrm{HNO}_{2}(g)$ are inconsistent with the solubility of

$5541 \mathrm{HNO}_{2}$ by about $4.6 \mathrm{~kJ} \mathrm{~mol}^{-1}$. At this time, it is unclear whether these considerations imply an

5542 error in $\Delta_{\mathrm{f}} G^{\circ}\left(\mathrm{NO}_{2}{ }^{-}(a q)\right)$, but the potential magnitude of the error is less than the $8 \mathrm{~kJ}$ uncertainty

5543 for $\Delta_{\mathrm{f}} G^{\circ}\left(\mathrm{NO}_{2}{ }^{-}(a q)\right)$ indicated above. Overall, we conclude that the $E^{\circ}\left(\mathrm{NO}_{2}{ }^{\bullet}(a q) / \mathrm{NO}_{2}{ }^{-}(a q)\right)$ value

5544 derived from the NBS data is consistent with the value derived from the equilibrium constant for 5545 reaction 92.1 .

5546 In summary, the various routes to determining $E^{\circ}\left(\mathrm{NO}_{2}{ }^{\circ}(a q) / \mathrm{NO}_{2}{ }^{-}(a q)\right)$ discussed above

5547 are all reasonably consistent with a value of $+1.04 \mathrm{~V}$. The result derived from reaction 91.1 is not

5548 used in the final recommendation because of the difficulties in making accurate corrections for

5549 activity coefficients in $0.3 \mathrm{M}$ ionic strength. The final recommendation is the one derived from

5550 reaction 92.1: $E^{\circ}\left(\mathrm{NO}_{2}{ }^{\bullet}(a q) / \mathrm{NO}_{2}^{-}(a q)\right)=+(1.04 \pm 0.02) \mathrm{V}$.

\section{Recommended value:}


$5554 E^{\circ}\left(\mathrm{NO}_{2}{ }^{\bullet}(a q) / \mathrm{NO}_{2}{ }^{-}(a q)\right)=+(1.04 \pm 0.02) \mathrm{V}$

5555

5556 References

5557

5558 1. S. E. Schwartz, W. H. White. Adv. Environ. Sci. Eng. 4, 1-45 (1981).

5559 2. J.-Y. Park, Y.-N. Lee. J. Phys. Chem. 92, 6294-6302. (1988).

55603 3. D. D. Wagman, W. H. Evans, V. B. Parker, R. H. Schumm, I. Halow, S. M. Bailey, K. L.

5561 Churney, R. L. Nuttall. J. Phys. Chem. Ref. Data 11, Suppl. No. 2 (1982).

5562 4. M. W. Chase. NIST-JANAF Thermodynamicchemical Tables, 4th ed, American Institute 5563 of Physics, Woodbury, NY (1998).

5564 5. M. S. Ram, D. M. Stanbury. Inorg. Chem. 24, 2954-2962 (1985).

5565 6. M. S. Ram, D. M. Stanbury. J. Am. Chem. Soc. 106, 8136-8142 (1984).

5566

5567 


\section{Data Sheet 89}

\section{List of reports:}

$K_{\text {eq }}=1.53 \times 10^{-5} \mathrm{M}$ presumably at room temperature, obtained by Grätzel and co-workers using pulse radiolysis to generate $\mathrm{NO}_{2}{ }^{\bullet}$ from $\mathrm{NO}_{2}{ }^{-}$and spectrophotometric $\mathrm{NO}_{2}{ }^{\bullet}$ detection [1]. experiment with spectrophotometric $\mathrm{NO}_{2} \bullet$ detection by Treinin and Hayon [2].

$K_{\text {eq }}=(0.75 \pm 0.06) \times 10^{-5} \mathrm{M}$ at pH 8.8 and $K_{\text {eq }}=1.8 \times 10^{-5} \mathrm{M}$ at pH 3.3, both at $25^{\circ} \mathrm{C}$, derived from experiments on flash photolysis of nitrate with conductivity detection by Strehlow and coworkers [3].

\section{Discussion} preferred, as the significant amount of primary data showing little scatter is reported. Treinin and Hayon [2] have performed essentially the same experiment with similar results, but show no primary data for determining $K_{\text {eq. }}$. Both determinations rely on knowing $\varepsilon_{400}\left(\mathrm{NO}_{2}^{\bullet}\right)$, to which $K_{\text {eq }}$ is inversely proportional; both have used $\varepsilon_{400}\left(\mathrm{NO}_{2}{ }^{\circ}\right)=200 \mathrm{M}^{-1} \mathrm{~cm}^{-1}$. Recently, some $10 \%$ lower $\varepsilon_{400}\left(\mathrm{NO}_{2}{ }^{\bullet}\right)$ value have been reported [4]; the difference is mainly due to the different $G$ values used. Additional uncertainty (possibly another 10\%) comes from the $\mathrm{H}^{\bullet}+\mathrm{NO}_{2}{ }^{-}$reaction [4] leading to $\mathrm{NO}^{\bullet}$ that scavenges $\mathrm{NO}_{2}$.

The latest reported $K_{\mathrm{eq}}$ has been obtained by fitting to a complex mechanism suggested by Strehlow and co-workers for flash photolysis of nitrate [3]. However, this mechanism has been recently completely revised [5]. It is also difficult to see how $K_{\text {eq }}$ can be $\mathrm{pH}$-dependent.

\section{Recommended value:}

$$
K_{\text {eq }}=(1.5 \pm 0.3) \times 10^{-5} \mathrm{M} \text {, at room temperature }
$$




\section{References}

5605

5606 1. M. Grätzel, A. Henglein, J. Lilie, G. Beck. Ber. Bunsen-Ges. Phys. Chem. 73, 646-653 5607 (1969).

$5608 \quad 2 . \quad$ A. Treinin, E. Hayon. J. Am. Chem. Soc. 92, 5821-5828 (1970).

5609 3. I. Wagner, H. Strehlow, G. Busse. Z. Phys. Chem. (Wiesbaden) 123, 1-33 (1980).

5610 4. S. V. Lymar, H. A. Schwarz, G. Czapski. J. Phys. Chem. A 106, 7245-7259 (2002).

56115 5. Madsen, J. Larsen, S. K. Jensen, S. R. Keiding, J. Thogersen. J. Am. Chem. Soc. 125, 5612 15571-15576 (2003).

5613

5614 


\section{Data Sheet 90}

5617 Chemical equilibrium: $\mathrm{NO}^{\bullet}(g) \rightleftharpoons \mathrm{NO}^{\bullet}(a q)$

\section{List of reports:}

$K_{H}=(1.95 \pm 0.06) \times 10^{-3} \mathrm{M} / \operatorname{atm}\left(1.93 \times 10^{-2} \mathrm{M} \mathrm{MPa}^{-1}\right)$ at $25^{\circ} \mathrm{C}$, obtained from the equilibrium

$K_{H}=1.92 \times 10^{-2} \mathrm{M} \mathrm{MPa}^{-1}$ at $25^{\circ} \mathrm{C}$, obtained from the volumetric determination of equilibrium $\mathrm{NO}{ }^{\bullet}$ solubility near atmospheric pressure [2]. The uncertainty appears to be less than $1 \%$. dissolved $\mathrm{NO}^{\bullet}$ at low $\mathrm{NO}^{\bullet}$ partial pressures in mixtures with other gases [3].

\section{Discussion}

The first two reported values are in excellent agreement. Quite possibly, even earlier original determinations not listed above exist in the literature. There are also several critical reviews that agree on the $K_{H}$ value of $(1.93 \pm 0.06) \times 10^{-3} \mathrm{M} /$ bar $\left\{\right.$ i.e. $\left.1.9 \times 10^{-2} \mathrm{M} \mathrm{MPa}^{-1}\right\}$ at $25^{\circ} \mathrm{C}$ (see, e.g., comprehensive tables and discussions in Wilhelm et al. [4], Schwartz and White [5], and Battino [6]). The last listed reported value is most likely less accurate, due to the less straight forward technique and the large scatter in the results, as admitted by the authors.

We thus adopt $K_{H}=(1.93 \pm 0.06) \times 10^{-3} \mathrm{M} \mathrm{bar}^{-1}\left\{\right.$ i.e. $\left(1.93 \times 10^{-2} \mathrm{M} \mathrm{MPa}^{-1}\right\}$ at $25^{\circ} \mathrm{C}$. the NBS $\Delta_{\mathrm{f}} G^{\circ}=+86.55 \mathrm{~kJ} \mathrm{~mol}^{-1}$ for $\mathrm{NO}(g)$ to calculate $\Delta_{\mathrm{f}} G^{\circ}$ for $\mathrm{NO}{ }^{\bullet}(a q)$; the $\pm 0.20 \mathrm{~kJ} \mathrm{~mol}^{-1}$ standard error is that what has been assumed for the NBS number.

\section{Recommended values:}

$$
\begin{aligned}
& K_{H}=(1.93 \pm 0.06) \times 10^{-2} \mathrm{M} \mathrm{MPa}^{-1} \text { at } 25^{\circ} \mathrm{C} . \\
& \Delta_{\mathrm{f}} G^{\circ}=+102.0 \pm 0.2 \mathrm{~kJ} \mathrm{~mol}^{-1} \text { for } \mathrm{NO}^{\bullet}(a q)
\end{aligned}
$$

Nomenclature: $\mathrm{NO}^{\bullet}$, oxidonitrogen $(\bullet)$ or nitrogen monoxide; nitric oxide is outdated. 
5653 1. J. N. Armor, J. Chem. Eng. Data 19, 82-84 (1974).

5654 2. A. W. Shaw, A. J. Vosper, J. Chem. Soc., Faraday Trans. 73, 1239-1244 (1977).

5655 3. O. C. Zafiriou, M. McFarland, Analyt. Chem. 52, 1662-1667 (1980).

5656 4. E. Wilhelm, R. Battino, R. J. Wilcock, Chem. Rev. 77, 219-262 (1977).

5657 5. S. E. Schwartz, W. H. White, Adv. Environ. Sci. Eng. 4, 1-45 (1981).

56586 Battino, R., In Oxides of Nitrogen, (Young, C. L., ed.), p. 260-335. Pergamon Press, Elmsford, $5659 \quad$ NY (1981).

5660 7. D. D. Wagman, W. H. Evans, V. B. Parker, R. H. Schumm, I. Halow, S. M. Bailey, K. L. 


\section{Data Sheet 91}

Chemical equilibrium: $\mathrm{NO}_{2}{ }^{-}+\left[\mathrm{Fe}(\mathrm{TMP})_{3}\right]^{3+} \rightleftharpoons \mathrm{NO}_{2}{ }^{\bullet}+\left[\mathrm{Fe}(\mathrm{TMP})_{3}\right]^{2+}$

(TMP = 3,4,7,8-tetramethyl-1,10-phenanthroline)

\section{List of reports:} result was obtained from the ratio of the forward and reverse rate constants. The forward rate constant was measured by stopped-flow spectrophotometry [2], and the reverse by pulse radiolysis [1].

\section{Discussion}

The forward rate constant was determined at $25.0^{\circ} \mathrm{C}$ and $0.3 \mathrm{M}$ ionic strength and reported as $(3.94 \pm 0.09) \times 10^{3} \mathrm{M}^{-1} \mathrm{~s}^{-1}$. The reverse rate constant was obtained at room temperature $\left(23{ }^{\circ} \mathrm{C}\right)$ and $0.005 \mathrm{M}$ ionic strength, with $k_{\mathrm{r}}$ reported as $(1.0 \pm 0.3) \times 10^{7} \mathrm{M}^{-1} \mathrm{~s}^{-1}$. It is reasonable to anticipate that, within its error margins, $k_{\mathrm{r}}$ is insensitive to ionic strength, so the value of $K_{\text {eq }}$ is $(3.9 \pm 1.2) \times 10^{-4}$ at $25^{\circ} \mathrm{C}$ and $\mu=0.3 \mathrm{M}$. This uncertainty is determined largely by the uncertainty in $k_{\mathrm{r}}$. Note that the value for $K_{\text {eq }}$ derived from the published value of $1 / K_{\text {eq }}$

5684 deviates somewhat (but insignificantly) from the result given here because of some incorrect 5685 handling of significant figures in the original publication.

Potentiometric titration of [Fe(TMP) $)_{3}^{2+}$ with $\mathrm{Ce}(\mathrm{IV})$ in $0.3 \mathrm{M} \mathrm{H}_{2} \mathrm{SO}_{4}$ led to $E^{\circ}$, $=+0.84$

$5687 \mathrm{~V}$ vs NHE for the Fe(III/II) couple [2]. This result leads to $E^{\circ}=+1.04 \mathrm{~V}$ for $\mathrm{NO}_{2}{ }^{\bullet}(a q) / \mathrm{NO}_{2}{ }^{-}$at $\mu$ $5688=0.3 \mathrm{M}$. The presumed uncertainty is $\pm 0.01 \mathrm{~V}$.

\section{Recommended values:}

$K_{\text {eq }}=(3.94 \pm 1.2) \times 10^{-4}$ at $25^{\circ} \mathrm{C}$ and $\mu=0.3 \mathrm{M}$.

$E^{\circ}\left(\mathrm{NO}_{2}{ }^{\circ}(a q) / \mathrm{NO}_{2}{ }^{-}\right)=+1.04 \pm 0.01 \mathrm{~V}$ at $25^{\circ} \mathrm{C}$ and $\mu=0.3 \mathrm{M}$.

List of auxiliary thermodynamic data: none. 


\section{References}

5700

5701 1. M. S. Ram, D. M. Stanbury. Inorg. Chem. 24, 2954-2962 (1985).

5702 2. M. S. Ram, D. M. Stanbury. J. Am. Chem. Soc. 106, 8136-8142 (1984).

5703

5704 


\section{Data Sheet 92}

\section{List of reports:}

$1 / K_{\text {eq }}=8.8 \times 10^{4}$ at $\mu=0.1 \mathrm{M}$ and $25^{\circ} \mathrm{C}$ [1]. Result obtained from the rate constant for reduction of $\mathrm{RNO}^{+}$by $\mathrm{NO}_{2}{ }^{-}$, which is taken as $2\left(K_{\text {eq }}\right)^{2} k_{\text {disp }}$ and $k_{\text {disp }}$ refers to the disproportionation of $\mathrm{NO}_{2}{ }^{\bullet}$. A literature value of $7.6 \times 10^{7} \mathrm{M}^{-1} \mathrm{~s}^{-1}$ was used for $k_{\text {disp. }}$.

$1 / K_{\text {eq }}=7 \times 10^{4}$ at $\mu=0.02 \mathrm{M}$ and $25^{\circ} \mathrm{C}[1]$. Obtained from the kinetics of reduction of $\mathrm{C}\left(\mathrm{NO}_{2}\right)_{4}$ by $\mathrm{RNO}^{\bullet}$ with $\mathrm{RNO}^{\bullet}$ as the limiting reagent. In these reactions, $\mathrm{NO}_{2}{ }^{-}$inhibits the rates and causes the $\mathrm{RNO}^{\bullet}$ concentration to attain a steady state. Analysis of the steady-state concentration leads directly to a value for $\left(k_{1} / k_{\text {disp }}\right)^{1 / 2} / K_{\text {eq. }}$. Use of literature values for $k_{\text {disp }}$ and $k_{1}$ then lead to the reported value for $K_{\text {eq. }}$. Here, $k_{1}$ is the second-order rate constant for oxidation of $\mathrm{NO}_{2}^{-}$by $\mathrm{C}\left(\mathrm{NO}_{2}\right)_{4}$.

\section{Discussion}

Goldstein et al. mention that the forward and reverse rate constants obtained in the above-mentioned studies are incorrect, but the equilibrium constant is not compromised by these errors [2]. A more significant potential source of error is the uncertainty in $k_{\text {disp. }}$. Reported values of $k_{\text {disp }}$ range from $2.7 \times 10^{7} \mathrm{M}^{-1} \mathrm{~s}^{-1}$ [3] to $1.0 \times 10^{8} \mathrm{M}^{-1} \mathrm{~s}^{-1}$ [4]. Much of the range in $k_{\text {disp }}$ arises

5728 from the various values used for the Henry's law constant for $\mathrm{NO}_{2}{ }^{\bullet}$, as is discussed in Data Sheet 93. Accordingly, we assign an uncertainty of a factor of 2 to $K_{\text {eq. }}$ Given the small difference between the two determinations of $K_{\text {eq }}$ at $\mu=0.1 \mathrm{M}$ and $0.02 \mathrm{M}$, we make the approximation that the result also applies at $\mu=0 \mathrm{M}$.

Given our recommended $E^{\circ}$ for $\mathrm{TEMPO}^{+/ 0}$ of $+0.750 \pm 0.005 \mathrm{~V}$ (Data Sheet S-7), the

5733 value of $E^{\circ}$ given below is derived.

5734

\section{Recommended values:}

$K_{\mathrm{eq}}=1.3 \times 10^{-5}$ within a factor of \pm 2 at $25^{\circ} \mathrm{C}$ and $\mu=0.0 \mathrm{M}$. 
5742 Nomenclature: See Data Sheet 91.

5743

5744 References

5745

$5746 \quad$ 1. A. N. Petrov, Y. N. Kozlov. Russ. J. Phys. Chem. 60, 195-198 (1986).

5747 2. S. Goldstein, A. Samuni, A. Russo. J. Am. Chem. Soc. 125, 8364-8370 (2003).

5748 3. J. L. Cheung, Y. Q. Li, J. Boniface, Q. Shi, P. Davidovits, D. R. Worsnop, J. T. Jayne, C.

5749 E. Kolb. J. Phys. Chem. A. 104, 2655-2662 (2000).

$5750 \quad 4$ 4. Y.-N. Lee, S. E. Schwartz. J. Phys. Chem. 85, 840-848 (1981).

5751

5752 
5753

5754

5755

5756

5757

5758

5759

5760

5761

5762

5763

5764

5765

5766

5767

5768

5769

5770

5771

5772

5773

5774

5775

5776

5777

5778

5779

5780

5781

5782

5783

5784

5785

5786

5787

5788

\section{Data Sheet 93}

Chemical equilibrium: $\mathrm{NO}_{2}^{\bullet}(g) \rightleftharpoons \mathrm{NO}_{2}^{\bullet}(a q)$

\section{List of reports:}

$K_{\mathrm{H}}=(7.0 \pm 0.5) \times 10^{-3} \mathrm{M} \mathrm{atm}^{-1}$ \{i.e. $6.9 \times 10^{-2} \mathrm{M} \mathrm{MPa}^{-1}$ at $22{ }^{\circ} \mathrm{C}$, obtained from the absorption kinetics of $\mathrm{NO}_{2}{ }^{\bullet}$ bubbled into a water column [1].

$K_{H}=2.0 \times 10^{-2} \mathrm{M}$ bar $^{-1}\left\{\right.$ i.e. $2.0 \times 10^{-1} \mathrm{M} \mathrm{MPa}^{-1}$ at $20{ }^{\circ} \mathrm{C}$, obtained from the $\mathrm{NO}_{2}{ }^{\bullet}$ gas uptake measurement at $15{ }^{\circ} \mathrm{C}$ by Komiyama and Inoue [2] and later temperature-adjusted by Cheung and co-workers [3].

$K_{H}=(1.4 \pm 0.2) \times 10^{-2} \mathrm{M} \mathrm{bar}^{-1}$ \{i.e. $\left(1.4 \times 10^{-1} \mathrm{M} \mathrm{MPa}^{-1}\right.$ at $20{ }^{\circ} \mathrm{C}$, obtained from the measurement of gas-phase $\mathrm{NO}_{2}{ }^{\bullet}$ uptake by water in a bubble train flow reactor [3].

$K_{\mathrm{H}}=(5.5 \pm 0.6) \times 10^{-2} \mathrm{M} \mathrm{atm}^{-1}$ i.e. $\left(5.4 \times 10^{-1} \mathrm{M} \mathrm{MPa}^{-1}\right\}$ at $10^{\circ} \mathrm{C}$ [4]. Obtained by bubbling $\mathrm{NO}_{2} \bullet$ into water.

$K_{\mathrm{H}}=1.2 \times 10^{-2} \mathrm{M} \mathrm{atm}^{-1}$ i.e. $\left.1.18 \times 10^{-1} \mathrm{M} \mathrm{MPa}^{-1}\right\}$ at $25^{\circ} \mathrm{C}$ [5]. Obtained with a formula published by Chameides [6].

\section{Discussion}

The Henry's constant measurements for $\mathrm{NO}_{2}{ }^{\bullet}$ are complicated by the $\mathrm{NO}_{2}{ }^{\bullet}$ dimerization in both gas and aqueous phases and by its second-order hydrolysis

$$
2 \mathrm{NO}_{2}^{\bullet}+\mathrm{H}_{2} \mathrm{O} \rightarrow \mathrm{HNO}_{2}+\mathrm{HNO}_{3}
$$

that occurs with a bimolecular rate constant $k$, which is subject to significant uncertainty. As a result, most measurements could only provide a product $K_{H} k^{1 / 2}$. These products are fairly consistent across 4 studies and range from $\left\{(70 \pm 9)\right.$ to $\left.(106 \pm 20) \mathrm{M}^{1 / 2} \operatorname{bar}^{-1} \mathrm{~s}^{-1 / 2}\right\}$ i.e (700 to 1060) $\mathrm{M}^{1 / 2} \mathrm{MPa}^{-1} \mathrm{~s}^{-1 / 2}$ ), as has been summarized by Cheung and co-workers [3]. Three of these measurements are within their experimental uncertainties. The Henry's law constant of Lee and Schwartz was obtained under relatively high $\mathrm{NO}_{2} \bullet$ concentrations, where dissolution and disproportionation are competitive. The other two measurements (of Cheung and coworkers and 
of Komiyama and Inoue) were obtained under conditions where the disproportionation could be neglected.

In 1983 Schwartz and White published a very thorough review on the dissolution on nitrogen oxides, including $\mathrm{NO}_{2}{ }^{\bullet}$ [7]. Figure 7 of their review is notable in conveying the various reports on the Henry's law constant for $\mathrm{NO}_{2}{ }^{\circ}$, and it provides strong evidence from 6 different 5794 sources that the value lies between $\left(6 \times 10^{-3}\right.$ and $\left.2 \times 10^{-2}\right) \mathrm{M} \mathrm{atm}^{-1}$ i.e. 0.059 to $0.197 \mathrm{M} \mathrm{MPa}^{-}$

$5795{ }^{1}{ }^{1}$. After detailed consideration of the data in their Fig. 7, Schwartz and White conclude that $K_{\mathrm{H}}$ must lie between $\left(0.7 \times 10^{-2}\right.$ and $\left.1.3 \times 10^{-2}\right) \mathrm{M} \mathrm{atm}^{-1}$ \{i.e. 0.069 to $\left.0.128 \mathrm{M} \mathrm{MPa}^{-1}\right\}$. temperature dependence of the solubility we prfer to rely on other data obtained at temperatures closer to $25^{\circ} \mathrm{C}$.

Mertes and Wahner [5] derived a value for $K_{\mathrm{H}}$ from the temperature-dependent equation given by Chameides [6]. Chameides, in turn, obtained his equation with data from the 1965 NBS tables. The current (1982) NBS tables do not provide data for $\mathrm{NO}_{2}{ }^{\circ}(a q)$, so we infer that NBS decided that the old data were unreliable.

From this discussion, it appears safe to base our evaluation on $K_{H}=(1.4 \pm 0.2) \times 10^{-2} \mathrm{M} / \mathrm{bar}$ \{i.e. $\left.0.14 \mathrm{M} \mathrm{MPa}^{-1}\right\}$ at $20^{\circ} \mathrm{C}$. The value for $K_{H}=(1.2 \pm 0.2) \times 10^{-2} \mathrm{M} /$ bar $\left\{\right.$ i.e. $\left.0.12 \mathrm{M} \mathrm{MPa}^{-1}\right\}$ at $25^{\circ} \mathrm{C}$ can be obtained assuming a value for the heat of $\mathrm{NO}_{2}{ }^{\bullet}$ hydration; following Cheung and co-workers here we use $-19 \mathrm{~kJ} \mathrm{~mol}^{-1}$ for this enthalpy of hydration (same as for $\mathrm{O}_{3}$ ). This result is within the range recommended by Schwartz and White [7]. Combining this number with the NBS' $\Delta_{\mathrm{f}} G^{\circ}=+51.31 \mathrm{~kJ} \mathrm{~mol}^{-1}$ for $\mathrm{NO}_{2}{ }^{\circ}(g)$ and assuming $\pm 0.20 \mathrm{~kJ} \mathrm{~mol}^{-1}$ standard error in this value, we obtain $\Delta_{\mathrm{f}} G^{\circ}=+(62.3 \pm 0.5) \mathrm{kJ} \mathrm{mol}^{-1}$ for $\mathrm{NO}_{2}{ }^{\circ}(a q)$.

List of auxiliary thermodynamic data: $-19 \mathrm{~kJ} \mathrm{~mol}^{-1}$ for the enthalpy of hydration of $\mathrm{O}_{3}[8] ; \Delta_{\mathrm{f}} G^{\circ}$ $5818=+51.31 \mathrm{~kJ} \mathrm{~mol}^{-1}$ for $\mathrm{NO}_{2}{ }^{\circ}(\mathrm{g})$ from the NBS tables [9]. $1 \mathrm{bar}=0.987 \mathrm{~atm}$.

\section{References}

5824 1. Y.-N. Lee, S. E. Schwartz. J. Phys. Chem. 85, 840-848 (1981). 
5825 2. H. Komiyama, H. Inoue. Chem. Eng. Sci. 35, 154-161 (1980).

5826 3. J. L. Cheung, Y. Q. Li, J. Boniface, Q. Shi, P. Davidovits, D. R. Worsnop, J. T. Jayne, C.

5827 E. Kolb. J. Phys. Chem. A. 104, 2655-2662 (2000).

5828 4. J. N. Cape, R. L. Storeton-West, S. F. Devine, R. N. Beatty, A. Murdoch. Atmos.

5829 Environ. 27A, 2613-2621 (1993).

$5830 \quad$ 5. $\quad$ S. Mertes, A. Wahner. J. Phys. Chem. 99, 14000-14006 (1995).

5831 6. W. L. Chameides. J. Geophys. Res. 89, 4739-4755 (1984).

58327 7. Schwartz, S. E., White, W. H. In Trace Atmospheric Constituents: Properties,

5833 Transformations, \& Fates, (Schwartz, S. E., ed.), p. 1-116. Wiley, New York (1983).

5834 8. L. F. Kosak-Channing, G. R. Heiz. Environ. Sci. Technol. 17, 145-149 (1983).

5835 9. $\quad$ D. D. Wagman, W. H. Evans, V. B. Parker, R. H. Schumm, I. Halow, S. M. Bailey, K. L.

5836 Churney, R. L. Nuttall. J. Phys. Chem. Ref. Data 11, Suppl. No. 2 (1982). 


\section{Data Sheet 94}

\section{List of reports:}

$$
K_{\text {eq }}=8.5 \times 10^{-8} \text { at } 22^{\circ} \mathrm{C} \text { and } \mu=0.014 \mathrm{M} \text { [1]. Park and Lee obtained this result from the }
$$
steady-state gas-phase concentrations of $\mathrm{HNO}_{2}, \mathrm{NO}^{\bullet}$ and $\mathrm{NO}_{2}{ }^{\bullet}$ generated from an acidified $\mathrm{HNO}_{2}$ solution under vigorous $\mathrm{N}_{2}$ bubbling.

\section{Discussion}

Park and Lee did not actually report the value of $K_{\text {eq }}$ cited above but rather gave the corresponding values for the forward and reverse rate constants, which, in turn, were derived from a complex expression describing the mixed kinetics of gas evolution in a system under dynamic purging. The equation used to derive the equilibrium constant uses the Henry's law constant for $\mathrm{NO}_{2}{ }^{\circ}$, but the form of the equation is such that $K_{\text {eq }}$ and $H_{\mathrm{NO} 2}$ are not strictly correlated. Park and Lee also reported a $\sim 10 \%$ uncertainty in the rate constants. The equilibrium constant is expected to be independent of ionic strength. Park and Lee also reported results at 10 these data we interpolate $K_{\text {eq }}=(1.1 \pm 0.1) \times 10^{-7}$ at $25^{\circ} \mathrm{C}$ and $\mu=0 \mathrm{M}$.

\section{Recommended value:}

5862

List of auxiliary thermodynamic data: none.

Nomenclature: See Data Sheet 91.

\section{References}




\section{$5875 \quad$ Data Sheet 95}

5876

5877 Chemical equilibrium: $2 \mathrm{NO}_{2}{ }^{\bullet}(a q) \rightleftharpoons \mathrm{HNO}_{2}+\mathrm{H}^{+}+\mathrm{NO}_{3}{ }^{-}$

\section{List of reports:}

$$
K_{\text {eq }}=(3.8 \pm 1.5) \times 10^{9} \mathrm{M} \text { at } \mu=0 \text { and } 25^{\circ} \mathrm{C} \text {. Result obtained by Schwartz and White [1] }
$$
(1981) by evaluation of the potentiometric data of Vetter [2] (1949).

\section{Discussion}

\section{Recommended value:}

$K_{\text {eq }}=(3.8 \pm 1.5) \times 10^{9} \mathrm{M}$ at $\mu=0$ and $25^{\circ} \mathrm{C}$

5893

5894 List of auxiliary thermodynamic data: none.

5896 Nomenclature: See Data Sheet 91.

\section{References}

5899

$5900 \quad$ 1. S. E. Schwartz, W. H. White. Adv. Environ. Sci. Eng. 4, 1-45 (1981).

5901 2. K. Vetter. Z. Anorg. Chem. 260, 242-248 (1949). 


\section{Data Sheet 96}

Chemical equilibrium: $\mathrm{PO}_{3}{ }^{\bullet-}+\mathrm{PenSH} \rightleftharpoons \mathrm{HPO}_{3}{ }^{2-}+\mathrm{PenS}^{\bullet}$

PenSH is penicillamine, $\left(\mathrm{Pen}=-\mathrm{CMe}_{2}-\mathrm{C}\left(\mathrm{NH}_{2}\right) \mathrm{H}-\mathrm{CO}_{2}{ }^{-}\right)$

\section{List of reports:}

The equilibrium constant for reaction 96.1 was determined in a pulse radiolysis experiment in neutral, $\mathrm{N}_{2} \mathrm{O}$-saturated solutions by monitoring the yield of $\mathrm{PenS} \mathrm{S}^{\bullet}$ at any concentration ratio $5913 \mathrm{HPO}_{3}{ }^{2-} / \mathrm{PenSH}[1]$. The plot of $\left.\mathrm{G}\left(\mathrm{HO}^{\bullet}\right)-\mathrm{G}\left(\mathrm{PenS}^{\bullet}\right) / \mathrm{G}(\mathrm{PenS})^{\bullet}\right)$ vs. this ratio yields the 5914 equilibrium constant as the slope. $\mathrm{G}\left(\mathrm{HO}^{\bullet}\right)$ is obtained simply as the maximum $\mathrm{G}\left(\mathrm{PenS} \mathrm{S}^{\bullet}\right)$. The 5915 result was $K_{96.1}=8 \times 10^{2}$. No uncertainty was reported; inspection of the figure from which the equilibrium constant was derived suggests that $\pm 1 \times 10^{2}$ would be a conservative estimate.

The forward rate constant for this reaction was reported previously [2] as $k_{\mathrm{f}}=3.0 \times 10^{8} \mathrm{~L} \mathrm{~mol}^{-1}$ $\mathrm{s}^{-1}$; this then leads to $k_{\mathrm{r}}=3.8 \times 10^{5} \mathrm{~L} \mathrm{~mol}^{-1} \mathrm{~s}^{-1}$.

\section{Discussion}

5922

In this Report, the potential for the couple PenS ${ }^{\bullet} \mathrm{H}^{+} / \mathrm{PenSH}$ is reported to be $+1.37 \pm 0.03 \mathrm{~V}$ (Data Sheet S-8). Thus, the potential for the couple $\mathrm{PO}_{3}{ }^{\cdot 2-}, \mathrm{H}^{+} / \mathrm{HPO}_{3}{ }^{2-}$ is $E^{\mathrm{o}}=(1.37 \pm 0.03) \mathrm{V}+$ $0.059 \mathrm{~V} \log \left((8 \pm 1) \times 10^{2}\right)=+(1.54 \pm 0.04) \mathrm{V}$.

\section{Recommended value:}

$E^{\circ}\left(\mathrm{PO}_{3}{ }^{\bullet-}, \mathrm{H}^{+} / \mathrm{HPO}_{3}{ }^{2-}\right)=+(1.54 \pm 0.04) \mathrm{V}$

List of auxiliary thermodynamic data: none.

Nomenclature: $\mathrm{PO}_{3}{ }^{\bullet-}$, trioxidophosphate $(\bullet 2-)$; $\mathrm{HPO}_{3}{ }^{2-}$, hydroxidodioxidophosphate $(2-)$;

5934 penicillamine, $(2 S)$-2-amino-3-methyl-3-sulfanylbutanoic acid

\section{References}

$5938 \quad$ 1. K. Schäfer, K.-D. Asmus. J. Phys. Chem. 85, 852-855 (1981).

5939 2. K. Schäfer, K.-D. Asmus. J. Phys. Chem. 84, 2156-2160 (1980). 


\section{Data Sheet 97}

Chemical equilibrium: $\mathrm{HO}^{\bullet}+\mathrm{H}_{3} \mathrm{PO}_{4} \rightleftharpoons \mathrm{H}_{2} \mathrm{O}+\mathrm{H}_{2} \mathrm{PO}_{4}^{\bullet}$

\section{List of reports:}

Forward and reverse rate constants were derived from a study of the pulse radiolysis of concentrated $(3,5$, and 8$) \mathrm{mol} \mathrm{L}^{-1}$ phosphoric acid solutions [1]. The sum of initially produced $\mathrm{HO}^{\bullet}$ and $\mathrm{H}_{2} \mathrm{PO}_{4}{ }^{\bullet}$ was obtained by allowing these radicals to react with $\mathrm{Cl}^{-}$and measuring the yield of $\mathrm{Cl}_{2}{ }^{\bullet-}$, taking $\varepsilon_{340 \mathrm{~nm}}=8200 \mathrm{~L} \mathrm{~mol}^{-1} \mathrm{~cm}^{-1}$. The absorption coefficient of $\mathrm{H}_{2} \mathrm{PO}_{4}{ }^{\bullet}$ at $520 \mathrm{~nm}$ was determined to be $\varepsilon_{520 \mathrm{~nm}}=1850 \mathrm{~L} \mathrm{~mol}^{-1} \mathrm{~cm}^{-1}[2]$, and the radicals were monitored at this wavelength. At these high phosphoric acid concentrations, a substantial fraction of the phosphate radical is formed as a direct result of the pulse. The subsequent build-up of absorbance at $520 \mathrm{~nm}$ reflects primarily a competition among the forward reaction above, other loss reactions of $\mathrm{HO}^{\bullet}$, and the self-reaction of $\mathrm{H}_{2} \mathrm{PO}_{4}{ }^{\circ}$. Taking rate constants for critical reactions from the literature, and estimating rate constants for some less critical reactions, the authors modeled their results and concluded the rate constants for the forward and reverse reactions were, in $1-6 \mathrm{~mol} \mathrm{~L}-1$ phosphoric acid: $k_{\mathrm{f}}=(4.2 \pm 0.4) \times 10^{4} \mathrm{~L} \mathrm{~mol}^{-1} \mathrm{~s}^{-1}$ and $k_{\mathrm{r}}=(2.5 \pm 0.2) \times 10^{3} \mathrm{~L} \mathrm{~mol}^{-1} \mathrm{~s}^{-1}$.

From these, $K_{97.1}=16.8$ (where the concentration of water is explicitly included).

(At 8 mol L ${ }^{-1}$ phosphoric acid, slightly lower rate constants were obtained.)

\section{Discussion}

From the equilibrium constant, $K_{97.1}=16.8$, an electrode potential of $+2.65 \mathrm{~V}$ was calculated, based on $+2.72 \mathrm{~V}$ for $E^{\circ}\left(\mathrm{HO}^{\bullet}, \mathrm{H}^{+} / \mathrm{H}_{2} \mathrm{O}\right)$.

The reported reverse rate constant takes $\left[\mathrm{H}_{2} \mathrm{O}\right]=$ number of moles of water per liter of

5968 solution. But the correct procedure should be to take the standard state of water, $1 \mathrm{~mol} \mathrm{~L}^{-1}$. As a

5969 first-order reaction, the reverse rate constant becomes $k_{\mathrm{r}}=(1.4 \pm 0.1) \times 10^{5} \mathrm{~s}^{-1}$ and $K_{97.1}=(0.30$

$5970 \pm 0.05) \mathrm{L} \mathrm{mol}^{-1}$. If it is assumed that the value of $K_{97.1}$ is not significantly affected by the

5971 phosphoric acid concentration, this leads to the correct value of the standard potential: $E^{\circ}=+2.72$ $5972-(0.059 \log 0.3)=+2.75 \pm 0.01 \mathrm{~V}$, with no uncertainty assumed in $E^{\circ}\left(\mathrm{HO}^{\bullet}\right)$.

5973 A much larger value of the forward rate constant, $k_{\mathrm{f}}=2.7 \times 10^{6} \mathrm{~mol}^{-1} \mathrm{~s}^{-1}$, was reported at 
5975 reported for the reaction of $\mathrm{HO}^{\bullet}$ with $\mathrm{H}_{2} \mathrm{PO}_{4}^{-}\left(\sim 2 \times 10^{4} \mathrm{~L} \mathrm{~mol}^{-1} \mathrm{~s}^{-1}[2]\right), \mathrm{HPO}_{4}^{2-}\left(1.5 \times 10^{5} \mathrm{~L}\right.$ $\left.5976 \mathrm{~mol}^{-1} \mathrm{~s}^{-1}[2]\right)$, or with $\mathrm{PO}_{4}^{3-}\left(<1 \times 10^{7} \mathrm{~L} \mathrm{~mol}^{-1} \mathrm{~s}^{-1}[4]\right)$.

5978 The existence of a reasonably fast reverse reaction is supported by the observation of $\mathrm{O}_{2}$

5979 generation in the continuous photolysis of peroxydiphosphate solutions [5].

5980

5981 Recommended value:

5982

$5983 E^{\circ}\left(\mathrm{H}_{2} \mathrm{PO}_{4}, \mathrm{H}^{+} / \mathrm{H}_{3} \mathrm{PO}_{4}\right)=+(2.75 \pm 0.01) \mathrm{V}$

5984

5985 List of auxiliary thermodynamic data: none.

5986

5987 References

5988

5989 1. P.-Y. Jiang, Y. Katsumura, M. Domae, K. Ishikawa, R. Nagaishi, K. Ishigure, Y.

5990 Yoshida. J. Chem. Soc., Faraday Trans. 88, 3319-3322 (1992).

5991 2. P. Maruthamuthu, P. Neta. J. Phys. Chem. 82, 710-713 (1978).

5992 3. G. Grabner, N. Getoff, F. Schwörer. Int. J. Rad. Phys. Chem. 5, 393-403 (1973).

5993 4. E. D. Black, E. Hayon. J. Phys. Chem. 74, 3199-3203 (1970).

5994 5. D. O. Mártire, M. C. Gonzalez. Prog. React. Kin. Mech. 26, 201-218 (2001).

5995

5996 


\section{Data Sheet 98}

5998 Couple: carbon dioxide/Dioxocarbonate $(\bullet 1-)$

\section{List of reported equilibrium constants:}

6001

6002

$\mathrm{CO}_{2}^{\bullet-}+\mathrm{Tl}^{+} \rightleftharpoons \mathrm{CO}_{2}(\mathrm{aq})+\mathrm{Tl}$

6003

6004 Schwarz and Dodson, 1989 [1].

$6005 K=0.2$, after correction for $\mu$ (experimental conditions: $\mu=0.05 \mathrm{M}, \mathrm{pH} 3.7$, room

6006 temperature). Combined with $E^{\circ}\left(\mathrm{Tl}^{+} / \mathrm{Tl}^{\circ}\right)=-1.94 \mathrm{~V}$, estimated, and a $K$ of $140 \mathrm{M}^{-1}$ for the

6007 equilibrium $\mathrm{Tl}^{\circ}+\mathrm{Tl}^{+} \rightleftharpoons \mathrm{Tl}_{2}{ }^{+}, E^{\circ}\left(\mathrm{CO}_{2}(\mathrm{aq}) / \mathrm{CO}_{2}{ }^{\bullet-}\right)=-(1.90 \pm 0.01) \mathrm{V}$.

6008

6009

$\mathrm{CO}_{2}{ }^{--}+\mathrm{RSH} \rightleftharpoons \mathrm{HCO}_{2}^{-}+\mathrm{RS}^{\bullet}$

6010

6011 Surdhar et al., 1989 [2].

6012 For the reactions with lipoamide (LS), penicillamine, and $\beta$-mercaptoethanol, equilibrium

6013 constants of $61 \pm 15$ (and $53 \pm 20$ ), $256 \pm 30$, and $2000 \pm 250$, respectively, were determined.

6014 Given electrode potentials $E^{\circ}(\mathrm{RS} / \mathrm{RSH})$ of $+1.43 \mathrm{~V}$ (for $\left.E^{\circ}\left[\mathrm{LS}_{2} \mathrm{H}^{\bullet}, \mathrm{H}^{+} / \mathrm{L}(\mathrm{SH})_{2}\right]\right),+1.32 \mathrm{~V}$ and

$6015+1.33 \mathrm{~V}$, respectively, the standard electrode potential of the couple $\mathrm{CO}_{2}{ }^{-} / \mathrm{HCO}_{2}^{-}$was estimated 6016 at $+(1.49 \pm 0.03) \mathrm{V}$. With this value and $2 E^{\circ}\left(\mathrm{HCO}_{2}{ }^{-} / \mathrm{CO}_{2} \mathrm{aq}\right)=-0.364 \mathrm{~V}$, the authors arrive at $6017-(1.85 \pm 0.06) \mathrm{V}$ for $E^{\circ}\left(\mathrm{CO}_{2} \mathrm{aq} / \mathrm{CO}_{2}{ }^{\bullet-}\right)$

6018

6019 Corrections:

6020 The potentials involving penicillamine and $\beta$-mercaptoethanol were based on equilibria with the 6021 the chlorpromazine radical/chlorpromazine couple. The electrode potential of this couple has 6022 been revised (see Data Sheet S-9) and, based on these $0.03 \mathrm{~V}$ higher values and an independently 6023 revised lipoamide electrode potential $\left(E^{\circ}\left[\mathrm{LS}_{2}{ }^{\bullet-}, 2 \mathrm{H}^{+} / \mathrm{L}(\mathrm{SH})_{2}\right]=+(1.78 \pm 0.06) \mathrm{V}\right.$, see Data Sheet $6024 \mathrm{~S}-10)$, the value of $E^{\circ}\left(\mathrm{CO}_{2}{ }^{\bullet-} / \mathrm{HCO}_{2}{ }^{-}\right)$changes to $+1.52 \mathrm{~V}$, and $E^{\circ}\left(\mathrm{CO}_{2} \mathrm{aq} / \mathrm{CO}_{2}{ }^{\bullet-}\right)$ from $-1.85 \mathrm{~V}$ to $6025-1.89 \mathrm{~V}$. The error is estimated at $0.06 \mathrm{~V}$.

6026

Recommended values: Given the excellent agreement between the two determinations, 6029

$E^{\circ}\left(\mathrm{CO}_{2}(\mathrm{aq}) / \mathrm{CO}_{2}{ }^{\bullet-}\right)=-(1.90 \pm 0.02) \mathrm{V}$

6031 $\Delta_{\mathrm{f}} G^{\circ}\left(\mathrm{CO}_{2}^{\bullet-}\right)=-(205 \pm 2) \mathrm{kJ} \mathrm{mol}^{-1}$, see also Data Sheet 100 . 
6033 List of auxiliary thermodynamic data.

6034

6035 Koppenol and Rush [3] estimated a standard potential of $-(1.84 \pm 0.22) \mathrm{V}$ based on the electron 6036 affinity of carbon dioxide and an solvation Gibbs energy for $\mathrm{CO}_{2}{ }^{--}$assumed to be similar to 6037 those of other triatomic anions. Older literature values are discussed there. The Gibbs energy of 6038 formation of $-205 \mathrm{~kJ} \mathrm{~mol}^{-1}$ was also derived by Yu et al. [4].

6039

6040 Nomenclature: $\mathrm{CO}_{2}$, dioxidocarbon, carbon dioxide is allowed; $\mathrm{CO}_{2}^{\bullet-}$, dioxidocarbonate $(\bullet-)$;

$6041 \mathrm{HCO}_{3}{ }^{-}$, hydroxidodioxidocarbonate $(1-) ; \mathrm{Tl}^{+}$, thallium $(+) ; \mathrm{Tl}^{2+}$, dithallium(+)

6042

6043 References

6044

6045 1. H. A. Schwarz, R. W. Dodson. J. Phys. Chem. 93, 409-414 (1989).

6046 2. P. S. Surdhar, S. P. Mezyk, D. A. Armstrong. J. Phys. Chem. 93, 3360-3363 (1989).

6047 3. W. H. Koppenol, J. D. Rush. J. Phys. Chem. 91, 4429-4430 (1987).

6048 4. D. Yu, A. Rauk, D. A. Armstrong. J. Chem. Soc., Perkin Trans. 2 2207-2215 (1994).

6049

6050 


\section{Data Sheet 99}

6052 Couple: trioxocarbonate $(\cdot 1-) /$ trioxocarbonate $(2-)$

6053

6054

6055

6056 Chemical equilibrium: $\mathrm{Br}_{2}{ }^{\circ-}+\mathrm{CO}_{3}{ }^{2-} \rightleftharpoons 2 \mathrm{Br}^{-}+\mathrm{CO}_{3}{ }^{\bullet}$

6057

6058

Huie et al. [1].

6059

6060

$K=(3.2 \pm 0.7)(\mu=3 \mathrm{M}, \mathrm{pH} 12.0), \Delta E=0.030 \pm 0.006 \mathrm{~V}$.

6061

6062

Based on Reaction 99.1 and $E^{\circ}\left(\mathrm{Br}_{2}{ }^{-} / 2 \mathrm{Br}^{-}\right)=+(1.625 \pm 0.02) \mathrm{V}$ [2] (see Data Sheet 26),

6063 $E^{\circ}\left(\mathrm{CO}_{3}{ }^{--} / \mathrm{CO}_{3}{ }^{2-}\right)=+(1.59 \pm 0.02) \mathrm{V}$.

6064

6065

6066

Chemical equilibrium: $\mathrm{CO}_{3}{ }^{\bullet-}+2 \mathrm{SCN}^{-} \rightleftharpoons \mathrm{CO}_{3}{ }^{2-}+(\mathrm{SCN})_{2}{ }^{--}$

6067

6068

Lymar et al., 2000 [3].

6069

6070

$K=(1.5 \pm 0.3) \times 10^{4} \mathrm{M}^{-1}$ and $(2.1 \pm 0.2) \times 10^{4} \mathrm{M}^{-1}$ at $0.5 \mathrm{M}$ and $1.5 \mathrm{M}$ ionic strength,

6071 respectively. Based on these equilibrium constants $E^{\circ}\left(\mathrm{CO}_{3}{ }^{-} / \mathrm{CO}_{3}{ }^{2-}\right)$ is $0.25 \mathrm{~V}$ higher than

6072 $E^{\circ}\left((\mathrm{SCN}) 2^{\bullet-} / 2 \mathrm{SCN}^{-}\right)$. The authors have noted that this difference can be somewhat smaller at

6073 low ionic strength, as the electrolyte would tend to stabilize $\mathrm{CO}_{3}{ }^{2-}$ the most. Given $E^{\circ}\left((\mathrm{SCN})_{2}{ }^{\circ}\right.$ $\left.6074 / 2 \mathrm{SCN}^{-}\right)=+1.30 \mathrm{~V}($ see Data Sheet 101$), E^{\circ}\left(\mathrm{CO}_{3}{ }^{-} / \mathrm{CO}_{3}{ }^{2-}\right)=+1.55 \mathrm{~V}$.

6075

6076

Chemical equilibrium: $\mathrm{CO}_{3}{ }^{-}+\mathrm{ClO}^{-} \rightleftharpoons \mathrm{CO}_{3}^{2-}+\mathrm{ClO}^{\bullet}$

6077

6078

Huie et al. [1].

6079

6080

$K=(9.5 \pm 3.0) \times 10^{2}\left(\mu=3.0 \mathrm{M}, \mathrm{pH} 12.2,22.2^{\circ} \mathrm{C}\right), \Delta E=(0.176 \pm 0.010) \mathrm{V}$.

6081

6082

6083 Comments: The equilibrium constant for reaction 99.1 is the average of ( $3.3 \pm 0.3)$, derived 6084 from the absorbance at $360 \mathrm{~nm}\left(\mathrm{Br}_{2}{ }^{-}\right)$at equilibrium and of $(3.1 \pm 0.5)$ from the rate constants 6085 for the decay of $\mathrm{Br}_{2}{ }^{\circ-}$ to its equilibrium value. The error in the assessment of the $\mathrm{Br}_{2}{ }^{-}-/ 2 \mathrm{Br}^{-}$ 6086 electrode potential determines that in $E^{\circ}\left(\mathrm{CO}_{3}{ }^{-} / \mathrm{CO}_{3}{ }^{2-}\right)$. The difference of $0.04 \mathrm{~V}$ between two 
6087 careful measurements may be due to medium effects. The $E^{\circ \prime}$ value derived in this way involves 6088 combining data at various ionic strengths and thus is not very well defined.

6089

6090 The standard electrode potential of the $\mathrm{ClO}^{\bullet} / \mathrm{ClO}^{-}$couple is not known precisely enough to 6091 determine $E^{\circ}\left(\mathrm{CO}_{3}{ }^{--} / \mathrm{CO}_{3}{ }^{2-}\right)$; in fact the value of $+1.59 \mathrm{~V}$ is used to estimate $E^{\circ}\left(\mathrm{ClO}^{\bullet} / \mathrm{ClO}^{-}\right)[1]$. 6092

6093

\section{Recommended values:}

6095

$6096 E^{\circ}\left(\mathrm{CO}_{3}{ }^{--} / \mathrm{CO}_{3}{ }^{2-}\right)=+(1.57 \pm 0.03) \mathrm{V}$

$6097 \Delta_{\mathrm{f}} G^{\circ}\left(\mathrm{CO}_{3}{ }^{\bullet-}\right)=-(89.1 \pm 0.8) \mathrm{kcal} \mathrm{mol}^{-1}$, or $-(373 \pm 3) \mathrm{kJ} \mathrm{mol}^{-1}$

6098

6099 List of auxiliary thermodynamic data

Based on a review of earlier literature Stanbury proposed a value of $+1.5 \mathrm{~V}$ [2]. In an ab initio

6102 study, Armstrong et al. [4] suggest a value of $+(1.23 \pm 0.15) \mathrm{V}$. While not as accurate as the two 6103 experimentally derived values, this result is impressive for an ab initio calculation.

6104

6105 Chemical equilibrium: $\mathrm{HCO}_{3}{ }^{\bullet} \rightleftharpoons \mathrm{H}^{+}+\mathrm{CO}_{3}^{\bullet}$

6106

6107 Czapski et al. [5].

6108

$6109 \mathrm{~A} \mathrm{p} K_{\mathrm{a}}$ smaller than 0 has been determined [5], as expected for a $\mathrm{HOXO}_{2}$ acid.

6110

\section{Recommended value:}

6112

6113 Except that $\mathrm{p} K_{\mathrm{a}}$ is negative, no numerical recommendation can be made.

6115 Auxiliary thermodynamic data: Earlier $\mathrm{p} K_{\mathrm{a}}$ estimates of 9.6 and $7.0-8.2$ are discussed by

6116 Czapski et al. [5]. A recent value of 9.5 [6] was shown to be in error [3]. The result of an $a b$

6117 initio calculation [4], -4.1 , also does not support the $\mathrm{p} K_{\mathrm{a}} \geq 7$ values.

\section{References}

6121 1. R. E. Huie, C. L. Clifton, P. Neta. Radiat. Phys. Chem. 38, 477-481 (1991).

6122 2. D. M. Stanbury. Adv. Inorg. Chem. 33, 69-138 (1989). 
6123 3. S. V. Lymar, H. A. Schwarz, G. Czapski. Rad. Phys. Chem. 59, 387-392 (2000).

6124 4. D. A. Armstrong, W. L. Waltz, A. Rauk. Can. J. Chem. 84, 1614-1619 (2006).

6125 5. G. Czapski, S. V. Lymar, H. A. Schwarz. J. Phys. Chem. A 103, 3447-3450 (1999).

6126 6. Z. Zuo, Z. Cai, Y. Katsumura, N. Chitose, Y. Muroya. Radiat. Phys. Chem. 55, 15-23

6127 (1999).

6128

6129 


\section{Data Sheet 100}

6131 Dioxidocarbonate $(\bullet 1-) /$ hydrogendioxidocarbonate $(1-)$

6132

$\mathrm{CO}_{2}{ }^{\bullet-}+\mathrm{HSLSH} \rightleftharpoons \mathrm{HCO}_{2}^{-}+\mathrm{HSLS}^{\bullet}$

Surdhar et al. [1].

$6136 \mathrm{HSLSH}$ is dihydrolipoamide ( $\left.\mathrm{HS}-\mathrm{CH}_{2}-\mathrm{CH}_{2}-\mathrm{C}(\mathrm{SH}) \mathrm{H}-\left(\mathrm{CH}_{2}\right)_{4}-\mathrm{CONH}_{2}\right) . K=61 \pm 15$, and $53 \pm 20$

6137 from kinetic data, at $\mathrm{pH} 4$ and $10 \mathrm{mM}$ formate. $\Delta_{\mathrm{rxn}} G^{\circ}=-(10 \pm 1) \mathrm{kJ} \mathrm{mol}^{-1}$. Given

$6138 E^{\circ}\left(\mathrm{SLS}^{\bullet-} / \mathrm{HSLSH}\right)=+1.75 \mathrm{~V}[2]$ and a $\mathrm{p} K_{\mathrm{a}}$ of 5.5 for $\mathrm{HSLSH}, E^{\circ}\left(\mathrm{CO}_{2}{ }^{--} / \mathrm{HCO}_{2}^{-}\right)=+1.52 \mathrm{~V}$.

$\mathrm{CO}_{2}^{\bullet-}+\mathrm{PenSH} \rightleftharpoons \mathrm{HCO}_{2}^{-}+\mathrm{PenS}^{\bullet}$

6142 Surdhar et al. [1].

6143 PenSH is penicillamine $\left(\mathrm{Pen}=-\mathrm{CMe}_{2}-\mathrm{C}\left(\mathrm{NH}_{2}\right) \mathrm{H}-\mathrm{CO}_{2}{ }^{-}\right) \cdot K=(256 \pm 3)$ at $\mathrm{pH} 6$ and $100 \mathrm{mM}$

6144 formate. $\Delta_{\mathrm{rxn}} G^{\circ}=-(13.6 \pm 0.3) \mathrm{kJ} \mathrm{mol}^{-1}$. Given $E^{\circ}\left(\mathrm{PenS}{ }^{\bullet-} / \mathrm{PenSH}\right)=+1.32 \mathrm{~V}$ [2],

$6145 E^{\circ}\left(\mathrm{CO}_{2}^{\bullet-} / \mathrm{HCO}_{2}^{-}\right)=+1.46 \mathrm{~V}$.

$\mathrm{CO}_{2}^{\bullet-}+\beta-\mathrm{RSH} \rightleftharpoons \mathrm{HCO}_{2}^{-}+\beta-\mathrm{RS}^{\bullet}$

Surdhar et al. [1].

$6150 \beta$-RSH is $\beta$-mercaptoethanol $\left(\mathrm{HOCH}_{2} \mathrm{CH}_{2} \mathrm{SH}\right) . K=(2000 \pm 250)$ at $\mathrm{pH} 3$ and $0.1 \mathrm{M}$ to $0.3 \mathrm{M}$

6151 formate. $\Delta_{\mathrm{rxn}} G^{\circ}=-(13.6 \pm 0.3) \mathrm{kJ} \mathrm{mol}^{-1}$. Given $E^{\circ}(\beta-\mathrm{RS} / \beta-\mathrm{RSH})=+1.33 \mathrm{~V}[2]$,

$6152 E^{\circ}\left(\mathrm{CO}_{2}^{\bullet-} / \mathrm{HCO}_{2}^{-}\right)=+1.48 \mathrm{~V}$.

6153

\section{Discussion}

The above three reactions are symmetric with respect to reactant and product charges,

6157 and thus the equilibrium constants are expected to be minimally affected by ionic strength. For

6158 this reason, the derived electrode potentials can be considered to be $E^{\circ}$ rather than $E^{\circ \prime}$ values.

6159 Given the uncertainty in the determination of the standard electrode potentials of the used

6160 substituted sulfanyl/sulfane couples, Surdhar et al. [1] calculate an average of $+(1.49 \pm 0.06) \mathrm{V}$

6161 for $E^{\circ}\left(\mathrm{CO}_{2}{ }^{\bullet-}, \mathrm{H}^{+} / \mathrm{HCO}_{2}^{-}\right)$. This value can be corrected, given a new evaluation of the

6162 chlorpromazine electrode potential (see Data Sheet S-9) which was the reference electrode

6163 potential for Reactions 100.2 and 100.3, and a new evaluation of the lipoamide electrode

6164 potential (see Data Sheet S-10). On average, the electrode potential of the used substituted 
6165 sulfanyl/sulfane couples increased by $0.03 \mathrm{~V}$, which yields $+(1.52 \pm 0.06) \mathrm{V}$ for $E^{\circ}\left(\mathrm{CO}_{2}{ }^{\circ-}\right.$,

$\left.6166 \mathrm{H}^{+} / \mathrm{HCO}_{2}{ }^{-}\right)$, see evaluation of $E^{\circ}\left(\mathrm{CO}_{2} \mathrm{aq} / \mathrm{CO}_{2}{ }^{--}\right)$(Data Sheet 98).

Recommended value:

Fojtik et al., 1970 [3].

$\mathrm{p} K_{\mathrm{a}}=(3.0 \pm 0.3)$

Buxton and Sellers, 1973 [4].

$6178 \quad \mathrm{p} K_{\mathrm{a}}=1.4$

6180 Jeevajaran et al., 1990 [5].

$6181 \quad \mathrm{p} K_{\mathrm{a}}=-(0.2 \pm 0.1)$

6183 Flyunt et al., 2001 [6].

$6184 \mathrm{p} K_{\mathrm{a}} \sim 2.3$

\section{Discussion}

Flyunt et al. [6] report that the Buxton and Sellers [4] result was an artifact. They also argue that the result of Jeevarajan et al. [5] should be attributed to the protonation of $\mathrm{COOH}^{\circ}$. 6190 Flyunt et al. [6] are at a loss to explain the discrepancy between their result and that of Fojtik et 6191 al. [3].

This $\mathrm{p} K_{\mathrm{a}}$ is interpreted by Loeff $e t$ al. [7] to correspond to the species ${ }^{\bullet} \mathrm{COOH}$. The Gibbs 6194 of Jeevarajan et al. [5], a resemblance in the UV-spectra of $\mathrm{HCO}_{2}{ }^{-}$and $\mathrm{Cl}^{-}$, and a coMParison 6195 with electrode potentials of alkylperoxyl/alkylperoxide couples, a standard electrode potential of $6196>2.4 \mathrm{~V}$ is suggested for $\mathrm{HCO}_{2}{ }^{\circ} / \mathrm{HCO}_{2}{ }^{-}$[7]. Rauk and Armstrong calculate, with ab initio 6197 methods, a potential of $+2.3 \mathrm{~V}$ for this couple, and $+2.5 \mathrm{~V}$ for $E^{\circ}\left(\mathrm{HCO}_{2} / \mathrm{HCO}_{2} \mathrm{H}\right)$ [8]. Flyunt et 6198 al. [6] are in agreement with the interpretation that $\mathrm{CO}_{2}{ }^{-}$protonates preferentially on one of its 6199 oxygen atoms rather than carbon. We accept this interpretation and recommend a $\mathrm{p} K_{\mathrm{a}}$ for $6200 \mathrm{COOH}^{\bullet}$ that is the average of the results of Fojtik et al. [3] and Flyunt et al. [6]. 
6202 Recommended value:

6203

$6204 \mathrm{p} K_{\mathrm{a}}=(2.6 \pm 0.3)$ for $\mathrm{COOH}^{\bullet} \rightleftharpoons \mathrm{H}^{+}+\mathrm{CO}_{2}^{\bullet-}$

6205

6206 References

6207

6208 1. P. S. Surdhar, S. P. Mezyk, D. A. Armstrong. J. Phys. Chem. 93, 3360-3363 (1989).

6209 2. P. S. Surdhar, D. A. Armstrong. J. Phys. Chem. 91, 6532-6537 (1987).

6210 3. A. Fojtik, G. Czapski, A. Henglein. J. Phys. Chem. 74, 3204-3208 (1970).

6211 4. G. V. Buxton, R. M. Sellers. J. Chem. Soc., Faraday Trans. 1 69, 555-559 (1973).

$6212 \quad 5 . \quad$ A. S. Jeevarajan, I. Carmichael, R. W. Fessenden. J. Phys. Chem. 94, 1372-1376 (1990).

6213 6. R. Flyunt, M. N. Schuchmann, C. von Sonntag. Chem. Eur. J. 7, 796-799 (2001).

6214 7. I. Loeff, S. Goldstein, A. Treinin, H. Linschitz. J. Phys. Chem. 95, 4423-4430 (1991).

6215 8. D. Yu, A. Rauk, D. A. Armstrong. J. Chem. Soc., Perkin Trans. 2 2207-2215 (1994).

6216

6217 


\section{Data Sheet 101}

Chemical equilibrium: $\mathrm{SCN}^{\bullet}+\mathrm{SCN}^{-} \rightleftharpoons(\mathrm{SCN})_{2}^{\bullet-}$

\section{List of reported equilibrium constants:}

6223

6224

Baxendale et al., 1968 [1].

6225

Thiocyanate was oxidized by hydroxyl radicals generated by pulse radiolysis. The equilibrium constant is $2.0 \times 10^{5} \mathrm{M}^{-1}$ at both $\mathrm{pH} 2$ and 7 . Forward and backward rate constants are $7.0 \times 10^{9}$ $\mathrm{M}^{-1} \mathrm{~s}^{-1}$ and $3.4 \times 10^{4} \mathrm{~s}^{-1}$, respectively at $22.0^{\circ} \mathrm{C}$. Ionic strength not stated. Given uncertainties of $10 \%$ in each rate constant, an error of $0.3 \times 10^{5} \mathrm{M}^{-1}$ is estimated.

Baxendale and Bevan, 1969 [2]. interpolate the value of $K$ at $25{ }^{\circ} \mathrm{C}$ from a $\ln K$ vs. $1 / \mathrm{T}$ graph: $K=1.99 \times 10^{5} \mathrm{M}^{-1}$.

Elliot and Sopchyshyn, 1984 [3].

6235

Temperature study $(10-90){ }^{\circ} \mathrm{C}$; reports $K=1.08 \times 10^{5} \mathrm{M}^{-1}$ at $22{ }^{\circ} \mathrm{C}$. Conditions: $\mathrm{pH} 7$ implied, concentrations of $\mathrm{SCN}^{-}$between $0.1 \mathrm{mM}$ and $100 \mathrm{mM}$. Regarding the difference with the results obtained by Baxendale and coworkers $[1,2]$, the authors state: "No explanation can be given for this difference..."

Chin and Wine, 1992 [4].

6241 Hydroxyl radicals were generated by flash photolysis of hydrogen peroxide. $K=(2.2 \pm 0.3) \times$

$624210^{5} \mathrm{M}^{-1}$ at $297 \mathrm{~K}$. Forward and backward rate constants are $(6.9 \pm 0.7) \times 10^{9} \mathrm{M}^{-1} \mathrm{~s}^{-1}$ and $(3.09 \pm$ $62430.25) \times 10^{4} \mathrm{~s}^{-1}$, respectively. Ionic strength is below $\mathrm{mM}$. The $\mathrm{pH}$ was not stated, and no buffer 6244 was used.

Lymar et al., 2000 [5].

6247 Forward rate constant taken from Nagarajan and Fessenden [6], $9 \times 10^{9} \mathrm{M}^{-1} \mathrm{~s}^{-1}$ combined with $62484.2 \times 10^{4} \mathrm{~s}^{-1}$ at $0.5 \mathrm{M}$ ionic strength, yields $K=2.1 \times 10^{5} \mathrm{M}^{-1}$.

$6250 \mathrm{Wu}$ et al., 2001 [7].

6251 Temperature study $(25-400){ }^{\circ} \mathrm{C}$; reports $K=1 \times 10^{5} \mathrm{M}^{-1}$ at $25^{\circ} \mathrm{C}$. The Van 't Hoff plot shows 6252 good agreement with results obtained by Elliot and Sopchyshyn [3]. 
6254 Recommendation: The choice, in essence, is between $\left(1 \times 10^{5}\right.$ and $\left.2 \times 10^{5}\right) \mathrm{M}^{-1} \mathrm{~s}^{-1}$ at $25^{\circ} \mathrm{C}$.

6255 Given the excellent agreement between an experimental and a simulated increase of absorbance

6256 at $472 \mathrm{~nm}$ of the $(\mathrm{SCN}) 2^{\bullet-}$ radical obtained by Milosavljevic and LaVerne [8], $K_{101.1}=(2.0 \pm 0.3)$

$6257 \times 10^{5} \mathrm{M}^{-1} \mathrm{~s}^{-1}$ at $25^{\circ} \mathrm{C}$. The standard Gibbs energy of Reaction 101.1 is $-(30.3 \pm 0.5) \mathrm{kJ}$. Given

6258 the charge-type of reaction 101.1 it is reasonable to expect that the $K$ value is independent of

6259 ionic strength. Consequently, $E^{\circ}\left(\mathrm{SCN}^{\bullet} / \mathrm{SCN}^{-}\right)$is $(314 \pm 5) \mathrm{mV}$ higher than $E^{\circ}\left((\mathrm{SCN}) 2^{\bullet-} / 2 \mathrm{SCN}^{-}\right)$.

Chemical equilibrium: $\mathrm{BrSCN}^{\bullet-}+\mathrm{SCN}^{-} \rightleftharpoons(\mathrm{SCN})_{2}{ }^{-}+\mathrm{Br}^{-}$

\section{List of reported equilibrium constants:}

Schöneshofer and Henglein, 1970 [9].

Chemical equilibrium: $\mathrm{BrSCN}^{\bullet-}+\mathrm{Br}^{-} \rightleftharpoons \mathrm{Br}_{2}^{\bullet-}+\mathrm{SCN}^{-}$

\section{List of reported equilibrium constants:}

6275

6276 $K=1.1 \times 10^{2}$. Conditions: $10 \mathrm{mM}$ ionic strength, no buffer, $\mathrm{pH}$ not known, no estimate of error. with $K_{37.1} K_{-36.1}=9 \times 10^{-6}$. This equilibrium constant is expected to be minimally affected by ionic strength, given the ionic charge distribution. It leads to a difference in electrode potential 
Chemical equilibrium: $\mathrm{ISCN}^{\bullet-}+\mathrm{SCN}^{-} \rightleftharpoons(\mathrm{SCN})_{2}{ }^{\bullet-}+\mathrm{I}^{-}$

List of reported equilibrium constants:

6294

6295 Schöneshofer and Henglein, 1970 [9].

6296

$6297 K=2.5 \times 10^{-3}$. Conditions: $0.3 \mathrm{M}$ to $1.0 \mathrm{M}$ ionic strength, no buffer, $\mathrm{pH}$ not known, no estimate 6298 of error.

Chemical equilibrium: $\mathrm{ISCN}^{\bullet-}+\mathrm{I}^{-} \rightleftharpoons \mathrm{I}_{2}^{\bullet-}+\mathrm{SCN}^{-}$

\section{List of reported equilibrium constants:}

6304

6305 Schöneshofer and Henglein, 1970 [9].

6306

$K=55$. Conditions: $10 \mathrm{mM}$ ionic strength, no buffer, $\mathrm{pH}$ not known, no estimate of error.

Reactions 55.1 and -56.1 can be added to yield:

6314 with $K_{55.1} K_{-56.1}=4.55 \times 10^{-5}$. Given the ionic charges involved, this equilibrium constant is

6315 expected to be minimally dependent on ionic strength. It leads to a difference in electrode 6316 potential between $E^{\circ}\left(\mathrm{I}_{2}{ }^{\bullet-} / 2 \mathrm{I}^{-}\right)$and $\left.E^{\circ}(\mathrm{SCN})_{2}{ }^{\bullet-} / 2 \mathrm{SCN}^{-}\right)$of $257 \mathrm{mV}$. [see also the evaluation of $6317 E^{\circ}\left(\mathrm{I}_{2}{ }^{\bullet-} / 2 \mathrm{I}^{-}\right)$, Data Sheet 45$]$. Given estimated errors of $15 \%$ in $K_{55.1}$ and $K_{56.1}$, the electrode 6318 potential difference has an uncertainty of $7 \mathrm{mV}$. 
$6325 K=0.0125 \mathrm{M}^{-1}$ at low $\mathrm{pH}$ and high ionic strength. The conditions are not clearly stated. The 6326 same study gives the $\mathrm{p} K_{\mathrm{a}}$ of $\operatorname{TrpH} \mathrm{H}^{\bullet+}$ as 4.3 .

Posener et al., 1976 [10].

$K=6.3 \times 10^{-8}$ at low $\mathrm{pH}$ and high ionic strength. The conditions are not clearly stated. The equilibrium constant was obtained by combining the measured equilibrium constant for reaction 101.4 and a literature value of $2.0 \times 10^{-5} \mathrm{M}^{-1}$ for reaction 101.1 .

Chemical equilibrium: $(\mathrm{SCN}) 2^{\bullet-}+\mathrm{Os}(\mathrm{bpy}) 3^{2+} \rightleftharpoons 2 \mathrm{SCN}^{-}+\mathrm{Os}(\mathrm{bpy}) 3^{3+}$

Nord et al., 1982 [11].

6341

Forward and backward rate constants are $(2.8 \pm 0.2) \times 10^{9} \mathrm{M}^{-1} \mathrm{~s}^{-1}$ and $(25 \pm 5) \mathrm{M}^{-2} \mathrm{~s}^{-1}$, respectively. Thus, $K=(1.1 \pm 0.2) \times 10^{8} \mathrm{M}$ at $22{ }^{\circ} \mathrm{C}$ and $0.1 \mathrm{M}$ ionic strength. The $\mathrm{pH}$ for the forward reaction was 3 , and the hydron concentration for the backward reaction was $0.5 \mathrm{M}$, although the ionic strength was reported as $0.1 \mathrm{M}$ ! Given $E^{\circ}\left(\mathrm{Os}(\mathrm{bpy}) 3^{3+} / \mathrm{Os}(\mathrm{bpy}) 3^{2+}\right)=+0.857 \pm$ $0.004 \mathrm{~V}$ at $\mu=0.1 \mathrm{M}$ and $22{ }^{\circ} \mathrm{C}[11], E^{\circ}\left((\mathrm{SCN}) 2^{\circ-} / 2 \mathrm{SCN}^{-}\right)$is $+(1.331 \pm 0.008) \mathrm{V}$ at $\mu=0.1 \mathrm{M}$. $K=(1.69 \pm 0.30) \mathrm{M}$ at $0.02 \mathrm{M}$ ionic strength. Determined $E^{\circ}\left(\mathrm{Ru}(\mathrm{bpy}) 3^{3+} / \mathrm{Ru}(\mathrm{bpy}) 3^{2+}\right)=+1.28$ $\mathrm{V}$, at $25^{\circ} \mathrm{C}, 0.1 \mathrm{M}$ ionic strength and $\mathrm{pH}$ 7. With this electrode potential and the equilibrium constant a value for $E^{\circ}\left((\mathrm{SCN})_{2}{ }^{\bullet-} / 2 \mathrm{SCN}^{-}\right)$was calculated as $+(1.29 \pm 0.01) \mathrm{V}$. A value for $E^{\circ}\left(\mathrm{SCN}^{\bullet} / \mathrm{SCN}^{-}\right)$of $+1.61 \mathrm{~V}$ was calculated by use of a literature value for $K_{101.1}$. 
Lymar et al., 2000 [5].

$6362 K=2.3 \times 10^{4} \mathrm{M}^{-1}$ near $\mathrm{pH} 11$ and high $(1.5 \mathrm{M})$ ionic strength; $K=1.7 \times 10^{4} \mathrm{M}^{-1}$ near $\mathrm{pH} 11$ and $63630.5 \mathrm{M}$ ionic strength. Experiments performed at $25{ }^{\circ} \mathrm{C}$ (Lymar, personal communication). Values 6364 obtained by both measuring the position of equilibrium and from the ratio of the forward and 6365 reverse rate constants.

Chemical equilibrium: $\mathrm{CO}_{3}^{\bullet-}+\mathrm{SCN}^{-} \rightleftharpoons \mathrm{CO}_{3}{ }^{2-}+\mathrm{SCN}^{\bullet}$

6369

6370

Lymar et al., 2000 [5].

6371

$K=0.08$ near $\mathrm{pH} 11$ and high $(0.5 \mathrm{M})$ ionic strength. Value obtained by combining the measured equilibrium constants for reactions 99.2 and 101.1. From this equilibrium constant $E^{\circ}\left(\mathrm{CO}_{3}{ }^{--} / \mathrm{CO}_{3}{ }^{2-}\right)$ is $0.06 \mathrm{~V}$ lower than $E^{\circ}\left(\mathrm{SCN}^{\bullet} / \mathrm{SCN}^{-}\right)$. Given the reevaluation of $E^{\circ}\left(\mathrm{CO}_{3}{ }^{--} / \mathrm{CO}_{3}{ }^{2-}\right),+(1.57 \pm 0.03) \mathrm{V}($ Data Sheet 99$), E^{\circ}\left(\mathrm{SCN}^{\bullet} / \mathrm{SCN}^{-}\right)=+(1.63 \pm 0.03) \mathrm{V}$.

\section{Indirect determinations and estimates of $E^{\circ}\left(\mathrm{SCN}^{\bullet} / \mathrm{SCN}^{-}\right)$}

Sarala et al., 1980 [13].

Based on $E^{\circ}\left(\mathrm{I}^{\bullet} / \mathrm{I}^{-}\right)=+1.33 \mathrm{~V}$ (assumed), $E^{\circ}\left(\mathrm{SCN}^{\bullet} / \mathrm{SCN}^{-}\right)$is recalculated from the energetics of I $E^{\circ}\left(\mathrm{SCN}^{\bullet} / \mathrm{SCN}^{-}\right)$.

Butler et al., 1982 [14].

Literature calculation:

$$
\mathrm{I}^{-}+\mathrm{SCN}^{\bullet} \rightleftharpoons \mathrm{ISCN}^{\bullet-}
$$$$
K=1 /\left(1.3 \times 10^{-8} \mathrm{M}\right)[9]
$$$$
\mathrm{ISCN}^{\bullet-} \rightleftharpoons \mathrm{SCN}^{-}+\mathrm{I}^{\bullet}
$$$$
K=4.8 \times 10^{-4} \mathrm{M} \text { [9] }
$$$$
\mathrm{I}^{\bullet}+\mathrm{e}^{-} \rightleftharpoons \mathrm{I}^{-}
$$

$$
E^{\circ}=+1.3 \mathrm{~V} \text { [15] }
$$


From the kinetics of the reaction of $\mathrm{HO}_{2}{ }^{\bullet}$ with $\mathrm{I}_{2}$ at $\mu=1 \mathrm{M}$ and a value of $1.1 \mathrm{kcal} \mathrm{mol}^{-1}(4.6 \mathrm{~kJ}$ $\mathrm{mol}^{-1}$ ) for $\Delta_{\mathrm{f}} G^{\circ}$ of $\mathrm{HO}_{2}{ }^{\bullet}$ these authors determined a standard Gibbs energy of formation of $\mathrm{I}_{2}{ }^{\circ-}$ of $-0.9 \mathrm{kcal} \mathrm{mol}^{-1}\left(-3.8 \mathrm{~kJ} \mathrm{~mol}^{-1}\right)$. Via reactions 55.1 and 56.1 they arrive at $\Delta_{\mathrm{f}} G^{\circ}(\mathrm{SCN}) 2^{\bullet-}=+74.0$ $6402 \mathrm{kcal} \mathrm{mol}^{-1}\left(+310 \mathrm{~kJ} \mathrm{~mol}^{-1}\right), E^{\circ}\left((\mathrm{SCN}) 2^{\bullet-} / 2 \mathrm{SCN}^{-}\right)=+1.31 \mathrm{~V}$, and $E^{\circ}\left(\mathrm{SCN}^{\bullet} / \mathrm{SCN}^{-}\right)=+1.62 \mathrm{~V}$. 6403 These potential are approximate because of the various ionic strengths used in their derivation.

Merényi et al., 1988 [17].

From the kinetics of the reaction of $\mathrm{ClO}_{2}{ }^{\bullet}$ with tryptophan, the authors derive a value of $1.08 \pm$ $0.02 \mathrm{~V}$ for $E^{\circ}$ ( $\left.\operatorname{trp}{ }^{\bullet} / \operatorname{trpH}\right)$ at $\mathrm{pH} 7$. With an equilibrium constant of $6.3 \times 10^{-8}$ for reaction 101.5

$6410\left(\mathrm{TrpH}^{\bullet+} / \mathrm{SCN}^{-}\right)$determined by Posener et al. [10], see above, there is a $426 \mathrm{mV}$ difference 6411 between $E^{\circ}\left(\operatorname{trpH} H^{\bullet+} / \operatorname{trpH}\right)$ and $E^{\circ}\left(\mathrm{SCN}^{\bullet} / \mathrm{SCN}^{-}\right)$. Given a $\mathrm{p} K_{\text {a }}$ of $4.3 \mathrm{of} \mathrm{TrpH}^{\bullet+}$, this leads to $6412 E^{\circ}\left(\mathrm{SCN}^{\bullet} / \mathrm{SCN}^{-}\right)=+1.67 \mathrm{~V}$, although the authors list $+1.66 \pm 0.02 \mathrm{~V}$. More recent investigations 6413 of the $\operatorname{TrpH}^{\bullet+} / \operatorname{TrpH}$ couple indicate that its potential is $\sim 0.05 \mathrm{~V}$ lower (see Supplementary Data 6414 Sheet S-12.

\section{Discussion}

There are only two direct determinations (the reactions with $\left[\mathrm{Os}(\mathrm{bpy})_{3}\right]^{2+}$ and $\left.\left[\mathrm{Ru}(\mathrm{bpy})_{3}\right]^{2+}\right)[11$, 6419 12] of which the one by Nord et al. [11] is based on a rather large equilibrium constant under 6420 uncertain ionic strength conditions. We therefore give more weight to the determination by 6421 DeFelippis et al. [12]. Unfortunately, the results from DeFelippis et al. were obtained by 6422 combining data at differing ionic strengths; we consider that accurate correction of the values to 6423 the same ionic strength would be unreliable. As a result, the derived potentials are $E^{\circ 1}$ values at 6424 an undefined ionic strength. Fortunately and surprisingly, the indirect determinations yield 6425 values that are very similar.

6427 A consistency test can be performed by considering the equilibrium constants for the following 6428 reactions:

$6431 \mathrm{BrSCN}^{\bullet-}+\mathrm{Br}^{-} \rightleftharpoons \mathrm{Br}_{2}^{--}+\mathrm{SCN}^{-}$

$6432 \mathrm{Br}_{2}^{\circ-}+\mathrm{CO}_{3}^{2-} \rightleftharpoons 2 \mathrm{Br}^{-}+\mathrm{CO}_{3}{ }^{--}$ 
This leads to $K_{99.1} /\left(K_{37.1} K_{36.1}\right)=3.4 \times 10^{4} \mathrm{M}^{-1}$, which is equivalent to the equilibrium constant for 6437 reaction 99.2 . The directly-measured value for $K_{99.2}$ is $2.3 \times 10^{4} \mathrm{M}^{-1}$, which demonstrates

6438 excellent self-consistency.

\section{Recommended values:}

6441

6442

$E^{\circ}\left(\mathrm{SCN}^{\bullet} / \mathrm{SCN}^{-}\right)=+(1.61 \pm 0.02) \mathrm{V}$

6443

$E^{\circ}\left((\mathrm{SCN})_{2}{ }^{\bullet-} / 2 \mathrm{SCN}^{-}\right)=+(1.30 \pm 0.02) \mathrm{V}$

$6444 \Delta_{\mathrm{f}} G^{\circ}\left(\mathrm{SCN}^{\bullet}\right)=+248 \pm 2 \mathrm{~kJ} \mathrm{~mol}^{-1}$

$6445 \Delta_{\mathrm{f}} G^{\circ}(\mathrm{SCN})_{2}{ }^{--}=+310 \pm 2 \mathrm{~kJ} \mathrm{~mol}^{-1}$

6446

6447 Nomenclature: $\mathrm{SCN}^{-}$, nitridosulfidocarbonate(1-), thiocyanate is allowed; $\mathrm{SCN}^{\bullet}$,

6448 nitridosulfidocarbon $(\bullet) ;(\mathrm{SCN})_{2}{ }^{\bullet-}$, bis(nitridosulfidocarbonate $)(S-S)(\bullet 1-)$; ISCN ${ }^{\bullet-}$,

6449 (iodosulfato)nitridocarbonate $(\bullet 1-)$

6450

6451

\section{References}

6452

6453 1. J. H. Baxendale, P. L. T. Bevan, D. A. Stott. Trans. Faraday Soc. 64, 2389-2397 (1968).

6454 2. J. H. Baxendale, P. L. T. Bevan. J. Chem. Soc. (A) 2240-2241 (1969).

$6455 \quad 3 . \quad$ A. J. Elliot, F. C. Sopchyshyn. Int. J. Chem. Kinet. 16, 1247-1256 (1984).

6456 4. M. Chin, P. H. Wine. J. Photochem. Photobiol. A 69, 17-25 (1992).

6457 5. S. V. Lymar, H. A. Schwarz, G. Czapski. Rad. Phys. Chem. 59, 387-392 (2000).

6458 6. V. Nagarajan, R. W. Fessenden. J. Phys. Chem. 89, 2330-2335 (1985).

6459 7. G. Wu, Y. Katsumura, Y. Muroya, M. Lin, T. Morioka. J. Phys. Chem. A 105, 4933-4939 6460 (2001).

$6461 \quad 8 . \quad$ B. H. Milosavljevic, J. A. LaVerne. J. Phys. Chem. A. 109, 165-168 (2005).

6462 9. M. Schöneshöfer, A. Henglein. Ber. Bunsenges. Phys. Chem. 74, 393-398 (1970).

6463 10. M. L. Posener, G. E. Adams, P. Wardman, R. B. Cundall. J. Chem. Soc., Faraday Trans. $6464 \quad 1$ 72, 2231-2239 (1976).

6465 11. G. Nord, B. Pedersen, E. Floryan-Løvborg, P. Pagsberg. Inorg. Chem. 21, 2327-2330 6466 (1982).

6467 12. M. R. DeFelippis, M. Faraggi, M. H. Klapper. J. Phys. Chem. 94, 2420-2424 (1990).

6468 13. R. Sarala, S. B. Rabin, D. M. Stanbury. Inorg. Chem. 30, 3999-4007 (1991). 
6469 14. J. Butler, E. J. Land, W. A. Prütz, Swallow, A, J. Biochim. Biophys. Acta 705, 150-162 6470 (1982).

6471 15. A. Henglein. Radiat. Phys. Chem. 15, 151-158 (1980).

6472 16. H. A. Schwarz, B. H. Bielski. J. Phys. Chem. 90, 1445-1448 (1986).

6473 17. G. Merényi, J. Lind, X. Shen. J. Phys. Chem. 92, 134-137 (1988).

6474 


\section{Data Sheet 102}

Chemical equilibrium: $\mathrm{HgCl}_{2}(a q)+\mathrm{MV}^{\bullet+} \rightleftharpoons \mathrm{HgCl}(a q)+\mathrm{Cl}^{-}+\mathrm{MV}^{2+}$

$\left(\mathrm{MV}^{2+}=\right.$ methyl viologen $)$

\section{List of reports:} concentration of phosphate buffer at $\mathrm{pH} \sim 6$ [1]. Result obtained by pulse radiolysis, measuring 6484 the equilibrium absorbance of $\mathrm{MV}^{\bullet+}$. The reported equilibrum constant (2.5) is actually for the reaction when written as $\mathrm{Hg}(\mathrm{I})+\mathrm{MV}^{2+} \rightleftharpoons \mathrm{Hg}(\mathrm{II})+\mathrm{MV}^{\bullet+}$, and thus is dependent on the chloride 6486 concentration.

\section{Discussion}

The authors convert the conditional equilibrium constant into a conditional electrode potential of $-0.47 \mathrm{~V}$ (at $0.05 \mathrm{M} \mathrm{Cl}^{-}$) by use of $E^{\circ}=-0.45 \mathrm{~V}$ for $\mathrm{MV}^{2+} / \mathrm{MV}^{\bullet+}$. They then derive a 6492 formal potential of $-0.55 \mathrm{~V}$ for $\mathrm{HgCl}_{2}(a q)+\mathrm{e}^{-} \rightleftharpoons \mathrm{HgCl}(a q)+\mathrm{Cl}^{-}$. This potential is expected to 6493 be dependent on ionic strength, but without knowledge of the ionic strength employed we are unable to estimate the magnitude of the correction. Given the uncertainties about the speciation of $\mathrm{Hg}(\mathrm{I})$, the uncertainty in the formal potential must be at least $20 \mathrm{mV}$. we consider this outcome to be contrary to expectations based on stability constant estimates: chloride should stabilize $\mathrm{Hg}(\mathrm{II})$ more than $\mathrm{Hg}(\mathrm{I})$ and thus $E^{\circ}\left(\mathrm{Hg}^{2+} / \mathrm{Hg}^{+}\right)$is expected to be positive of $E^{\circ}\left(\mathrm{HgCl}_{2} / \mathrm{HgCl}, \mathrm{Cl}^{-}\right)$.

\section{Recommended value:}

$$
E^{\circ \prime}=-(0.55 \pm 0.02) \mathrm{V} \text { for } \mathrm{HgCl}_{2}(a q)+\mathrm{e}^{-} \rightleftharpoons \mathrm{HgCl}(a q)+\mathrm{Cl}^{-}
$$

6505 List of auxiliary thermodynamic data: none.

\section{References}

6508

6509 1. K. Gårdfeldt, M. Jonsson. J. Phys. Chem. A 107, 4478-4482 (2003). 


\section{Data Sheet 103}

\section{Published reports:}

The electrode potential $E^{\circ}\left(\mathrm{NO}_{3}{ }^{\bullet} / \mathrm{NO}_{3}{ }^{-}\right)$has been evaluated by two methods:

a) Through the estimation of the Gibbs energy of formation of $\mathrm{NO}_{3}{ }^{\bullet}$ in the gas phase and in water. In chronological order: $E^{\circ}=+2.3 \pm 0.1 \mathrm{~V}$ [1]; $1.9 \mathrm{~V}$ [2]; $2.28 \mathrm{~V}$ [3]; $2.49 \mathrm{~V}$ [4].

b) From the positions of three equilibria with other radicals:

$$
\begin{aligned}
& \mathrm{HO}^{\bullet}+\mathrm{HNO}_{3}(a q) \rightleftharpoons \mathrm{H}_{2} \mathrm{O}+\mathrm{NO}_{3}^{\bullet}(a q) \\
& E^{\circ}=+2.67 \mathrm{~V}[5] ; E^{\circ}=+(2.48 \pm 0.01) \mathrm{V}[6] ; E^{\circ}=+(2.58 \pm 0.02) \mathrm{V}[7] . \\
& \mathrm{SO}_{4}^{\bullet-}+\mathrm{NO}_{3}{ }^{-} \rightleftharpoons \mathrm{SO}_{4}^{2-}+\mathrm{NO}_{3}^{\bullet}(a q) \\
& \quad E^{\circ \prime}=+(2.45 \pm 0.05) \mathrm{V}[8] . \\
& \mathrm{NO}_{3}^{\bullet}(a q)+\mathrm{Cl}^{-} \rightleftharpoons \mathrm{NO}_{3}^{-}+\mathrm{Cl}^{\bullet}(a q) \\
& \quad E^{\circ \prime}=+(2.47 \pm 0.01) \mathrm{V}[7] .
\end{aligned}
$$

\section{Discussion}

Historically, the thermodynamicchemical estimates preceded the equilibrium data. These estimates have been reviewed by Stanbury [4] and are not considered or discussed here. We only note a large spread in the $E^{\circ}$ values obtained by that method, although some of them come close to the recommended value given below.

The electrode potentials for reference radicals and the literature reports on their equilibria with $\mathrm{NO}_{3}{ }^{\bullet}$ have been individually assessed in this work. The following values are recommended: $K_{104.1}=$ none (see Data Sheet 104). Accordingly, all $E^{\circ}\left(\mathrm{NO}_{3}{ }^{\circ} \mathrm{NO}_{3}{ }^{-}\right)$reported from this equilibrium are to be considered unreliable. $K_{14.1}=(0.28 \pm 0.1)$ at $\mu=0 \mathrm{M} ; E^{\circ}\left(\mathrm{SO}_{4}{ }^{\bullet-} / \mathrm{SO}_{4}{ }^{2-}\right)=+(2.43 \pm 0.02) \mathrm{V}($ see Data Sheet 14$)$ From these values, $E^{\circ}\left(\mathrm{NO}_{3}{ }^{\bullet} / \mathrm{NO}_{3}{ }^{-}\right)=+(2.46 \pm 0.02) \mathrm{V}$.

$$
K_{16.1}=(3.33 \pm 0.24) \text { at } \mu=0 \mathrm{M} ; E^{\circ}\left(\mathrm{Cl}^{\circ} / \mathrm{Cl}^{-}\right)=+(2.43 \pm 0.02) \mathrm{V} \text { (see Data Sheet 16) }
$$
From these values, $E^{\circ}\left(\mathrm{NO}_{3} \cdot \mathrm{NO}_{3}{ }^{-}\right)=+2.46 \pm 0.02 \mathrm{~V}$. Excellent agreement between the last two evaluations gives significant confidence in the result.

The electrode potential $E^{\circ}\left(\mathrm{NO}_{3}{ }^{\circ}, \mathrm{H}^{+} / \mathrm{HNO}_{3}\right)=+(2.39 \pm 0.02) \mathrm{V}$ can be calculated from the equilibrium evaluated in this work:

$$
\begin{aligned}
& \mathrm{SO}_{4}^{{ }^{--}}+\mathrm{HNO}_{3} \rightleftharpoons \mathrm{HSO}_{4}^{-}+\mathrm{NO}_{3}(a q) \\
& K_{15.1}=(5 \pm 2) \times 10^{2}, \text { and } \\
& \mathrm{p} K_{\mathrm{a}}\left(\mathrm{HSO}_{4}^{-}\right)=1.96[9] .
\end{aligned}
$$


6547 The latest printed NBS tables [10] give an erroneous value for $\Delta_{\mathrm{f}} G^{\circ}\left(\mathrm{NO}_{3}{ }^{-}\right)_{a q}$, while the previous 6548 version contains the correct value of $-111.3 \mathrm{~kJ} \mathrm{~mol}^{-1}[11,12]$. With this value, $E^{\circ}\left(\mathrm{NO}_{3}{ }^{\bullet} / \mathrm{NO}_{3}{ }^{-}\right)=$ $6549+(2.46 \pm 0.02) \mathrm{V}$ corresponds to $\Delta_{\mathrm{f}} G^{\circ}\left(\mathrm{NO}_{3}{ }^{\bullet}\right)_{a q}=+(126 \pm 2) \mathrm{kJ} \mathrm{mol}^{-1}$. Accepting $K_{\mathrm{a}}\left(\mathrm{HNO}_{3}\right)=20$

$6550 \mathrm{M}$ [13], we calculate $E^{\circ}\left(\mathrm{NO}_{3}{ }^{\circ}, \mathrm{H}^{+} / \mathrm{HNO}_{3}\right)=+2.38 \mathrm{~V}$, which is within the uncertainty of the 6551 estimate based on $K_{3.21}$.

6552

6553

\section{Recommended values:}

6554

6555

$\mathrm{NO}_{3}^{\bullet}(a q)+\mathrm{e}^{-} \rightleftharpoons \mathrm{NO}_{3}^{-}(a q)$

$E^{\circ}=+(2.46 \pm 0.02) \mathrm{V}$

6556

$\mathrm{NO}_{3}^{\bullet}(a q)+\mathrm{H}^{+}+\mathrm{e}^{-} \rightleftharpoons \mathrm{HNO}_{3}(a q)$

$E^{\circ}=+(2.39 \pm 0.02) \mathrm{V}$

$6557 \mathrm{NO}_{3}{ }^{\circ}(\mathrm{aq})$

$\Delta_{\mathrm{f}} G^{\circ}=+(126 \pm 2) \mathrm{kJ} \mathrm{mol}^{-1}$

6558

6559

Nomenclature: $\mathrm{NO}_{3}{ }^{\bullet}$, trioxidonitrogen $(\bullet), \mathrm{NO}_{3}{ }^{-}$, trioxidonitrate $(1-)$, nitrate is acceptable.

6560

6561

\section{References}

6562

6563 1. V. M. Berdnikov, N. M. Bazhin. Russ. J. Phys. Chem. 44, 395-398 (1970).

6564 2. Endicott, J. F. In Concepts of Inorganic Photochemistry, (Adamson, A. W., Fleischauer, 6565 P. D., eds.), p. 81-142. Wiley, New York (1975).

6566 3. R. G. Pearson. J. Am. Chem. Soc. 108, 6109-6114 (1986).

6567 4. D. M. Stanbury. Adv. Inorg. Chem. 33, 69-138 (1989).

6568 5. P.-Y. Jiang, Y. Katsamura, K. Ishigure, Y. Yoshida. Inorg. Chem. 31, 5135-5136 (1992).

6569 6. G. A. Poskrebyshev, P. Neta, R. E. Huie. J. Geophys. Res. 106, 4995-5004 (2001).

65707 7. A. Poskrebyshev, R. E. Huie, P. Neta. J. Phys. Chem. A 107, 1964-1970 (2003).

65718 8. T. Løgager, K. Sehested, J. Holcman. Radiat. Phys. Chem. 41, 539-543 (1993).

6572 9. A. Albert, E. P. Serjeant. The Determination of Ionization Constants, Chapman and Hall, 6573 London (1984).

6574 10. D. D. Wagman, W. H. Evans, V. B. Parker, R. H. Schumm, I. Halow, S. M. Bailey, K. L. 6575 Churney, R. L. Nuttall. J. Phys. Chem. Ref. Data 11, Suppl. No. 2 (1982).

6576 11. D. G. Archer, personal communication to Lymar, S.V. The Standard Reference Data 6577 Program tape of the NBS Tables that supercedes the printed version contains the same Gibbs 6578 energy of formation for the nitrate ion as does the referenced here Technical Note 270-3, printed 6579 in 1968. (2003).

6580 12. D. D. Wagman, W. H. Evans, V. B. Parker, I. Halow, S. M. Bailey, R. H. Schumm. 6581 Selected Values of Chemical Thermodynamic Properties; National Bureau of Standards and 6582 Technology Note 270-3, U.S. Government Printing Office, Washington, D. C. (1968). 
6583 13. O. Redlich, R. W. Duerst, A. Merbach. J. Chem. Phys. 49, 2986-2994 (1968). 6584 


\section{Data Sheet 104}

\section{List of reports:}

$K_{\text {eq }}=1 \times 10^{2}$, dimensionless, in 0.2-1.5 $\mathrm{M} \mathrm{HNO}_{3}$, was estimated from the ratio of the rate constants $k_{\mathrm{f}}=5.3 \times 10^{7} \mathrm{M}^{-1} \mathrm{~s}^{-1}$ and $k_{\mathrm{r}}=5.3 \times 10^{5} \mathrm{M}^{-1} \mathrm{~s}^{-1}$ obtained by pulse radiolysis [1]. Both $k_{\mathrm{r}}$ and $K_{\text {eq }}$ have been reported in improper units because water was explicitly included in the reverse reaction rate law; this inclusion was also performed in an improper manner using water activity around $1 \mathrm{M}$. $K_{\text {eq }}=(2.8 \pm 0.4) \times 10^{5}$, dimensionless at $\mu=0 \mathrm{M}$, was obtained from the ratio of the rate constants $k_{\mathrm{f}}=(8.6 \pm 1.3) \times 10^{7} \mathrm{M}^{-1} \mathrm{~s}^{-1}$ and $k_{\mathrm{r}}=(3 \pm 1) \times 10^{2} \mathrm{M}^{-1} \mathrm{~s}^{-1}$ derived from pulse radiolysis in solutions of $\mathrm{HNO}_{3}$ [2]. As in the previous report by Katsumura and co-workers,

6600 water was explicitly included in the reverse reaction rate law and $k_{\mathrm{r}}$ and $K_{\text {eq }}$ had improper units. 6601 In the subsequent paper from the same laboratory [3], these values have been converted using 6602 water concentration of $55.6 \mathrm{M}$ to have appropriate dimensionalities, that is $k_{\mathrm{r}}=(1.7 \pm 0.6) \times 10^{4}$ $6603 \mathrm{~s}^{-1}$ and $K_{\mathrm{eq}}=(5.0 \pm 1.5) \times 10^{3} \mathrm{M}^{-1}$.

\section{Discussion}

In the earlier of these reports by Katsumura and co-workers [1], activities of the reagents instead

6608 of their concentrations were used in the rate law for the reaction approach to equilibrium. This 6609 treatment is kinetically incorrect.

6611 Poskrebyshev et al. also treated the rate laws in terms of activities [2], but our concerns about the 6612 validity of this approach are overshadowed by the concerns regarding the dose dependence.

6613 Three methods for the evaluation of $K_{\text {eq }}$ were applied by these authors. The first method was the 6614 same as used by Katsumura and co-workers [1] and was based on the approach to equilibrium; it 6615 yielded $K_{\text {eq }}=(5.5 \pm 2.2) \times 10^{4} \mathrm{M}^{-1}$. In the second method, a $K_{\text {eq }}$ ranging from about $\left(2.5 \times 10^{4}\right.$ to $\left.66167 \times 10^{4}\right) \mathrm{M}^{-1}$ at various radiation doses was obtained from the $\mathrm{NO}_{3}{ }^{\bullet}$ absorption maximum in its 6617 kinetic profile, where a complete equilibration was assumed. From the dose dependence shown 6618 by this latter method, the authors properly concluded that a significant loss of radicals due to the 6619 radical-radical reactions had occurred and resorted to kinetic modeling, which gave $K_{\text {eq }}=(2.8 \pm$ $66200.4) \times 10^{5}$ and this value was considered as the most reliable. However, just as with the 
6621 absorption maximum, the modeling result is heavily dependent upon the rates of the radical6622 radical reactions. It appears that the major radical loss should occur through the $\mathrm{HO}^{\bullet}+\mathrm{NO}_{2}{ }^{\bullet}$ 6623 reaction, but reasonable kinetic fits could be obtained only with the rate constant for this reaction 6624 that was more than an order of magnitude below the well-supported literature values [4-6]. These 6625 considerations seem to imply that there is insufficient reversibility in the reaction of $\mathrm{HO}^{\bullet}$ with $6626 \mathrm{NO}_{3}{ }^{\bullet}$ for accurate equilibrium measurements, unless exceedingly small doses can be employed.

6628 In summary, neither of the reported $K_{\text {eq }}$ can be recommended with reasonable confidence.

6629

6630 Recommended value:

6631

6632

None

6633

6634 List of auxiliary thermodynamic data: none

6635

6636 References

6637

6638 1. P.-Y. Jiang, Y. Katsumura, K. Ishigure, Y. Yoshida. Inorg. Chem. 31, 5135-5136 (1992).

6639 2. G. A. Poskrebyshev, P. Neta, R. E. Huie. J. Geophys. Res. 106, 4995-5004 (2001).

6640 3. G. A. Poskrebyshev, R. E. Huie, P. Neta. J. Phys. Chem. A 107, 1964-1970 (2003).

6641 4. T. Løgager, K. Sehested. J. Phys. Chem. 97, 6664-6669 (1993).

6642 5. G. Merényi, J. Lind, S. Goldstein, G. Czapski. J. Phys. Chem. A 103, 5685-5691 (1999).

6643 6. I. Wagner, H. Strehlow, G. Busse. Z. Phys. Chem. (Wiesbaden) 123, 1-33 (1980).

6644

6645 


\section{Data Sheet 105}

Chemical equilibria:

\section{List of reports:}

$\mathrm{p} K_{\mathrm{a}}\left(\mathrm{H}_{2} \mathrm{NOH}^{\bullet+}\right)=(4.2 \pm 0.1)$, at $\sim 22{ }^{\circ} \mathrm{C}$ with ionic strength uncontrolled and as high as $0.01 \mathrm{M}$ [1]. From pulse radiolysis of $\mathrm{NH}_{2} \mathrm{OH}$, by monitoring the absorbance at $240 \mathrm{~nm}$ of the radical intermediate between $\mathrm{pH} 2$ and 10 .

$\mathrm{p} K_{\mathrm{a}}\left(\mathrm{H}_{2} \mathrm{NOH}^{\bullet+}\right)=(4.0 \pm 0.1)$, presumably at room temperature, with ionic strength uncontrolled and as high as $0.5 \mathrm{M}$ [2]. From pulse radiolysis of $\mathrm{NH}_{2} \mathrm{OH}$, monitoring the absorbance of the radical intermediate as a function of $\mathrm{pH}$ at $230 \mathrm{~nm}$. A similar $\mathrm{pH}$ dependence of the absorbance was obtained from flash photolysis, although the $\mathrm{pH}$ range was limited to less than 4.

$\mathrm{p} K_{\mathrm{a}}\left(\mathrm{H}_{2} \mathrm{NO}\right)^{\bullet}=(12.6 \pm 0.3)$, presumably at room temperature, with ionic strength uncontrolled and as high as $1 \mathrm{M}$ [3]. Result from pulse radiolysis, monitoring the kinetics as a function of $\mathrm{pH}$ for the recombination of $\mathrm{H}_{2} \mathrm{NO}$, with the reaction of $\mathrm{H}_{2} \mathrm{NO}^{\bullet}$ with $\mathrm{MV}^{\bullet+}(\mathrm{MV}$ is methylviologen, 1,1'-dimethyl-4,4'-bipyridinium(2+)) as an indicator. Experiments were performed between $\mathrm{pH} 8$ and 14 . the three studies gives data over a sufficiently broad $\mathrm{pH}$ range to encoMPass both $\mathrm{p} K_{\mathrm{a}}$ regions, so one might argue that the radical has two successive $\mathrm{p} K_{\mathrm{a}}$ values. However, Lind and Merényi [3] argue that $\mathrm{H}_{3} \mathrm{NO}^{\bullet+}$ ( or $\mathrm{NH}_{2} \mathrm{OH}^{\bullet+}$ ) should be a strong acid with $\mathrm{p} K_{\mathrm{a}}<-5$; they base their argument on two lines of evidence: 1) The reactions of hydroxylamine with $\mathrm{Fe}^{3+}$ and $\mathrm{Pu}^{4+}$ have rate laws that require the radical to be unprotonated even in $1 \mathrm{M}$ acid, and 2) by analogy with TEMPO and related nitroxyl radicals, which are protonated only in concentrated $\mathrm{H}_{2} \mathrm{SO}_{4}$ solutions. Lind and

6678 Merényi also argue that the spectral changes that were previously interpreted in terms of a $\mathrm{p} K_{\mathrm{a}}$ 6679 near 4.1 were due instead to a diminished yield of the radical at low $\mathrm{pH}$. We are pursuaded by 6680 the results and interpretations of Lind and Merényi and thus recommend their values. 


\section{Recommended values:}

6684

$6685 \mathrm{NH}_{2} \mathrm{OH}^{\bullet+} \rightleftharpoons \mathrm{NH}_{2} \mathrm{O}^{\bullet}+\mathrm{H}^{+}$

$\mathrm{p} K_{\mathrm{a}}<-5$

$6686 \mathrm{NH}_{2} \mathrm{O}^{\bullet} \rightleftharpoons \mathrm{NHO}^{\bullet}+\mathrm{H}^{+}$ $\mathrm{p} K_{\mathrm{a}}=12.6 \pm 0.3$

6687

6688 List of auxiliary thermodynamic data:

6689

6690 Nomenclature: $\mathrm{NH}_{2} \mathrm{OH}$, dihydridohydroxidonitrogen or azanal, hydroxylamine is acceptable;

$6691 \mathrm{NH}_{2} \mathrm{OH}^{\bullet+}$, dihydridohydroxidonitrogen $(\bullet 1+)$; $\mathrm{NH}_{2} \mathrm{O}^{\bullet}$, dihydridooxidonitrogen $(\bullet)$; $\mathrm{NHO}^{\bullet}$, 6692 hydridoxidonitrate $(\bullet 1-)$

6693

\section{References}

6695

6696 1. M. Simic, E. Hayon. J. Am. Chem. Soc. 93, 5982-5986 (1971).

6697 2. D. Behar, D. Shapira, A. Treinin. J. Phys. Chem. 76, 180-186 (1972).

6698 3. J. Lind, G. Merényi. J. Phys. Chem. A. 110, 192-197 (2006).

6699

6700

6701 


\section{Data Sheet 106}

6704 Chemical equilibrium: $\mathrm{HPO}_{3}{ }^{--} \rightleftharpoons \mathrm{PO}_{3}{ }^{\bullet-}+\mathrm{H}^{+}$

List of reports:

6708 Over the wavelength range $230 \mathrm{~nm}$ to $290 \mathrm{~nm}$, the optical absorptivity of $\mathrm{PO}_{3}{ }^{\circ-}$ was found to be

6709 significantly higher than that for $\mathrm{HPO}_{3}{ }^{-}$[1]. This allowed a simple determination of the second

$6710 \mathrm{p} K_{\mathrm{a}}$ of this radical by measuring the absorptivity subsequent to the pulse irradiation of phosphite

6711 solutions at various $\mathrm{pH}$ values. From the inflection point of the S-shaped curve, $\mathrm{p} K_{106.1}=5.75$

6712 was obtained, in excellent agreement with earlier ESR measurements of $\mathrm{p} K_{106.1}=5.8$ [2].

6713

\section{Discussion}

6715

6716 The authors gave no uncertainty estimate. Based on the good agreement with the previous

6717 results, the large difference between the absorption coefficients for the two forms and the quality

6718 of the results, we recommend $\mathrm{p} K_{106.1}=(5.75 \pm 0.05)$.

6719

6720

Recommended value:

6721

$6722 \mathrm{p} K_{106.1}=(5.75 \pm 0.05)$

6723

6724 Nomenclature: $\mathrm{HPO}_{3}{ }^{\bullet-}$, hydroxidodioxidophosphate $(\bullet-) ; \mathrm{PO}_{3}{ }^{\bullet 2-}$, trioxidophosphate $(\bullet 2-)$.

6725

6726 References

6727

6728 1. K. Schäfer, K.-D. Asmus. J. Phys. Chem. 84, 2156-2160 (1980).

6729 2. O. P. Chawla, R. W. Fessenden. J. Phys. Chem. 79, 2693-2700 (1975).

6730

6731 


\section{Data Sheet 107}

6734 Chemical equilibrium: $\mathrm{H}_{2} \mathrm{PO}_{3}{ }^{\bullet} \rightleftharpoons \mathrm{HPO}_{3}{ }^{\bullet}+\mathrm{H}^{+}$

\section{List of reports:}

6739

The shift in the ${ }^{31} \mathrm{P}$ hyperfine constant in the ESR spectrum of $\mathrm{HPO}^{\circ}{ }^{\circ-}$ was measured as a function of acidity from $\mathrm{pH} 2.4$ to $61.2 \% \mathrm{HClO}_{4}$ [1]. It was argued that a plot of the reciprocal of the shift would be directly proportional to an acidity function applicable to this high acidity. An approach that assumes that each acid proton is associated with four water molecules to form $\mathrm{H}_{9} \mathrm{O}_{4}{ }^{+}$was taken, and the function $h / w^{4}$ utilized, where $h=\left[\mathrm{H}_{9} \mathrm{O}_{4}{ }^{+}\right]$and $w=\left[\mathrm{H}_{2} \mathrm{O}\right] /\left[\mathrm{H}_{2} \mathrm{O}\right]_{0}$, the

6745 total water concentration relative to pure water [2]. Although a linear relation between the

6746 reciprocal of the shift in the hyperfine constant and this acidity function was found for the

6747 ascorbate radical, which confirmed a single proton-transfer equilibrium, a non-linear relationship 6748 was found for hydroxidodioxidophosphate $(\bullet-)\left(\mathrm{HPO}_{3}{ }^{\circ}\right)$. This was taken to indicate the presence 6749 of two protonation equilibria, 107.1 and 107.2. The observed curve could be fit to a more complex expression involving these two equilibria.

6752 The equilibrium constant $K_{107.1}$ and its associated splitting constant were derived by a straight-

6753 line fit to the lowest four acid concentrations and similar parameters for reaction 107.2 were

6754 obtained from a fit to the highest acid concentrations.

6755

$6756 \quad K_{107.1}=1.1 \mathrm{~mol} \mathrm{~L}^{-1}$

6757

$K_{107.2}=54 \mathrm{~mol} \mathrm{~L}^{-1}$

\section{Discussion}

6762 These parameters and the splitting constants provided a good fit to the observations, but due to

6763 the nature of their derivation and their relative closeness, these values should be considered only

6764 approximate.

Recommended values: 
$6768 \quad K_{107.1}=1.1 \mathrm{~mol} \mathrm{~L}^{-1}$

$6769 \quad K_{107.2}=54 \mathrm{~mol} \mathrm{~L}^{-1}$

6770

6771 Nomenclature: $\mathrm{H}_{3} \mathrm{PO}_{3}{ }^{\bullet+}$, trihydroxidophoshorus $(\bullet 1+) ; \mathrm{H}_{2} \mathrm{PO}_{3}{ }^{\bullet}$, dihydroxidooxidophosphorus $(\bullet)$,

$6772 \mathrm{HPO}_{3}^{\bullet-}$, hydroxidodioxidophosphate $(\bullet 1-)$.

6773

6774 References

6775

6776 1. H. F. Davis, H. J. McManus, R. W. Fessenden. J. Phys. Chem. 90, 6400-6404 (1986).

6777 2. W. T. Dixon, D. Murphy. J. Chem. Soc., Faraday Trans. 2 74, 432-439 (1978).

6778

6779 
6782 Chemical equilibrium: $\mathrm{H}_{2} \mathrm{PO}_{4}{ }^{\bullet} \rightleftharpoons \mathrm{H}^{+}+\mathrm{HPO}_{4}^{\bullet-}$

Chemical equilibrium: $\mathrm{HPO}_{4}{ }^{\bullet-} \rightleftharpoons \mathrm{H}^{+}+\mathrm{PO}_{4}{ }^{\bullet-}$

\section{List of reports:}

The three acid-base forms of the phosphate radical were generated through the pulse radiolysis of bis(tetraoxidophosphate) $(\mathrm{O}-\mathrm{O})(4-)\left(\mathrm{P}_{2} \mathrm{O}_{8}{ }^{4}\right)$ solutions at $\mathrm{pH} \mathrm{4,} \mathrm{7,} \mathrm{and} 11$ [1]. The absorption spectra were measured over the range $400 \mathrm{~nm}$ to $600 \mathrm{~nm}$. The maximum absorption shifted from about $520 \mathrm{~nm}$ at $\mathrm{pH}$ 4, to $510 \mathrm{~nm}$ at $\mathrm{pH}$, and $530 \mathrm{~nm}$ at $\mathrm{pH} 11$. These shifts allowed the two $\mathrm{p} K_{\mathrm{a}}$ values to be determined by monitoring the absorption at a convenient wavelength, $540 \mathrm{~nm}$, over the $\mathrm{pH}$ range 4 to 11 . The best-fit curve gave $\mathrm{p} K_{108.1}=(5.7 \pm 0.2)$ and $\mathrm{p} K_{108.2}=(8.9 \pm 0.1)$,

6794 where the error estimates are from the authors.

6795

\section{Discussion}

The differences among the spectra are not too large, and the fact that there is a blue shift going from $\mathrm{H}_{2} \mathrm{PO}_{4}{ }^{\bullet}$ to $\mathrm{HPO}_{4}{ }^{\bullet-}$, but a red shift for $\mathrm{H}_{2} \mathrm{PO}_{4}{ }^{\bullet}$ to $\mathrm{PO}_{4}{ }^{\bullet-}$ suggests a somewhat greater uncertainty in these results. The general positions for these forms on the $\mathrm{pH}$ scale are supported by kinetic results. Generally, it appears that the order of electrode potential is: $\mathrm{H}_{2} \mathrm{PO}_{4}{ }^{\bullet}>\mathrm{HPO}_{4}{ }^{\bullet}$ $6802>\mathrm{PO}_{4}{ }^{\circ-}$.

6803

\section{Recommended values:}

6805

6806

$\mathrm{p} K_{108.1}=(5.7 \pm 0.4)$

6807

$\mathrm{pK}_{108.2}=(8.9 \pm 0.2)$

6808

6809 Nomenclature: $\mathrm{H}_{2} \mathrm{PO}_{4}{ }^{\bullet}$, dihydroxidodioxidophosphorus( $\bullet$ ); $\mathrm{HPO}_{4}{ }^{\bullet}$,

6810 hydroxidotrioxidophosphate $(\bullet 1-) ; \mathrm{PO}_{4}{ }^{\bullet 2-}$, tetraoxidophosphate $(\bullet 2-)$

6811

\section{References}

6813

6814 1. P. Maruthamuthu, P. Neta. J. Phys. Chem. 82, 710-713 (1978). 
6816 Data Sheet 109

6817

6818 Chemical equilibrium: $\mathrm{HPO}_{5}{ }^{--} \rightleftharpoons \mathrm{PO}_{5}{ }^{\bullet 2-}+\mathrm{H}^{+}$

6819

6820

List of reports:

6821

6822 The trioxidophosphate $(\bullet 2-)$ radical, or its hydronated form, which absorb over the wavelength 6823 range $230 \mathrm{~nm}$ to $290 \mathrm{~nm}$, react rapidly with dioxygen [1].

6824

6825

$\mathrm{PO}_{3}{ }^{\cdot 2-}, \mathrm{HPO}_{3}{ }^{\bullet-}+\mathrm{O}_{2} \rightarrow \mathrm{PO}_{5}{ }^{\bullet-}, \mathrm{HPO}_{5}{ }^{\bullet}$

6826

6827 The peroxy radicals have a weaker absorption over the wavelength range $240 \mathrm{~nm}$ to $340 \mathrm{~nm}$, 6828 with the doubly-charged anion somewhat red-shifted coMPared to the singly-charged anion.

6829 Transient conductivity measurements confirmed the formation of the two types of anions, and a

6830 point of inflection was observed in a plot of the conductivity against $\mathrm{pH}$ over the range $2-5$.

6831 This results in the value $\mathrm{p} K_{109.1}=3.4$.

6832

6833 Discussion

6834

6835 No uncertainty was quoted in the paper, but we estimate \pm 0.2 , due to the lack of confirmation by 6836 other experiments and to the observation that not quite full conductance appears to be attained at 6837 the highest $\mathrm{pH}$. The basic observation seems to be quite reliable, however.

6838

6839

Recommended value:

6840

6841

$\mathrm{p} K_{109.1}=(3.4 \pm 0.2)$.

6842

6843 Nomenclature: $\mathrm{HPO}_{3}{ }^{--}$, hydroxidodioxidophosphate $(\bullet 1-) ; \mathrm{PO}_{3}{ }^{\bullet-}$, trioxidophosphate $(\bullet 2-)$;

$6844 \mathrm{HPO}_{5}{ }^{\bullet}$, (dioxido)hydroxidodioxidophosphate $(\bullet 1-)$; $\mathrm{PO}_{5}{ }^{\bullet-}$, (dioxido)trioxidophosphate $(\bullet 2-)$. 6845

6846 References

6847

6848 1. K. Schäfer, K.-D. Asmus. J. Phys. Chem. 84, 2156-2160 (1980).

6849

6850 


\section{$6851 \quad$ Data Sheet 110}

6853 Chemical equilibrium: $\mathrm{As}(\mathrm{OH})_{4}{ }^{\bullet} \rightleftharpoons \mathrm{As}(\mathrm{OH})_{3} \mathrm{O}^{\bullet-}+\mathrm{H}^{+}$

Chemical equilibrium: $\mathrm{HAsO}_{3}{ }^{--}+\mathrm{H}_{2} \mathrm{O} \rightleftharpoons \mathrm{As}(\mathrm{OH})_{3} \mathrm{O}^{\bullet}$

Chemical equilibrium: $\mathrm{HAsO}_{3}{ }^{-}+\mathrm{H}_{2} \mathrm{O}+\mathrm{H}^{+} \rightleftharpoons \mathrm{As}(\mathrm{OH})_{4}{ }^{\bullet}$

\section{List of reports:}

As(IV) species were generated through the pulse radiolysis of $\mathrm{N}_{2} \mathrm{O}$-saturated arsenite or 6864 arseneous acid solutions [1].

6865

$\mathrm{As}(\mathrm{III})+\mathrm{HO}^{\bullet} \rightarrow \operatorname{As}(\mathrm{IV})$

6867

Spectra corresponding to four different protonation forms of As(IV) were recorded. These species exhibit a somewhat complicated relationship that depended on $\mathrm{pH}$ and time, and appear to be related through protonation and hydration equilibria.

Below $\mathrm{pH} 3$, only one species was observed, which is formed in a rapid reaction and underwent a second order decay. Between $\mathrm{pH} 3$ and 6 , this species also decayed by first-order reaction to other absorbing species. A second, rapidly formed species was observed in the $\mathrm{pH} 8.5$ to 10 range, which also decayed by a combination of first- and second-order processes. In the $\mathrm{pH}$ range 7 to 8 , the two species that were formed in a rapid, primary reaction existed in an acid-base equilibrium. al. [1] suggested that $\mathrm{HO}^{\bullet}$ reacts with $\mathrm{As}(\mathrm{III})$ by addition 
The anion in 110.1 has a spectrum red-shifted from the spectrum of the neutral form. From a plot involving the logarithm of the absorption ratio against $\mathrm{pH}$, the acid dissociation constant at an ionic strength of $0.1 \mathrm{~mol} \mathrm{~L}^{-1}$ was determined to be $\mathrm{p} K_{110.1}=7.26$. This was corrected to $(7.38 \pm$ $0.06)$ at zero ionic strength.

Both $\mathrm{As}(\mathrm{OH})_{4}{ }^{\bullet}$ and $\mathrm{As}(\mathrm{OH})_{3} \mathrm{O}^{\bullet}$ - decay through first-order reactions to two species with considerably changed spectra. One species appears to exist in equilibrium with $\mathrm{As}(\mathrm{OH}) 4^{\bullet}$ in the $\mathrm{pH}$ range 5 to 6 . A $\mathrm{p} K$ value could be derived from an analysis of the molar absorption of these species after attainment of equilibrium. Values of $\mathrm{p} K=(3.78 \pm 0.05)$ at ionic strength $0.002 \mathrm{~mol}$ $\mathrm{L}^{-1}$ and $\mathrm{p} K=(3.64 \pm 0.05)$ at $0.1 \mathrm{~mol} \mathrm{~L}^{-1}$ were derived. These values corrected to zero ionic strength become 3.82 and 3.88, identical within experimental error. This supports the

6902 suggest that this equilibrium corresponds to the dehydration reaction

6903

$$
\mathrm{As}(\mathrm{OH}) 4^{\bullet} \rightleftharpoons \mathrm{HAsO}_{3}^{\bullet}+\mathrm{H}_{2} \mathrm{O}+\mathrm{H}^{+}
$$
and $\mathrm{p} K_{-110.5}=-(3.85 \pm 0.05)$.

6913 followed by deprotonation

$$
\mathrm{HAsO}_{3}{ }^{\bullet-} \rightleftharpoons \mathrm{AsO}_{3}{ }^{\bullet 2-}+\mathrm{H}^{+}
$$

6916

6917 with $\mathrm{p} K_{110.2}=(7.81 \pm 0.04)$.

6918

6919 The equilibrium constant for reaction 110.3 is obtained as $K_{110.3}=K_{110.1} \times K_{110.4}=$ $69203 \times 10^{-4}$ or $\mathrm{p} K_{110.3}=3.53$.

\section{Discussion}


6923

6924 Recommended values:

6925

6926

$\mathrm{As}(\mathrm{OH})_{4}{ }^{\bullet} \rightleftharpoons \mathrm{As}(\mathrm{OH})_{3} \mathrm{O}^{\bullet-}+\mathrm{H}^{+}$

$\mathrm{p} K_{110.1}=(7.38 \pm 0.06)$

$6927 \mathrm{HAsO}_{3}{ }^{\bullet-} \rightleftharpoons \mathrm{AsO}_{3}{ }^{\circ-}+\mathrm{H}^{+}$

$\mathrm{p} K_{110.2}=(7.81 \pm 0.04)$

6928

$\mathrm{HAsO}_{3}{ }^{\circ-}+\mathrm{H}_{2} \mathrm{O} \rightleftharpoons \mathrm{As}(\mathrm{OH})_{3} \mathrm{O}^{\bullet}$

$\mathrm{p} K_{110.3}=(3.53 \pm 0.11)$

$6929 \mathrm{HAsO}_{3}{ }^{--}+\mathrm{H}_{2} \mathrm{O}+\mathrm{H}^{+} \rightleftharpoons \mathrm{As}(\mathrm{OH})_{4}$

$\mathrm{p} K_{110.4}=-(3.85 \pm 0.05)$

6930

6931 References

6932

6933 1. U. K. Kläning, B. H. Bielski, K. Sehested. Inorg. Chem. 28, 2717-2724 (1989).

6934

6935 


\section{Data Sheet 111}

6938 Chemical equilibrium: $\mathrm{HOSCN}^{\bullet-}+\mathrm{SCN}^{-} \rightleftharpoons(\mathrm{SCN})_{2}^{\bullet-}+\mathrm{HO}^{-}$

\section{List of reports:}

6943 radiolysis with optical measurement of the position of equilibrium.

\section{Discussion}

6952 We presently recommend an association constant of $(2.0 \pm 0.3) \times 10^{5} \mathrm{M}^{-1}$ for the reaction 6953 of SCN $^{\bullet}$ with $\mathrm{SCN}^{-}\left(\right.$See Data Sheet 101) Taking $K_{\mathrm{w}}=1 \times 10^{-14} \mathrm{M}^{2}$ then leads to $K_{\mathrm{a}}=12.5 \pm$ 69540.1 for $\mathrm{SCN}^{\bullet}+\mathrm{H}_{2} \mathrm{O} \rightleftharpoons \mathrm{SCNOH}^{\bullet-}+\mathrm{H}^{+}$.

6955

Recommended values:

6957

$6958 K_{\mathrm{eq}}=(6.5 \pm 1.3) \times 10^{3}$ at $22^{\circ} \mathrm{C}$ and zero ionic strength.

$6959 \mathrm{p} K_{\mathrm{a}}=(12.5 \pm 0.1)$ for $\mathrm{SCN}^{\bullet}+\mathrm{H}_{2} \mathrm{O} \rightleftharpoons \mathrm{HOSCN}^{\bullet-}+\mathrm{H}^{+}$

6960

6961 Nomenclature: $\mathrm{SCN}^{-}$, nitridosulfidocarbonate $(1-)$, thiocyanate is allowed; $(\mathrm{SCN})_{2}{ }^{\bullet-}$,

6962 bis(nitridosulfidocarbonate) $(S-S)(\bullet 1-)$; $\operatorname{HOSCN}^{\bullet}$, cyanidohydroxidosulfate $(\bullet 1-)$.

6963

6964 List of auxiliary thermodynamicchemical data: none.

6965

6966

\section{References}

6967

6968 1. D. Behar, P. L. T. Bevan, G. Scholes. J. Phys. Chem. 76, 1537-1542 (1972).

6969

6970 


\section{Data Sheet 112}

6973 Chemical equilibrium: $\mathrm{Tl}+\mathrm{Tl}^{+} \rightleftharpoons \mathrm{Tl}_{2}^{+}$

\section{List of reports:}

$K_{\text {eq }}=2.3 \times 10^{3} \mathrm{M}^{-1}$, with $\mu$ ranging from $0.1 \mathrm{mM}$ to $0.1 \mathrm{M}$, presumably at room temperature [1]. Obtained from the equilibrium optical absorbance as a function of $\left[\mathrm{Tl}^{+}\right]$. Result confirmed by Butler and Henglein (1980) [2]. temperature [3]. Obtained from the equilibrium optical absorbance as a function of $\left[\mathrm{Tl}^{+}\right]$.

\section{Discussion}

The disagreement between the two above results is substantial. Schwarz and Dodson [3] presented convincing arguments that the original absorbance data of Cercek et al. [1] were

6987 misinterpreted and that proper manipulation of the data yield a value for $K_{\text {eq }}$ that is in agreement 6988 with the more recent determination. Schwarz and Dodson [3] were less confident in their 6989 explanation of the discrepant results of Butler and Henglein [2], but they suggest that the 6990 absorbance data of Butler and Henglein [2] may have been distorted by subsequent reactions. 6991 Overall, we favor the results of Schwarz and Dodson [3]. Although these experiments were 6992 performed at various ionic strengths, the magnitude of $K_{\text {eq }}$ is expected not to be sensitive to this 6993 variation.

\section{Recommended values:}

6996

6997

$K_{\text {eq }}=(140 \pm 7) \mathrm{M}^{-1}$

6998

List of auxiliary thermodynamic data: none.

Nomenclature: $\mathrm{Tl}$, thallium, $\mathrm{Tl}_{2}{ }^{+}$, dithallium $(+)$

7002

7003

\section{References}

7004

7005 1. B. Cercek, M. Ebert, A. J. Swallow. J. Chem. Soc. (A) 612-615 (1966).

7006 2. J. Butler, A. Henglein. Radiat. Phys. Chem. 15, 603-612 (1980). 
7007 3. H. A. Schwarz, R. W. Dodson. J. Phys. Chem. 93, 409-414 (1989). 7008 


\section{Data Sheet 113}

7010

7011

Chemical equilibrium: $\mathrm{Tl}^{2+}+\mathrm{Cl}^{-} \rightleftharpoons \mathrm{TlCl}^{+}$

7012

\section{List of reports:}

7014

$7015 K_{\mathrm{eq}}=(6.2 \pm 0.7) \times 10^{4} \mathrm{M}^{-1}$ at $\mu=1.0 \mathrm{M}$ and room temperature [1]. Data obtained by pulse 7016 radiolysis with optical detection. Equilibrium constant determined from the position of 7017 equilibrium.

7018

7019

\section{Discussion}

The experiments appear to have been conducted properly and reliably. No other 7022

\section{Recommended values:}

7036

7037

7038

7039

$$
\mathrm{Tl}^{2+}+\mathrm{Cl}^{-} \rightleftharpoons \mathrm{TlCl}^{+}(a q)
$$$$
K_{\text {eq }}=(6.2 \pm 0.7) \times 10^{4} \mathrm{M}^{-1} \text { in } 1 \mathrm{M} \mathrm{H}^{+} \text {. }
$$

$\mathrm{TlCl}^{+}$

$$
\Delta_{\mathrm{f}} G^{\circ}=+(23.3 \pm 0.4) \mathrm{kJ} \mathrm{mol}^{-1}
$$

$\mathrm{TlCl}^{2+}+\mathrm{e}^{-} \rightleftharpoons \mathrm{TlCl}^{+}$

$E^{\circ}=+(0.179 \pm 0.004) \mathrm{V}$

$$
\mathrm{TlCl}^{+}+\mathrm{e}^{-} \rightleftharpoons \mathrm{TlCl}
$$$$
E^{\circ}=+(1.972 \pm 0.004) \mathrm{V}
$$

\section{References}

7042

7043

1. R. W. Dodson, H. A. Schwarz, J. Phys. Chem. 78, 892-899 (1974). 
$7044 \quad 2 . \quad$ D. D. Wagman, W. H. Evans, V. B. Parker, R. H. Schumm, I. Halow, S. M. Bailey, K. L. 7045 Churney, R. L. Nuttall, J. Phys. Chem. Ref. Data 11, Suppl. No. 2 (1982).

7046

7047 


\section{Data Sheet 114}

7049

7050

Chemical equilibrium: $\mathrm{TlCl}^{+}+\mathrm{Cl}^{-} \rightleftharpoons \mathrm{TlCl}_{2}$

7051

7052

\section{List of reports:}

7053

7054

$K_{\text {eq }}=(1.9 \pm 0.4) \times 10^{3} \mathrm{M}^{-1}$ at $\mu=1.0 \mathrm{M}$ and room temperature [1]. Data were obtained by pulse 7055 radiolysis with optical detection. The equilibrium constant was determined from the position of

7056 equilibrium.

7057

7058

\section{Discussion}

7059

7060

The experiments appear to have been conducted properly and reliably. No other

7061

7062

7063 conflicting data are known. Thus we recommend the equilibrium constant as given.

With use of this equilibrium constant, the NBS value [2] of $\Delta_{\mathrm{f}} \mathrm{G}^{\circ}$ for $\mathrm{Cl}^{-}$and the

7064 derive $\Delta_{\mathrm{f}} G^{\circ}=-(126.6 \pm 0.7) \mathrm{kJ} \mathrm{mol}^{-1}$ for $\mathrm{TlCl}_{2}$. From the NBS values for $\Delta_{\mathrm{f}} G^{\circ}$ for $\mathrm{TlCl}_{2}{ }^{+}$and $7065 \mathrm{TlCl}_{2}{ }^{-}$we derive $E^{\circ}=+(0.029 \pm 0.008) \mathrm{V}$ for the $\mathrm{TlCl}_{2}{ }^{+} / \mathrm{TlCl}_{2}$ couple and $E^{\circ}$ ' $=+(1.754 \pm$ 7066 $0.008) \mathrm{V}$ for the $\mathrm{TlCl}_{2} / \mathrm{TlCl}_{2}{ }^{-}$couple.

7067

7068

\section{Recommended values:}

7069

7070

7071

7072

7073

$\mathrm{TlCl}^{+}+\mathrm{Cl}^{-} \rightleftharpoons \mathrm{TlCl}_{2}(a q) \quad K_{\mathrm{eq}}=(1.9 \pm 0.4) \times 10^{3} \mathrm{M}^{-1}$ in $1 \mathrm{M} \mathrm{H}^{+}$.

$\mathrm{TlCl}_{2}$ $\Delta_{\mathrm{f}} G^{\circ}=-(126.6 \pm 0.7) \mathrm{kJ} \mathrm{mol}^{-1}$

$\mathrm{TlCl}_{2}^{+}+\mathrm{e}^{-} \rightleftharpoons \mathrm{TlCl}_{2}$

$E^{\circ}=+(0.029 \pm 0.008) \mathrm{V}$

$\mathrm{TlCl}_{2}+\mathrm{e}^{-} \rightleftharpoons \mathrm{TlCl}_{2}^{-}$

$E^{\circ}=+(1.754 \pm 0.008) \mathrm{V}$

7074

7075

List of auxiliary thermodynamic data: $\Delta_{\mathrm{f}} G^{\circ}$ for $\mathrm{TlCl}^{+}, \mathrm{TlCl}_{2}{ }^{+}, \mathrm{TlCl}_{2}{ }^{-}$and $\mathrm{Cl}^{-}$.

7076

7077

Nomenclature: $\mathrm{TlCl}^{+}$, thallium chloride(1+); $\mathrm{TlCl}_{2}$, thallium dichloride.

7078

7079

\section{References}

7080

708

1. R. W. Dodson, H. A. Schwarz. J. Phys. Chem. 78, 892-899 (1974).

7082 2. D. D. Wagman, W. H. Evans, V. B. Parker, R. H. Schumm, I. Halow, S. M. Bailey, K. L. 7083 Churney, R. L. Nuttall. J. Phys. Chem. Ref. Data 11, Suppl. No. 2 (1982). 
7084

7085

7086

7087

7088

7089

7090

7091

7092

7093

7094

7095

7096

7097

7098

7099

7100

7101

7102

7103

7104

7105

7106

7107

7108

7109

7110

7111

7112

7113

7114

7115 1. R. W. Dodson, H. A. Schwarz. J. Phys. Chem. 78, 892-899 (1974).

7116 2. D. D. Wagman, W. H. Evans, V. B. Parker, R. H. Schumm, I. Halow, S. M. Bailey, K. L.

7117 Churney, R. L. Nuttall. J. Phys. Chem. Ref. Data 11, Suppl. No. 2 (1982).

The experiments appear to have been conducted properly and reliably. No other conflicting data are known. Thus we recommend the equilibrium constant as given.

With use of this equilibrium constant, the NBS value [2] of $\Delta_{\mathrm{f}} G^{\circ}$ for $\mathrm{Cl}^{-}$and the recommended value of $\Delta_{\mathrm{f}} G^{\circ}$ for $\mathrm{TlCl}_{2}(-126.6 \pm 0.4) \mathrm{kJ} \mathrm{mol}^{-1}$ from reaction $114.1\left(\mathrm{TlCl}^{+}+\mathrm{Cl}^{-}\right)$ we derive $\Delta_{\mathrm{f}} G^{\circ}=-(264.2 \pm 0.7) \mathrm{kJ} \mathrm{mol}^{-1}$ for $\mathrm{TlCl}_{3}{ }^{-}$. From the NBS value for $\Delta_{\mathrm{f}} G^{\circ}$ for $\mathrm{TlCl}_{3}$ we derive $E^{\circ}=-(0.106 \pm 0.007) \mathrm{V}$ for the $\mathrm{TlCl}_{3} / \mathrm{TlCl}_{3}{ }^{-}$couple. Corrections for the effect of ionic strength were not applied, and hence the electrode potential is designated an $E^{\circ 1}$ value.

\section{Recommended values:}

$\mathrm{TlCl}_{2}+\mathrm{Cl}^{-} \rightleftharpoons \mathrm{TlCl}_{3}{ }^{-} K_{\mathrm{eq}}=(13 \pm 3) \mathrm{M}^{-1}$ in $1 \mathrm{M} \mathrm{H}^{+}$.

$\mathrm{TlCl}_{3}{ }^{-} \quad \Delta_{\mathrm{f}} G^{\circ}=-(264.2 \pm 0.7) \mathrm{kJ} \mathrm{mol}^{-1}$

$\mathrm{TlCl}_{3}+\mathrm{e}^{-} \rightleftharpoons \mathrm{TlCl}_{3}^{-} \quad E^{\circ}=-(0.106 \pm 0.007) \mathrm{V}$

List of auxiliary thermodynamic data: $\Delta_{\mathrm{f}} G^{\circ}$ for $\mathrm{TlCl}_{2}(a q), \mathrm{TlCl}_{3}(a q)$ and $\mathrm{Cl}^{-}(\mathrm{aq})$.

Nomenclature: $\mathrm{TlCl}_{2}$, thallium dichloride; $\mathrm{TlCl}_{3}{ }^{-}$, trichloridothallate(1-).

\section{References}




\section{Data Sheet 116}

7122 Chemical equilibrium: $\mathrm{HO}^{\bullet}(a q) \rightleftharpoons \mathrm{O}^{\bullet-}(a q)+\mathrm{H}^{+}(a q)$

\section{List of reports:}

$\mathrm{p} K_{\mathrm{a}}=(11.9 \pm 0.2)$ at $23{ }^{\circ} \mathrm{C}$. Result obtained by pulse radiolysis determination of the kinetics of oxidation of $\left[\mathrm{Fe}(\mathrm{CN})_{6}\right]^{4-}$ by $\mathrm{HO}^{\bullet} / \mathrm{O}^{\bullet-}[1]$.

$\mathrm{p} K_{\mathrm{a}}=(11.9 \pm 0.2)$ at $23{ }^{\circ} \mathrm{C}(?)$ and low ionic strength. Result obtained by pulse radiolysis determination of the kinetics of oxidation of $\left[\mathrm{Fe}(\mathrm{CN})_{6}\right]^{4-}$ by $\mathrm{OH} / \mathrm{O}^{-}[2]$.

$\mathrm{p} K_{\mathrm{a}}=(11.8 \pm 0.2)$ at $\sim 23{ }^{\circ} \mathrm{C}$ at low ionic strength. Result obtained by pulse radiolysis determination of the kinetics of oxidation of $\mathrm{CO}_{3}{ }^{2-}$ by $\mathrm{HO}^{\bullet} / \mathrm{O}^{\bullet-}[3]$.

$K_{\mathrm{a}} / K_{\mathrm{w}}=(56 \pm ?)\left(\mathrm{p} K_{\mathrm{a}}=12.2\right)$ at $25^{\circ} \mathrm{C}$ at $\sim 0.01 \mathrm{M}$ ionic strength. Baxendale et al. obtained this result by pulse radiolysis determination of the kinetics of oxidation of $\mathrm{BH}_{4}^{-}$by $\mathrm{HO}^{\bullet} / \mathrm{O}^{\bullet-}[4]$.

$\mathrm{p} K_{\mathrm{a}}=(11.9 \pm ?)$ presumably at room temperature at $\sim 0.01 \mathrm{M}$ ionic strength. Result obtained by pulse radiolysis determination of the kinetics of oxidation of $\mathrm{IO}_{3}{ }^{-}$by $\mathrm{HO}^{\bullet} / \mathrm{O}^{\bullet-}[5]$.

$\mathrm{p} K_{\mathrm{a}}=(11.8 \pm ?)$ at $25^{\circ} \mathrm{C}$ without control of ionic strength. Result obtained by pulse radiolysis determination of the kinetics of oxidation of $\mathrm{CO}_{3}{ }^{2-}$ by $\mathrm{HO} \% \mathrm{O}^{\bullet-}$ [6]. Value of $\mathrm{p} K_{\mathrm{a}}$ obtained by

7143 inspection of Figure 3 in the paper.

$\mathrm{p} K_{\mathrm{a}}=(11.7 \pm 0.1)$ at zero ionic strength and $25^{\circ} \mathrm{C}$. Elliot and McCracken obtained this result by pulse radiolysis determination of the kinetics of oxidation of $\left[\mathrm{Fe}(\mathrm{CN})_{6}\right]^{4-}$ by $\mathrm{HO}^{\bullet} / \mathrm{O}^{\bullet-}[7] . \mathrm{p} K_{\mathrm{a}}$ values obtained from measurements of $K_{\mathrm{a}} / K_{\mathrm{w}}$ and then using $K_{\mathrm{w}}$ values at appropriate temperature and ionic strength. Value of $\mathrm{p} K_{\mathrm{a}}$ at $25^{\circ} \mathrm{C}$ interpolated from data at $20^{\circ} \mathrm{C}$ and $30{ }^{\circ} \mathrm{C}$. $\mathrm{p} K_{\mathrm{a}}=(12.0 \pm 0.2)$ at $22{ }^{\circ} \mathrm{C}$ and $\sim 0.01 \mathrm{M}$ ionic strength. Hickel et al. obtained this result by pulse radiolysis determination of the ratio of the forward and reverse rate constants as revealed by the

7152 kinetics of addition of $\mathrm{O}^{\bullet-}$ to $\mathrm{O}_{2}$ at $P\left(\mathrm{O}_{2}\right)=(10-140)$ atm \{i.e. (1.01-14.2) $\left.\mathrm{MPa}\right\}$ [8]. An

7153 essentially identical result was obtained from the $\mathrm{pH}$ dependence of the addition reaction under 7154 conditions where proton transfer was at equilibrium at $P\left(\mathrm{O}_{2}\right)=0.2 \mathrm{~atm}$ (i.e. 0.02) MPa. Both 7155 calculations depended on $\mathrm{p} K_{\mathrm{w}}$, for which a value of 14.08 was selected. 
$\mathrm{p} K_{\mathrm{a}}=(11.54 \pm 0.04)$ at $25^{\circ} \mathrm{C}$ and $\sim 0.01 \mathrm{M}$ ionic strength. Poskrebyshev et al. obtained this

result by pulse radiolysis determination of the kinetics of oxidation of benzoate by $\mathrm{HO}^{\bullet} / \mathrm{O}^{\bullet-}[9]$. A value of $\left(1.01 \times 10^{-14}\right) \mathrm{M}^{2}$ for $K_{\mathrm{w}}$ was used in deriving $\mathrm{p} K_{\mathrm{a}}$ from the measured $K_{\mathrm{b}}$.

\section{Discussion}

The result of Baxendale et al. can be converted into a $p K_{\mathrm{a}}$ by use of $K_{\mathrm{w}}=\left(1.01 \times 10^{-14}\right)$ $\mathrm{M}^{2}: \mathrm{p} K_{\mathrm{a}}=12.2$. With this addition, the extensive list of measurements of the $\mathrm{p} K_{\mathrm{a}}$ of $\mathrm{HO}^{\bullet}$ gives considerable confidence that the value lies in the range of 11.5 to 12.2 ; most of the reports suggest a value near 11.9.

We exclude from detailed consideration the three early reports from the Rabani group [1-

3 ] because the results were obtained without temperature control and not extrapolated to zero ionic strength. Likewise we exclude the result from Barat et al. [5], which also failed to report an uncertainty analysis.

We exclude the result of Buxton et al. [6] because the $\mathrm{p} K_{\mathrm{a}}$ was derived from experiments spanning a wide range of ionic strengths and no appropriate correction was applied. Moreover, there is no meaningful analysis of uncertaintes.

One of the extreme values, as inferred from the work of Baxendale et al. [4], was not actually reported in the original work, was not assigned an uncertainty, and was not coMPared to prior work; for these reasons we exclude it from further consideration.

Another of the extreme $\mathrm{p} K_{\mathrm{a}}$ values $(11.54 \pm 0.04)$ [9] requires discussion. The unusually high precision assigned to the measurement appears only in the abstract of the paper. The high assigned precision implies that the deviation of the $\mathrm{p} K_{\mathrm{a}}$ value from the prior determinations is statistically significant; however, the paper presents no discussion of this fact, nor does it provide any suggestions as to the origins of the deviation. We note that Figure 1 of the paper presents plots of $k_{\text {obs }}$ vs [benzoate] at various $\mathrm{pH}$ values, where the $\mathrm{pH}$ values are given to only 0.1 unit precision. It seems likely that the uncertainty in the derived $\mathrm{p} K_{\mathrm{a}}$ is overly optimistic. In view of these concerns we consider this report [9], although the most recent, not necessarily the best. significant in that they include data at $25^{\circ} \mathrm{C}$ with well-defined uncertainty estimates. The work

7187 of Elliot and McCracken [7] shows substantial temperature dependence for $\mathrm{p} K_{\mathrm{a}}$, which

7188 underscores the importance of obtaining data at $25^{\circ} \mathrm{C}$. The work of Hickel et al. [8] is important

7189 because it is the only study to determine $\mathrm{p} K_{\mathrm{a}}$ from the ratio of the forward and reverse proton7190 transfer rate constants (rather than just from the $\mathrm{pH}$ dependence of an irreversible $\mathrm{HO}^{\bullet} / \mathrm{O}^{\bullet-}$

7191 reaction); as such it provide strong additional support that the quantity being determined is 
actually the $\mathrm{p} K_{\mathrm{a}}$. One weakness in the paper by Hickel et al. $[8]$ is in the way that $\left[\mathrm{HO}^{-}\right]$was obtained: for $\mathrm{pH}>11$ it was calculated "from the weight of $\mathrm{NaOH}$ in the solutions", which is a quite unreliable method. For $\mathrm{pH}<11$ it was calculated from the $\mathrm{pH}$, but the details of the calculation are not described. In contrast, the work of Elliot and McCracken determined $\left[\mathrm{OH}^{-}\right]$ by titration [7]. Of these two papers, the one by Elliot and McCracken [7] is preferrred because

7197 of its greater precision, its more reilable method of determining $\left[\mathrm{OH}^{-}\right]$, and its use of ionic7198 strength dependent $K_{\mathrm{w}}$ values.

In comparing the results from the papers of Poskrebyshev et al. [9] and of Elliot and McCracken [7] it is difficult to find any flaws in either, with the exception of the weak handling of uncertainties in the former. However, since the Poskrebyshev paper [9] yields a value that is so far from the values reported elsewhere we regard it as anomalous and recommend the result of Elliot and McCracken [7].

\section{Recommended values:}

7206

7207

$$
\mathrm{HO}^{\bullet}(a q) \rightleftharpoons \mathrm{O}^{\bullet}(a q)+\mathrm{H}^{+}(a q) \quad \mathrm{p} K_{\mathrm{a}}=(11.7 \pm 0.1)
$$

7208

7209 List of auxiliary thermodynamic data: $K_{\mathrm{w}}$

7210

\section{References}

7212

7213 1. J. Rabani, M. S. Matheson. J. Am. Chem. Soc. 86, 3175-3176 (1964).

7214 2. J. Rabani, M. S. Matheson. J. Phys. Chem. 70, 761-769 (1966).

7215 3. J. L. Weeks, J. Rabani. J. Phys. Chem. 70, 2100-2106 (1966).

7216 4. J. H. Baxendale, M. D. Ward, P. Wardman. Trans. Faraday Soc. 67, 2532-2537 (1971).

7217 5. F. Barat, L. Gilles, B. Hickel, B. Lesigne. J. Phys. Chem. 76, 302-307 (1972).

7218 6. G. V. Buxton, N. D. Wood, S. Dyster. J. Chem. Soc., Faraday Trans. 1 84, 1113-1121

7219 (1988).

72207 7. J. Elliot, D. R. McCracken. Rad. Phys. Chem. 33, 69-74 (1989).

$7221 \quad 8 . \quad$ B. Hickel, H. Corfitzen, K. Sehested. J. Phys. Chem. 100, 17186-17190 (1996).

7222 9. G. A. Poskrebyshev, P. Neta, R. E. Huie. J. Phys. Chem. A 106, 11488-11491 (2002). 


\section{Data Sheet 117}

Chemical equilibrium:

$$
\mathrm{S}^{\bullet-}+\mathrm{SH}^{-} \rightleftharpoons \mathrm{HSS}^{\bullet-}
$$

\section{List of reports:}

$K=1 \times 10^{4} \mathrm{M}^{-1}$, determined by pulse radiolysis of $\mathrm{H}_{2} \mathrm{~S}$ solutions at $\mathrm{pH} 7.0$ in $2 \mathrm{mM}$ phosphate 7233 buffer [1]. $K=8 \times 10^{3} \mathrm{M}^{-1}$, determined by flash photolysis of $\mathrm{H}_{2} \mathrm{~S}$ solutions buffered at $\mathrm{pH} 7$ and 7.5, calculated from the ratio of $k_{\mathrm{f}}$ and $k_{\mathrm{r}}$ [2]. The ionic strength was not specified; $(20 \pm 2){ }^{\circ} \mathrm{C}$.

\section{Discussion}

The two determinations are in good agreement despite the likely differing ionic strengths.

7241 We recommend the average value: $9 \times 10^{3} \mathrm{M}^{-1}$, and we suggest an uncertainty of $\pm 20 \%$ given 7242 the unknown effect of ionic strength. The first determination was performed at rather low ionic 7243 strength, so the ionic strength correction could be negligible. Although the exact $\mathrm{p} K_{\mathrm{a}} \mathrm{s}$ of HS ${ }^{\bullet}$ and $7244 \mathrm{HSSH}^{\circ-}$ are unknown, Das et al. [2] provide evidence that they are low enough that the 7245 protonated species do not affect the measurements at $\mathrm{pH} 7$ significantly.

\section{Recommended value:}

$$
K(117.1)=(9 \pm 2) \times 10^{3} \mathrm{M}^{-1} .
$$

\section{References} (1987). 
The radical derived from 2-tert-butyl-1,4-benzoquinone:<smiles>CC(C)(C)C1=CC(=O)C=CC1=O</smiles>

Method: ESR Solvent: $1 \%$ acetone in water

Supporting measurements: The authors measured potentiometrically $E^{\circ}\left(\mathrm{TBQ} / \mathrm{TBQH}_{2}\right)=$ $+(0.232 \pm 0.003) \mathrm{V}$ vs NHE at $\mathrm{pH} 7$, which is the potential for the 2-electron reduction of TBQ at $\mathrm{pH}$ 7. At this $\mathrm{pH}$ the semiquinone is fully deprotonated $\left(\mathrm{p} K_{\mathrm{a}}\left(\mathrm{TBQH}^{\bullet}=4.3\right)\right.$ and the hydroquinone is doubly protonated $\left(\mathrm{p} K_{\mathrm{a}}\left(\mathrm{TBQH}_{2}\right)=10.6\right)$. Combination of $K^{\prime}(\mathrm{S}-1)$ and $E^{\circ}\left(\mathrm{TBQ} / \mathrm{TBQH}_{2}\right)$ gives $E^{\circ}\left(\mathrm{TBQ} / \mathrm{TBQ}^{\circ}\right)=-(0.025 \pm 0.006) \mathrm{V}$, which is the formal potential of the TBQ/TBQ ${ }^{-}$couple at $\mu=0.12 \mathrm{M}$. A correction for the activity coefficient of $\mathrm{TBQ}^{--}$then leads to $E^{\circ}\left(\mathrm{TBQ} / \mathrm{TBQ}^{\circ}\right)=-(0.032 \pm 0.006) \mathrm{V}$. Note that eqs 20 and 22 in the paper by Dohrman and Bergmann have typos: the right-hand terms should be divided by 2 . Apparently the results were calculated without making this mistake.

Derived potentials: The standard electrode potential of the $\mathrm{TBQ}, \mathrm{H}^{+} / \mathrm{TBQH}^{\bullet}$ couple was derived from the above $E^{\circ}$ value by use of the $\mathrm{p} K_{\mathrm{a}}$ of $\mathrm{TBQH}{ }^{\bullet}$ equals $(4.3 \pm 0.1)$ at essentially zero ionic strength. The $\mathrm{p} K_{\mathrm{a}}$ was determined by pulse radiolysis of TBQ in $1 \mathrm{M}$ 2-propanol, measuring the $\mathrm{pH}$ dependence of the absorbance of the semiquinone at $430 \mathrm{~nm}$. The outcome was $E^{\circ}\left(\mathrm{TBQ}, \mathrm{H}^{+} / \mathrm{TBQH}^{\bullet}\right)=+(0.219 \pm 0.015) \mathrm{V}$.

The standard electrode potential of the $\mathrm{TBQ}^{\bullet}, \mathrm{H}^{+} / \mathrm{TBQH}_{2}$ couple $E^{\circ}=+(1.315 \pm 0.006)$ $\mathrm{V}$ was determined as above from the measured $E^{\circ}$, and $K^{\prime}$ values at $\mathrm{pH} 7$ with a correction for the activity coefficient of $\mathrm{TBQ}{ }^{-}$, and $E^{\circ}=+(1.061 \pm 0.015) \mathrm{V}$ for the $\mathrm{TBQH}{ }^{\bullet}, \mathrm{H}^{+} / \mathrm{TBQH}_{2}$ couple was calculated by using the $\mathrm{p} K_{\mathrm{a}}$ of $\mathrm{TBQH}^{\bullet}$. A value for $E^{\circ}\left(\mathrm{TBQ}^{\bullet} / \mathrm{TBQ}^{2-}\right)$ of $-(0.112 \pm 0.015) \mathrm{V}$ was obtained by use of $\mathrm{p} K_{\mathrm{a}, 1}$ and $\mathrm{p} K_{\mathrm{a}, 2}$ for $\mathrm{TBQH}_{2}$, but in this case the accuracy of the result is overstated, since activity coefficients are not reliably estimated for di-anions at $\mu=0.12 \mathrm{M}$. 
7295 Discussion: The comproportionation equilibrium was also investigated by Roginsky et al. [2]. Roginsky et al. used ESR to determine the equilibrium constant in $50 \mathrm{mM}$ phosphate buffer, and they obtained a value approximately 4-fold greater than reported by Dohrmann and Bergmann. The origin of the discrepancy is not understood, but the consequence is a $36 \mathrm{mV}$ difference in the derived potentials. We thus recommend the potentials derived by Dohrmann and Bergman after adjusting them by $36 / 2 \mathrm{mV}$; we increase the incertainties accordingly by $10 \mathrm{mV}$. In the case of $E^{\circ}\left(\mathrm{TBQ}^{--} / \mathrm{TBQ}^{2-}\right)$ we add another $5 \mathrm{mV}$ of uncertainty because of the ionic strength issues. The $E_{\mathrm{m}}$ values recommended below are from Dohrmann and Bergmann, adjusted again by $18 \mathrm{mV}$ and with a correspondingly increased uncertainty.

A further check on the TBQ potential is provided by data in the Dohrmann and Bergmann paper, where they use pulse radiolysis to measure the redox equilibrium constant for the reaction of $\mathrm{TBQ}^{\bullet-}$ with 4-(dimethylamino)phenoxyl (DMAP): $\mathrm{TBQ}^{2-}+\mathrm{DMAP}^{\bullet}=\mathrm{TBQ}^{\bullet-}+$ $\mathrm{DMAP}^{-}$. They obtain an equilibrium constant of $(1.1 \pm 0.5) \times 10^{3}$ at $22^{\circ} \mathrm{C}$ and $\mu \sim 0.5 \mathrm{M}$ in 0.9 $\mathrm{M}$ ethylene glycol at $\mathrm{pH} 13.5$. Then they use their $E^{\circ}$ value for $\mathrm{TBQ}^{\circ} / \mathrm{TBQ}^{2-}$ and estimated activity coefficients for $\mathrm{TBQ}^{\circ-}$ and $\mathrm{TBQ}^{2-}$ to obtain $E^{\circ}\left(\mathrm{DMAP}^{\circ} / \mathrm{DMAP}^{-}\right)=+(0.10 \pm 0.02) \mathrm{V}$ at $22{ }^{\circ} \mathrm{C}$ and $\mu \sim 0.5 \mathrm{M}$ in $0.9 \mathrm{M}$ ethylene glycol. This differs by $70 \mathrm{mV}$ from the DMAP potential reported by Steenken and Neta. Dohrmann and Bergmann sugested various sources for the

7312 disagreement and principal among them seems to be the possibility that the organic cosolvents affect the equilibria. Given the doubts introduced by these considerations, the uncertainties presented below may be highly optimistic.

7315

\section{Recommended values:}

7330

\section{References}

1. J. K. Dohrmann, B. Bergmann. J. Phys. Chem. 99, 1218-1227 (1995).

2. V. A. Roginsky, L. M. Pisarenko, W. Bors, C. Michel. J. Chem. Soc., Perkin Trans. 2 871-876 (1999). 


\section{Supplementary Data Sheet S-2}

Chemical equilibrium: $\mathrm{ClO}_{2}{ }^{\bullet}+\mathrm{PhO}^{-} \rightleftharpoons \mathrm{ClO}_{2}^{-}+\mathrm{PhO}^{\bullet}$

$K=2.2 \times 10^{2}$ from absorbance, $(2.5 \pm 0.9) \times 10^{2}$ from kinetics, $\mathrm{pH} 13$ [1].

7338

7339

Taking $E^{\circ}\left(\mathrm{ClO}_{2}{ }^{\circ} / \mathrm{ClO}_{2}{ }^{-}\right)=+0.936 \mathrm{~V}$ at $298 \mathrm{~K}$ [2].

7340

$E^{\circ}\left(\mathrm{PhO}^{\circ} / \mathrm{PhO}^{-}\right)=+(0.796 \pm 0.010) \mathrm{V}$

7341

$k_{\mathrm{f}}=(1.6 \pm 0.3) \times 10^{7} \mathrm{~L} \mathrm{~mol}^{-1} \mathrm{~s}^{-1}, k_{\mathrm{r}}=(6.3 \pm 1.2) \times 10^{4} \mathrm{~L} \mathrm{~mol}^{-1} \mathrm{~s}^{-1}$

7343 Taking $E^{\circ}\left(\mathrm{ClO}_{2}{ }^{\circ} / \mathrm{ClO}_{2}^{-}\right)=+0.936 \mathrm{~V}[2]$.

$7344 E^{\circ}\left(\mathrm{PhO}^{\circ} / \mathrm{PhO}^{-}\right)=+(0.791 \pm 0.010) \mathrm{V}$

$7345 k_{\mathrm{f}}=3.5 \times 10^{7} \mathrm{~L} \mathrm{~mol}^{-1} \mathrm{~s}^{-1}, k_{\mathrm{r}}=1.3 \times 10^{5} \mathrm{~L} \mathrm{~mol}^{-1} \mathrm{~s}^{-1}$

7346

$7347 \quad K=(2.1 \pm 0.3) \times 10^{2}$ from absorbance, $\mathrm{pH} 11.5, \mu=0.12 \mathrm{M}[4]$.

7348 Taking $E^{\circ}\left(\mathrm{ClO}_{2} \cdot \mathrm{ClO}_{2}^{-}\right)=+0.934 \mathrm{~V}[5]$.

$7349 E^{\circ}\left(\mathrm{PhO}^{\circ} / \mathrm{PhO}^{-}\right)=+(0.796 \pm 0.005) \mathrm{V}$

7350

Electrochemistry

7352

7353

$E^{\circ}=+0.803 \mathrm{~V}$, by cyclic voltametry, from a Pourbaix diagam, at an ionic strength estimated

7354 near $0.15 \mathrm{M}$ ( $0.05 \mathrm{M}$ Britton-Robinson buffer) at, presumably, room temperature. The

7355 concentration of phenol was $0.2 \mathrm{mM}$, the scan rate $0.2 \mathrm{~V} \mathrm{~s}^{-1}[6]$.

\section{Discussion}

7358

Average of all $5 \mathrm{~K}$ 's is $(2.5 \pm 0.5) \times 10^{2}$. Assuming all measured equilibrium constants at $295 \mathrm{~K}$ are the same as that at $298 \mathrm{~K}$, and taking $E^{\circ}\left(\mathrm{ClO}_{2}{ }^{\circ} / \mathrm{ClO}_{2}^{-}\right)=+(0.935 \pm 0.003) \mathrm{V}$ (Data Sheet 24), we find $E^{\circ}\left(\mathrm{PhO}^{\circ} / \mathrm{PhO}^{-}\right)=+(0.793 \pm 0.008) \mathrm{V}$, a value in excellent agreement with the very solid study on the electrochemistry of phenol [6]. As the value of $K(\mathrm{~S}-2)$ is expected to be independent of ionic strength, the derived electrode potential can be regarded as a standard potential.

\section{Recommended value}

7367 List of auxiliary thermodynamic data 
$7368 p K_{\mathrm{a}}(\mathrm{PhOH})=10.0$

$7369 p K_{\mathrm{a}}\left(\mathrm{PhOH}^{\bullet+}\right)=-2.0[7]$ or $-2.75[8]$

$7370 E^{\circ}\left(\mathrm{PhO}^{\bullet}, \mathrm{H}^{+} / \mathrm{PhOH}\right)=+1.38 \mathrm{~V}$ or $+1.42 \mathrm{~V}$

$7371 E^{\circ}(\mathrm{pH} 7)=+0.97 \mathrm{~V}$.

7372

7373 Das [8] argues that the $\mathrm{p} K_{\mathrm{a}}$ of -2.0 previously reported for $\mathrm{PhOH}^{\bullet+}$ is in error because the prior 7374 report overlooked the association of $\mathrm{PhOH}$ with $\mathrm{PhOH}^{\bullet+}$; the revised $\mathrm{p} K_{\mathrm{a}}$ is $-(2.75 \pm 0.05)$.

7375

7376

\section{References}

7377

$7378 \quad$ 1. G. Merényi, J. Lind, X. Shen. J. Phys. Chem. 92, 134-137 (1988).

7379 2. N. V. Troitskaya, K. P. Mishchenko, I. E. Flis. Russ. J. Phys. Chem. 33, 77-79 (1959).

7380 3. J. Lind, X. Shen, T. E. Eriksen, G. Merényi. J. Am. Chem. Soc. 112, 479-482 (1990).

7381 4. T. N. Das, R. E. Huie, P. Neta. J. Phys. Chem. A 103, 3581-3588 (1999).

7382 5. D. M. Stanbury. Adv. Inorg. Chem. 33, 69-138 (1989).

7383 6. C. Costentin, C. Louault, M. Robert, J.-M. Savéant. Proc. Natl. Acad. Sci. U.S.A. 106, 7384 18143-18148 (2009).

7385 7. W. T. Dixon, D. Murphy. J. Chem. Soc., Faraday Trans. 2 72, 1221-1230 (1976).

$7386 \quad$ 8. T. N. Das. J. Phys. Chem. A 109, 3344-3351 (2005). 


\section{Supplementary Data Sheet S-3}

7390

$$
\text { Chemical equilibrium: } \mathrm{PhO}^{\bullet}+\mathrm{MePhO}^{-} \rightleftharpoons \mathrm{PhO}^{-}+\mathrm{MePhO}^{\bullet}
$$$$
\mathrm{PhOH}=\text { phenol }
$$

$K=(12.4 \pm 1.2)$ from absorbance, $\mathrm{pH} 13, I=0.1 \mathrm{M}$ [1].

7396 Taking $E^{\circ}\left(\mathrm{PhO}^{\bullet} / \mathrm{PhO}^{-}\right)=+0.80 \mathrm{~V}($ Data Sheet S-2)

The equilibrium constant for reaction S-3.1 is expected to be insensitive to ionic strength, which enables the derived electrode potential to be regarded as a standard potential.

Recommended value:

7402

7403

$E^{\circ}\left(\mathrm{MePhO}^{*} / \mathrm{MePhO}^{-}\right)=+(0.74 \pm 0.01) \mathrm{V}$ at $\mu=0$

7404

7405 List of auxiliary thermodynamic data:

$7406 \quad p K_{\mathrm{a}}(\mathrm{MePhOH})=10.0$

\section{References}




\section{Supplementary Data Sheet S-4}

7414 tyrosine

$K_{\mathrm{S}-4.1}=21$ from absorbance, 18 from kinetics, $\mathrm{pH} 11-12, \mu=0.5 \mathrm{M}$ [1].

The authors took $E^{\circ}\left(\mathrm{PhO}^{*} \mathrm{PhO}^{-}\right)=+0.80 \mathrm{~V}$ to derive $E^{\circ}\left(\mathrm{TyrO} \% \mathrm{TyrO}^{-}\right)=+(0.72 \pm 0.02) \mathrm{V}$. $k_{\mathrm{f}}=4.9 \times 10^{8} \mathrm{~L} \mathrm{~mol}^{-1} \mathrm{~s}^{-1}, k_{\mathrm{r}}=2.8 \times 10^{7} \mathrm{~L} \mathrm{~mol}^{-1} \mathrm{~s}^{-1}$

$K_{\mathrm{S}-4.1}=(12.0 \pm 1.2)$ from absorbance, $\mathrm{pH} 11.3, \mu=0.076 \mathrm{M}[2]$.

The authors took $E^{\circ}\left(\mathrm{PhO}^{\bullet} / \mathrm{PhO}^{-}\right)=+0.80 \mathrm{~V}$ to derive $E^{\circ}\left(\mathrm{TyrO} / \mathrm{TyrO}^{-}\right)=+(0.736 \pm 0.005) \mathrm{V}$ at $7425 \mu=0$.

$K_{\mathrm{S}-4.1}=(11.5 \pm 1.2)$ from absorbance, $\mathrm{pH} 11.3, \mu=0.5 \mathrm{M}[2]$.

The authors took $E^{\circ}\left(\mathrm{PhO} / \mathrm{PhO}^{-}\right)=+0.80 \mathrm{~V}$ to derive $E^{\circ}\left(\mathrm{TyrO} \% \mathrm{TyrO}^{-}\right)=+(0.737 \pm 0.005) \mathrm{V}$ at $\mu=0$.

Chemical equilibrium: $\mathrm{TyrO}^{\bullet}+\mathrm{ABTS}^{2-}+\mathrm{H}^{+} \rightleftharpoons \mathrm{TyrOH}+\mathrm{ABTS}^{\bullet-}$

$K_{\mathrm{S}-4.2}$ was determined at $\mathrm{pH} 9.08,10.00$, and 11.03 by pulse radiolysis, both from the equilibrium absorbance and from the ratio of the forward and reverse rate constants [3]. Taking $E^{\circ}\left(\mathrm{ABTS}^{\bullet-}\right.$ $\left./ \mathrm{ABTS}^{2-}\right)=+0.68 \mathrm{~V}$ and a $\mathrm{p} K_{\mathrm{a}}$ of 10.4 for the $\mathrm{TyrOH}$ phenolic dissociation the authors calculated $E^{\circ}\left(\mathrm{TyrO}^{\bullet} / \mathrm{TyrO}^{-}\right)=+(0.717 \pm 0.002) \mathrm{V}$, and $E^{\circ},=+(0.93 \pm 0.02) \mathrm{V}$ at $\mathrm{pH} 7$. We note that Table 1 of this publication has several typos: $k_{6}$ and $k_{-6}$ should be reversed, $K_{6}$ should be $1 / K_{6}$, and $\Delta E_{6}$ should be $-\Delta E_{6} ; E_{\mathrm{m}}$, however, is correct.

\section{Discussion}

The various determinations of $E^{\circ}\left(\mathrm{TyrO}^{\bullet} / \mathrm{TyrO}^{-}\right)$span a range of $20 \mathrm{mV}$, which exceeds some of 7444 the stated uncertainties. On the other hand, the smaller stated uncertainties seem overly 7445 optimistic. In the case of the ABTS reaction (S-4.2) the uncertainty in $E^{\circ}\left(\mathrm{ABTS}^{\bullet-} / \mathrm{ABTS}^{2-}\right)$ was 7446 not included in calculating $E^{\circ}\left(\mathrm{TyrO}^{\bullet} / \mathrm{TyrO}^{-}\right)$; that uncertainty is probably at least $10 \mathrm{mV}$. Thus, 7447 the various reports of $E^{\circ}\left(\mathrm{TyrO}^{\bullet} / \mathrm{TyrO}^{-}\right)$are in reasonable agreement. 
7449 An indirect calculation of $K_{\mathrm{S}-4.1}$ can be performed by combining the equilibrium constants for 7450 two reactions involving sulfite:

The sum of the two reactions gives the reverse of reaction S-4.1: $1 / K_{\mathrm{S}-4.1}=\left(K_{63.1}\right)\left(K_{64.1}\right)=3.4 \times$ $10^{-2}$ (or $K_{\mathrm{S}-4.1}=29$ ) at $\mu=0 \mathrm{M}$. This result is in reasonable agreement with the direct measurements of $K_{\mathrm{S}-4.1}$ summarized above, given the effects of propagation of error.

Overall, the value of $K_{\mathrm{S}-4.1}$ determined by Das et al. appears to be the most reliable, while the uncertainty is probably best estimated by considering all of the above reports. Thus we recommend a value of $(12 \pm 5)$ for $K_{\mathrm{S}-4.1}\left(\right.$ or $\left.\Delta E^{\circ}=64 \mathrm{mV}\right)$. We currently recommend $E^{\circ}\left(\mathrm{PhO} \% \mathrm{PhO}^{-}\right)=(0.793 \pm 0.008)($ Data Sheet $\mathrm{S}-2)$, and thus we derive $E^{\circ}\left(\mathrm{TyrO}^{\bullet} / \mathrm{TyrO}^{-}\right)=$ $+(0.729 \pm 0.01) \mathrm{V}$ from $K_{\mathrm{S}-4.1}$. Combining this result with that derive from reaction $\mathrm{S}-4.2$ leads to $E^{\circ}\left(\mathrm{TyrO}^{\bullet} / \mathrm{TyrO}^{-}\right)=+(0.723 \pm 0.01) \mathrm{V}$.

\section{Recommended values:}

$K_{\mathrm{S}-4.1}=12 \pm 5$

$E^{\circ}\left(\mathrm{TyrO}^{\bullet} / \mathrm{TyrO}^{-}\right)=(0.723 \pm 0.010) \mathrm{V}$

List of auxiliary thermodynamic data

$7473 E^{\circ}(\mathrm{pH} 7)=+0.91 \mathrm{~V}$ (assuming $\mathrm{p} K_{\mathrm{a}} \mathrm{s}$ of amino and carboxyl group are the same in the radical as

7474 in the parent tyrosine).

\section{Further comments:}

During the 1980s proton-coupled electron transfer from tyrosine to the tryptophan radical in peptides and proteins has been observed at $\mathrm{pH} 7$ by pulse radiolysis [5-8]. Given the values that we find for the equilibrium constants of those reactions, the difference in electrode potential is at most $60 \mathrm{mV}$; this inference excludes the data of Faraggi et al. because it is unclear whether

7482 the reactions reached equilibrium [6]. As the couple $\operatorname{Trp}^{\bullet}, \mathrm{H}^{+} / \mathrm{TrpH}$ has an electrode potential of $7483+(1.03 \pm 0.02) \mathrm{V}$ at $\mathrm{pH} 7$ (see Data Sheet $\mathrm{S} 12$ ), that of the $\mathrm{TyrO}^{\bullet}, \mathrm{H}^{+} / \mathrm{TyrOH}$ couple is expected 7484 to be near $+0.97 \mathrm{~V}$. However, the values cited above yield a value of $+0.91 \mathrm{~V}$. Of course, one can 
7485

7486

accept a value of $+0.91 \mathrm{~V}$, but then the electrode potential of the $\operatorname{Trp}^{\bullet}, \mathrm{H}^{+} / \operatorname{TrpH}$ couple would be incorrect. The origin of this discrepancy is not known. Recent cyclic voltammetry experiments yield $+0.97 \pm 0.01 \mathrm{~V}$ for $E^{\circ}\left(\mathrm{TyrO}^{\bullet}, \mathrm{H}^{+} / \mathrm{TyrOH}\right)$ at $\mathrm{pH} 7$ (L. Mahmoudi, R. Kisner, T. Nauser, W. H. Koppenol, 2014, unpublished.), quite close to that obtained for a tyrosine in an artificial protein, $+0.98 \mathrm{~V}[9]$.

Experimental measurements at $\mathrm{pH} 7[10]$ gave $E^{\circ}\left(\mathrm{TyrO}^{\bullet} / \mathrm{TyrO}^{-}\right)$between +0.90 and $+0.97 \mathrm{~V}$, but it is not clear whether real equilibrium was achieved in those cases (because of the slow electron transfer with neutral phenols). The results were:

Reference $\quad$ Ref. $E^{\circ} / \mathrm{V} \quad E^{\circ}\left(\mathrm{TyrO}^{\bullet} / \mathrm{TyrO}^{-}\right) / \mathrm{V} \quad E^{\circ}\left(\mathrm{TyrO}^{\circ} / \mathrm{TyrO}^{-}\right) / \mathrm{V}$ from kinetics from absorbance

$\begin{array}{llll}\mathrm{IrBr}_{6}{ }^{2-/ 3-} & +0.80 & +0.92 & +0.92 \\ \mathrm{Os}(\text { bpy })_{3}{ }^{3+/ 2+} & +0.83 & +0.97 & +0.94 \\ \mathrm{IrCl}_{6}{ }^{2-/ 3-} & +0.91 & +0.94 & +0.96 \\ \mathrm{ClO}_{2}{ }^{\circ} / \mathrm{ClO}_{2}{ }^{-} & +0.92 & +0.94 & \\ \mathrm{Os}(\text { terpy })_{2}^{3+/ 2+}+0.93 & & +0.90\end{array}$

Harriman [11] and DeFilippis et al. [12] determined electrode potentials of $+0.93 \mathrm{~V}$ and $+0.94 \mathrm{~V}$, respectively, by cyclic voltammetry and differential pulse polarography. As the tyrosyl radical dimerizes rapidly, the cathodic peak is hardly observable in a cyclic voltammogram. Still, with an equation derived by Nicholson [13], an electrode potential can be derived from the CV data. However, that equation was incorrectly modified by Harriman [11], and used as such by DeFillipis et al. [12]. While differential pulse polarography is very sensitive, it does not yield a reliable potential if the oxidation product undergoes subsequently a rapid reaction; for this reason we do not trust the value of $+0.83 \mathrm{~V}$ by Nocera and coworkers [14].

\section{References}

1. J. Lind, X. Shen, T. E. Eriksen, G. Merényi. J. Am. Chem. Soc. 112, 479-482 (1990).

2. T. N. Das, R. E. Huie, P. Neta. J. Phys. Chem. A 103, 3581-3588 (1999).

3. L. K. Folkes, M. Trujillo, S. Bartesaghi, R. Radi, P. Wardman. Arch. Biochem. Biophys. 506, 242-249 (2011).

4. R. B. Martin, J. T. Edsall, D. B. Wetlaufer, B. R. Hollingsworth. J. Biol. Chem. 233, 1429-1435 (1958). 
7520 5. J. Butler, E. J. Land, W. A. Prütz, Swallow, A, J. Biochim. Biophys. Acta 705, 150-162 7521 (1982).

7522 6. M. Faraggi, M. R. DeFelippis, M. H. Klapper. J. Am. Chem. Soc. 111, 5141-5145 (1989).

75237 W. A. Prütz, J. Butler, E. J. Land, A. J. Swallow. Biochem. Biophys. Res. Commun. 96, 7524 408-414 (1980).

75258 8. W. A. Prütz, E. J. Land, R. W. Sloper. J. Chem. Soc., Faraday Trans. I 77, 281-292 7526 (1981).

7527 9. B. W. Berry, M. C. Martinez-Rivera, C. Tommos. Proc. Nat. Acad. Sci. 109, 9739-9743 7528 (2012).

7529 10. M. R. DeFelippis, C. P. Murthy, M. Faraggi, M. H. Klapper. Biochemistry 28, 4847-4853 7530 (1989).

7531 11. A. Harriman. J. Phys. Chem. 91, 6102-6104 (1987).

7532 12. M. R. DeFelippis, C. P. Murthy, F. Broitman, D. Weinraub, M. Faraggi, M. H. Klapper. 7533 J. Phys. Chem. 95, 3416-3419 (1991).

7534 13. R. S. Nicholson. Analyt. Chem. 37, 667-671 (1965).

7535 14. C. S. Yee, M. R. Seyedsayamdost, M. C. Y. Chang, D. G. Nocera, J. Stubbe.

7536 Biochemistry 42, 14541-14552 (2003). 


\section{Supplementary Data Sheet S-5}

$K=(69 \pm 7)$ from absorbance measurements, $\mathrm{pH} \mathrm{12, \mu}=0.18,2.7 \mathrm{~mol} \mathrm{~L}^{-1}$ ethylene glycol [1]

$E^{0}\left(\mathrm{PhNMe}_{2}{ }^{\bullet+} / \mathrm{PhNMe}_{2}\right)=+(0.69 \pm 0.01) \mathrm{V}$ at $I=0$

\section{Discussion}

The authors used a high concentration of ethylene glycol to help dissolve $N, N$-dimethylaniline, Furthermodynamicre, they used a linear accelerator, not a Febetron, thus the dose per pulse was 7552 lower.

Holcman and Sehested [2] report $\mathrm{PhNMe}_{2}{ }^{\bullet+}+\mathrm{HO}^{-} \rightarrow \mathrm{PhNMeCH}_{2}{ }^{\bullet}+\mathrm{H}_{2} \mathrm{O}$ with $k \approx 1 \times 10^{5} \mathrm{~L}$ $\mathrm{mol}^{-1} \mathrm{~s}^{-1}$, thus, at $\mathrm{pH} 12, k \approx 1 \times 10^{3} \mathrm{~s}^{-1}$

7555

7556 Earlier study:

7557 Chemical equilibrium: $\mathrm{ClO}_{2}{ }^{\bullet}+\mathrm{PhNMe}_{2} \rightleftharpoons \mathrm{ClO}_{2}^{-}+\mathrm{PhNMe}_{2}{ }^{+}$

$7558 K=(15 \pm 5)$ from kinetics measurements at $\mathrm{pH} 9.6[3]$.

7559 Taking $E^{\circ}\left(\mathrm{ClO}_{2} / \mathrm{ClO}_{2}^{-}\right)=+0.936 \mathrm{~V} \mathrm{[4],} E^{\circ}\left(\mathrm{PhNMe}_{2}{ }^{++} / \mathrm{PhNMe}_{2}\right)=+(0.87 \pm 0.02) \mathrm{V}$.

7560 The authors used a Febetron with a high dose per pulse. The limited solubility of $\mathrm{PhNMe}_{2}$ is an

7561 issue here as the authors did not use ethylene glycol, with the consequence that, if not all

$7562 \mathrm{PhNMe}_{2}$ was dissolved, $K$ will be higher. We will not use this value.

7563

7564 Recommended value:

7565

7566

$E^{\circ}\left(\mathrm{PhNMe}_{2}{ }^{\bullet+} / \mathrm{PhNMe}_{2}\right)=+(0.69 \pm 0.01) \mathrm{V}$ at $\mu=0$.

List of auxiliary thermodynamic data

7569

$p K_{\mathrm{a}}\left(\mathrm{PhNMe}_{2} \mathrm{H}^{+}\right)=5.1$

7570

7571

7572

7573

\section{References}

7574

1. T. N. Das, R. E. Huie, P. Neta, J. Phys. Chem. A 103, 3581-3588 (1999).

2. J. Holcman, K. Sehested, Proc. Tihany Symp. Rad. Chem. 5, 693-696 (1982). 
7575 3. R. E. Huie, P. Neta, J. Phys. Chem. 90, 1193-1198 (1986).

7576 4. N. V. Troitskaya, K. P. Mishchenko, I. E. Flis, Russ. J. Phys. Chem. 33, $77-79$ (1959).

7577

7578 


\section{Supplementary Data Sheet S-6}

7580

7581 Chemical equilibrium: $\mathrm{I}_{2}^{\bullet-}+\mathrm{CNPhO}^{-} \rightleftharpoons 2 \mathrm{I}^{-}+\mathrm{CNPhO}^{\bullet}$

$\mathrm{CNPhOH}=4$-cyanophenol

7583

$7584 K=0.1 \mathrm{M}$ from absorbance measurements, $0.07 \mathrm{M}$ from kinetics, $\mathrm{pH} 11-12, \mu=1 \mathrm{M}[1]$.

7585 Taking $E^{\circ}\left(\mathrm{I}_{2}{ }^{\bullet-} / 2 \mathrm{I}^{-}\right)=+1.03 \mathrm{~V}$ (from Data Sheet 45)

7586 $E^{\circ}\left(\mathrm{CNPhO}^{\bullet} / \mathrm{CNPhO}^{-}\right)=+(1.09 \pm 0.03) \mathrm{V}$ (the paper uses $E^{\circ}\left(\mathrm{I}_{2}^{\bullet-} / 2 \mathrm{I}^{-}\right)=+1.06 \mathrm{~V}$ and gives $E^{\circ}=$ $7587+1.12 \mathrm{~V})$

$k_{\mathrm{f}}=7 \times 10^{4} \mathrm{~L} \mathrm{~mol}^{-1} \mathrm{~s}^{-1}, k_{\mathrm{r}}=1 \times 10^{6} \mathrm{~L} \mathrm{~mol}^{-2} \mathrm{~s}^{-1}$

This equilibrium constant is expected to be insensitive to ionic strength, so the derived electrode 7592 potential at $1 \mathrm{M} \mathrm{H}^{+}$may be regarded a standard potential.

7593

7594 List of auxiliary thermodynamic data

$7595 p K_{\mathrm{a}}(\mathrm{CNPhOH})=7.95$

7596

7597

Recommended values:

7598

7599

$E^{\circ}\left(\mathrm{CNPhO}^{\bullet} / \mathrm{CNPhO}^{-}\right)=+(1.09 \pm 0.03) \mathrm{V}$

7600

$E^{\circ}\left(\mathrm{CNPhO}^{\bullet}, \mathrm{H}^{+} / \mathrm{CNPhOH}\right)=+1.56 \mathrm{~V}$

7601

$$
E^{\circ}(\mathrm{pH} 7)=+1.14 \mathrm{~V}
$$

7602

7603

\section{References}

7604

7605

1. J. Lind, X. Shen, T. E. Eriksen, G. Merényi, J. Am. Chem. Soc. 112, 479-482 (1990).

7606

7607

7608 


\section{Supplementary Data Sheet S-7}

Aqueous electrode potentials involving the nitroxyl radical TEMPO`.

7612

7613

7614

7615

Nitroxyl radical

als: $\mathrm{R}_{2} \mathrm{ON}$

$\mathrm{N}^{\bullet}, \mathrm{TEMPO}^{\bullet}=$ 2,2,6,6-tetramethylpiperidine-1-oxyl

\section{7}

Abbreviations used here:

7619

\section{List of Reports.}

Neimann et al. reported on the polarography (reduction at $\mathrm{Hg}$ ) of TEMPO ${ }^{\bullet}$ [1]. They note some specific medium effects, but these effects are not severe in alkaline media. Their data (Fig. 2) suggest $E^{\circ} \sim-250 \mathrm{mV}$ vs SCE at $\mathrm{pH} 11$ for reduction of TEMPO ${ }^{\bullet}$ to TEMPOH, but the exact results are not clearly stated.

Golubev et al. [2] reported in 1975 on the acid-induced disproportionation of TEMPO` and its reverse, both for kinetics and equilibrium constants. From the ratio of the forward and reverse rate constants they obtained $K_{\text {disp }}=(3.3 \pm 0.2) \times 10^{4} \mathrm{M}^{-2}$ at $25^{\circ} \mathrm{C}$ for the reaction

$$
2 \mathrm{TEMPO}^{\bullet}+2 \mathrm{H}^{+} \rightleftharpoons \mathrm{TEMPO}^{+}+\mathrm{TEMPHOH}^{+}
$$

From the equilibrium concentration of TEMPO ${ }^{\bullet}$ they obtained $K_{\text {disp }}=(1.0 \pm 0.4) \times 10^{4} \mathrm{M}^{-2}$, in reasonable agreement with the kinetics result.

In 1976, Golubev et al. used potentiometry to determine $E^{\circ}$ for $\mathrm{TEMPO}^{+} / \mathrm{TEMPO}^{\bullet}:+(750 \pm 5)$ $\mathrm{mV}$ vs $\mathrm{NHE}$ at $25^{\circ} \mathrm{C}$, extrapolating data at various ionic strengths to get a value at $\mu=0 \mathrm{M} \mathrm{[3]}$. 
In 1977, Golubev et al. (1977) reported on the reaction of alcohols with oxoammonium ions [4]. These studies lead to a value for the comproportionation constant for TEMPO $: K_{\text {disp }}=(3 \pm 1) \times$ $10^{4} \mathrm{M}^{-2}$ at $25^{\circ} \mathrm{C}$ for the following reaction:

This result is in good agreement with that of Golubev et al. from (1975) [2]. From this equilibrium constant, their prior value for $E^{\circ}\left(\mathrm{TEMPO}^{+/ 0}\right)$, and their prior value for $\mathrm{p} K_{\mathrm{a}}(\mathrm{TEMPOH})$ they [4] derived a value for the two-electron $E^{\circ}$ for $\mathrm{TEMPO}^{+} / \mathrm{TEMPOH}$ of +0.68 V vs NHE.

In 1986, Petrov and Kozlov used the reaction of tetranitromethane with nitroxyls to measure a rate constant $k$, which is assigned in terms of the following mechanism [5]:

Thus, $k=k_{\mathrm{NO} 2} K_{\text {et. }}$. With use of a literature value for $k_{\mathrm{NO} 2}$ they derive $K_{\text {et }}=8.8 \times 10^{4}$. An alternative method, using the steady-state concentration of TEMPO', gave a value for $K_{\text {et }}$ of $7 \times$ $10^{4}$. They combined $K_{\mathrm{et}}$ with a literature electrode potential for $\mathrm{TEMPO}^{+/ 0}$ to derive $E^{\circ}=+1.04$ $\mathrm{V}$ for $\mathrm{NO}_{2}{ }^{\bullet} / \mathrm{NO}_{2}{ }^{-}$, which is in good agreement with alternative determinations. Note that Goldstein et al. [6] subsequently reported rate constants for this reaction that disagree drastically with those of Petrov and Kozlov [5]; as discussed by Goldstein et al. [6], this disagreement does not, however, extend to the values of the equilibrium constant.

7663

7664 Fish et al. reported CV data on the $\mathrm{TEMPO}^{+/ 0}$ redox couple [7]. They obtain $E^{\circ}{ }^{\prime}=+0.49 \mathrm{~V}$ vs

$7665 \mathrm{SCE}$ at $\mu=0.08 \mathrm{M}$, presumably at room temperature. We correct their potential to $+0.73 \mathrm{~V}$ vs 7666 NHE.

7668 Krishna et al. reported CV data on $\mathrm{R}_{2} \mathrm{NO}^{+}+\mathrm{e}^{-} \rightleftharpoons \mathrm{R}_{2} \mathrm{NO}$ for TEMPO [8]. They report $E^{\circ}$ '= $7669+722 \mathrm{mV}$ vs NHE at $\mu=0.15 \mathrm{M}$ and $23{ }^{\circ} \mathrm{C}$.

Kato et al. reported reversible CVs for reduction of TEMPO [9]. Inspection of their CV's, 7672 however, reveals that the reduction process is irreversible, with the two CV waves having a 7673 peak-to-peak separation of $\sim 1.4 \mathrm{~V}$. It is highly unlikely that thermodynamic data can be derived 7674 from such voltammograms. 
Baur et al. reported CVs of nitroxyls, giving $E_{1 / 2}=+0.62 \mathrm{~V}$ vs $\mathrm{Ag} / \mathrm{AgCl}$ for TEMPO ${ }^{\bullet}$ [10]. The data were obtained by rapid-scan voltammetry and hence the difference between the peak potentials is $+360 \mathrm{mV}$. Accordingly, such data should not be used for obtaining accurate thermodynamic cell potentials.

Goldstein et al. reported the equilibrium constant for the following reaction, as determined from the ratios of the forward and reverse rate constants [11].

$$
\mathrm{TEMPO}^{\bullet}+\mathrm{HO}_{2}{ }^{\bullet} \rightleftharpoons \mathrm{TEMPO}^{+}+\mathrm{HO}_{2}^{-} \quad K=0.86 \pm 0.22
$$

From this equilibrium constant and the $\mathrm{HO}_{2} \bullet / \mathrm{HO}_{2}{ }^{-}$electrode potential they [11] derived $E^{\circ}\left(\mathrm{TEMPO}^{+} / \mathrm{TEMPO}^{\bullet}\right)=+0.75 \mathrm{~V}$.

Goldstein et al. reported the equilibrium constant for reduction of $\mathrm{TEMPO}^{+}$by $\mathrm{NO}^{\bullet}[12]$ :

$$
\mathrm{TEMPO}^{+}+\mathrm{NO}^{\bullet}+\mathrm{H}_{2} \mathrm{O} \rightleftharpoons \mathrm{TEMPO}^{\bullet}+\mathrm{HNO}_{2}+\mathrm{H}^{+} \quad K=0.045 \pm 0.005 \mathrm{M}
$$

From this equilibrium constant and the $\mathrm{NO} \bullet / \mathrm{HNO}_{2}$ electrode potential, they [12] derived $E^{\circ}\left(\mathrm{TEMPO}^{+} / \mathrm{TEMPO}^{\bullet}\right)=+0.74 \mathrm{~V}$.

Sen and Golubev (2009) report on the kinetics of disproportionation of TEMPO in strong acid [13]. From the $\mathrm{pH}$ dependence in strongly acidic $\mathrm{H}_{2} \mathrm{SO}_{4}$ media they obtained the $\mathrm{p} K_{\mathrm{a}}$ of the protonated TEMPO radical: $\mathrm{p} K_{\mathrm{a}}=-(5.8 \pm 0.3)$. This is in good agreement with Malatesta and Ingold's [14] prior estimate.

Meaningful interpretation of the comproportionation/disproportionation data requires knowledge of the $\mathrm{p} K_{\mathrm{a}}$ 's of $\mathrm{R}_{2} \mathrm{NHOH}^{+}$. Reports on this are summarized below.

Kato et al. obtained $\mathrm{p} K_{\mathrm{a}}=7.95$ for TEMPOH from the $\mathrm{pH}$ dependence of the reductive CVs of TEMPO ${ }^{\bullet}$ [9]. The theoretical basis for obtaining $\mathrm{p} K_{\mathrm{a}}$ s from such data is not indicated, and we suspect that the results may refer to the $\mathrm{p} K_{\mathrm{a}}$ of surface species at the graphite electrode. 
7711 Sosnovsky and Bell determined the $\mathrm{p} K_{\mathrm{a}}$ potentiometrically at $20^{\circ} \mathrm{C}$, and obtained $\mathrm{p} K_{\mathrm{a}}=6.29$ for

7712 TEMPOH [15].

7714 Israeli et al. determined $\mathrm{p} K_{\mathrm{a}}=(7.5 \pm 0.2)$ by an electrochemical method [16]. The

7715 electrochemical determination used essentially the same method as was used by Kato et al. [9],

7716 and it likewise lacks theoretical justification.

Israeli et al. also determined $\mathrm{p} K_{\mathrm{a}}=(7.5 \pm 0.1)$ at $25^{\circ} \mathrm{C}$ and unspecified ionic strength by a kinetic method [16]. The kinetics determination was based on the $\mathrm{pH}$-dependence of the rate of comproportionation of $\mathrm{TEMPO}^{+}$with TEMPOH.

\section{Discussion}

7723

The electrochemical data on the oxidation of TEMPO• to $\mathrm{TEMPO}^{+}$generally agree that $7725 E^{\circ}$ is near $+730 \mathrm{mV}$ vs NHE. The most reliable study appears to be that of Golubev et al. [3];

7726 these workers used potentiometry, rather than $\mathrm{CV}$, thermodynamic stated their solutions, and 7727 obtained data as a function of ionic strength. Support for this result also comes from the equilibrium constants determined for the reactions with $\mathrm{HO}_{2}{ }^{\bullet}, \mathrm{NO}_{2}{ }^{\bullet}$, and $\mathrm{NO}$, but none of these can be considered as accurate as the direct potentiometric measurement of Golubev et al. [3]. the grounds that it has no theoretical justification. The electrochemical determination by Israeli et al. [16] used essentially the same method as was used by Kato et al. [9] and is likewise rejected. The kinetic determination by Israeli et al. [16] appears reliable but differs substantially from the

7734 two potentiometric determinations. The other two (Golubev et al. [2] and Sosnovsky and Bell

7735 [15] used the same method, potentiometric titration, and would be expected to give highly accurate results; the outcome, however, is unsatisfactory, with the two $\mathrm{p} K_{\mathrm{a}}$ reports differing by 0.6 units. The temperature difference between the two studies is unlikely to cause such a large

7738 difference in $\mathrm{p} K_{\mathrm{a}}$. This outcome is rather unsatisfactory, with the reports of Israeli et al. [16],

7739 Golubev et al. [2], and Sosnovsky and Bell [15] leading to an average $\mathrm{p} K_{\mathrm{a}}$ of $6.9 \pm 0.6$. Sen and

7740 Golubev have reinvestigated this problem very recently [13]. They claim that the addition of

$7741 \mathrm{OH}^{-}$to TEMPO ${ }^{+}$in alkaline media was not taken into account in the voltammetric and kinetic

7742 studies of Israeli et al., and that this will perturb the apparent $\mathrm{p} K_{\mathrm{a}}$ significantly. Thus, they place 7743 great confidence in their $\mathrm{p} K_{\mathrm{a}}$ of $(6.90 \pm 0.02)$.

7744 The Golubev et al. reports $[2,4]$ on the disproportionation of TEMPO ${ }^{\bullet}$ are in good 7745 agreement, leading to a recommended value of $K_{\text {disp }}=(3 \pm 1) \times 10^{4} \mathrm{M}^{-2}$. If we then use the 
recommended values for $E^{\circ}\left(\mathrm{TEMPO}^{+/ 0}\right)$ and $\mathrm{p} K_{\mathrm{a}}(\mathrm{TEMPOH})$, we derive $E^{\circ}=+(0.61 \pm 0.04) \mathrm{V}$ for TEMPO ${ }^{\bullet}, \mathrm{H}^{+} / \mathrm{TEMPOH}$.

\section{Recommended values:}

7750

7751

7752

$$
\mathrm{TEMPO}^{+}+e^{-} \rightleftharpoons \mathrm{TEMPO}^{\bullet}
$$$$
E^{\circ}=+(0.750 \pm 0.005) \mathrm{V}
$$$$
\mathrm{TEMPHOH}^{+} \rightleftharpoons \mathrm{TEMPOH}+\mathrm{H}^{+}
$$$$
\mathrm{p} K_{\mathrm{a}}=(6.90 \pm 0.02)
$$

7753

$$
\mathrm{TEMPO}^{\bullet}+\mathrm{H}^{+}+\mathrm{e}^{-} \rightleftharpoons \mathrm{TEMPOH}
$$$$
E^{\circ}=+(0.61 \pm 0.04) \mathrm{V}
$$

$2 \mathrm{TEMPO}^{\bullet}+2 \mathrm{H}^{+} \rightleftharpoons \mathrm{TEMPO}^{+}+\mathrm{TEMPHOH}^{+}$

$$
K_{\text {disp }}=(3 \pm 1) \times 10^{4} \mathrm{M}^{-2}
$$

7755

7756

\section{References.}

1. M. B. Neimann, S. G. Mairanovskii, B. M. Kovarskaya, E. G. Rozantsev, E. G. Gintsberg. Bull. Acad. Sci. USSR, Chem. Sci. 1424-1426 (1964).

7760

2. V. A. Golubev, V. D. Sen', I. V. Kulyk, A. L. Aleksandrov. Bull. Acad. Sci. USSR, Chem. Sci. 24, 2119-2126 (1975).

7762

3. V. A. Golubev, T. S. Rudyk, V. D.

D. Sen', A. L. Aleksandrov. Bull. Acad. Sci. USSR, Chem.

7763 Sci. 25, 744-750 (1976).

7764

4. V. A. Golubev, V. N. Borislavskii, A. L. Aleksandrov. Bull. Acad. Sci. USSR, Chem. Sci.

7765

7766 1874-1881 (1977).

7767

5. A. N. Petrov, Y. N. Kozlov. Russ. J. Phys. Chem. 60, 195-198 (1986).

7768

6. S. Goldstein, A. Samuni, A. Russo. J. Am. Chem. Soc. 125, 8364-8370 (2003).

7769

7.

J. R. Fish, S. G. Swarts, M. D. Sevilla, T. Malinski. J. Phys. Chem. 92, 3745-3751 (1988).

7770

7771

7772

7773

8. M. C. Krishna, D. A. Grahame, A. Samuni, J. B. Mitchell, A. Russo. Proc. Natl. Acad. Sci. 89, 5537-5541 (1992).

9. Y. Kato, Y. Shimizu, L. Yijing, K. Unoura, H. Utsumi, T. Ogata. Electrochim. Acta 40, 2799-2802 (1995).

7774

10. J. E. Baur, S. Wang, M. C. Brandt. Anal. Chem. 68, 3815-3821 (1996).

7775

11. S. Goldstein, G. Merényi, A. Russo, A. Samuni. J. Am. Chem. Soc. 125, 789-795 (2003).

7776

12. S. Goldstein, A. Samuni, G. Merényi. Chem. Res. Toxicol. 17, 250-257 (2004).

7777

13. V. D. Sen, V. A. Golubev. J. Phys. Org. Chem. 22, 138-143 (2009).

7778

7779

14. V. Malatesta, K. U. Ingold. J. Am. Chem. Soc. 95, 6404-6407 (1973).

7780

15. G. Sosnovsky, P. Bell. Life Sci. 62, 639-648 (1998).

16. Israeli, A, M. Patt, M. Oron, A. Samuni, R. Kohen, S. Goldstein. Free Rad. Biol. Med. 38, 317-324 (2005). 
7782

7783

7784

7785

7786

7787

7788

7789

7790

7791

7792

7793

7794

7795

7796

7797

7798

7799

7800

7801

7802

7803

7804

7805

7806

7807

7808

7809

7810

7811

7812

\section{Supplementary Data Sheet S-8}

Penicillamine Thiyl Radical.

Couple: PenS ${ }^{\bullet}, \mathrm{H}^{+} / \mathrm{PenSH},\left(\mathrm{Pen}=-\mathrm{CMe}_{2}-\mathrm{C}\left(\mathrm{NH}_{2}\right) \mathrm{H}-\mathrm{CO}_{2}{ }^{-}\right)$.

Published value(s):

Method: Pulse radiolysis Solvent: Water

Measurement by electron transfer equilibrium:

$$
\text { PenS• }+\mathrm{D}(\mathrm{SH})_{2}=\text { PenSH }+\mathrm{H}^{+}+{ }_{\Gamma} \bullet^{\bullet} \mathrm{S}_{\top}
$$

Reference: Dithiothreitol (dithiothreitol $=(2 S, 3 S)-1$,4-bis(sulfanyl)butane-2,3-diol, $\left.\mathrm{C}_{4} \mathrm{H}_{10} \mathrm{O}_{2} \mathrm{~S}_{2}\right)$ :

$$
\Gamma^{\mathrm{S}} \because{ }^{-} \mathrm{S}_{\top}+\mathrm{e}+2 \mathrm{H}^{+}=\mathrm{D}(\mathrm{SH})_{2}
$$

Other solutes: Gas: $\mathrm{N}_{2} \mathrm{O} \quad$ Buffer: Phosphate

$\mathrm{pH}=7.0$. Ambient temperature stated to be: $(296.2 \pm 2) \mathrm{K}$. Ionic strength: $0.01 \mathrm{M}$.

Ionic strength effects estimated: Yes.

Observed equilibrium constant/measurement corresponds to $\Delta E=(0.38 \pm 0.02) \mathrm{V}$ [1].

Reference electrode potential: $E^{\mathrm{o}}\left(\mathrm{DS}_{2}{ }^{\bullet-}, 2 \mathrm{H}^{+} / \mathrm{D}(\mathrm{SH})_{2}\right)=+(1.75 \pm 0.03) \mathrm{V}$ vs NHE [2].

Standard electrode potential of couple: $+(1.37 \pm 0.03) \mathrm{V}$ vs NHE.

\section{Recommended value:}

$$
E^{\circ}\left(\mathrm{PenS}^{\bullet}, \mathrm{H}^{+} / \mathrm{PenSH}\right)=+(1.37 \pm 0.03) \mathrm{V}
$$

\section{Comments:}

The thiyl radical of penicillamine and other thiols abstracts, to a limited extent $(K \sim 0.1$ for penicillamine), $\mathrm{H}$ from the $\alpha$-carbon [3]. This hydrogen-atom transfer equilibrates rather rapidly $\left(k_{\mathrm{f}}+k_{\mathrm{r}}=1.5 \times 10^{6} \mathrm{~s}^{-1}\right.$ for PenS $\mathrm{S}^{\bullet}$ [4]), and thus, on the time-scale that bimolecular redox equilibria are attained by pulse radiolysis, the equilibrium constants for reaction S-8.1 and others involving "PenS ${ }^{\bullet "}$ will reflect the contribution of the carbon-centered form of the "thiyl" radical. Thus, the recommended value given above for $E^{\circ}\left(\mathrm{PenS}{ }^{\bullet}, \mathrm{H}^{+} / \mathrm{PenSH}\right)$ is not strictly a thiyl radical potential. Nevertheless, when this redox couple is used in establishing electron-transfer equilibria 
7813 for the $\mathrm{CO}_{2}{ }^{\bullet-}$ and $\mathrm{PO}_{3}{ }^{\bullet-}$ radicals (Data Sheets 96 and 98) the net result should not be 7814 compromised by this effect.

An estimate of $(1.63 \pm 0.03) \mathrm{V}$ for $E^{\mathrm{o}}\left(\mathrm{DS}_{2}{ }^{\bullet-} / \mathrm{D}(\mathrm{SH})_{2}\right)$ can be obtained by extrapolation of $7816 E^{\circ}=+0.81 \mathrm{~V}$ at $\mathrm{pH} 7$ [5]. The value at $\mathrm{pH} 7$ was obtained by combining several quantities: one 7817 was obtained by making the assumption that $E^{\circ}\left(\mathrm{D}\left(\mathrm{S}^{\bullet}\right)(\mathrm{SH}), \mathrm{H}^{+} / \mathrm{D}(\mathrm{SH})_{2}\right)=E^{\circ}\left(\mathrm{GS}^{\bullet}, \mathrm{H}^{+} / \mathrm{GSH}\right)=$ $78180.92 \mathrm{~V}$ at $\mathrm{pH}$ 7. Another was the equilibrium constant $\left(K_{1}\right)$ for formation of $\mathrm{DS}_{2}{ }^{\bullet-}$ from $\mathrm{D}\left(\mathrm{S}^{-}\right)\left(\mathrm{S}^{\bullet}\right)$ $7819\left(=7.9 \times 10^{3}\right)$, which was calculated from two other reactions:

$$
K_{1}=K_{\mathrm{a}}\left(\mathrm{DS}_{2} \mathrm{H}^{\bullet}\right) / K_{\mathrm{a}}\left(\mathrm{D}(\mathrm{SH})\left(\mathrm{S}^{\bullet}\right)\right.
$$

A value of $6.3 \times 10^{-6} \mathrm{M}$ was used for $K_{\mathrm{a}}\left(\mathrm{DS}_{2} \mathrm{H}^{\bullet}\right)$, as measured by Akhlaq and von Sonntag [6]; it should be noted that Akhlaq and von Sonntag expressed the opinion that their $K_{\mathrm{a}}$ value actually is an overall acid dissociation constant for the sum of $\mathrm{D}\left(\mathrm{S}_{2} \mathrm{H}^{\bullet}\right)$ and $\mathrm{D}(\mathrm{SH})\left(\mathrm{S}^{\bullet}\right)$. A value of $7.9 \times$ $10^{-10} \mathrm{M}$ was used for $K_{\mathrm{a}}\left(\mathrm{D}(\mathrm{SH})\left(\mathrm{S}^{\bullet}\right)\right.$, assumed to be equal to the first $K_{\mathrm{a}}$ of $\mathrm{D}(\mathrm{SH})_{2}$. Given the approximations made, the estimate of $+1.63 \mathrm{~V}$ [5] should be regarded as support for the experimental value of $+1.75 \mathrm{~V}[2]$.

7833 Radical values (lowest first): $\mathrm{p} K_{\mathrm{s} 1} \quad$ None [7].

7834 Reductant values (lowest first): $\mathrm{p} K_{\mathrm{s} 1}=7.9 ; \mathrm{p} K_{\mathrm{s} 2}=10.46$ [8].

7835

\section{References}

1. P. S. Surdhar, D. A. Armstrong. J. Phys. Chem. 91, 6532-6537 (1987).

7839 2. Armstrong, D. A. In S-Centered Radicals, (Alfassi, Z. B., ed.), p. 27-61. John Wiley \& 7840 Sons, New York (1999).

7841 3. C. Schöneich, O. Mozziconacci, W. H. Koppenol, T. Nauser. Israel J. chem. 54, 265-271 7842 (2014).

7843 4. T. Nauser, W. H. Koppenol, C. Schöneich. J. Phys. Chem. B 116, 5329-5341 (2012).

7844 5. T. Nauser, D. Steinmann, G. Grassi, W. H. Koppenol. Biochemistry 53, 5017-5022 7845 (2014).

7846 6. M. S. Akhlaq, C. von Sonntag. Z. Narturforsch. 42c, 134-140 (1987).

7847 7. J. W. Purdie, H. A. Gillis, N. V. Klassen. Can. J. Chem. 51, 3132-3142 (1973).

7848 8. E. W. Wilson, R. B. Martin. Arch. Biochem. Biophys. 142, 445-454 (1971). 


\section{Supplementary Data Sheet S-9}

7850

7851 Subject: Chlorpromazine radical cation.

7852 Chlorpromazine IUPAC PIN: 3-(2-chloro-10H-phenothiazin-10-yl)- $N, N$-dimethylpropan-1-

7853 amine

7854

7855 Couple type: $\mathrm{CPZH}^{\bullet 2+}+\mathrm{e}^{-} \rightleftharpoons \mathrm{CPZH}^{+}$

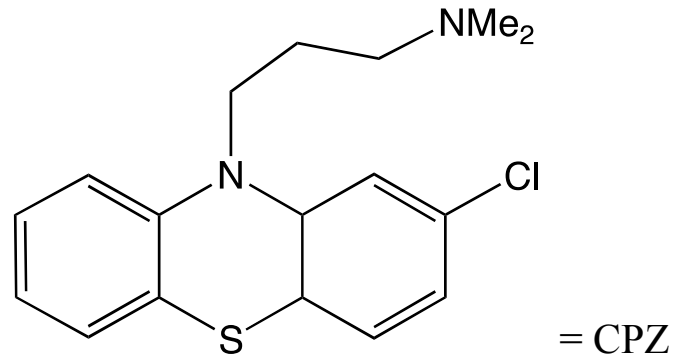

The conjugate acid of the amine sidechain of CPZ has $\mathrm{p} K_{\mathrm{a}} \sim 8$, and the $\mathrm{p} K_{\mathrm{a}}$ of the radical (1989) cited four reports published prior to 1989 on $E^{\circ}$ for $\mathrm{CPZ}$, the values ranging from $766 \mathrm{mV}$ to $844 \mathrm{mV}$, and he recommended $E^{\circ}=+0.78 \mathrm{~V}$ [2]. Madej and Wardman (2006) have reinvestigated this system carefully, both by pulse radiolysis and cyclic voltammetry, and they

7863 arrived at a significantly revised potential [1].

\section{List of reports:}

$E^{\circ}=+0.541 \mathrm{~V}$ vs $\mathrm{NCE}$ (normal calomel electrode) in $0.1 \mathrm{~N} \mathrm{H}_{2} \mathrm{SO}_{4}$, presumably at room temperature. Kabasakalian and McGlotten [3] obtained this result polarographically. Correction

7869 of this to NHE $(+0.280 \mathrm{~V})$ leads to $E^{\circ \prime}=+0.821 \mathrm{~V}$ vs NHE. Later workers argue that the radical 7870 is unstable at this $\mathrm{pH}[4,5]$.

7872 Polarographic oxidation of $\mathrm{CPZH}^{+}$to the radical occurs with $E^{\circ} \sim+0.4 \mathrm{~V}$ vs $\mathrm{SCE}$ in $12 \mathrm{~N}$ $7873 \mathrm{H}_{2} \mathrm{SO}_{4}$, presumably at room temperature [4]. The high acid concentration was used to stabilize 7874 the radical. 
$7876 E_{1 / 4}=+0.570 \mathrm{~V}$ vs $\mathrm{Ag} / \mathrm{AgCl}$ in $3 \mathrm{M} \mathrm{H}_{2} \mathrm{SO}_{4}$, presumably at room temperature [5]. Result obtained 7877 by chronopotentiometry. Correction of $E_{1 / 4}$ to NHE (addition of $0.197 \mathrm{~V}$ ) leads to $E^{01}=+0.767 \mathrm{~V}$ 7878 vs NHE. Patriarche and Lingane [5] cited the prior work of Merkle and Discher [4], claimed the 7879 oxidation of $\mathrm{CPZH}^{+}$to be reversible, and made no comment regarding apparent irreversibility in 7880 the work of they cited.

$7882 E^{\circ \prime}=+0.78 \mathrm{~V}$ in $1.0 \mathrm{M} \mathrm{HClO}_{4}$ at $25.0^{\circ} \mathrm{C}[6]$. Obtained from the equilibrium constant for the 7883 oxidation of $\mathrm{CPZH}^{+}$by $\mathrm{Fe}^{3+}$ and taking $E^{\circ 1}=+0.738 \mathrm{~V}$ for $\mathrm{Fe}(\mathrm{III}) / \mathrm{Fe}(\mathrm{II})$ in this medium. Note 7884 that no tests were performed to determine whether Fe(III) or Fe(II) binds CPZ in any of its 7885 forms.

7886 $E^{\circ}=+0.83 \mathrm{~V}$ in $0.01 \mathrm{M}$ phosphate buffer at $\mathrm{pH} 6$ [7]. Surdhar and Armstrong cite unpublished $\mathrm{CV}$ results of Hinman and Surdhar for this value.

$E^{\circ}=+0.859-+0.864 \mathrm{~V}$ vs NHE at room temperature $\left(23 \pm 2{ }^{\circ} \mathrm{C}\right)$, extrapolated from data in 0.1 $\mathrm{M} \mathrm{KCl}$ [1]. Data obtained by cyclic voltammetry with a sweep rate of $100 \mathrm{mV} \mathrm{s}^{-1}$ with a macroelectrode and $10 \mathrm{mV} \mathrm{s}^{-1}$ with a microelectrode. The $\mathrm{CV}$ experiments showed that the couple is reversible and that $E^{\circ}$ is constant over the $\mathrm{pH}$ range from 3 to 6 . $E^{\circ \prime}=+0.614 \mathrm{~V}$ vs SCE in $0.1 \mathrm{M}$ phosphate buffer at $\mathrm{pH} 2$ at $(20 \pm 2){ }^{\circ} \mathrm{C}$, by cyclic voltammetry [8]. We adjust this value to NHE by adding $0.241 \mathrm{~V}$ to obtain $E^{\circ \prime}=+0.855 \mathrm{~V}$.

\section{Discussion}

Madej and Wardman used pulse radiolysis to measured equilibrium constants for electron transfer between $\mathrm{CPZH}^{+}$and 5 other phenothiazines [1]. They also used cyclic voltammetry to determine $E^{\circ}$ for these 5 other phenothiazines, and they got excellent agreement between the 5 measured electron-transfer equilibrium constants and the equilibrium constants calculated from $\Delta E^{\circ}$.

The results of Mielech-Lukasiewicz et al. [8] are in good agrement with those of Madej and Wardman [1], but the former were not obtained with the objective of determining an accurate value of $E^{\circ}$. For this reason we prefer the result of Madej and Wardman. 
The disagreement between the results of Madej and Wardman and the prior studies most

7908 likely reflects the combined effects of unrecognized radical reactions at the relatively long time

7909 scales of the prior studies, the high acidity of the prior studies, and the possibility of $\mathrm{Fe}^{3+}$ binding

7910 to CPZ. The mild disagreement between the results of Madej and Wardman and those cited by

7911 Surdhar and Armstrong [7] is disregarded because of the incomplete publication status of the

7912 latter. Overall, we recommend the result of Madej and Wardman, including their indicated

7913 uncertainty of $\pm 10 \mathrm{mV}$.

7914

7915 Recommended value:

7916

$7917 \mathrm{CPZH}^{\bullet 2+}+\mathrm{e}^{-} \rightleftharpoons \mathrm{CPZH}^{+} \quad E^{\circ}=+(0.860 \pm 10) \mathrm{mV}$ between $\mathrm{pH} 5$ to 7.

7918

7919 References:

7920

7921 1. E. Madej, P. Wardman. Rad. Phys. Chem. 75, 990-1000 (2006).

7922 2. P. Wardman. J. Phys. Chem. Ref. Data 18, 1637-1755 (1989).

7923 3. P. Kabasakalian, J. McGlotten. Analyt. Chem. 31, 431-433 (1959).

7924 4. F. H. Merkle, C. A. Discher. Analyt. Chem. 36, 1639-1643 (1964).

7925 5. G. J. Patriarche, J. J. Lingane. Analyt. Chim. Acta 49, 25-34 (1970).

7926 6. E. Pelizzetti, E. Mentasti. Inorg. Chem. 18, 583-588 (1979).

7927 7. P. S. Surdhar, D. A. Armstrong. J. Phys. Chem. 91, 6532-6537 (1987).

7928 8. K. Mielech-Lukasiewicz, H. Puzanowska-Tarasiewicz, A. Panuszko. Analyt. Lett. 41, 789-

7929 805 (2008). 


\section{3}

7934

7935

7936

7937

7938

7939

7940

7941

7942

7943

7944

7945

7946

7947

7948

7949

7950

7951

7952

7953

7954

7955

7956

7957

7958

7959

7960

7961

7962

7963

7964

7965

7966

7967

7968

\section{Supplementary Data Sheet S-10}

Disulphide Anion Radical of Lipoamide,

Dihydrolipoamide $=\mathrm{HS}-\mathrm{CH}_{2}-\mathrm{CH}_{2}-\mathrm{C}(\mathrm{SH}) \mathrm{H}-\left(\mathrm{CH}_{2}\right)_{4}-\mathrm{CONH}_{2}, \quad\left(\mathrm{~L}(\mathrm{SH})_{2}\right)$.

Couple:

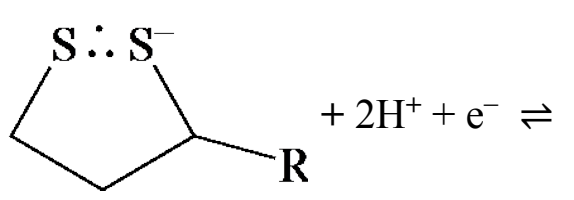<smiles>SCCCS</smiles>

References:

Armstrong, D. A., "Thermodynamicchemistry of Sulfur Radicals" in "S-Centered Radicals", Chapter 2, Alfassi, Z. B. Ed., Wiley, New York 1999;

Surdhar, P. S.; Armstrong, D. A. J. Phys. Chem. 1987, 91, 6532.

\section{Published value(s):}

Method: Pulse radiolysis Solvent: Water

Measurements by electron transfer equilibrium:

$$
\left[\mathrm{S} \cdot \mathrm{S}_{]}^{-}+\mathrm{PhOH}+\mathrm{H}^{+}=\mathrm{HS} \longrightarrow \mathrm{SH}+\mathrm{PhO} \cdot\right.
$$

Reference: $\mathrm{PhO}^{*}, \mathrm{H}^{+} / \mathrm{PhOH}$

Other solutes:

Gas: $\mathrm{N}_{2} \mathrm{O} \quad$ Buffer: Phosphate

$\mathrm{pH}=9$. Temperature: Ambient temperature stated to be: $(296 \pm 2) \mathrm{K}$. Ionic strength: $0.010 \mathrm{M}$.

Uncorrected equilibrium constant from concentrations: $3.2 \times 10^{-8}$.

Ionic strength effects estimated: Yes.

Corrected equilibrium constant given: $2.5 \times 10^{-8}$ (calculated allowing for ionisation of reactants and ionic strength effects on the redox reaction).

Observed equilibrium constant/measurement corresponds to $\Delta E=(0.45 \pm 0.03) \mathrm{V}$.

Reference potential assumed: $E^{\circ}=+(1.38 \pm 0.03) \mathrm{V}$.

Standard electrode potential of the couple as indicated by author: $+(1.83 \mathrm{~V} \pm 0.03) \mathrm{V}$ vs NHE.

\section{Discussion}

No correction for ionic strength effects is nececessary. Surdhar and Armstrong's paper does not mention whether one of the enantiomers of dihydrolipoamide or a racemic mixture was used; however, the results should not depend on this aspect of the stereochemistry.

\section{References:}

Armstrong, D. A, "Thermodynamicchemistry of Sulfur Radicals" in "S-Centered Radicals", Chapter 2, Alfassi, Z. B. Ed., Wiley, New York 1999.

Surdhar, P. S.; Armstrong, D. A. J. Phys. Chem. 1987, 91, 6532. 
7969 Method: Pulse radiolysis Solvent: Water

7970 Measurements by electron transfer equilibrium:

$7971 \quad \mathrm{RSH}=\beta$-mercaptoethanol $=\mathrm{HSCH}_{2} \mathrm{CH}_{2} \mathrm{OH}$

$$
\mathrm{RS}^{\bullet}+\mathrm{L}(\mathrm{SH})_{2}=\mathrm{RSH}+\mathrm{H}^{+}+\Gamma_{\mathrm{S}} \cdot \overline{\mathrm{S}}_{\mathrm{T}}
$$

7972 Reference: $\mathrm{RS}^{\bullet}, \mathrm{H}^{+} / \mathrm{RSH}$

7973 Other solutes: Gas: $\mathrm{N}_{2} \mathrm{O}$ Buffer: Phosphate

$7974 \mathrm{pH}=7$. Temperature: Ambient temperature stated to be: $(296.2 \pm 2) \mathrm{K}$. Ionic strength: $0.01 \mathrm{M}$.

7975 Ionic strength effects estimated: Yes.

7976 Corrected equilibrium constant given: $4.3 \times 10^{-7}$ (calculated for $\mathrm{pH}=0.0$ ).

7977 Observed equilibrium constant/measurement corresponds to $\Delta E^{\circ}=0.37 \mathrm{~V}$.

7978 Reference potential assumed: $E^{\circ}=+(1.35 \pm 0.03) \mathrm{V}$

7979 Standard electrode potential of couple indicated by author: $+1.72 \mathrm{~V} v$ s NHE.

7980 Reviewer's revised calculations

7981 No correction for ionic strength effects is nececessary.

7982

7983 Average from the two equilibria $=(1.78 \pm 0.06) \mathrm{V}$.

7984

7985

7986 Other data

7987 Oxidant $\mathbf{p} K_{\mathrm{a}}$ values (lowest first): $\mathrm{p} K_{\mathrm{ol}} \mathrm{PhOH}=1 \times 10^{-10}$

7988 References: Biggs, A. I.; Robinson, R. A. J. Chem. Soc. 1961, 388; Chen, D. T. Y.; Laidler, K. J. 7989 Trans. Faraday. Soc. 1962, 58, 480.

7990 Radical values (lowest first): $\mathrm{L}(\mathrm{S})_{2} \mathrm{H}^{\bullet}, \mathrm{p} K_{\mathrm{s} 1}=5.85$.

7991 Reference: von Sonntag, C. "The Chemical Basis of Radiation Biology", Taylor and Francis, 7992 London (1987), p 359.

$7993 \quad \mathbf{L}(\mathbf{S H})_{2}$ values (lowest first): $\mathrm{p} K_{\mathrm{s} 1}=10.4 ; \mathrm{p} K_{\mathrm{s} 2}=11.0$.

7994 References: Gascoigne, I. M.; Radda, G. K. Biochim. Biophys. Acta 1967, 131, 498; Szajewski, 7995 R. P.; Whitesides, G. M.; J. Am. Chem. Soc. 1980, 102, 2011.

7997 Reviewers' evaluation

7998 There are sufficient experimental details available to evaluate data

7999

8000

8001 


\section{Supplementary Data Sheet S-11}

\section{Chemical equilibrium}

$$
\mathrm{MeOPhNH}_{2}{ }^{\bullet+}+\mathrm{Pz}^{+}=\mathrm{MeOPhNH}_{2}+\mathrm{Pz}^{\bullet 2+}
$$

$\mathrm{MeOPhNH}_{2}=4$-methoxyaniline;

$\mathrm{Pz}=$ promethazine; IUPAC PIN: N,N-dimethyl-2-(10H-phenothiazin-10-yl)propan-2-amine

\section{List of Reports} $K=9.3 \times 10^{-3}$ from absorbance, $\left(\approx 6.7 \times 10^{-3}\right.$ from kinetics $), \mathrm{pH} 5.7, \mu \approx 0.010 \mathrm{M}$ [1]. Data obtained by pulse radiolytic generation of the $\mathrm{N}_{3}{ }^{\bullet}$ as the primary oxidant.

\section{Discussion}

Jonsson et al. derived $E^{\circ}\left(\mathrm{MeOPhNH}_{2}{ }^{\bullet+} / \mathrm{MeOPhNH}_{2}\right)=+(0.79 \pm 0.02) \mathrm{V}$ by using a value of $+0.91 \mathrm{~V}$ for $E^{\circ}\left(\mathrm{Pz}^{\bullet 2+} / \mathrm{Pz}^{+}\right)[1]$ and assuming that the value of $K(\mathrm{~S} 11.1)$ is independent of ionic strength. This latter assumption was based on the concept that the net charge on a side chain of promethazine, remote from the reactive site, does not introduce ionic strength dependence (see footnote 33 of [1]). However, this concept overlooks that the activity coefficients of the reactants and products in equilibrium such as S11.1 are independent of the structure of the transition state, and, for the calculation of activity coefficients with the Debye-Hückel theory, it is the net charge that counts. On the other hand, the measurement of $K(\mathrm{~S} 11.1)$ was performed at a rather low ionic strength $(0.01 \mathrm{M})$, so the correction to zero ionic strength should be rather small.

Subsequent to the work of Jonsson et al. the promethazine potential has been extensively reinvestigated [2]. If we adopt the revised $E^{\circ}\left(\mathrm{Pz}^{\bullet 2+} / \mathrm{Pz}^{+}\right)=+0.925 \mathrm{~V}$ [2], then we obtain $E^{\circ}\left(\mathrm{MeOPhNH}_{2}{ }^{\bullet+} / \mathrm{MeOPhNH}_{2}\right)=+(0.80 \pm 0.02) \mathrm{V}$. The $20 \mathrm{mV}$ uncertainty encompasses the uncertainties introduced by the ionic-strength issue noted above, enabling the potential to be regarded as a standard potential.

\section{Recommended value:}

$$
E^{\circ}\left(\mathrm{MeOPhNH}_{2}{ }^{\bullet+} / \mathrm{MeOPhNH}_{2}\right)=+(0.80 \pm 0.02) \mathrm{V}
$$

List of auxiliary thermodynamic data: $p K_{\mathrm{a}}\left(\mathrm{MeOPhNH}_{3}{ }^{+}\right)=5.3 ; p K_{\mathrm{a}}\left(\mathrm{MeOPhNH}_{2}{ }^{\bullet+}\right)=9.6[1]$

\section{References}


8038 1. M. Jonsson, J. Lind, T. E. Eriksen, G. Merényi. J. Am. Chem. Soc. 116, 1423-1427

8039 (1994).

$8040 \quad$ 2. E. Madej, P. Wardman. Rad. Phys. Chem. 75, 990-1000 (2006).

8041 


\section{Supplementary Data Sheet S-12}

8043

8044 Tryptophan

8045

8046 Chemical equilibrium

8047

$$
\mathrm{ClO}_{2}{ }^{\bullet}+\mathrm{TrpH} \rightleftharpoons \mathrm{ClO}_{2}^{-}+\mathrm{TrpH}^{\bullet+}
$$

$8048 \operatorname{TrpH}=$ tryptophan

8049

$8050 K=(1.6 \pm 0.6) \times 10^{-5}$ from kinetics, $\mathrm{pH} 4, \mu=0.5 \mathrm{M}[1]$.

8051 At $\mu=0, K=(8.1 \pm 3.2) \times 10^{-6}$.

8052 Taking $E^{\circ}\left(\mathrm{ClO}_{2} \% \mathrm{ClO}_{2}{ }^{-}\right)=0.936 \mathrm{~V}$ (Data Sheet 24 recommends $0.935 \pm 0.003 \mathrm{~V}$ )

$8053 E^{\circ}\left(\operatorname{TrpH}^{\bullet+} / \operatorname{TrpH}\right)=+(1.24 \pm 0.01) \mathrm{V}$

$8054 \quad k_{\mathrm{f}}=(8.8 \pm 3.1) \times 10^{3} \mathrm{~L} \mathrm{~mol}^{-1} \mathrm{~s}^{-1}, k_{\mathrm{r}}=(5.5 \pm 0.2) \times 10^{8} \mathrm{~L} \mathrm{~mol}^{-1} \mathrm{~s}^{-1}$

8055

8056

8057 List of auxiliary thermodynamic data

$8058 p K_{a}(\operatorname{Trp})=2.38,9.39$

$8059 p K_{a}\left(\operatorname{TrpH}^{\bullet+}\right)=4.3[2]$

$8060 E\left(\operatorname{Trp}^{\bullet}, \mathrm{H}^{+} / \operatorname{TrpH}\right)(\mathrm{pH} 7)=+1.08 \mathrm{~V}$ (assuming $p K_{\mathrm{a}}$ values of amino and carboxyl groups are the 8061 same in the radical and parent molecule).

8062

8063 Chemical equilibrium

8064

$$
(\operatorname{tacn})_{2} \mathrm{Ni}^{3+}+\mathrm{TrpH} \rightleftharpoons(\operatorname{tacn})_{2} \mathrm{Ni}^{2+}+\mathrm{Trp}^{\bullet}+\mathrm{H}^{+}
$$

$8065(\operatorname{tacn})_{2} \mathrm{Ni}^{3+}=\operatorname{bis}(1,4,7$-triazacyclononane $) \mathrm{Ni}(\mathrm{III})$

8066

$8067 K=(0.10 \pm 0.03)$ from absorbance, $(0.104 \pm 0.03)$ from kinetics, $\mathrm{pH} 7, \mu=0.1 \mathrm{M}[3]$

8068 Taking $E^{\circ}\left((\operatorname{tacn})_{2} \mathrm{Ni}^{3+} /(\operatorname{tacn})_{2} \mathrm{Ni}^{2+}\right)=+0.95 \mathrm{~V}[4]$

$8069 E\left(\operatorname{Trp}^{\bullet}, \mathrm{H}^{+} / \operatorname{TrpH}\right)(\mathrm{pH} 7)=1.01 \mathrm{~V}$

$8070 \quad k_{\mathrm{f}}=(5 \pm 1) \times 10^{4} \mathrm{~L} \mathrm{~mol}^{-1} \mathrm{~s}^{-1}, k_{\mathrm{r}}=(4.8 \pm 0.5) \times 10^{5} \mathrm{~L} \mathrm{~mol}^{-1} \mathrm{~s}^{-1}$

8071

8072 Chemical equilibrium

8073

$$
\mathrm{Pz}^{\bullet 2+}+\mathrm{TrpH} \rightleftharpoons \mathrm{Pz}^{+}+\operatorname{Trp}^{\bullet}+\mathrm{H}^{+}
$$

$8074 \mathrm{Pz}=$ promethazine

8075

$8076 K=5.5 \times 10^{-3}$ from absorbance, $(5.7 \pm 1) \times 10^{-3}$ from kinetics, $\mathrm{pH} 6, \mu=0.1 \mathrm{M}$ [3]

8077 Taking $E^{\circ}\left(\mathrm{Pz}^{\bullet 2+} / \mathrm{Pz}^{+}\right)=+0.925 \mathrm{~V}$ [5] 
8078

8079

8080

8081

8082

8083

8084

8085

8086

8087

8088

8089

8090

8091

8092

8093

8094

8095

8096

8097

8098

8099

8100

8101

8102

8103

8104

8105

8106

8107

8108

8109

8110

8111

8112

$E\left(\operatorname{Trp}^{\bullet}, \mathrm{H}^{+} / \operatorname{TrpH}\right)(\mathrm{pH} 6)=+1.06 \mathrm{~V}, E\left(\operatorname{Trp}^{\bullet}, \mathrm{H}^{+} / \operatorname{TrpH}\right)(\mathrm{pH} 7)=+1.00 \mathrm{~V}$

$k_{\mathrm{f}}=(6.2 \pm 1) \times 10^{5} \mathrm{~L} \mathrm{~mol}^{-1} \mathrm{~s}^{-1}, k_{\mathrm{r}}=(1.1 \pm 0.1) \times 10^{8} \mathrm{~L} \mathrm{~mol}^{-1} \mathrm{~s}^{-1}$

Chemical equilibrium

$$
\mathrm{X}^{\bullet}+\operatorname{TrpH} \rightleftharpoons \mathrm{X}^{-}+\operatorname{Trp}^{\bullet}+\mathrm{H}^{+}
$$

$K$ values not given, experiments at $\mathrm{pH} 7$ [6]

Based on $E^{\circ}\left(\mathrm{X}^{\bullet} / \mathrm{X}^{-}\right) / \mathrm{V}$

$E\left(\operatorname{Trp} \bullet, \mathrm{H}^{+} / \operatorname{TrpH}\right) / \mathrm{V}$ at $(\mathrm{pH} 7)$

from kinetics from absorbance

$\mathrm{ClO}_{2} \% \mathrm{ClO}_{2}^{-}+0.92+1.03+1.04$

Os(terpy) $2^{3+/ 2+}+0.93+1.06+1.03$

$\mathrm{NO}_{2}{ }^{\bullet} / \mathrm{NO}_{2}{ }^{-}+1.03+1.07$

$\mathrm{Fe}(\mathrm{bpy}) 3^{3+/ 2+}+1.05 \quad+1.09 \quad+1.00$

Average value given $E\left(\operatorname{Trp}^{\bullet}, \mathrm{H}^{+} / \operatorname{TrpH}\right)(\mathrm{pH} 7)=(+1.05 \pm 0.01) \mathrm{V}$ at $298 \mathrm{~K}$

\section{Recommended values:}

$E^{\circ}\left(\operatorname{TrpH}^{\bullet+} / \operatorname{TrpH}\right)=+(1.24 \pm 0.01) \mathrm{V}$ at $\mu=0$.

$E^{\circ}\left(\operatorname{Trp}^{\bullet}, \mathrm{H}^{+} / \mathrm{TrpH}\right)$ at $\mathrm{pH} 7:+(1.03 \pm 0.02) \mathrm{V}$.

Harriman [7] and DeFelippis et al. [8] determined electrode potentials of $+1.015 \mathrm{~V}$ and $+1.02 \mathrm{~V}$ at $\mathrm{pH} 7$, respectively, by cyclic voltammetry and differential pulse polarography. Although these values fit with the recommended value, they are based on a formula derived by Nicholson [9] that was incorrectly modified by Harriman [7]. Recent cyclic voltammetry experiments yield $+(0.99 \pm 0.01)$ V at pH 7 (L. Mahmoudi, R. Kisner, T. Nauser, W. H. Koppenol, 2014, unpublished.)

Nomenclature: tryptophan, (2S)-2-amino-3-(1H-indol-3-yl)propanoic acid.

\section{References}

1. G. Merényi, J. Lind, X. Shen. J. Phys. Chem. 92, 134-137 (1988). 
8113 2. M. L. Posener, G. E. Adams, P. Wardman, R. B. Cundall. J. Chem. Soc., Faraday Trans. 81141 72, 2231-2239 (1976).

8115 3. S. V. Jovanovic, S. Steenken, M. G. Simic. J. Phys. Chem. 95, 684-687 (1991).

81164 4. Wieghardt, W. Schmidt, W. Herrmann, H.-J. Kuppers. Inorg. Chem. 22, 2953-2956

8117 (1983).

8118 5. E. Madej, P. Wardman. Rad. Phys. Chem. 75, 990-1000 (2006).

8119 6. M. R. DeFelippis, C. P. Murthy, M. Faraggi, M. H. Klapper. Biochemistry 28, 4847-4853 8120 (1989).

$8121 \quad 7 . \quad$ A. Harriman. J. Phys. Chem. 91, 6102-6104 (1987).

8122 8. M. R. DeFelippis, C. P. Murthy, F. Broitman, D. Weinraub, M. Faraggi, M. H. Klapper. 8123 J. Phys. Chem. 95, 3416-3419 (1991).

8124 9. R. S. Nicholson. Analyt. Chem. 37, 667-671 (1965).

8125 